Check for updates

Cite this: RSC Adv., 2017, 7, 28234

\title{
Two-dimensional transition metal dichalcogenide- based counter electrodes for dye-sensitized solar cells
}

\author{
Eric Singh, (D) abc Ki Seok Kim, (DD ${ }^{b}$ Geun Young Yeom (D) *bc and Hari Singh Nalwa (D) *d
}

Dye-sensitized solar cells (DSSCs) are gaining considerable interest as alternatives to semiconductor-based thin film solar cells. The noble metal platinum (Pt) is conventionally used as a counter electrode (CE) material for fabricating DSSCs, since Pt is expensive and scarce, therefore, new materials have been explored to develop cost-effective Pt-free counter electrodes. Two-dimensional (2D) graphene-based counter electrodes have achieved the highest power conversion efficiency (PCE, $\eta$ ) of $13 \%$, which has stimulated research activities in 2D layered transition metal dichalcogenides (TMDs) for developing Pt-free DSSCs. In this review, progress made on alternative counter electrodes for fabricating low-cost Pt-free DSSCs, based on earth-abundant 2D TMDs including $\mathrm{MoS}_{2}, \mathrm{WS}_{2}, \mathrm{TiS}_{2}, \mathrm{FeS}_{2}, \mathrm{CoS}_{2}, \mathrm{NiS}_{2}, \mathrm{SnS}_{2}, \mathrm{MoSe}_{2}, \mathrm{NbSe}_{2}$, $\mathrm{TaSe}_{2}, \mathrm{NiSe}_{2}, \mathrm{FeSe}_{2}, \mathrm{CoSe}_{2}, \mathrm{Bi}_{2} \mathrm{Se}_{3}$ and their based composites, are discussed and summarized. Also, the considerable progress made on thin films of $\mathrm{MoS}_{2}$ and $\mathrm{MoS}_{2}$ based carbon, graphene, carbon nanotubes (CNTs), carbon nanofibers (CNFs), and poly(3,4-ethylenedioxythiophene):poly(styrenesulfonate) (PEDOT:PSS) composites as efficient counter electrodes (CES) for DSSCs are discussed, in terms of their electrochemical and photovoltaic properties. At present, PCE values higher than that of standard Pt CE have been recorded for a number of TMD-based CEs, which include $\mathrm{MoS}_{2}$ and $\mathrm{MoSe}_{2} /$ thin films deposited on Mo foil, $\mathrm{MoS}_{2} / \mathrm{CNTS}, \mathrm{MoS}_{2}$ /graphene, MoS 2 /carbon, MoSe 2 /PEDOT:PSS, NbSe $2, \mathrm{FeS}_{2}, \mathrm{FeSe}_{2}$ nanosheets, $\mathrm{TiS}_{2}$ /graphene, and $\mathrm{NiS}_{2}$ /graphene hybrid systems in DSSCs, for the reduction of triiodide $\left(\mathrm{I}_{3}{ }^{-}\right)$to iodide $\left(\mathrm{I}^{-}\right)$. The highest PCE $(\eta=10.46 \%)$ versus Pt CE $(\eta=8.25 \%)$ at 1 Sun $\left(100 \mathrm{~mW} \mathrm{~cm}^{-2}, \mathrm{AM}\right.$ $1.5 G)$ was measured for DSSCs having a low cost and flexible $\mathrm{CoSe}_{2} /$ carbon-nanoclimbing wall counter electrode deposited on a nickel foam. Though TMD-based materials show great potential for solar cell devices, their long-term stability is equally important. The DSSCs with a $\mathrm{TiS}_{2} /$ graphene hybrid, and $\mathrm{TiS}_{2} /$ PEDOT:PSS composite CEs, showed stability up to 20 to 30 days, respectively, without any measurable degradation in the photovoltaic performance. The long-term stability of TMDs-based DSSCs under different environmental conditions is also described in view of their commercial applications.

Received 28th March 2017

Accepted 14th May 2017

DOI: $10.1039 / c 7 r a 03599 c$

rsc.li/rsc-advances fabricated using nanocrystalline porous $\mathrm{TiO}_{2}$ as optically transparent thin-film photoelectrodes and a ruthenium(II)bipyridyl complex as a photosensitizer (dye), which generated a power conversion efficiency of $7.9 \%$ for the triiodide/iodide $\left(\mathrm{I}_{3}{ }^{-} / \mathrm{I}^{-}\right)$redox couple. This inspired a new field of research based on DSSCs where a broad range of novel materials are now being explored for electrodes (photoanode and counter electrode (CE; cathode)), photosensitizers (dyes), and reductionoxidation (redox) electrolytes for fabricating DSSC devices.

The commonly used components in dye-sensitized solar cells are a photoanode, a CE, a photosensitizing dye, and an electrolyte. These include tris(2,2'-bipyridyl)cobalt(II/III) $\left[\mathrm{Co}(\mathrm{bpy})_{3}\right]\left(\mathrm{Co}^{2+} / \mathrm{Co}^{3+}\right)$, triiodide/iodide $\left(\mathrm{I}_{3}{ }^{-} / \mathrm{I}^{-}\right)$and $5,5^{\prime}-$ dithiobis(1-methyltetrazole)/1-methyltetrazole-5-thiolate $\quad\left(\mathrm{T}_{2} /\right.$ $\mathrm{T}^{-}$) as redox couples, poly(3,4-ethylenedioxythiophene) (PEDOT), poly(styrenesulfonate) (PSS), poly(3-hexylthiophene) (Р3HT), 2,2',7,7'-tetrakis( $N, N$ - $p$-dimethoxy-phenylamino)-9,9'spirobifluorene (spiro-OMETAD) as solid-state hole-transport 
materials (HTM); cis-bis(isothiocyanato)bis(2,2'-bipyridyl-4,4' dicarboxylato)ruthenium(II), (N3 dye), ditetrabutylammonium cis-bis(isothiocyanato)bis(2,2'-bipyridyl-4,4'-dicarboxylato)ruthenium(II), where tetrabutyl-ammonium cation: $\left[\left(\mathrm{C}_{4} \mathrm{H}_{9}\right)_{4} \mathrm{~N}^{+}\right]$ (N719 dye), and (tris(cyanato)-2,2',2 $2^{\prime \prime}$-terpyridyl-4,4 $4^{\prime}, 4^{\prime \prime}$-tricarboxylate)ruthenium(II) (N749 or black dye) as photosensitizing dyes, are regularly used. The dye-sensitized mesoporous $\mathrm{TiO}_{2}$ is used as a photoanode, while the Pt-coated fluorinedoped tin oxide (FTO) on a glass substrate is used as a CE, which facilitates the catalysis process. The counter electrode in a DSSC device acts as a catalyst. Pt counter electrodes yield the maximum electrocatalytic activity for the triiodide/iodide $\left(\mathrm{I}_{3}{ }^{-}\right.$/ $\mathrm{I}^{-}$) redox couple, but are poorly effective for iodine-free redox couple such as $\mathrm{Co}^{2+} / \mathrm{Co}^{3+}$ and $\mathrm{T}_{2} / \mathrm{T}^{-}$. Transparent conducting oxides such as FTO or indium-tin oxide (ITO) on glass is the common substrate used in assembling DSSCs with different CE materials. The power conversion efficiency of DSSCs is governed by many factors including light absorbing capacity of photosensitizing dyes and catalytic materials.

The classical photosensitizing dyes were developed by Grätzel's research team, ${ }^{2,3}$ including $\mathrm{N} 3$ dye that absorbs up to $800 \mathrm{~nm}$, and N749 dye (also known as black dye) which absorbs sunlight in the longer wavelength region up to $920 \mathrm{~nm}$. In 2014, Mathew et al. ${ }^{4}$ used graphene nanoplatelets as a CE, a new push-pull porphyrin with a donor $-\pi$-bridge acceptor $(\mathrm{D}-\pi-\mathrm{A})$ chemical structure as a sensitizing dye, and $\mathrm{Co}$ (II)/Co(III) redox mediator for developing a DSSC, which exhibited a $J_{\text {sc }}$ of $18.1 \mathrm{~mA} \mathrm{~cm}^{-2}, V_{\text {oc }}$ of $0.91 \mathrm{~V}, \mathrm{FF}$ of 0.78 and the highest power conversion efficiency (PCE) of $13 \%$ under $100 \mathrm{~mW} \mathrm{~cm}^{-2}$ (AM 1.5) illumination. The high PCE of DSSCs originated from a molecularly engineered porphyrin dye, 4-(7-\{2-[(2Z,7Z,11E,16Z)-7,17-bis[2,6-bis(octyloxy)phenyl]-12[bis(\{4-[2,4-bis(hexyloxy)phenyl]phenyl $\}$ )amino]-21,23,24,25tetraaza-22-zincahexacyclo[9.9.3.13,6.113,16.08,23.018,21]pentacosa 1(20),2,4,6(25),7,9,11,13(24),14,16,18-undecane-2-yl]ethynyl\}-2,1,3-benzothiadiazole-4-yl)benzoic acid, coded as SM315 dye. The sensitizing dyes as a light harvester play a very significant role in achieving high PCE for DSSCs, therefore, dyes such as N3, N719, N749, Y123, Z907, JK-303 those absorb as much sunlight as possible is of a great interest, i.e., Y123 dye $=3-[6-[4-$ [bis $\left(2^{\prime}, 4^{\prime}\right.$-dihexyloxybiphenyl-4-yl)amino-]phenyl[-4,4-dihexylcyclopenta-[2,1- $b: 3,4-b]$ dithiphene-2-yl]-2-cyanoacrylic acid; Z907 $=$ cis-bis(isothiocyanato) (2,2'-bipyridyl-4,4'-dicarboxylato) (4,4'-di-nonyl-2'-bipyridyl)ruthenium(II); and JK-306 $=(E)-3-\left\{5^{\prime}-\right.$ $\left\{4\right.$-[bis $\left(2^{\prime}, 4^{\prime}\right.$-dihexyloxybiphenyl-4-yl)amino]phenyl $\}-2,2^{\prime}$-bithiophene-5-yl\}-2-cyanoacrylic acid. The many types of dyesensitizers such as ruthenium dyes, metal-free organic dyes, porphyrin dyes, quantum dots, and perovskites have been explored for DSSCs. Over the past 30 years, significant progress has been made in exploring diverse aspects of DSSC components, including dye-sensitizers, CEs, electrolytes and photoanodes, and many outstanding reviews are available in the literature on this exciting research topic. ${ }^{5-17}$ Chemical structures of photosensitizing dyes generally used in evaluating the photovoltaic performance of CEs in DSSCs are also discussed elsewhere. Many different types of Pt-free CE materials have been studied for DSSCs including carbon-based materials such as carbon black, mesoporous carbon, carbon nanotubes
(CNTs), carbon fibers, fullerenes, graphene-based materials, metals, transition metal oxides, sulfides, carbides, nitrides, selenides, tellurides, chalcogenides, layered double hydroxides, phosphides and their alloys, conducting polymers such as PEDOT:PSS and other composites materials. ${ }^{\mathbf{1 8 - 2 2}}$

Platinum (Pt) and ITO are the traditional materials used in fabricating different types of solar cell devices. In DSSCs, the Pt deposited on a FTO transparent conductive glass substrate is used as a $\mathrm{CE}$ for the reduction of triiodide $\left(\mathrm{I}_{3}{ }^{-}\right)$ions to iodide $\left(\mathrm{I}^{-}\right)$ions. In this case, Pt acts as a catalyst for the regeneration of redox couples while FTO acts as an electron collector. Pt is a highly expensive metal which has been identified as one of the most critically important metals for the U.S. economic growth. ${ }^{23,24}$ Among electrocatalysts for DSSCs, Pt shows the best photovoltaic performance due to its high conductivity, chemical stability, and electrochemical activity but it is scarce. The current idea is to explore new alternative catalytic materials to replace the conventional Pt CE in DSSCs using easily available, inexpensive, highly electrically conductive, and high electrocatalytic activity materials. Earth-abundant 2D materials that offer high optical transparency and high electrocatalytic activity have been explored as potential candidate materials for CEs (cathode) and for replacing Pt in DSSC devices. During the last decade, graphene-based materials in the form of their thin films, nanosheets, fibers, multilayers, nanoplatelets, quantum dots, nanofoams and their nanocomposites with metals, CNTs, organic polymers, upconversion nanoparticles, titanium dioxide $\left(\mathrm{TiO}_{2}\right)$, ionic liquids, and halide perovskites, have been extensively investigated as Pt-free CEs for DSSCs ${ }^{25}$ and heterojunction solar cells. ${ }^{26,27}$ The merit of graphene-based CEs in DSSC devices includes their high optical transparency, high electrical conductivity, large effective specific surface area, and the flexibility to fabricate them on different types of substrates.

Layered 2D TMDs are graphene analogs, therefore, research activities have been strongly diverted towards this new class of low-cost 2D materials. Among 2D TMDs, transition-metal disulfides and diselenides such as $\mathrm{MoS}_{2}, \mathrm{MoSe}_{2}, \mathrm{WS}_{2}, \mathrm{TiS}_{2}$, $\mathrm{NbSe}_{2}, \mathrm{TaSe}_{2}, \mathrm{NiSe}_{2}, \mathrm{FeSe}_{2}, \mathrm{CoSe}_{2}, \mathrm{SnS}_{2}, \mathrm{Bi}_{2} \mathrm{Se}_{3}$ and other TMD thin films have been investigated as CEs to fabricate Pt-free DSSCs. The CE acts as an electrocatalyst, and is one of the main components of a DSSC device which facilitates the reduction of triiodide $\left(\mathrm{I}_{3}{ }^{-}\right)$ions to iodide $\left(\mathrm{I}^{-}\right)$ions in a redox electrolyte for dye generation. In this review, electrochemical and photovoltaic properties of low-cost catalytic CEs developed from earth-abundant TMDs and their composites with carbon, graphene, CNTs, carbon nanofibers, PEDOT:PSS and other materials are discussed. The impact of materials processing and morphology associated with PCEs of DSSCs has also been analyzed. Finally, this review discusses the electrochemical and environmental stability of TMDs-based CEs for DSSCs.

\section{Two-dimensional transition metal dichalcogenides (2D TMDs)}

Two-dimensional (2D) transition metal dichalcogenides (TMDs), i.e. $\mathrm{MX}_{2}$ where $\mathrm{M}$ is a transition metal (Mo, W, Ti, Zr, 
Table 1 Library of 2D materials. Blue cells represent monolayers of 2D materials showing stability under ambient conditions; green denotes probability of stability of 2D materials in air; pink denotes 2D unstable materials in air, but may be stable under inert atmosphere. Grey cells show 3D compounds easily exfoliated down to monolayers. Reprinted with permission from ref. 32, A. K. Geim and I. V. Grigorieva, van der Waals heterostructures. Nature, 2013, 499, 419-425. Copyright@ Nature Publishing Group

\begin{tabular}{|c|c|c|c|c|c|}
\hline $\begin{array}{l}\text { Graphene } \\
\text { family }\end{array}$ & Graphene & $\begin{array}{c}\mathrm{hBN} \\
\text { 'white graphene' }\end{array}$ & $\mathrm{BCN}$ & Fluorographene & Graphene oxide \\
\hline \multirow{2}{*}{$\begin{array}{c}2 \mathrm{D} \\
\text { chalcogenides }\end{array}$} & \multirow{2}{*}{$\begin{array}{c}\mathrm{MoS}_{2}, \mathrm{WS}_{2} \\
\mathrm{MoSe}_{2}, \mathrm{WSe}_{2}\end{array}$} & \multirow{2}{*}{\multicolumn{2}{|c|}{$\begin{array}{l}\text { Semiconducting dichalcogenides: } \\
\mathrm{MoTe}_{2}, \mathrm{WTe}_{2}, \mathrm{ZrS}_{2}, \mathrm{ZrSe}_{2} \text { and so on }\end{array}$}} & \multicolumn{2}{|c|}{$\begin{array}{l}\text { Metallic dichalcogenides: } \mathrm{NbSe}_{2} \text {, } \\
\mathrm{NbS}_{2}, \mathrm{TaS}_{2}, \mathrm{TiS}_{2}, \mathrm{NiSe}_{2} \text { and so on }\end{array}$} \\
\hline & & & & \multicolumn{2}{|c|}{$\begin{array}{l}\text { Layered semiconductors: GaSe, } \\
\text { GaTe, } \mathrm{InSe}, \mathrm{Bi}_{2} \mathrm{Se}_{3} \text { and so on }\end{array}$} \\
\hline \multirow[b]{2}{*}{ 2D oxides } & Micas, BSCCO & $\mathrm{MoO}_{3}, \mathrm{WO}_{3}$ & \multirow{2}{*}{$\begin{array}{l}\text { Perovskite-type: } \\
\text { LaNb } \mathrm{O}_{2} \mathrm{O}_{7} \\
\left(\mathrm{Ca}, \mathrm{Sr}_{2} \mathrm{Nb}_{3} \mathrm{O}_{10}\right. \\
\mathrm{Bi}_{4} \mathrm{Ti}_{3} \mathrm{O}_{12} \\
\mathrm{Ca}_{2} \mathrm{Ta}_{2} \mathrm{TiO}_{10} \\
\text { and so on }\end{array}$} & \multicolumn{2}{|c|}{$\begin{array}{c}\text { Hydroxides: } \mathrm{Ni}(\mathrm{OH})_{2}, \mathrm{Eu}(\mathrm{OH})_{2} \\
\text { and so on }\end{array}$} \\
\hline & $\begin{array}{l}\text { Layered } \mathrm{Cu} \\
\text { oxides }\end{array}$ & $\begin{array}{c}\mathrm{TiO}_{2}, \mathrm{MnO}_{2} \\
\mathrm{~V}_{2} \mathrm{O}_{5}, \mathrm{TaO}_{3}, \mathrm{RuO}_{2} \\
\text { and so on }\end{array}$ & & \multicolumn{2}{|c|}{ Others } \\
\hline
\end{tabular}

Hf, V, Nb, Ta, Tc, Re, Pd, Pt) and $\mathrm{X}$ is a chalcogen ( $\mathrm{S}, \mathrm{Se}, \mathrm{Te})$, such as $\mathrm{MoS}_{2}, \mathrm{WS}_{2}, \mathrm{MoSe}_{2}$, WSe 2 , form 2D layered structures and are abundantly available in nature. In a $\mathbf{M X}_{2}$ monolayer structure $(\mathrm{X}-\mathrm{M}-\mathrm{X})$, an atomic layer of a transition metal (M) is sandwiched between two chalcogen (X) atomic layers, where transition metal atoms (M) such as Mo and $\mathrm{W}$ are covalently bonded with chalcogen atoms (X) such as S, Se, Te. Each layer is 6-7 A thick in the TMD layered structures. Weak van der Waals interactions occur between two adjacent $\mathrm{MX}_{2}$ layers of TMDs, whereas the intra-layer $\mathrm{M}-\mathrm{X}$ bonds are covalent. ${ }^{28-31}$ From an electrical point of view, $\mathrm{MoS}_{2}, \mathrm{MoSe}_{2}, \mathrm{WS}_{2}$ and $\mathrm{WSe}_{2}$ are semiconductors, $\mathrm{WTe}_{2}$ and $\mathrm{TiSe}_{2}$ are semimetals, $\mathrm{VSe}_{2}$ and $\mathrm{NbS}_{2}$ are metals, while $\mathrm{NbSe}_{2}$ and $\mathrm{TaS}_{2}$ are superconductors in their bulk crystalline forms. ${ }^{26,30}$ Geim and Grigorieva ${ }^{32}$ created a library of 2D materials (Table 1 ) where the 2D materials were classified into three different classes. Their graphene family includes graphene-based materials hBN, and $\mathrm{BCN}$; the $2 \mathrm{D}$ chalcogenides include a large family of TMDs having insulator to semiconducting to metallic behavior; and the 2D oxides include layered oxides, perovskite-based materials, hydroxides, and others. The 2D TMDs include $\mathrm{MoS}_{2}, \mathrm{WS}_{2}, \mathrm{VS}_{2}, \mathrm{NbS}_{2}, \mathrm{ZrS}_{2}, \mathrm{TiS}_{2}$, $\mathrm{NbSe}_{2}, \mathrm{WSe}_{2}, \mathrm{MoSe}_{2}, \mathrm{ZrSe}_{2}, \mathrm{WTe}_{2}$, and $\mathrm{MoTe}_{2}$, and layered semiconductor chalcogenides such as GaSe, GaTe, InSe, $\mathrm{Bi}_{2} \mathrm{Se}_{3}$, and $\mathrm{Bi}_{2} \mathrm{Te}_{3}$. $2 \mathrm{D}$ materials represented by different colors denote their stability under ambient conditions. 2D materials among the graphene family have been extensively studied so far. 2D TMDs such as $\mathrm{MoS}_{2}, \mathrm{WS}_{2}, \mathrm{WSe}_{2}$ and $\mathrm{MoSe}_{2}$ are structurally similar. Among 2D TMDs, W based materials have stronger spin-orbit coupling while Se materials exhibit lower stability.

Research activities into 2D TMDs were intensified after the monolayers of $\mathrm{MoS}_{2}$ showed high carrier mobility of $100 \mathrm{~cm}^{2}$ $\mathrm{V}^{-1} \mathrm{~s}^{-1}$ and on/off current ratios of $>10^{8}$ because of the interesting bandgap of $\mathrm{MoS}_{2} \cdot{ }^{33}$ The monolayers of $\mathrm{MoS}_{2}$ are direct semiconductors whereas $\mathrm{MoS}_{2}$ bilayers, trilayers, few-layers are indirect semiconductors. Thickness dependent bandgap energies of 2D TMDs-based semiconductors, including $\mathrm{MoS}_{2}$, $\mathrm{MoSe}_{2}, \mathrm{MoTe}_{2}, \mathrm{WS}_{2}$, and $\mathrm{WSe}_{2}(2 \mathrm{H}-\mathrm{MX} 2)$, were calculated by
Yun et al. ${ }^{34}$ using the first-principles calculations as shown in Fig. $1 .^{34}$ As the number of layers in the TMDs is reduced to a single layer, the band curvatures lead to significant changes of effective masses. When a single layer of the TMDs is strained, the direct bandgap turns to an indirect bandgap. It was found that bandgap energy and effective masses are reduced by tensile strain, contrary to the compressive strain that increases both parameters. Also the applied larger tensile stress gives rise to a metallic character. This study emphasized the electronic structures of 2D TMDs.

The photoluminescence and absorption spectra of monolayers of $\mathrm{MoS}_{2}, \mathrm{MoSe}_{2}, \mathrm{WS}_{2}$, and $\mathrm{WSe}_{2}$ have been measured. ${ }^{35}$ TMDs as bulk crystals are indirect-bandgap semiconductors, however they become direct-bandgap semiconductors as their thickness is reduced to monolayers. The bandgap increases as the number of layers decreases. Photoluminescence peaks at

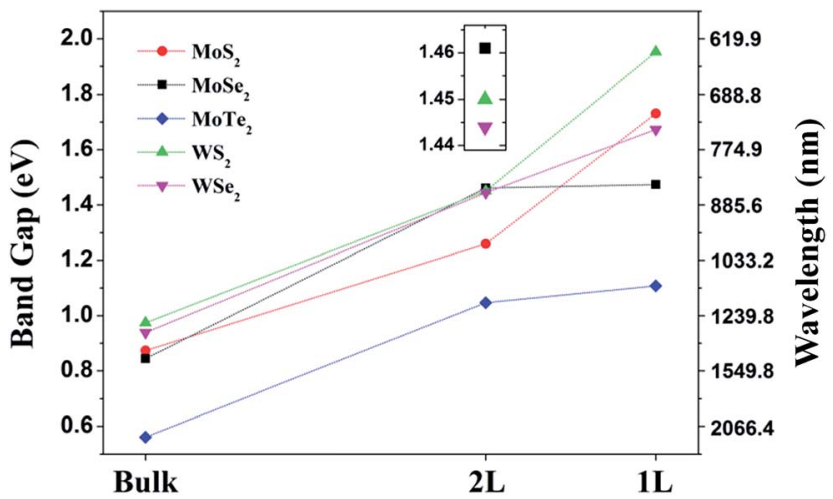

Fig. 1 Colored lines representing thickness dependence of bandgap energies of 2D TMDs including $\mathrm{MoS}_{2}, \mathrm{MoSe}_{2}, \mathrm{MoTe}_{2}, \mathrm{WS}_{2}$, and $\mathrm{WSe}_{2}$ attain ( $2 \mathrm{H}-\mathrm{MX}_{2}$ semiconductors). Reprinted with permission from ref. 34, W. S. Yun, S. W. Han, S. C. Hong, I. G. Kim and J. D. Lee, thickness and strain effects on electronic structures of transition metal dichalcogenides: $2 \mathrm{H}-M X_{2}$ semiconductors ( $\left.M=M o, W ; X=S, S e, T e\right)$. Phys. Rev. B, 2012, 85, 033305. Copyright@ American Physical Society. 
$1.84 \mathrm{eV}$ for $\mathrm{MoS}_{2}, 1.65 \mathrm{eV}$ for $\mathrm{WSe}_{2}$ and $1.56 \mathrm{eV}$ for $\mathrm{MoSe}_{2}$ have been observed. ${ }^{36}$ The indirect bandgap at $1.2 \mathrm{eV}$ for bulk crystals of $\mathrm{WSe}_{2}$ was reported, ${ }^{37}$ whereas the monolayer showed a photoluminescence peak at $1.65 \mathrm{eV}(752 \mathrm{~nm})$. In the case of bulk crystals of $\mathrm{MoSe}_{2}$, the indirect bandgap was measured as $1.1 \mathrm{eV}$ $(1.13 \mu \mathrm{m})$ while the monolayer exhibited a photoluminescence peak at $1.57 \mathrm{eV}$ (792 nm). The photoluminescence emission peak for monolayer $\mathrm{WS}_{2}$ appeared at $1.97 \mathrm{eV} .^{38}$
Mechanical exfoliation is the most common approach for peeling off monolayers or a few-layers of TMD materials from their bulk crystals, ${ }^{39-41}$ which is a top-down method. A second widely used approach is chemical vapor deposition (CVD), which is a bottom-up method to consecutively deposit desired thickness layers of TMDs. ${ }^{\mathbf{4 2}-45}$ Other approaches for preparing layers of TMDs include chemical, ${ }^{46}$ lithium intercalation, ${ }^{47-49}$ and ultrasonic-assisted liquid exfoliation in organic solvents, ${ }^{50-54}$ and salt-assisted liquid-phase exfoliation, ${ }^{55}$ all of
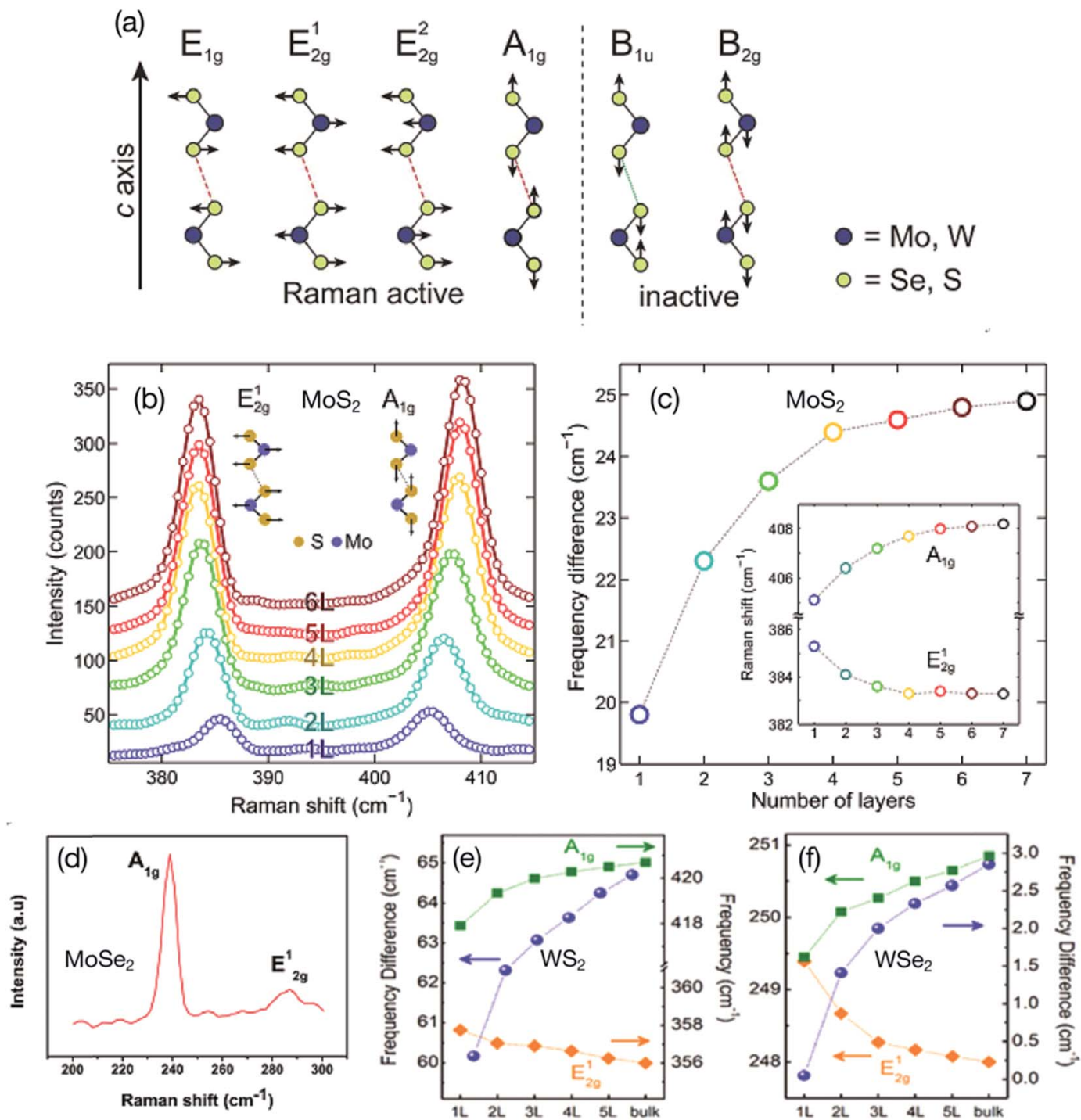

Fig. 2 (a) Schematic representation of the four Raman active modes and two Raman inactive modes of $T M D s M X_{2}(M=M o, W$ and $X=S e, S e)$. Reprinted with permission from ref. 37, P. Tonndorf, R. Schmidt, P. Böttger, X. Zhang, J. Borner, A. Liebig, M. Albrecht, C. Kloc, O. Gorgan, D. R. T. Zahn, S. M. de Vasconcellos and R. Bratschitsch, Photoluminescence Emission and Raman Response of Monolayer MoS 2 MoSe 2 , and WSe 2 . Opt.

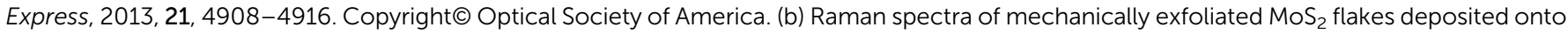
a transparent poly(dimethylsiloxane) (PDMS) substrate with different number of layers, single-layer to six-layers of $\mathrm{MoS}_{2}$. (c) Peak frequency difference $(\Delta)$ between Raman modes as a function of the number of $\mathrm{MoS}_{2}$ layers. Reprinted with permission from ref. 60, A. Castellanos-Gomez, J. Quereda, H. P. van der Meulen, N. Agraït and G. Rubio-Bollinger, spatially resolved optical absorption spectroscopy of single-and few-layer $\mathrm{MoS}_{2}$ by hyperspectral imaging. Nanotechnol., 2016, 27, 115705. Copyright@ Institute of Physics (IOP). (d) Raman spectrum of few-layer MoSe 2 nanosheets showing two distinct Raman active modes; $A_{1 g}$ and $E_{2 g}^{1}$. Reprinted with permission from ref. $61, S$. K. Balasingam, J. S. Lee and $Y$. Jun, few-layered $\mathrm{MoSe}_{2}$ nanosheets as an advanced electrode material for supercapacitors, Dalton Trans., 2015, 44, 15491-15498. Copyright@ Royal Society of Chemistry. (e, f) Thickness dependence of Raman $A_{1 g}$ and $E_{2 g}^{1}$ modes of 1 to 5 layers and bulk WS $\mathrm{S}_{2}$ and WSe $\mathrm{W}_{2}$. Reprinted with permission from ref. 62, W. Zhao, Z. Ghorannevis, K. K. Amara, J. R. Pang, M. Toh, X. Zhang, C. Kloc, P. H. Tan and G. Eda, lattice dynamics in mono-and fewlayer sheets of $\mathrm{WS}_{2}$ and $\mathrm{WSe}_{2}$. Nanoscale, 2013, 5, 9677-9683. Copyright@ Royal Society of Chemistry. 
which can prepare mono-layers to multi-layers of TMDs, such as $\mathrm{MoS}_{2}, \mathrm{MoSe}_{2}, \mathrm{WS}_{2}$, and $\mathrm{WSe}_{2}$.

Raman scattering methods for single-layer, multi-layer and bulk 2D TMDs, including $\mathrm{MoS}_{2}, \mathrm{MoSe}_{2}, \mathrm{WS}_{2}$, and $\mathrm{WSe}_{2}$, in terms of phonons with respect to the number of layers, has been reviewed and analyzed..$^{56,57}$ Tonndorf et al. ${ }^{37}$ studied photoluminescence and Raman characteristics of the monolayers of $\mathrm{MoS}_{2}, \mathrm{MoSe}_{2}$, and $\mathrm{WSe}_{2}$. Fig. 2a shows a schematic representation of the four Raman active modes and two Raman inactive modes of $\mathrm{TMDs} \mathrm{MX}_{2}(\mathrm{M}=\mathrm{Mo}, \mathrm{W}$ and $\mathrm{X}=\mathrm{Se}, \mathrm{Se})$ as predicted for the D6h point group..$^{58}$ The Raman active modes include three inplane modes referred as $\mathrm{E}_{1 \mathrm{~g}}$, $\mathrm{E}_{2 \mathrm{~g}}^{1}$, and $\mathrm{E}_{2 \mathrm{~g}}^{2}$, and one out-of-plane mode referred as $\mathrm{A}_{1 \mathrm{~g}}$. However, experimentally only the two active Raman modes $\mathrm{E}_{2 \mathrm{~g}}^{1}$ and $\mathrm{A}_{1 \mathrm{~g}}$ were observed. The active Raman $E_{2 g}^{2}$, mode appears at very low frequencies, whereas the $\mathrm{E}_{1 \mathrm{~g}}$ mode is forbidden. ${ }^{59} \mathrm{~A}$ systematic study of the optical absorption of single-layer and few-layers of $\mathrm{MoS}_{2}$ from the $385 \mathrm{~nm}(3.22 \mathrm{eV})$ to $1000 \mathrm{~nm}(1.24 \mathrm{eV})$ spectral range was conducted by Castellanos-Gomez et $a .^{60}$ using a hyperspectral imaging technique. Poly(dimethylsiloxane) (PDMS) was used as a transparent substrate for depositing mechanically exfoliated $\mathrm{MoS}_{2}$ thin films. The optical absorbance spectra of $\mathrm{MoS}_{2}$ flakes consisting of single-layer to six-layer were recorded as a function of different excitation wavelengths. The bandgap of a monolayer $\mathrm{MoS}_{2}$ was measured as $1.85 \mathrm{eV}$, which decreased with increasing number of $\mathrm{MoS}_{2}$ layers, reaching a bandgap value of $1.35 \mathrm{eV}$ for the bulk $\mathrm{MoS}_{2}$. Fig. $2 \mathrm{~b}$ and $\mathrm{c}$ shows Raman spectra for the $\mathrm{E}_{2 \mathrm{~g}}^{1}$ and $\mathrm{A}_{1 \mathrm{~g}}$ modes of the exfoliated $\mathrm{MoS}_{2}$ flakes ranging from single-layer to six-layer, and the variation of peak frequency difference $(\Delta)$ between the $E_{2 g}^{1}$ and $A_{1 g}$ modes as a function of the number of $\mathrm{MoS}_{2}$ layers. The $\Delta$ value increases with the increasing number of layers from $19.8 \mathrm{~cm}^{-1}$ for a single-layer to $25 \mathrm{~cm}^{-1}$ for bulk $\mathrm{MoS}_{2}$.

Raman spectroscopy for few-layer $\mathrm{MoSe}_{2}$ nanosheets was recorded by Balasingam et al. ${ }^{61}$ which showed Raman peaks at $239 \mathrm{~cm}^{-1}$ and $287.11 \mathrm{~cm}^{-1}$ (Fig. 2d) corresponding to the $A_{1 g}$ mode (out-of-plane) and $\mathrm{E}_{2 \mathrm{~g}}^{1}$ mode (in-plane) of $\mathrm{MoSe}_{2}$, respectively. For bulk crystal $\mathrm{MoSe}_{2}$, the $\mathrm{A}_{1 \mathrm{~g}}$ and $\mathrm{E}_{2 \mathrm{~g}}^{1}$ modes appear at $242 \mathrm{~cm}^{-1}$ and $286 \mathrm{~cm}^{-1}$, respectively. The red shift in the $\mathrm{A}_{1 \mathrm{~g}}$ mode and a blue shift in the $\mathrm{E}_{2 \mathrm{~g}}^{1}$ mode indicate the formation of a few-layered $\mathrm{MoSe}_{2}$ nanosheet. Raman spectra of monolayers, few-layers and bulk $\mathrm{WS}_{2}$ and $\mathrm{WSe}_{2}$ were evaluated by Zhao et al. ${ }^{62}$ Thickness dependent Raman $\mathrm{A}_{1 \mathrm{~g}}$ and $\mathrm{E}_{2 \mathrm{~g}}^{1}$ modes of 1 to 5 layers, as well as bulk $\mathrm{WS}_{2}$ and $\mathrm{WSe}_{2}$, are shown in (Fig. 2e and f). As discussed above, the frequency difference $(\Delta)$ can be used to distinguish the number of layers. McCreary et al. ${ }^{38}$ reported the $\mathrm{E}_{2 \mathrm{~g}}^{1}$ mode at $357.5 \mathrm{~cm}^{-1}$ (in-plane) and $\mathrm{A}_{1 \mathrm{~g}}$ mode at $419 \mathrm{~cm}^{-1}$ (out-of-plane) with a frequency difference $(\Delta)$ of $61.5 \mathrm{~cm}^{-1}$ for $\mathrm{WS}_{2}$ monolayer. Photoluminescence emission and Raman scattering of 2D TMDs have been extensively studied and analyzed by several research groups around the world. ${ }^{63-71}$

\section{TMD-based counter electrodes for DSSCS}

The new materials used as CEs in DSSC devices are generally characterized by their molecular structure and surface morphology using a wide variety of spectroscopic techniques, including X-ray diffraction (XRD), Raman spectroscopy, X-ray photoelectron spectroscopy (XPS), UV-vis (Ultraviolet-visible) spectrometry, atomic force microscopy (AFM), field-emission scanning electron microscopy (FESEM), high-resolution transmission electron microscopy (HRTEM) and energy dispersive Xray spectroscopy (EDX). The electrochemical catalytic activity and photovoltaic performance of CEs in DSSCs are evaluated using different methods. Electrocatalytic activity can be evaluated by cyclic voltammetry (CV), rotating disk electrode (RDE) for determining rate constant and effective catalytic surface area, interfacial charge transfer parameters (series resistance and charge-transfer resistance) measurements by electrochemical impedance spectroscopy (EIS) and Tafel polarization plots for electrocatalytic ability, incident photon-to-current conversion efficiency (IPCE) spectra measurements; these measurements of a DSSC device and their electro-catalytic activities are compared with a standard Pt CE. Photovoltaic tests of a DSSC device are performed by measuring photocurrent density-voltage $(J-V)$ characteristic curves of CEs under

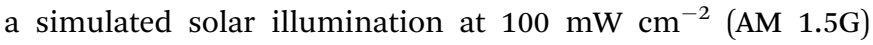
corresponding to 1 Sun intensity unless specified for other sunlight intensity. The photovoltaic and electrochemical parameters of the DSSC system include short-circuit photocurrent density $\left(J_{\mathrm{sc}}\right)$, open-circuit voltage $\left(V_{\mathrm{oc}}\right)$, fill factor $(\mathrm{FF})$, power conversion efficiency (PCE) which is the solar-to-electricity conversion efficiency $(\eta)$, series resistance $\left(R_{\mathrm{S}}\right)$, charge-transfer resistance $\left(R_{\mathrm{CT}}\right)$ at the $\mathrm{CE} /$ electrolyte interface, capacitance, and Nernst diffusion impededance $\left(Z_{\mathrm{N}}\right)$. When using a new material as a CE catalyst, the electrochemical and photovoltaic properties of a DSSC device are compared with a conventional Pt CE due to its optimal electrocatalytic activity and chemical stability in the electrolyte. The dye-adsorbed $\mathrm{TiO}_{2}$ mesoporous film deposited on a FTO glass substrate is used as a photoanode (working electrode) of the DSSC device. The ruthenium N719 dye has been commonly used for the reduction of triiodide $\left(\mathrm{I}_{3}{ }^{-}\right)$ to iodide $\left(\mathrm{I}^{-}\right)$. DSSCs are assembled with different CEs to be studied, and filled with the same redox electrolyte solution such as triiodide/iodide $\left(\mathrm{I}_{3}{ }^{-} / \mathrm{I}^{-}\right)$redox couple. The CE reduces the triiodide $\left(\mathrm{I}_{3}{ }^{-}\right)$ions to iodide ions $\left(\mathrm{I}^{-}\right)$. For example, a typical iodide electrolyte solution contains $0.1 \mathrm{M}$ of LiI, $0.05 \mathrm{M}$ of iodine $\left(\mathrm{I}_{2}\right), 0.6 \mathrm{M}$ of 1,2-dimethyl-3- $n$-propylimidazolium iodide (DMPII), and 0.5 M of 4-tert-butylpyridine (TBP) in acetonitrile. All these spectroscopic techniques and electrochemical measurements were performed, which have been discussed throughout this review as needed in order to evaluate the potential of 2D TMDs (such as $\mathrm{MoS}_{2}, \mathrm{WS}_{2}, \mathrm{TiS}_{2}, \mathrm{FeS}_{2}, \mathrm{CoS}_{2}, \mathrm{NiS}_{2}$, $\mathrm{SnS}_{2}, \mathrm{MoSe}_{2}, \mathrm{NbSe}_{2}, \mathrm{TaSe}_{2}, \mathrm{NiSe}_{2}, \mathrm{FeSe}_{2}, \mathrm{CoSe}_{2}, \mathrm{Bi}_{2} \mathrm{Se}_{3}$ and their based hybrids/composites) as CEs for fabricating low-cost Ptfree DSSCs.

\section{1 $\mathrm{MoS}_{2}$ counter electrodes}

3.1.1 Pristine $\operatorname{MoS}_{2}$. TMDs have been traditionally used as solid lubricants ${ }^{72-80}$ but recently have found the potential for applications in the fields of electronics and photonics. Like 2D graphene-based materials, layered transition-metal 
dichalcogenides $\mathrm{MX}_{2}(\mathrm{M}=\mathrm{W}$, Mo, Hf, Nb, Re, Ta; $\mathrm{X}=\mathrm{S}, \mathrm{Se}, \mathrm{Te})$ have become of great interest due to their unique electronic and photonic properties and a very wide range of applications in field-effect transistors (FETs), ${ }^{\mathbf{8 1}-99}$ photodetectors, ${ }^{100-102}$ lightemitting diodes (LEDs), ${ }^{\mathbf{1 0 3 , 1 0 4}}$ ferroelectric memories, ${ }^{\mathbf{1 0 5}}$ static random access memory (RAM), ${ }^{\mathbf{3}}$ high-frequency resonators, ${ }^{\mathbf{1 0 6}}$ supercapacitors, ${ }^{\mathbf{1 0 7 , 1 0 8}}$ energy conversion and storage devices, ${ }^{109-112}$ gas sensors, ${ }^{113,114}$ biosensors, ${ }^{115,116}$ biomedical applications, ${ }^{117}$ organic solar cells, ${ }^{118}$ and photonics/ optoelectronics. ${ }^{\mathbf{1 1 9 , 1 2 0}}$

TMDs are one of the $2 \mathrm{D}$ graphene analogs which show great potential for both bulk-heterojunction (BHJ) and dye-sensitized solar cells. A review article on atomically thin $\mathrm{MoS}_{2}$ layers used as the electron-transport layer (ETL), hole-transport layer (HTL), interfacial layer, and protective layer in fabricating bulkheterojunction (BHJ) solar cells has been recently published by Singh et al. ${ }^{118}$ Here, the applications of $\mathrm{MoS}_{2}$ thin films as CEs for fabricating Pt-free dye-DSSCs are discussed.

Polytypism in $\mathrm{MoS}_{2}$ has been studied by using Raman spectroscopy. ${ }^{121}$ Layered $\mathrm{MoS}_{2}$ exists in 2H, 3R and 1T phases where monolayers are stacked in a different sequence. ${ }^{\mathbf{1 2 2 - 1 2 4}}$ The semiconducting $2 \mathrm{H}-\mathrm{MoS}_{2}$ phase of the bulk crystal contains two-layer per unit cell stacked in a hexagonal symmetry, where each Mo atom is coordinated with six sulfur (S) atoms. The 3R$\mathrm{MoS}_{2}$ phase contains three-layer per unit cell stacked in a rhombohedral symmetry. The metallic $1 \mathrm{~T}$ phase contains one $\mathrm{MoS}_{2}$ layer per unit cell in tetragonal symmetry with octahedral coordination. A structural phase transition of $2 \mathrm{H}-\mathrm{MoS}_{2}$ to $1 \mathrm{~T}-$ $\mathrm{MoS}_{2}(2 \mathrm{H} \rightarrow 1 \mathrm{~T})$ has been reported due to a lithium ion

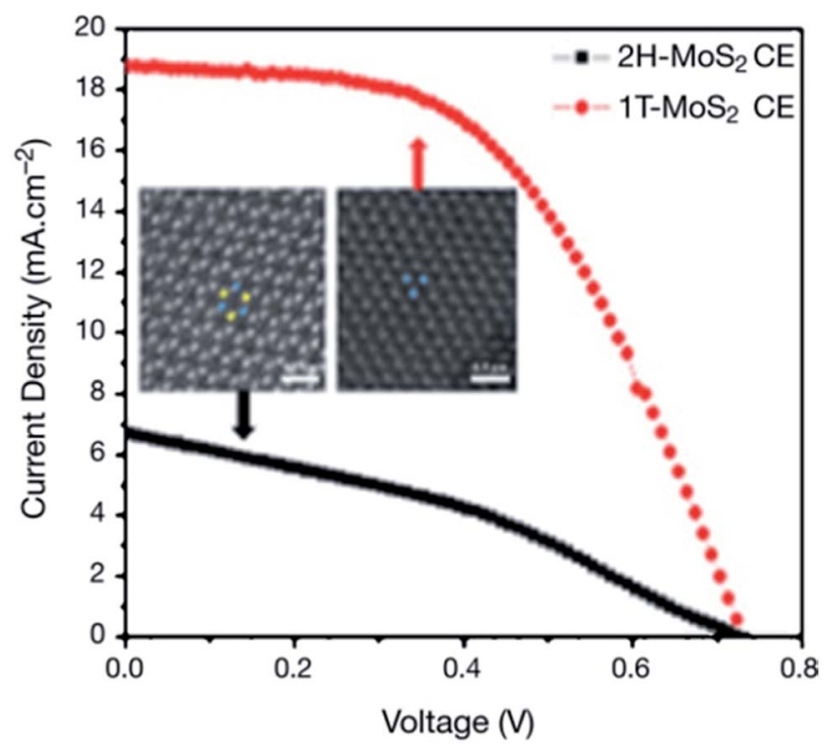

Fig. 3 Photocurrent density-voltage $\left(\mathrm{J}-\mathrm{V}\right.$ ) curves of $2 \mathrm{H}$-type $\mathrm{MOS}_{2}$ and flower-structured $1 \mathrm{~T}$ metallic phase $\mathrm{MoS}_{2}$. Insert shows highangle annular dark-field scanning transmission electron microscopy (HAAD-FSTEM) confirming $2 \mathrm{H}$ and $1 \mathrm{~T}$ metallic phase of $\mathrm{MoS}_{2}$. Reprinted with permission from ref. 130, W. Wei, K. Sun and Y. H. Hu, an efficient counter electrode material for dye-sensitized solar cellsflower-structured 1T metallic phase $\mathrm{MoS}_{2}$. J. Mater. Chem. A, 2016, 4, 12398-12401. Copyright@ Royal Society of Chemistry. intercalation process. ${ }^{\mathbf{1 2 2 - 1 2 5}}$ The metallic $1 \mathrm{~T}$ phase of $\mathrm{MoS}_{2}$ exhibits very interesting electronic properties. ${ }^{\mathbf{1 2 6 - 1 2 9}}$ Therefore, Wei et al. ${ }^{130}$ used metastable $1 \mathrm{~T}$ metallic phase $\mathrm{MoS}_{2}$ in fabricating DSSCs. In that work, $\mathrm{MoS}_{2}$ films were deposited on FTO glass substrate by a hydrothermal method, performing reactions at 180 or $200{ }^{\circ} \mathrm{C}$ for 24 hours. The $\mathrm{MoS}_{2}$ films prepared at $200{ }^{\circ} \mathrm{C}$ showed lumps, while those grown at $180{ }^{\circ} \mathrm{C}$ had flowerlike structures. High-angle annular dark-field scanning transmission electron microscopy (HAAD-FSTEM) images, Raman spectroscopy, and XPS also showed the formation of $2 \mathrm{H}$ and $1 \mathrm{~T}$ metallic phases of $\mathrm{MoS}_{2}$. Fig. 3 represents the $J-V$ curves of $2 \mathrm{H}-$ $\mathrm{MoS}_{2}$ and flower-structured 1T metallic phase $\mathrm{MoS}_{2}$. The flowerstructured 1T metallic $\mathrm{MoS}_{2}$ film was grown onto an FTO substrate as a CE of DSSC, which exhibited PCE $(\eta)$ of $7.08 \%$, that is a three times higher PCE compared with $2 \mathrm{H}$ phase $\mathrm{MoS}_{2}$ $(\eta=1.72 \%)$ and comparable to a Pt CE $(\eta=7.25 \%)$. Such a large difference in PCE values of $1 \mathrm{~T}$ and $2 \mathrm{H}$ phases occurs because the electrical conductivity of $1 \mathrm{~T}-\mathrm{MoS}_{2}$ is $10^{7}$ times larger compared with $2 \mathrm{H}-\mathrm{MoS}_{2}$, which gives rise to a higher electrocatalytic activity for the $1 \mathrm{~T}$ phase than that of the $2 \mathrm{H}$ phase. The $1 \mathrm{~T}-\mathrm{MoS}_{2} \mathrm{CE}$ also demonstrated lower charge-transfer resistance $\left(R_{\mathrm{CT}}\right)$. The IPCE curves and $\mathrm{CV}$ measurements also showed a better electrocatalytic activity of $1 \mathrm{~T}-\mathrm{MoS}_{2} \mathrm{CE}$ in DSSC than that of $2 \mathrm{H}-\mathrm{MoS}_{2}$.

A very interesting study was conducted by Infant et al. ${ }^{131}$ who developed CE materials for DSSCs by vertically oriented $\mathrm{MoS}_{2}$ on an FTO substrate, in order to increase the reflectivity of $\mathrm{MoS}_{2} \mathrm{CE}$. Fig. 4 shows high resolution SEM images of CVD-deposited $\mathrm{MoS}_{2}$ thin films, the reflectivity of $\mathrm{MoS}_{2} \mathrm{CE}$ measured by UV-vis spectrophotometer, and CV measurements using standard hydrogen electrode (SHE) as a reference electrode. The high quality thin films of $\mathrm{MoS}_{2}$ were obtained at the optimum conditions of $600{ }^{\circ} \mathrm{C}$ with a 15 minute reaction time at a flow rate of $50 \mathrm{sccm}$. The FTO substrate is damaged if temperature is increased above $600{ }^{\circ} \mathrm{C}$ and the reaction time is over 15 minutes, leading to excessive deposition of sulfur on the surface. The layered $\mathrm{MoS}_{2}$ thin films are polycrystalline and have $0.18-0.27 \mathrm{~nm}$ spacing as evidenced by the TEM image and SEAD pattern. The CVD-prepared $\mathrm{MoS}_{2}$ thin films are vertically oriented on the FTO substrate, which yields more active sites and eventually enhance the reflectivity so that more photons are absorbed, and also created active edge sites facilitating the generation of the $\mathrm{I}^{-} / \mathrm{I}_{3}{ }^{-}$redox couple. The reflectance of vertically inclined $\mathrm{MoS}_{2}$ films on the FTO substrate was measured by a UV-vis spectrophotometer between 350$800 \mathrm{~nm}$ wavelength for reaction temperatures varying from 400 to $700{ }^{\circ} \mathrm{C}$, a reaction time ranging from 5 to 30 minutes, and different flow rates of Ar gas (Fig. 4). The maximum reflectance of $38 \%$ was observed for a vertically inclined $\mathrm{MoS}_{2}$ thin film under optimized conditions, due to high crystallinity, and the inclined angle of $26^{\circ}$ was estimated that supports the reflectivity of photons to dye molecules. The reflectivity of $38 \%$ was observed for $\mathrm{MoS}_{2}$ thin films prepared at $50 \mathrm{sccm}$ due to its crystallinity and higher inclination angle, which contributes to more absorption photons, and hence leads to a higher PCE of $7.50 \%$ compared to PCE of $7.38 \%$ for $150 \mathrm{sccm}$ with $25 \%$ reflectivity, due to smaller angle of $\mathrm{MoS}_{2}$ inclination. This approach yielded a PCE of $7.50 \%$ for the $\mathrm{MoS}_{2} \mathrm{CE}$, exceeding the PCE of Pt based CE $(\eta=$ 

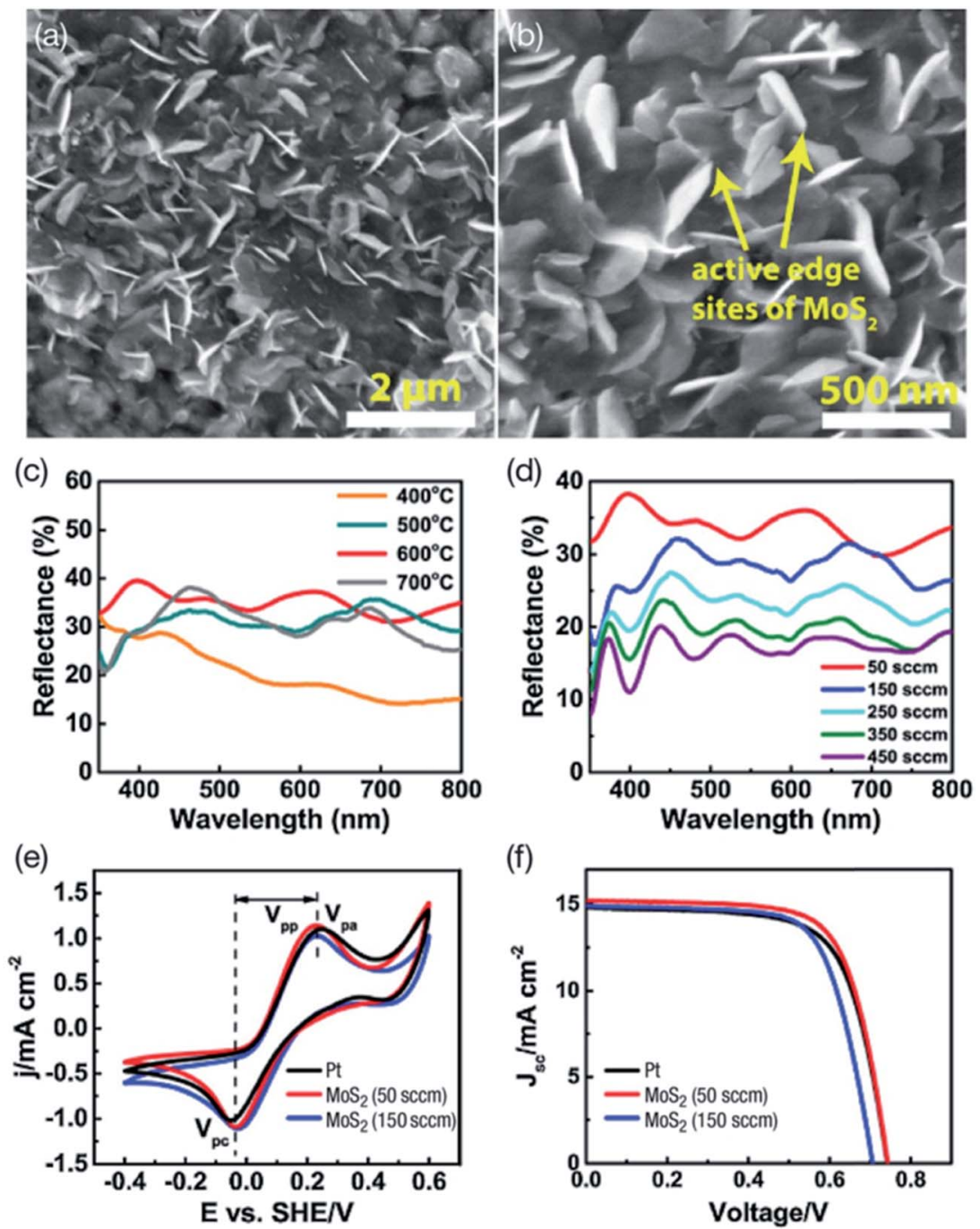

Fig. 4 SEM (a) and high resolution SEM (b) of CVD-deposited $\mathrm{MoS}_{2}$ thin films. The highest quality thin films of $\mathrm{MoS}_{2}$ were prepared at $600{ }^{\circ} \mathrm{C}$ with 15 minute reaction time at the Ar flow rate of $50 \mathrm{sccm}$. (c) Optical properties of $\mathrm{MoS}_{2}$ thin films between 350-800 nm range prepared at different temperature. (d) Flow rates of Ar gas between 50 to $450 \mathrm{sccm}$ for preparing $\mathrm{MoS}_{2}$ thin films by CVD technique. (e) Cyclic voltammetry (CV) plots using standard hydrogen electrode (SHE) as a reference electrode and (f) photocurrent density-voltage $(J-V)$ curves of MoS 2 and Pt based $C E s$ prepared at 50 and $150 \mathrm{sccm}$ flow rates of Ar gas. Reprinted with permission from ref. 131, R. S. Infant, X. Xu, W. Yang, F. Yang, L. Hou and Y. Li, highly active and reflective $\mathrm{MoS}_{2}$ counter electrode for enhancement of photovoltaic efficiency of dye sensitized solar cells. Electrochim. Acta, 2016, 212, 614-620. Copyright@ Elsevier.

7.28\%). The $\mathrm{MoS}_{2}$ CE shows a higher $J_{\mathrm{sc}}$ value of $15.2 \mathrm{~mA} \mathrm{~cm}{ }^{-2}$, and is higher than Pt CE $\left(J_{\mathrm{sc}}=14.6 \mathrm{~mA} \mathrm{~cm}{ }^{-2}\right)$ due to high reflectivity. The $R_{\mathrm{CT}}$ of $\mathrm{MoS}_{2} \mathrm{CE}$ was lower than Pt CE, indicating the higher electro-catalytic activity of vertically inclined $\mathrm{MoS}_{2}$ film on the FTO substrate was due to more active edge sites, which gives rise to enhanced electrocatalytic activity of the $\mathrm{MoS}_{2} \mathrm{CE}$. Two redox peaks are observed in the CV curves of Pt and $\mathrm{MoS}_{2}$ CEs, one corresponding to the reduction of $\mathrm{I}_{3}{ }^{-}$, which is a cathodic peak $\left(V_{\mathrm{pc}}\right)$, and the other corresponding to the oxidation of $\mathrm{I}^{-}$, which is an anodic peak $\left(V_{\mathrm{pa}}\right)$. The value of anodic peak to cathodic peak separation $\left(V_{\mathrm{pp}}\right)$ was found to be less for the $\mathrm{MoS}_{2} \mathrm{CE}(0.456 \mathrm{~V})$ than that of Pt $(0.484 \mathrm{~V})$, which also indicates a better electrocatalytic activity of $\mathrm{MoS}_{2} \mathrm{CE}$ due to the presence of active edge sites, as evidenced in the SEM images.
Vertical $\mathrm{MoS}_{2}$ nanosheets on different substrates using CVD and $\mathrm{CS}_{2}$ as a sulfur precursor have been developed. ${ }^{132}$ The DSSC CEs with vertical $\mathrm{MoS}_{2}$ nanosheets showed a comparable electro-catalytic activity to $\mathrm{Pt} \mathrm{CE}$ for the triiodide $\left(\mathrm{I}_{3}{ }^{-}\right)$reduction, resulting from large specific surface areas and more active edges. Li et al. ${ }^{\mathbf{1 3 3}}$ prepared molybdenum disulfide-based CEs for DSSCs with different morphologies (multilayers, few-layers and nanoparticles) using the thermal decomposition method. The $\mathrm{X}$-ray diffraction and transmission electron microscopy showed edge area to basal-plane ratio in the following order: $\mathrm{MoS}_{2}$ nanoparticles $>$ multilayered $\mathrm{MoS}_{2}>$ few-layered $\mathrm{MoS}_{2}$. A similar order was observed for the PCE values with corresponding CEsbased DSSCs. The $\mathrm{MoS}_{2}$ nanoparticles-based $\mathrm{CE}$ had the minimum $R_{\mathrm{CT}}$, while the few-layered $\mathrm{MoS}_{2}$ based $\mathrm{CE}$ had the maximum, as measured by EIS. The active sites of $\mathrm{MoS}_{2}$ 
responsible for the reduction of triiodide lie on the edges of layered materials, instead of their basal planes. $\mathrm{MoS}_{2}$ nanoparticle CE showed the highest PCE value of 5.41\%, compared with $6.58 \%$ of Pt CE. A novel approach for improving PCE of $\mathrm{MoS}_{2}$ CE based DSSCs has been developed, ${ }^{\mathbf{1 3 4}}$ where electrocatalytic activity was enhanced by artificially generating active edge sites on $\mathrm{MoS}_{2}$ atomic layers by hole patterning. The PCE of the DSSC increased from $2 \%$ to $5.8 \%$ after applying the hole patterning approach. Al-Mamun et al. ${ }^{135}$ deposited $\mathrm{MoS}_{2}$ nanoscale thin films onto FTO substrates using a low temperature one-pot hydrazine assisted hydrothermal method. Both the hydrothermal reaction temperature as well as the different molar ratio of reaction precursors was found to impact the structure and performance of $\mathrm{MoS}_{2}$ films used as CEs for DSSCs. The $\mathrm{MoS}_{2}$ thin films having surface exposed layered nanosheets were obtained by the hydrothermal process with a molar ratio of reaction precursors as $1: 28$ of $\left(\mathrm{NH}_{4}\right)_{6} \mathrm{Mo}_{7} \mathrm{O}_{24} \cdot 4 \mathrm{H}_{2} \mathrm{O}$ and $\mathrm{NH}_{2}$ $\mathrm{CSNH}_{2}$ (thiourea) at $150{ }^{\circ} \mathrm{C}$ for 24 hours, referred to as MS-15028. The molar ratio of $\left(\mathrm{NH}_{4}\right)_{6} \mathrm{Mo}_{7} \mathrm{O}_{24} \cdot 4 \mathrm{H}_{2} \mathrm{O}$ and $\mathrm{NH}_{2} \mathrm{CSNH}_{2}$ was fixed at $1: 7,1: 14,1: 28$ and $1: 42$ and the hydrothermal temperature was maintained at either $120,150,180$ or $210{ }^{\circ} \mathrm{C}$. The DSSCs having $\mathrm{MoS}_{2}$ CEs fabricated using different molar ratios of reaction precursors at a temperature of $150{ }^{\circ} \mathrm{C}$ (referred to as MS-150-7, MS-150-14, MS-150-28 and MS-150-42) exhibited PCEs of 3.70, 4.97, 7.41 and $4.96 \%$, respectively. The DSSCs with MS-120-28, MS-180-28, and MS-210-28 CEs showed PCEs of 5.52, 7.15 and $5.47 \%$, respectively. The $\mathrm{MoS}_{2}$ film based CEs showed a PCE of $7.41 \%$, higher than the Pt electrode based DSSCs $(\eta=$ 7.13\%) using $\mathrm{TiO}_{2}$ photoanodes sensitized by N719 dye.

Pulse electrochemical deposited thin films of molybdenum sulfide $\left(\mathrm{MoS}_{x}\right)$ on indium tin oxide/poly(ethylene naphthalate) (ITO/PEN) substrates have been studied as flexible CEs for DSSC, and these showed a PCE of $4.39 \%$ for the triiodide $\left(\mathrm{I}_{3}{ }^{-}\right)$ reduction. ${ }^{136}$ The nanostructured $\mathrm{MoS}_{2}$ thin films developed by a low-temperature thermally reduced technique on a FTO substrate have also been used for DSSCs. ${ }^{137} \mathrm{MoS}_{2}$ thin film annealed at $300{ }^{\circ} \mathrm{C}$ were also used as CEs for DSSCs, which showed a PCE of $6.351 \%$, slightly lower than the Pt reference CE ( $\eta=6.929 \%$ ). The performance of DSSCs was impacted by the molar ratio of reaction precursors and the temperature of thermal reaction. Thermally reduced (TR) $\mathrm{MoS}_{2}$ thin film annealed at $250{ }^{\circ} \mathrm{C}$ showed PCE of $1.917 \%$, while those annealed at $350{ }^{\circ} \mathrm{C}$ showed PCE of $3.479 \%$. The $300{ }^{\circ} \mathrm{C}$ annealed TR- $\mathrm{MoS}_{2} \mathrm{CE}$ also has larger exchange current density than those of $250{ }^{\circ} \mathrm{C}$ and $350{ }^{\circ} \mathrm{C}$ annealed TR-MoS ${ }_{2} \mathrm{CEs}$ and comparable with thermally deposited (TD) Pt CE. The $R_{\mathrm{CT}}$ values that correspond to the charge-transfer resistance at the electrolyte-electrode interface were $14.98 \Omega \mathrm{cm}^{2}$ for TD-Pt CE and $30.98,141.41 \Omega \mathrm{cm}^{2}$ for TR- $\mathrm{MoS}_{2}$ CEs annealed at $300{ }^{\circ} \mathrm{C}$ and $350{ }^{\circ} \mathrm{C}$, respectively. TR- $\mathrm{MoS}_{2} \mathrm{CEs}$ annealed at $250{ }^{\circ} \mathrm{C}$ has no $R_{\mathrm{CT}}$ value being too large. The annealing temperature of $300{ }^{\circ} \mathrm{C}$ generates much larger active area, providing the highest electrocatalytic activity for the reduction of $\mathrm{I}_{3}{ }^{-}$, while $350{ }^{\circ} \mathrm{C}$ annealing decreases the active sites of the edge-planes in $\mathrm{MoS}_{2}$. A PCE of 7.01\% was achieved for DSSCs using pristine $\mathrm{MoS}_{2}$ as a CE, chemically synthesized by low-temperature wet-chemical process, which has a comparable PCE of $7.31 \%$ for DSSCs with Pt CEs. ${ }^{138}$ The $R_{\mathrm{S}}$ and $R_{\mathrm{CT}}$ values of 23.51 and $18.50 \Omega \mathrm{cm}^{2}$, respectively, for the $\mathrm{MoS}_{2} \mathrm{CE}$ were lower than those of Pt CE (26.73 and $22.88 \Omega \mathrm{cm}^{2}$ ), suggesting better electro-catalytic activity of $\mathrm{MoS}_{2}$ for the reduction of triiodide $\left(\mathrm{I}_{3}{ }^{-}\right)$.

A correlation between the electrical conductivity of the $\mathrm{CE}$, PCE, and the crystallinity of $\mathrm{MoS}_{2}$ was also demonstrated. ${ }^{139}$ The XRD, XPS, EIS and Hall measurements established a link between the PCE, carrier concentration, mobility, and $J_{\text {sc }}$ value. The DSSCs having pristine (non-annealed), vacuum-annealed and $\mathrm{N}_{2}$-annealed $\mathrm{MoS}_{2}$ CEs showed PCE values of 1.0, 1.7 and $0.8 \%$, respectively. Thermal annealing in vacuum was found to reduce the over-potential that leads to an increased $J_{\mathrm{sc}}$ value of $7.95 \mathrm{~mA} \mathrm{~cm}^{-2}$ due to high $\mathrm{MoS}_{2}$ crystallinity, whereas the $\mathrm{N}_{2}$ annealing of $\mathrm{MoS}_{2}$ CEs increases over-potential, which gives rise to lower $J_{\mathrm{sc}}$ value of $4.35 \mathrm{~mA} \mathrm{~cm}{ }^{-2}$ due to the poor crystallinity of $\mathrm{MoS}_{2}$. Interestingly, the electrical conductivity of $\mathrm{MoS}_{2}$ CEs follows the order: $\mathrm{N}_{2}$-annealed > vacuum-annealed > nonannealed $\mathrm{MoS}_{2}$. This indicates that the PCE of the DSSCs is influenced by the over-potential that involves an electron transferring from the $\mathrm{MoS}_{2} \mathrm{CE}$ to the electrolyte, instead of the electrical conductivity of the CE. Antonelou et al. ${ }^{\mathbf{1 4 0}}$ reported the growth of monolayer and few-layer $\mathrm{MoS}_{2}$ films by the sulfurization of molybdenum (Mo) foils at $800{ }^{\circ} \mathrm{C}$. The few-layer thick $\mathrm{MoS}_{2}$ films were used as CEs for DSSCs for the reduction of $\mathrm{I}_{3}{ }^{-}$ to $\mathrm{I}^{-}$. The electrocatalytic activity of $\mathrm{MoS}_{2} \mathrm{CE}$ on flexible Mo substrates depends upon the number of monolayers in the DSSC. DSSCs having the $\mathrm{MoS}_{2} / \mathrm{Mo}$ CE yield a PCE of $8.4 \%$, close to Pt/FTO-based DSSCs (PCE of 8.7\%). Stability of a threemonolayer thick $\mathrm{MoS}_{2} \mathrm{CE}$ was studied for 100 consecutive cycles, where no degradation of the peak current density was noticed for 100 repeated cycles, confirming long term electrochemical stability in an electrolyte solution. $\mathrm{MoS}_{2}$ layers with 1$2 \mathrm{~nm}$ thickness showed long term chemical stability of the DSSC device for the electrolyte solution comparable to Pt CE. The increased number of active sites due to a grainy surface texture of Mo foil leads to the higher electro-catalytic activity of $\mathrm{MoS}_{2}$ films.

A very interesting comparison was made by $\mathrm{Wu}$ et al. ${ }^{\mathbf{1 4 1}}$ for chemically synthesized $\mathrm{MoS}_{2}$ and $\mathrm{WS}_{2}$ as CEs in the reduction of $\mathrm{I}_{3}{ }^{-}$to $\mathrm{I}^{-}$and disulfide/thiolate $\left(\mathrm{T}_{2} / \mathrm{T}^{-}\right)$based DSSCs. The $R_{\mathrm{CT}}$ values of $0.5 \Omega \mathrm{cm}^{2}$ for $\mathrm{MoS}_{2}$ and $0.3 \Omega \mathrm{cm}^{2}$ for $\mathrm{WS}_{2}$, respectively, compared with $R_{\mathrm{CT}}$ of $3.0 \Omega \mathrm{cm}^{2}$ for Pt CE, indicates that both $\mathrm{MoS}_{2}$ and $\mathrm{WS}_{2}$ are as effective as CEs as standard Pt for triiodide $\left(\mathrm{I}_{3}{ }^{-}\right)$reduction in DSSCs. The high FFs of 73\% for $\mathrm{MoS}_{2}$ CEs and $70 \%$ for $\mathrm{WS}_{2}$ CEs also confirm high electro-catalytic activities for the reduction of triiodide $\left(\mathrm{I}_{3}{ }^{-}\right)$to iodide $\left(\mathrm{I}^{-}\right)$. Therefore, high PCE values of $7.59 \%$ for $\mathrm{MoS}_{2}$ and $7.73 \%$ for $\mathrm{WS}_{2}$ were observed, which are comparable to the PCE of $7.64 \%$ for Pt CEs in DSSCs under simulated AM 1.5 illumination. The $Z_{\mathrm{N}}$ of $>100 \Omega$ for triiodide $\left(\mathrm{I}_{3}{ }^{-}\right)$reduction on the sulfide electrodes was found to be higher compared with a $Z_{\mathrm{N}}$ of $9.5 \Omega$ on the Pt CE. The photocurrent density voltage $(J-V)$ curves of the DSSCs having $\mathrm{MoS}_{2}, \mathrm{WS}_{2}$, and Pt based CEs for the triiodide/iodide $\left(\mathrm{I}_{3}{ }^{-} / \mathrm{I}^{-}\right)$ redox couple and disulfide/thiolate $\left(\mathrm{T}_{2} / \mathrm{T}^{-}\right)$redox couple are shown in (Fig. 5). The $\mathrm{TiO}_{2}$ film photoanode was obtained after pre-heating at $80{ }^{\circ} \mathrm{C}$ and immersing in a $5 \times 10^{-4} \mathrm{M}$ solution of N719 dye in acetonitrile/tert-butyl alcohol for 20 hours. The 

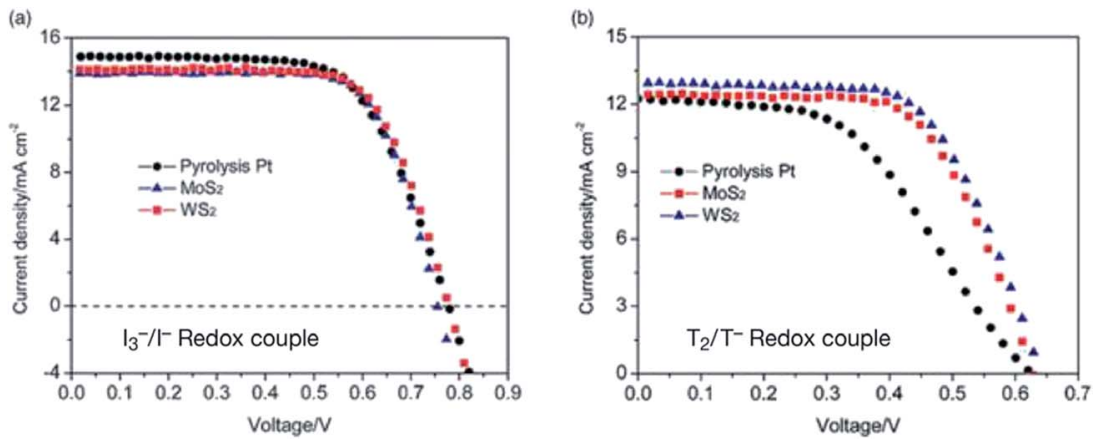

Fig. 5 (a) Photocurrent density-voltage $(J-V)$ curves of the DSSCs having $\mathrm{MoS}_{2}, \mathrm{WS}_{2}$, and Pt counter electrodes for triiodide to iodide $\left(I_{3}{ }^{-} / I^{-}\right)$ reduction. (b) J-V curves of the DSSCs using $\mathrm{MoS}_{2}, \mathrm{WS}_{2}$ and Pt CEs for redox couple of disulfide/thiolate $\left(\mathrm{T}_{2} / \mathrm{T}^{-}\right)$. Reprinted with permission from ref. 141, M. Wu, Y. Wang, X. Lin, N. Yu, L. Wang, L. Wang, A. Hagfeldt and T. Ma, economical and effective sulfide catalysts for dye-sensitized solar cells as counter electrodes. Phys. Chem. Chem. Phys., 2011, 13, 19298-19301. Copyright@ Royal Society of Chemistry/Owner Societies.

triiodide/iodide $\left(\mathrm{I}_{3}{ }^{-} / \mathrm{I}^{-}\right)$electrolyte is made of $0.06 \mathrm{M}$ of lithium

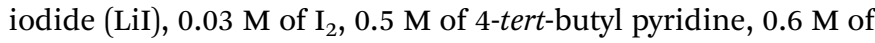
1-butyl-3-methylimidazolium iodide, and $0.1 \mathrm{M}$ of guanidinium thiocyanate in acetonitrile. The 5-mercapto-1-methyltetrazole di-5-(1-methyltetrazole) disulfide $/ N$-tetramethylammonium salt $\left({ }^{+} \mathrm{NMe}_{4} \mathrm{~T}^{-}\right)\left(\mathrm{T}_{2} / \mathrm{T}^{-}\right)$electrolyte consists of $0.4 \mathrm{M}$ of ${ }^{+} \mathrm{NMe}_{4} \mathrm{~T}^{-}$, $0.05 \mathrm{M}$ of $\mathrm{LiClO}_{4}, 0.4 \mathrm{M}$ of di-5-(1-methyltetrazole) disulfide $\left(\mathrm{T}_{2}\right)$, and $0.5 \mathrm{M}$ 4-tert-butylpyridine in acetonitrile and ethylene carbonate solution. For both DSSCs, a spray-coating technique was used for fabricating $\mathrm{MoS}_{2}$ and $\mathrm{WS}_{2}$ CEs. The $J-V$ curves of the DSSCs having sulfide CEs and $\mathrm{T}_{2} / \mathrm{T}^{-}$electrolyte show PCE values of $4.97 \%$ for $\mathrm{MoS}_{2}, 5.24 \%$ for $\mathrm{WS}_{2}$, and $3.70 \%$ for Pt CE. The PCE values were increased $36 \%$ for $\mathrm{MoS}_{2}$ and $41 \%$ for $\mathrm{WS}_{2}$ compared to the Pt CE, showing that DSSCs having $\mathrm{MoS}_{2}$ and $\mathrm{WS}_{2}$ are better than that of the Pt CE for the $\mathrm{T}_{2} / \mathrm{T}^{-}$redox couple.

The interfaced exfoliated $\mathrm{MoS}_{2}$ thin films with different porphyrin molecules, where the $\mathrm{MoS}_{2}$ was functionalized with zinc(II) porphyrin (ZnPP), showed a 10-fold increase in photocurrent compared to $\mathrm{MoS}_{2}$ films. ${ }^{142}$ Exfoliated ultrathin porous $\mathrm{MoS}_{2}$ sheets prepared by a tetraethylorthosilicate (TEOS)assisted hydrothermal method were used as CEs in DSSCs. ${ }^{\mathbf{1 4 3}}$ The cyclic voltammograms and electrochemical impedance spectroscopy showed low $R_{\mathrm{CT}}$ and high electro-catalytic activity for porous $\mathrm{MoS}_{2}$ sheets CEs in DSSCs, with a PCE of $6.35 \%$, slightly better than that of Pt CEs $(\eta=6.19 \%)$ under similar experimental conditions. A CE created by spin-coating of $\mathrm{MoS}_{2}$ nanosheets followed by thermal treatment was also prepared. ${ }^{\mathbf{1 4 4}}$ DSSCs having $\mathrm{MoS}_{2}$ nanosheets thermally treated at $100{ }^{\circ} \mathrm{C}$ showed a PCE value of $7.35 \%$, comparable to conventional a Pt CE (7.53\%). When $\mathrm{MoS}_{2}$ nanosheets were thermally treated at $300{ }^{\circ} \mathrm{C}$, the PCE value decreased significantly due to the transformation of $\mathrm{MoS}_{2}$ to $\mathrm{MoO}_{3} \cdot \mathrm{MoS}_{2}$ films deposited on FTO glass using an RF sputtering method were also used as CEs for $\mathrm{TiO}_{2}{ }^{-}$ based DSSCs. ${ }^{145} \mathrm{CV}$, EIS, and Tafel polarization curve measurements conducted on the $\mathrm{MoS}_{2}$ CE showed high electrocatalytic activity, low charge-transfer resistance as well as the fast reaction kinetics for triiodide $\left(\mathrm{I}_{3}{ }^{-}\right)$reduction. The $\mathrm{MoS}_{2} \mathrm{CE}$ prepared after 5 minutes of sputtering showed a PCE of $6.0 \%$, comparable to Pt CEs $(\eta=6.6 \%)$ in DSCCs. The PCE of DSSCs having $\mathrm{MoS}_{2}$ CEs sputtered for 1, 3, 5 and 7 minutes were 5.7,
5.8, 6.0, and 5.2\%, respectively. $\mathrm{MoS}_{2}$ CEs were also developed by synthesizing $\mathrm{MoS}_{2}$ films at $70{ }^{\circ} \mathrm{C}$ using molybdenum(v) chloride and thioacetamide, followed by near-infrared lasersintering for 1 minute to enhance crystallinity and interconnectivity between the $\mathrm{MoS}_{2}$ particles. ${ }^{146}$ The DSSC with lasersintered $\mathrm{MOS}_{2}$ CE exhibited a PCE of 7.19\%, much higher than heat-sintered $\mathrm{MoS}_{2} \mathrm{CE}(5.96 \%)$ and comparable with a Pt CE ( $\eta$ $=7.42 \%$ ). The laser-sintered $\mathrm{MoS}_{2} \mathrm{CE}$ offers superior electrocatalytic activity for the triiodide $\left(\mathrm{I}_{3}{ }^{-}\right)$to iodide $\left(\mathrm{I}^{-}\right)$redox couple. Also, a solution-phase process was used to grow $\mathrm{MoS}_{2}$ nanofilms on FTO glass as a CE for a DSSC, which showed a PCE of $8.3 \%{ }^{147}$ Finally, exfoliated and annealed $\mathrm{MoS}_{2 x} \mathrm{Se}_{2}(1-x)$ as

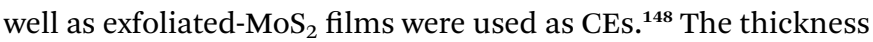
and size of exfoliated $\mathrm{MoS}_{2}$ nanosheets were 0.9 by $1.2 \mathrm{~nm}$ and 0.2 by $2 \mu \mathrm{m}$, corresponding to a single-layer. The $\mathrm{MoS}_{2}$ based CE showed a PCE of $6 \%$, compared to $5.1 \%$ for the annealed $\mathrm{MoS}_{2}$ films.

3.1.2 $\mathrm{MoS}_{2}$ /graphene composites. 2D TMDs based composites have been extensively investigated. ${ }^{\mathbf{1 4 9 , 1 5 0}}$ Like graphene, $\mathrm{MoS}_{2}$ can be mechanically exfoliated into nanosheets from its bulk crystals and used for studying electronics and photonic properties. These 2D layered materials can be combined into a single hybrid structure, so that both $\mathrm{MoS}_{2}$ and graphene components can synergistically enhance photovoltaic properties. The nanocomposites of $\mathrm{MoS}_{2}$ and graphene have been investigated as CEs for DSSCs.

To fabricate a Pt-free DSCC, Lin et al. ${ }^{151}$ used a $\mathrm{MoS}_{2} /$ graphene nanosheet composite as a $\mathrm{CE}$ and nanocrystalline $\mathrm{TiO}_{2}$ as a photoanode. The redox electrolyte solution in the DSSC was made of $1 \mathrm{M}$ 1,3-dimethylimidazolium iodide, $0.15 \mathrm{M}$ iodine, 0.5 M 4-tert-butylpyridine and 0.1 $\mathrm{M}$ guanidine thiocyanate in 3methoxypropionitrile. The $\mathrm{MoS}_{2} /$ graphene nanosheet based CE showed a PCE of $5.81 \%$, in comparison to a PCE of $6.24 \%$ for the conventional sputtered Pt CE. Yue et al. ${ }^{152}$ used a $\mathrm{MoS}_{2} /$ graphene flake composite film as the CEs for DSSCs with N719 dye for the reduction of triiodide $\left(\mathrm{I}_{3}{ }^{-}\right)$to iodide $\left(\mathrm{I}^{-}\right)$. The $\mathrm{MoS}_{2}$ powder (ARCOS, 99\%) and $8 \mathrm{~nm}$ flakes of multi-layer graphene nanopowder (Uni-Onward Corp., 99.5\%) were mixed in specific ratios to prepare the composites. The electrocatalytic activity increased after adding graphene flakes to the $\mathrm{MoS}_{2}$ film. 
Charge-transfer resistances $\left(R_{\mathrm{CT}}\right)$ of $3.98 \Omega \mathrm{cm}^{2}$ for graphene, $2.71 \Omega \mathrm{cm}^{2}$ for $\mathrm{MoS}_{2}, 2.09 \Omega \mathrm{cm}^{2}$ for $\mathrm{MoS}_{2} /$ graphene, and $2.01 \Omega$ $\mathrm{cm}^{2}$ for Pt CEs were measured. The current density of the $\mathrm{MoS}_{2} /$ graphene composite $\mathrm{CE}$ was recorded to be higher than that of the $\mathrm{MoS}_{2}$, graphene and Pt CEs. The $J-V$ characteristics of the DSSCs having $\mathrm{MoS}_{2}$ /graphene as CEs and ranging in thickness from single-layer to six-layer were investigated and compared with conventional Pt CEs. The thickness of the $\mathrm{MoS}_{2} /$ graphene layers affected the PCE of the DSSCs, and $J_{\mathrm{sc}}$ and $V_{\mathrm{oc}}$ increased with increasing number of plaster layers from single to 3-layer, and, thereafter, a decrease was noticed for 4-layers and 5-layers. The effect of graphene content was also studied, where, the $R_{\mathrm{CT}}$ was found to decrease for the $\mathrm{MoS}_{2} /$ graphene CE, from $0.5 \mathrm{wt} \%$ to $1.5 \mathrm{wt} \%$ of graphene content. The PCE of the $\mathrm{MoS}_{2} /$ graphene composite CE having $1.5 \mathrm{wt} \%$ graphene was 5.98\%, compared to the PCE of $6.23 \%$ for Pt CE. Yu et al. ${ }^{153}$ used $\mathrm{MoS}_{2}$ nanosheets and graphene composites for fabricating CEs for the triiodide $\left(\mathrm{I}_{3}{ }^{-}\right)$reduction. Graphene thin films were prepared by the chemical vapor deposition (CVD) technique in combination with a hydrothermal process. $\mathrm{MoS}_{2}$ nanosheets with $210 \mathrm{~nm}$ thickness were in situ grown on FTO glass substrate, and uniformly dispersed on the surface of a graphene film. Fig. 6 shows the morphology of the synthesized graphene- $\mathrm{MoS}_{2}$ composites, using field-emission scanning electron microscopy (FESEM) and high-resolution transmission electron microscopy (HRTEM) with different magnifications. The thickness of the graphene film was found to be $2.48 \mathrm{~nm}$ by atomic force microscopy, which corresponds to seven layers of graphene. The top-view FESEM images of graphene- $\mathrm{MoS}_{2}$ hybrids showed fully covered graphene film with 5 to $20 \mathrm{~nm}$ thick $\mathrm{MoS}_{2}$ nanosheets. The nucleation and growth of $\mathrm{MoS}_{2}$ nanosheets depends upon the graphene film. Graphene films play an active role for higher electrical conductivity by speeding up the charge transfer process and generating active sites for dispersion and integration of $\mathrm{MoS}_{2}$ nanosheets. The presence of $\mathrm{MoS}_{2}$ nanosheets increases the electrode-electrolyte contact area, and therefore helps in improving the electrocatalytic activity. The low $R_{\mathrm{CT}}$ of $1.5 \Omega \mathrm{cm}^{2}$ for $\mathrm{MoS}_{2} /$ graphene CE, $1.7 \Omega \mathrm{cm}^{2}$ for $\mathrm{MoS}_{2}, 1.70 \Omega$ $\mathrm{cm}^{2}$ for graphene, and a high $R_{\mathrm{CT}}$ of $2.1 \Omega \mathrm{cm}^{2}$ for a Pt CE, indicates better interaction and contact formation of $\mathrm{MoS}_{2}$ nanosheets and graphene film with fluorine doped tin oxide (FTO) substrates and a fast charge transfer. The FF of graphene is $24 \%$ compared to a $\mathrm{FF}$ of $65 \%$ for $\mathrm{MoS}_{2}$, however when both materials are combined into a composite system, the $\mathrm{FF}$ raises to $68 \%$. Therefore, $\mathrm{MoS}_{2}$ nanosheet/graphene composite CEs resulted in a higher PCE of $7.1 \%$ because of the synergetic interactions between graphene and $\mathrm{MoS}_{2}$, compared to the low PCE values of $2.8 \%$ for graphene and $5.6 \%$ for $\mathrm{MoS}_{2}$, and a comparable PCE of $7.4 \%$ for Pt reference CEs. $\mathrm{MoS}_{2} /$ graphene based CEs in a DSSC offer higher electrocatalytic activity for triiodide $\left(\mathrm{I}_{3}{ }^{-}\right)$reduction induced by the synergetic interactions. Fig. 7 represents the $J-V$ characteristics of DSSCs having graphene- $\mathrm{MoS}_{2}$ as CEs with increasing number of layers ${ }^{\mathbf{1 5 2}}$ and
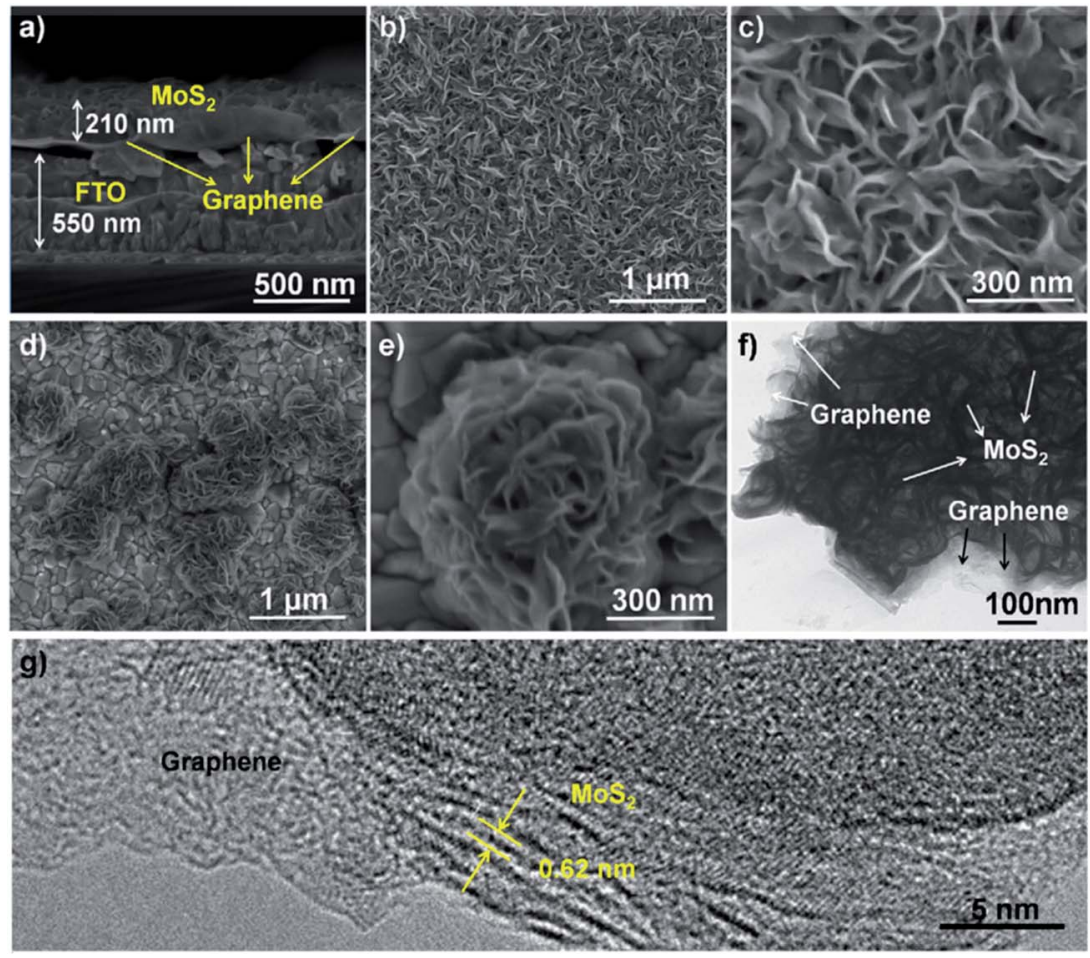

Fig. 6 Field-emission scanning electron microscopy (FESEM) images of graphene-MoS 2 composites with different magnifications; (a) side-view, (b) and (c) top-view. (d) and (e) top-view FESEM images of flower-like MoS $_{2}$ clusters without graphene film. (f) and (g) high-resolution transmission electron microscopy (HRTEM) images of as-prepared graphene-MoS 2 hybrids. Reprinted with permission from ref. 153, C. Yu, X. Meng, X. Song, S. Liang, Q. Dong, G. Wang, C. Hao, X. Yang, T. Ma, P. M. Ajayan and J. Qiu, graphene-mediated highly-dispersed MoS 2 nanosheets with enhanced triiodide reduction activity for dye-sensitized solar cells. Carbon, 2016, 100, 474-483. Copyright@ Elsevier. 
graphene- $\mathrm{MoS}_{2}$ nanosheet based CEs for the triiodide $\left(\mathrm{I}_{3}{ }^{-}\right)$ reduction. ${ }^{153}$

$\mathrm{MoS}_{2}$ nanosheets/graphene electrodes were also studied by Lynch et al. ${ }^{154}$ the PCE of $95 \%$ of the Pt electrode was achieved after adding $10 \mathrm{wt} \% \mathrm{MoS}_{2}$ nanosheets to a graphene film CE. This again confirms that the $\mathrm{MoS}_{2}$ nanosheet/graphene composite ECs have higher catalytic activity than graphene CEs, though the graphene nanosheets contribute to higher electrical conductivity in the composite. An electrochemical strategy ${ }^{\mathbf{1 5 5}}$ was used for preparing $\mathrm{MoS}_{2} /$ graphene composite as CEs of DSSCs, which included electro-deposition and electroreduction of graphene oxide, and thereafter electro-deposition of $\mathrm{MoS}_{2}$ on reduced graphene oxide (GO) layers. The $\mathrm{MoS}_{2}$ / graphene composites were characterized by SEM, TEM and Raman spectroscopy. The $\mathrm{MoS}_{2} /$ graphene CEs based DSCCs exhibited a PCE of $8.01 \%$, comparable to a PCE of $8.21 \%$ for the Pt CE. In another study, nanocomposites of $\mathrm{MoS}_{2}$ and nitrogendoped graphene oxide (N-GO) were used as a CE for DSSCs. ${ }^{156}$ The $\mathrm{MoS}_{2} / \mathrm{N}-\mathrm{GO}$ nanocomposites were characterized by HRTEM, XPS, and Raman spectroscopy, and their electrochemical properties were evaluated by EIS, CV, and Tafel measurements. The $\mathrm{MoS}_{2} / \mathrm{N}-\mathrm{GO}$ nanocomposite formation offered high specific surface area of N-GO and many edge sites of $\mathrm{MoS}_{2}$. The $\mathrm{MoS}_{2} / \mathrm{N}-\mathrm{GO}$ nanocomposite based CE exhibited a PCE of 5.95\%, lower than the standard Pt CE (PCE of $6.43 \%$ ).

Composite films of $\mathrm{MoS}_{2}$ with nitrogen-doped graphene (Ngraphene) were prepared using a drop-coating method and used as a CE of DSSCs. ${ }^{157}$ The $\mathrm{N}$-graphene supported an increase in electrical conductivity, whereas $\mathrm{MoS}_{2}$ increased the electrocatalytic activity in the composite thin film. The N-graphene/ $\mathrm{MoS}_{2}$ composite film showed a PCE of $7.82 \%$, lower than the Pt CE $(\eta=8.25 \%)$ based DSSC. The electrocatalytic capability of $\mathrm{N}-$ graphene/ $\mathrm{MoS}_{2}$ composite films for the triiodide $\left(\mathrm{I}_{3}{ }^{-}\right)$reduction was much higher compared with pristine $\mathrm{N}$-graphene and $\mathrm{MoS}_{2}$ thin films, as studied using $\mathrm{CV}$, RDE, the Tafel polarization curve, and EIS. The graphene flakes (GF) into a nanosheet-like $\mathrm{MoS}_{2}$ matrix were dispersed using an in situ hydrothermal method, and used a $\mathrm{MoS}_{2} / \mathrm{GF}$ hybrid as a CE to fabricate Pt-free DSSCs. ${ }^{158}$ The incorporation of GFs into the $\mathrm{MoS}_{2}$ matrix was confirmed using scanning electron microscopy (SEM), transmission electron microscopy (TEM), XRD, and Raman spectroscopy. The electrochemical measurements showed improvement in the electrocatalytic activity after the GFs were integrated into the $\mathrm{MoS}_{2}$ matrix, where the hybrid containing $1.5 \mathrm{wt} \%$ of graphene flakes exhibited the highest electrocatalytic activity. The DSSC with the $\mathrm{MoS}_{2} / \mathrm{GF}$ hybrid CE showed a PCE of $6.07 \%$, which was $95 \%$ of the Pt CE $(\eta=6.41 \%)$.

3.1.3 $\mathrm{MoS}_{2} /$ carbon nanotubes composites. Carbon nanotubes (CNTs) are one of the most interesting materials because they offer high optical transparency, high electrical conductivity, high mechanical strength, and high thermal stability, and therefore CNTs have been studied as CEs for DSSCs. It is of great interest to combine the unique properties of both $\mathrm{MoS}_{2}$ and CNTs into a single hybrid system which could synergistically enhance the electrocatalytic activity of a DSSC system. Yue et $a l .{ }^{159}$ used a flower-like structure of $\mathrm{MoS}_{2} /$ single-wall carbon nanotubes ( $\left.\mathrm{MoS}_{2} / \mathrm{SWCNTs}\right)$ as CE catalyst for DSSCs, synthesized using a glucose and PEDOT:PSS assisted (G-P-A) hydrothermal process. The flower-like structure and surface morphology of the (G-P-A) $\mathrm{MoS}_{2} / \mathrm{SWCNTs}$ was confirmed by SEM and TEM techniques. The DSSC having (G-P-A) $\mathrm{MoS}_{2}$ / SWCNTs CE exhibits a lower $R_{\mathrm{CT}}$ of $1.46 \Omega \mathrm{cm}^{2}$ compared to the $R_{\mathrm{CT}}$ of $2.44 \Omega \mathrm{cm}^{2}$ for the Pt electrode. The PCE reached $8.14 \%$, better than that of the Pt-based DSSC (7.78\%) with the iodide/ triiodide $\left(\mathrm{I}_{3}{ }^{-}\right)$electrolyte. The speedy reduction of triiodide $\left(\mathrm{I}_{3}{ }^{-}\right)$to iodide $\left(\mathrm{I}^{-}\right)$by the $(\mathrm{G}-\mathrm{P}-\mathrm{A}) \mathrm{MoS}_{2} /$ SWCNTs CE is attributed to the fast transport of the electrolyte via the flower-like structure. The $\mathrm{MoS}_{2}$ and multi-walled carbon nanotube (MWCNTs) nanocomposites were employed as a CE in DSSCs for the reduction of triiodide $\left(\mathrm{I}_{3}{ }^{-}\right) \cdot{ }^{160}$ The microstructure of the MWCNTs@ $\mathrm{MoS}_{2}$ nanocomposite studied by transmission electron microscopy (TEM) confirmed the deposition of fewlayers $\mathrm{MoS}_{2}$ nanosheets on the MWCNTs surface. A MWCNTs@MoS $\mathrm{MO}_{2}$ composite based CE resulted in higher (a)

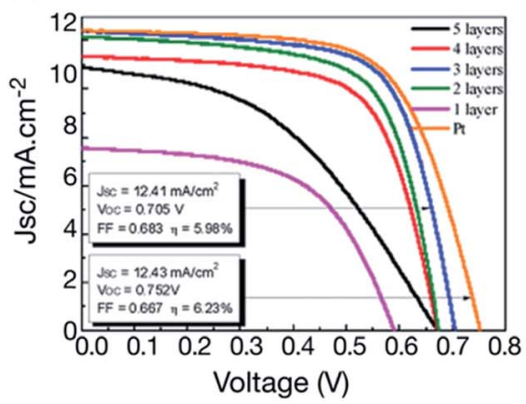

(b)

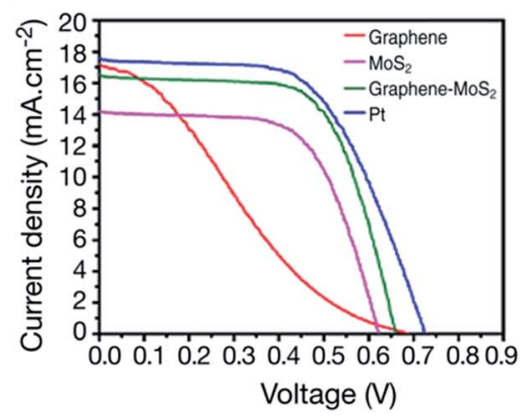

Fig. 7 (a) J-V characteristics of DSSCs having $M_{0} S_{2} /$ graphene as counter electrodes with different thickness ranging from single-layer to sixlayer and a comparison with sputtered Pt counter electrode (PEC of 6.23\%). Reprinted with permission from ref. 152, G. Yue, J. Y. Lin, S. Y. Tai, Y. Xiao and J. Wu, A catalytic composite film of $\mathrm{MoS}_{2} /$ graphene flake as a counter electrode for Pt-free dye-sensitized solar cells. Electrochim. Acta, 2012, 85, 162-168. Copyright@ Elsevier. (b) J-V curves of DSSCs based on Pt, graphene/MoS 2 , MoS 2 , and graphene CEs. Reprinted with permission from ref. 153, C. Yu, X. Meng, X. Song, S. Liang, Q. Dong, G. Wang, C. Hao, X. Yang, T. Ma, P. M. Ajayan and J. Qiu, graphene-mediated highly-dispersed $\mathrm{MoS}_{2}$ nanosheets with enhanced triiodide reduction activity for dye-sensitized solar cells. Carbon, $2016,100,474-483$. Copyright@ Elsevier. 
cathodic current density than those of MWCNTs, $\mathrm{MoS}_{2}$, and Pt CEs. The MWCNTs@MoS 2 CE showed a low charge-transfer resistance of $1.69 \Omega \mathrm{cm}^{2}$ and no degradation up to 100 repeated cyclic voltammogram tests. The DSSC having a MWCNTs@ $\mathrm{MoS}_{2}$ composite CE exhibited a PCE of 6.45\%, slightly better than that of the DSSC having sputtered Pt CE $(\eta=$ 6.41\%). The MWCNT@MoS 2 based CE also showed improved catalytic activity for the reduction of $\mathrm{I}_{3}{ }^{-}$.

The $\mathrm{MoS}_{2}$ nanosheets anchored onto the CNT surfaces were used in Pt-free CEs for DSSCs. ${ }^{161}$ The $\mathrm{MoS}_{2}$ nanosheets offer edge-plane electrocatalytically active sites for the reduction of $\mathrm{I}_{3}{ }^{-}$. The large surface area of CNTs supports the loading of $\mathrm{MoS}_{2}$ nanosheets in order to increase the electrochemical activity. The CNTs deposited onto the FTO substrate promoted charge transport, leading to a higher exchange current density and also to the lower charge-transfer resistance. The $\mathrm{MoS}_{2} / \mathrm{CNT}$ hybrid based DSSCs achieved a PCE of $7.83 \%$, which is $9.5 \%$ higher than that of the Pt CE $(\eta=7.15 \%)$ based DSSC.

Another research group ${ }^{162}$ used flower-like $\mathrm{MoS}_{2}$ and a multiwalled carbon nanotubes ( $\left.\mathrm{MoS}_{2} / \mathrm{MWCNTs}\right)$ hybrid as a $\mathrm{CE}$ for dye-sensitized solar cells. The flower-like $\mathrm{MoS}_{2} / \mathrm{MWCNTs}$ hybrid contains a large specific surface area and lamellar structure, as evidenced by field emission scanning electron microscopy (FESEM). The optimized $\mathrm{MoS}_{2} / \mathrm{MWCNTs}$ has a $R_{\mathrm{CT}}$ of $2.05 \Omega \mathrm{cm}^{2}$ and series resistance $\left(R_{\mathrm{S}}\right)$ of $1.13 \Omega \mathrm{cm}^{2}$ as measured by electrochemical impedance spectroscopy. Cyclic voltammogram measurements showed larger current density for $\mathrm{MoS}_{2} /$ MWCNTs based CEs than those of $\mathrm{MoS}_{2}$, MWCNTs, and Pt CEs.
$\mathrm{MoS}_{2}$ /MWCNTs CE based DSSCs exhibited a PCE of $7.50 \%$, comparable with the DSSC based on the Pt CE $(\eta=7.49 \%)$. A carbon nanotubes- $\mathrm{MoS}_{2}$-carbon (CNTs-MoS 2 -carbon) hybrid was prepared using wet impregnation and calcination with polyethylene glycol as a CE for DSSCs. ${ }^{163}$ Spectroscopic characterization by Raman spectra, XRD, TEM, XPS, BET and thermal methods indicated a homogenous coating of CNTs with thin layers of $\mathrm{MoS}_{2}$, as a result of wetting and emulsification of polyethylene glycol 400. The $\mathrm{CNTs}-\mathrm{MoS}_{2}$-carbon heterostructure was used as CEs for DSSCs, and showed high stability and electrocatalytic activity in the reduction of $\mathrm{I}_{3}{ }^{-}$to $\mathrm{I}^{-}$because of low $R_{\mathrm{CT}}$. Interestingly, a PCE of $7.23 \%$ achieved for the CNTs$\mathrm{MoS}_{2}$-carbon CEs based DSSC was higher than Pt CEs $(\eta=$ $6.19 \%)$.

In another study, nanocomposites of $\mathrm{MoS}_{2}$ and CNTs using a glucose aided (G-A) hydrothermal method were prepared by Yue et al. ${ }^{\mathbf{1 6 4}}$ The (G-A)MoS $/$ CNTs nanocomposites obtained by adding $0.5,1.0,1.5,2.0$ and $2.5 \mathrm{wt} \%$ of acid-treated CNTs were deposited onto a FTO substrate and used as CEs in DSSCs for the reduction of triiodide $\left(\mathrm{I}_{3}{ }^{-}\right)$to iodide $\left(\mathrm{I}^{-}\right)$. The dye-sensitized $\mathrm{TiO}_{2}$ anode was prepared by dipping the $\mathrm{TiO}_{2}$ anode in $0.3 \mathrm{mM}$ of dye N719 ethanol for 24 hours. Fig. 8 shows the SEM images of $\mathrm{MoS}_{2}$ nanopower and $\mathrm{MoS}_{2}$-MWCNTs composites, $J-V$ characteristics of the DSSCs fabricated with $\mathrm{MoS}_{2}, \mathrm{MoS}_{2} / \mathrm{C},(\mathrm{G}-$ A) $\mathrm{MoS}_{2} / \mathrm{CNTs}$ and Pt CEs, and the effect of CNT contents on the PCE of the DSSCs using (G-A) $\mathrm{MoS}_{2} / \mathrm{CNTs}$. Scanning and transmission electron microscopy showed tentacle-like structures of the $\mathrm{MoS}_{2}$ /CNTs composites, having large active surface area and

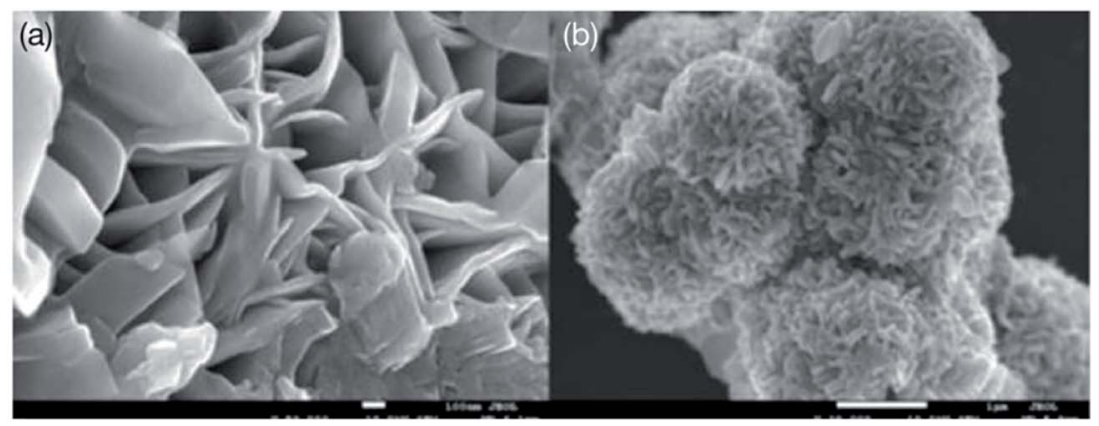

(c)

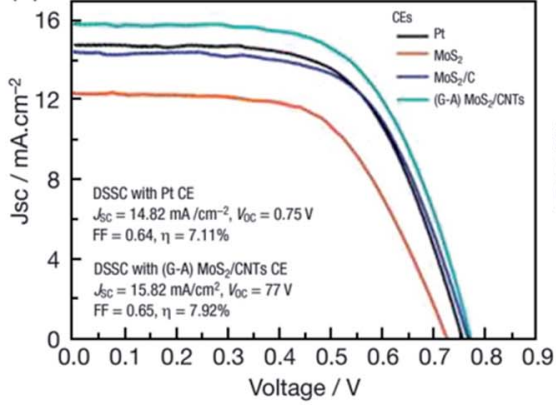

(d)

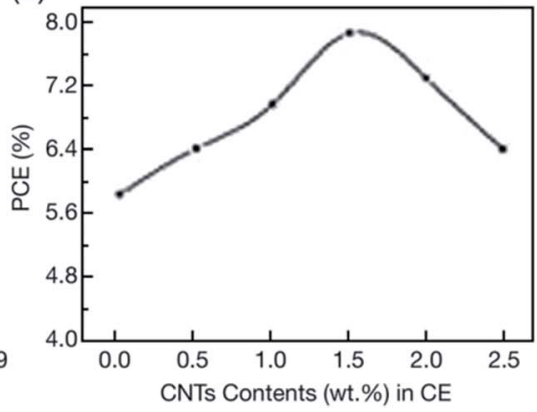

Fig. 8 Scanning electron microscopic image of $\mathrm{MOS}_{2}$ nanopower and $\mathrm{MOS}_{2}-\mathrm{MWCNTS}$ composites prepared by glucose aided (G-A) hydrothermal method. Photocurrent-voltage ( $\mathrm{J}-\mathrm{V}$ ) characteristics of the DSSCs fabricated with $\mathrm{MoS}_{2}, \mathrm{MoS}_{2} / \mathrm{C},(\mathrm{G}-\mathrm{A}) \mathrm{MoS} 2 / \mathrm{CNTS}$ and Pt CEs. Relationship between the contents of CNTs in (G-A)MoS 2 /CNTs CE and the PCE of DSSCs. Reprinted with permission from ref. 164, G. Yue, W. Zhang, J. Wu and Q. Jiang, glucose aided synthesis of molybdenum sulfide/carbon nanotubes composites as counter electrode for high performance dye-sensitized solar cells. Electrochim. Acta, 2013, 112, 655-662. Copyright@ Elsevier. 
interconnected networks for fast transport for the electrolyte. The CNTs functionalized with a $-\mathrm{COOH}$ functional group were used and $\mathrm{MoS}_{2}$ was anchored onto the functionalized CNTs. The (G-A)MoS $/$ CNTs had specific surface area of $411.7 \mathrm{~m}^{2} \mathrm{~g}^{-1}$ and exhibited a small overpotential and better conductivity. The Nernst diffusion impedance $\left(Z_{\mathrm{w}}\right)$ values of $1.85 \Omega \mathrm{cm}^{2}$ for (G-A) $\mathrm{MoS}_{2} / \mathrm{CNTs}$ CEs and $2.25 \Omega \mathrm{cm}^{2}$ for Pt CEs were measured, which indicates that the $(\mathrm{G}-\mathrm{A}) \mathrm{MoS}_{2} / \mathrm{CNTs}$ catalyst accelerated the reduction of triiodide ions $\left(\mathrm{I}_{3}{ }^{-}\right)$to iodide ions $\left(\mathrm{I}^{-}\right)$. The $(\mathrm{G}-$ A) $\mathrm{MoS}_{2} / \mathrm{CNTs}$ based CEs were found to exhibit enhanced electrocatalytic activity as evidenced by the CV, EIS, and Tafel polarization measurements. The photovoltaic performance of the DSSCs having $\mathrm{MoS}_{2}, \mathrm{MoS}_{2} / \mathrm{C},(\mathrm{G}-\mathrm{A}) \mathrm{MoS}_{2} / \mathrm{CNTs}$, and Pt CEs were compared. The photovoltaic performance of $(\mathrm{G}-\mathrm{A}) \mathrm{MoS}_{2} /$ CNTs CEs were also studied as a function of the CNT contents. The PCE of the DSSCs increased as the contents of the CNTs increased from 0 to $1.5 \mathrm{wt} \%$, however, further increase in CNT content leads to a decreased PCE. Likely, the maximum photovoltaic performance of the (G-A)MoS $/$ CNTs CE in the DSSCs was achieved for a film thickness of $12 \mu \mathrm{m}$. The (G-A) $\mathrm{MoS}_{2} / \mathrm{CNTs}$ composite CE has a lower $R_{\mathrm{CT}}$ of $1.77 \Omega \mathrm{cm}^{2}$ at the electrolyte/electrode interface than those of $\mathrm{MoS}_{2}, \mathrm{MoS}_{2} /$ carbon and conventional sputtered Pt CEs, and a PCE of $7.92 \%$ higher than the PCE of $7.11 \%$ for the Pt electrode in DSSCs for the triiodide/iodide $\left(\mathrm{I}_{3}{ }^{-} / \mathrm{I}^{-}\right)$system. Lin et al. ${ }^{165}$ fabricated nanocomposites of $\mathrm{MoS}_{2}$ /reduced graphene oxide (RGO) with CNTs using electrophoretic deposition. The $\mathrm{MoS}_{2}$ /RGO-CNTs hybrid was then used as a CE in DSSCs. In this hybrid, CNTs offer conductive networks for electron transport to increase the rate of charge-transfer at the $\mathrm{CE} /$ electrolyte interface. The $\mathrm{MoS}_{2} /$ RGO-CNTs hybrid CEs show improved electrocatalytic activity

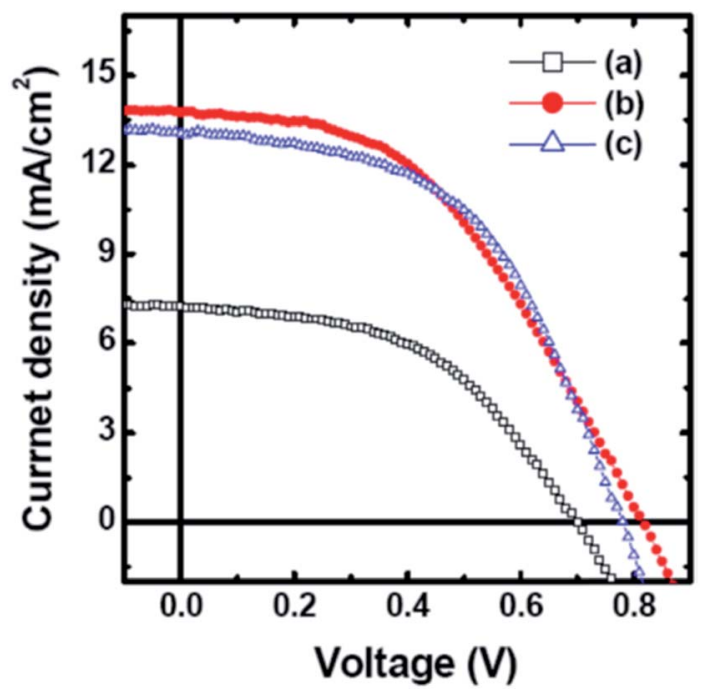

Fig. 9 Photocurrent density-voltage $(J-V)$ characteristics curves of DSSCs with (a) $\mathrm{MoS}_{2}$, (b) $\mathrm{MoS}_{2} / \mathrm{TiO}_{2}$ and (c) Pt counter electrodes measured under the solar light illumination of $100 \mathrm{~mW} \mathrm{~cm}^{-2}$ (AM 1.5G). Reprinted with permission from ref. 168, W. H. Jhang and Y. J. Lin, interface modification of $\mathrm{MoS}_{2}$ counter electrode/electrolyte in dyesensitized solar cells by incorporating $\mathrm{TiO}_{2}$ nanoparticles. Curr. Appl. Phys., 2015, 15, 906-909. Copyright@ Elsevier. in comparison with the $\mathrm{MoS}_{2} / \mathrm{RGO}$ alone. The DSSC having a $\mathrm{MoS}_{2} / \mathrm{RGO}-\mathrm{CNTs}$ hybrid CE achieved a PCE of $7.46 \%$, exceeding PCE values of DSSCs containing $\mathrm{MoS}_{2} / \mathrm{RGO} \mathrm{CE}(\eta=$ $6.82 \%)$ and Pt CE $(\eta=7.23 \%)$. Thin films of $\mathrm{MoS}_{2} /$ carbon nanotube composites have also been applied as electrodes for lithium ion batteries. ${ }^{166}$

3.1.4 $\mathrm{MoS}_{2} / \mathrm{TiO}_{2}$ composites. $\mathrm{MoS}_{2} / \mathrm{TiO}_{2}$ heterostructures were developed by Du et al. ${ }^{167}$ by depositing few-layer $\mathrm{MoS}_{2}$ on mesoporous $\mathrm{TiO}_{2}$ by a chemical-bath method. Raman spectrum and HRTEM images indicated a few-layer structure of the $\mathrm{MoS}_{2}$. After few-layer $\mathrm{MoS}_{2}$ deposition, the UV absorption spectra of the $\mathrm{TiO}_{2}$ photoanode showed enhanced absorption in the visible wavelength region and a PCE of $1.08 \%$ for the $\mathrm{MoS}_{2} / \mathrm{TiO}_{2}$ based DSSC. Photovoltaic performance of the DSSC was found to be optimized by both thermal annealing and the thickness of the $\mathrm{MoS}_{2}$ sensitized layer. Jhang et al. ${ }^{168}$ modified the interface of a $\mathrm{MoS}_{2} \mathrm{CE} /$ electrolyte by incorporating $\mathrm{TiO}_{2}$ nanoparticles, in order to control the overpotential loss. Their $\mathrm{MoS}_{2} / \mathrm{TiO}_{2}$ nanocomposite had a weight ratio of $5: 1$. Thermal annealing of the $\mathrm{MoS}_{2}$ and $\mathrm{MoS}_{2} / \mathrm{TiO}_{2}$ CEs was performed at $400{ }^{\circ} \mathrm{C}$ in vacuum for 2 hours. Fig. 9 shows the $J-V$ curves for $\mathrm{MoS}_{2}, \mathrm{MoS}_{2} / \mathrm{TiO}_{2}$, and Pt CEs in the DSSCs. The addition of $\mathrm{TiO}_{2}$ nanoparticles into the $\mathrm{MoS}_{2}$ CE significantly increased the $J_{\mathrm{sc}}$ value from 7.24 $\mathrm{mA} \mathrm{cm}{ }^{-2}$ for the $\mathrm{MoS}_{2} \mathrm{CE}$ to $13.76 \mathrm{~mA} \mathrm{~cm}{ }^{-2}$ for the $\mathrm{MoS}_{2} / \mathrm{TiO}_{2}$ CE. The $\mathrm{MoS}_{2} / \mathrm{TiO}_{2}$ CE based DSSC $(\eta=5.08 \%)$ shows two times better photovoltaic performance compared with the $\mathrm{MoS}_{2} \mathrm{CE}$ (2.54\%) and comparable to the Pt CE (5.27\%), because of an increased active surface area from the incorporated $\mathrm{TiO}_{2}$ nanoparticles and the low overpotential loss. Though the $\mathrm{MoS}_{2} /$ $\mathrm{TiO}_{2}$ CE exhibited high PCE, its electrical conductivity was found to be lower compared to the $\mathrm{MoS}_{2} \mathrm{CE}$, and, therefore, the high electrocatalytic activity was not related to its electrical conductivity.

The $\mathrm{MoS}_{2} / \mathrm{TiO}_{2}$ based CE doped with different Co contents for the DSSCs were found to influence the PCE by improving electrocatalytic activity. ${ }^{169}$ The Co content-optimized $\mathrm{MoS}_{2} / \mathrm{TiO}_{2}$ $\mathrm{CE}$ had enhanced catalytic activity at the electrolyte interfaces. The Co 3d orbit plays a role in increasing in the reduction of $\mathrm{I}_{3}{ }^{-}$ to $\mathrm{I}^{-}$. The photoanodes were developed using $\mathrm{MoS}_{2}$ and $\mathrm{TiO}_{2}$ nanoparticles. ${ }^{170}$ The DSSCs with $\mathrm{MoS}_{2} @ \mathrm{TiO}_{2}$ photoanode showed a PCE of $6.02 \%, 1.5$ times higher than that of the $\mathrm{TiO}_{2}$ film photoanode ( $\eta=4.43 \%$ ).

3.1.5 $\mathrm{MoS}_{2} /$ carbon composites. A very interesting study on $\mathrm{MoS}_{2} /$ carbon composites was conducted by Yue et al. ${ }^{171}$ who developed DSSCs using $\mathrm{MoS}_{2}$ and carbon composites as a CE with different contents of carbon. Fig. 10 represents the SEM images of hydrothermally synthesized $\mathrm{MoS}_{2}$ and a porous $\mathrm{MOS}_{2}$-carbon hybrid, a HRTEM image of $\mathrm{MoS}_{2}$-carbon hybrid, an IPCE spectra, and $J-V$ curves of the DSSCs with $\mathrm{MoS}_{2}, \mathrm{MoS}_{2}-$ carbon hybrid, and Pt CEs. The commercial $\mathrm{MoS}_{2}$ particles have lamellar structure with large surface area. The hydrothermally prepared $\mathrm{MoS}_{2}$ and $\mathrm{MoS}_{2}$-carbon hybrid contains a large number of interlaced nanosheets. The intercalated nanosheets in the $\mathrm{MoS}_{2}$-carbon hybrid are thinner compared with $\mathrm{MoS}_{2}$, indicating an increase in the specific surface area, which is highly suitable for improving the electrocatalytic activity. The $\mathrm{MoS}_{2}$ and $\mathrm{MoS}_{2}$-carbon hybrid CEs were characterized by CV, 

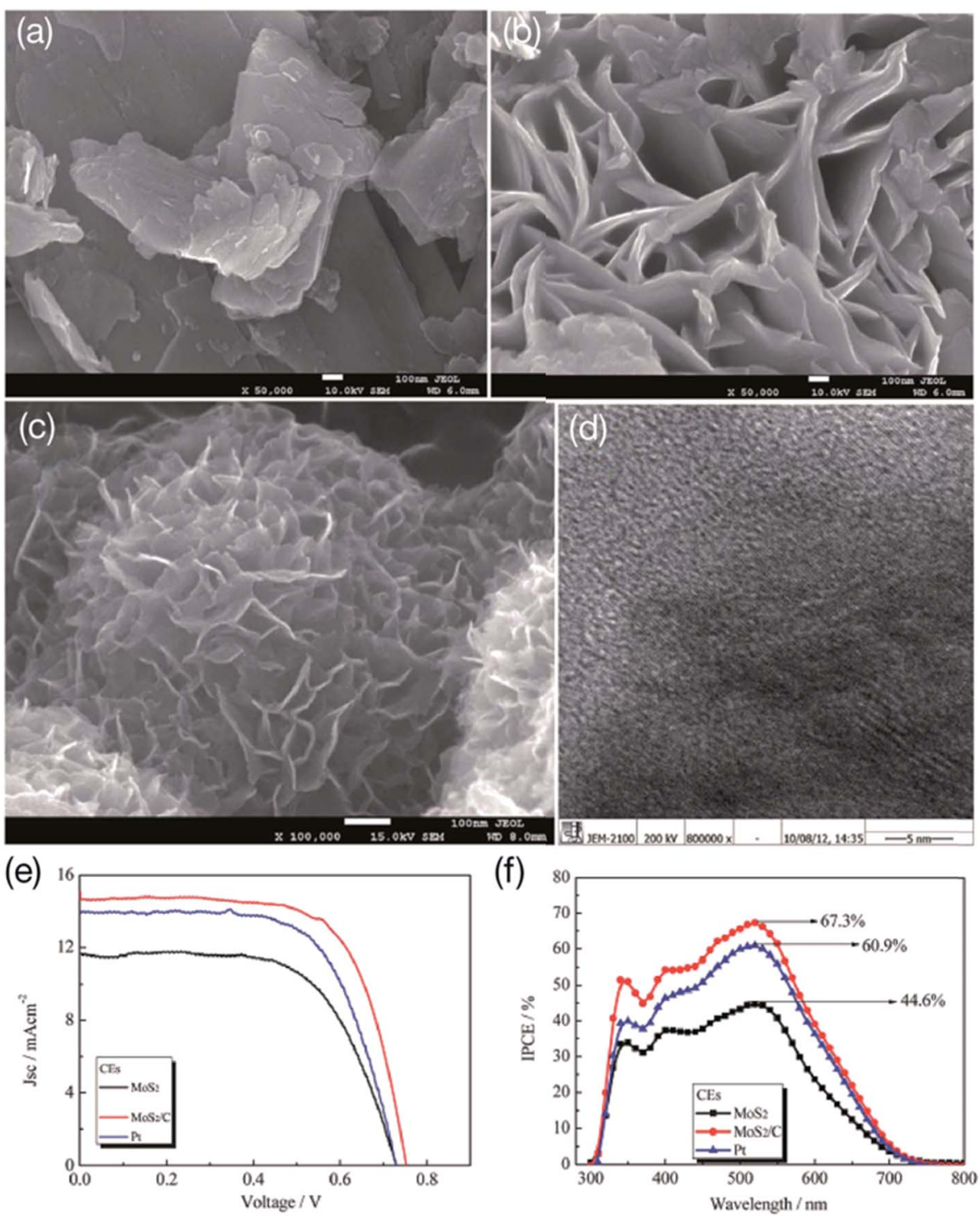

Fig. 10 Scanning electron microscopy (SEM) images of (a) commercial $\mathrm{MoS}_{2}$, (b) hydrothermal route synthesized MoS $\mathrm{S}_{2}$ (c) porous MoS 2 -carbon hybrid prepared by a hydrothermal route, (d) high-resolution TEM image of $\mathrm{MoS}_{2}$-carbon hybrid, (e) photocurrent-voltage $(J-V)$ curves of the DSSCs with $\mathrm{MoS}_{2}, \mathrm{MoS}_{2}-\mathrm{C}$ and Pt CEs and (f) incident photon-to-current efficiency (IPCE) spectra of the DSSCs with MoS 2 , MoS $2-C$ and Pt CEs. Reprinted with permission from ref. 171, G. Yue, J. Wu, Y. Xiao, M. Huang, J. Lin and J. Y. Lin, high performance platinum-free counter electrode of molybdenum sulfide-carbon used in dye-sensitized solar cells. J. Mater. Chem. A, 2013, 1, 1495-1501. Copyright@ Royal Society of Chemistry.

EIS, and Tafel polarization curve measurements, and compared with the Pt CE. IPCE spectra of $\mathrm{MoS}_{2}, \mathrm{MoS}_{2}-\mathrm{C}$, and Pt CEs in DSSCs measured in the $300-750 \mathrm{~nm}$ range show a similar photoelectric response. A strong photoelectric peak in the IPCE spectra appears at $340 \mathrm{~nm}$. DSSCs with $\mathrm{MoS}_{2}$ CE show the highest photoelectric response of $44.6 \%$ in the IPCE spectra at $520 \mathrm{~nm}$, which is lower compared to a DSSC having a Pt CE (60.9\%). Interestingly, in the IPCE spectra of the DSSC having porous $\mathrm{MoS}_{2}$-carbon CE, the highest photoelectric response of $67.3 \%$ is observed at $520 \mathrm{~nm}$, which is higher than that of the Pt CE based DSSC. If one compares the $R_{\mathrm{CT}}$ values of $4.13 \Omega \mathrm{cm}^{2}$ for $\mathrm{MoS}_{2}$ and $2.29 \Omega \mathrm{cm}^{2}$ for Pt electrodes, the $\mathrm{MoS}_{2} /$ carbon electrode had a low $R_{\mathrm{CT}}$ value of $2.07 \Omega \mathrm{cm}^{2}$, appearing as a result of the high conductivity and large surface area for the $\mathrm{MoS}_{2} /$ carbon composite, which eventually contributes to enhanced electrocatalytic activity of the CE. The $R_{\mathrm{CT}}$ values of the $\mathrm{MoS}_{2} /$ carbon electrode are also influenced by the carbon content, which decreases with the increase in carbon content, from 3.60 $\Omega \mathrm{cm}^{2}$ for $1.13 \mathrm{wt} \%$ carbon to $2.07 \Omega \mathrm{cm}^{2}$ for $3.30 \mathrm{wt} \%$ carbon. Thereafter, the $R_{\mathrm{CT}}$ values increased from $2.40 \Omega \mathrm{cm}^{2}$ for 4.35 wt $\%$ carbon content to $3.13 \Omega \mathrm{cm}^{2}$ for $5.38 \mathrm{wt} \%$ carbon content. PCE values of $6.01,7.03,7.69,7.33$ and $5.76 \%$ were measured for $\mathrm{MoS}_{2}$-carbon electrodes having 1.13, 2.23, 3.30, 4.35 and $5.38 \mathrm{wt} \%$ of carbon content, respectively. The highest value of $7.69 \%$ was achieved at $3.30 \mathrm{wt} \%$ carbon content in a $\mathrm{MoS}_{2} /$ carbon composite CE based DSSC for the $\mathrm{I}^{-} / \mathrm{I}_{3}{ }^{-}$redox reaction, and exceeded the PCE value of $6.74 \%$ for a Pt CE under similar experimental conditions. PCE values of the DSSCs were also 
Table 2 Photovoltaic parameters of $\mathrm{MoS}_{2}$ based counter electrodes (CEs) used for DSSCs. FTO glass is the common substrate used in assembling DSSCs with different CE materials. The measurements were conducted at a simulated solar light intensity of $100 \mathrm{~mW} \mathrm{~cm}^{-2}$ (AM $1.5 \mathrm{G}$ ) unless specified. The photovoltaic parameters short-circuit photocurrent density $\left(J_{\mathrm{sc}}\right)$, open-circuit voltage $\left(V_{\text {oc }}\right)$, fill factor $(F F)$, power conversion efficiency $(\eta)$, series resistance $\left(R_{\mathrm{s}}\right)$, charge-transfer resistance $\left(R_{\mathrm{CT}}\right)$, electrolyte and dye used of DSSCs of graphene/MoS 2 nanocomposites are summarized and compared with standard Pt counter electrode ${ }^{a}$

\begin{tabular}{|c|c|c|c|c|c|c|c|c|c|}
\hline Counter electrodes & Redox couple & Dye & $J_{\mathrm{sc}}\left(\mathrm{mA} \mathrm{cm}^{-2}\right)$ & $V_{\mathrm{oc}}(\mathrm{V})$ & $\mathrm{FF}(\%)$ & $\operatorname{PCE}(\eta, \%)$ & $R_{\mathrm{S}}\left(\Omega \mathrm{cm}^{2}\right)$ & $R_{\mathrm{CT}}\left(\Omega \mathrm{cm}^{2}\right)$ & Ref. \\
\hline $2 \mathrm{H}-\mathrm{MoS}_{2}$ (hydrothermal, $200^{\circ} \mathrm{C}$ ) & $\mathrm{I}^{-} / \mathrm{I}_{3}^{-}$ & N719 & 6.78 & 0.73 & 35 & 1.72 & 16 & 49 & 130 \\
\hline $1 \mathrm{~T}-\mathrm{MoS}_{2}$ (hydrothermal, $180^{\circ} \mathrm{C}$ ) & $\mathrm{I}^{-} / \mathrm{I}_{3}^{-}$ & N719 & 8.76 & 0.73 & 52 & 7.08 & 16 & 19 & 130 \\
\hline Pt reference & $\mathrm{I}^{-} / \mathrm{I}_{3}^{-}$ & N719 & 17.75 & 0.702 & 58 & 7.25 & - & - & 130 \\
\hline $\mathrm{MoS}_{2}$ (CVD) vertically inclined & $\mathrm{I}^{-} / \mathrm{I}_{3}^{-}$ & N719 & 15.2 & 0.707 & 69.7 & 7.50 & 9.5 & 3.10 & 131 \\
\hline Pt reference & $\mathrm{I}^{-} / \mathrm{I}_{3}^{-}$ & N719 & 14.6 & 0.712 & 70.0 & 7.28 & 6.7 & 5.36 & 131 \\
\hline $\mathrm{MoS}_{2} /$ graphite & $\mathrm{I}^{-} / \mathrm{I}_{3}^{-}$ & N719 & 15.64 & 0.685 & 67 & 7.18 & - & 8.05 & 132 \\
\hline Graphite & $\mathrm{I}^{-} / \mathrm{I}_{3}^{-}$ & N719 & 11.62 & 0.445 & 63 & 3.26 & - & 15.70 & 132 \\
\hline Pt reference & $\mathrm{I}^{-} / \mathrm{I}_{3}^{-}$ & N719 & 15.84 & 0.735 & 65 & 7.57 & - & 6.35 & 132 \\
\hline $\mathrm{MoS}_{2}$ (multi-layer) & $\mathrm{I}^{-} / \mathrm{I}_{3}^{-}$ & N719 & 15.81 & 0.745 & 25 & 2.92 & 27.3 & 186.2 & 133 \\
\hline $\mathrm{MoS}_{2}$ (few-layer) & $\mathrm{I}^{-} / \mathrm{I}_{3}^{-}$ & N719 & 14.90 & 0.744 & 16 & 1.74 & 35.8 & 281.2 & 133 \\
\hline $\mathrm{MoS}_{2}$ (nanoparticle) & $\mathrm{I}^{-} / \mathrm{I}_{3}^{-}$ & N719 & 14.72 & 0.745 & 49 & 5.41 & 26.9 & 93.0 & 133 \\
\hline Pt reference & $\mathrm{I}^{-} / \mathrm{I}_{3}^{-}$ & N719 & 13.41 & 0.754 & 65 & 6.58 & 34.2 & 3.9 & 133 \\
\hline $\mathrm{MoS}_{2}$ (hydrothermal method) & $\mathrm{I}^{-} / \mathrm{I}_{3}^{-}$ & N719 & 18.37 & 0.698 & 57.8 & 7.41 & - & 0.619 & 135 \\
\hline Pt reference & $\mathrm{I}^{-} / \mathrm{I}_{3}^{-}$ & N719 & 16.78 & 0.722 & 58.8 & 7.13 & - & 3.78 & 135 \\
\hline $\operatorname{MoS}_{2}\left(300{ }^{\circ} \mathrm{C}\right.$ annealed $)$ & $\mathrm{I}^{-} / \mathrm{I}_{3}^{-}$ & N719 & 16.905 & 0.727 & 51.7 & 6.351 & 23.89 & 30.98 & 137 \\
\hline Pt reference & $\mathrm{I}^{-} / \mathrm{I}_{3}^{-}$ & N719 & 17.056 & 0.724 & 55.7 & 6.929 & 27.17 & 14.98 & 137 \\
\hline $\operatorname{MoS}_{2}$ (chemical deposition) & $\mathrm{I}^{-} / \mathrm{I}_{3}^{-}$ & N719 & 18.46 & 0.68 & 58 & 7.01 & 23.51 & 18.50 & 138 \\
\hline Pt reference & $\mathrm{I}^{-} / \mathrm{I}_{3}^{-}$ & N719 & 16.80 & 0.71 & 60 & 7.31 & 26.73 & 22.88 & 138 \\
\hline $\mathrm{MoS}_{2}$ (non-annealed) & $\mathrm{I}^{-} / \mathrm{I}_{3}^{-}$ & N719 & 5.24 & 0.74 & 27 & 1.0 & 28 & - & 139 \\
\hline $\mathrm{MoS}_{2}$ (vacuum-annealed) & $\mathrm{I}^{-} / \mathrm{I}_{3}^{-}$ & N719 & 7.95 & 0.74 & 29 & 1.7 & 22 & - & 139 \\
\hline $\mathrm{MoS}_{2}\left(\mathrm{~N}_{2}\right.$-annealed $)$ & $\mathrm{I}^{-} / \mathrm{I}_{3}^{-}$ & N719 & 4.35 & 0.67 & 27 & 0.8 & 44 & - & 139 \\
\hline $\mathrm{MoS}_{2} / \mathrm{Mo}$ (in situ sulfurization) & $\mathrm{I}^{-} / \mathrm{I}_{3}^{-}$ & N719 & 22.6 & 0.74 & 50 & 8.4 & - & - & 140 \\
\hline Pt reference & $\mathrm{I}^{-} / \mathrm{I}_{3}^{-}$ & N719 & 21.9 & 0.735 & 53.4 & 8.7 & - & - & 140 \\
\hline $\operatorname{MoS}_{2}$ (hydrothermal method) & $\mathrm{I}^{-} / \mathrm{I}_{3}^{-}$ & N719 & 13.84 & 0.76 & 73 & 7.59 & 20.8 & 0.5 & 141 \\
\hline $\mathrm{WS}_{2}$ (hydrothermal method) & $\mathrm{I}^{-} / \mathrm{I}_{3}^{-}$ & N719 & 14.13 & 0.78 & 70 & 7.73 & 19.4 & 0.3 & 141 \\
\hline Pt reference & $\mathrm{I}^{-} / \mathrm{I}_{3}^{-}$ & N719 & 14.89 & 0.78 & 66 & 7.64 & 12.7 & 3.0 & 141 \\
\hline $\mathrm{MoS}_{2}$ (hydrothermal method) & $\mathrm{T}_{2} / \mathrm{T}^{-}$ & N719 & 12.52 & 0.63 & 63 & 4.97 & - & - & 141 \\
\hline $\mathrm{WS}_{2}$ (hydrothermal method) & $\mathrm{T}_{2} / \mathrm{T}^{-}$ & N719 & 12.99 & 0.64 & 64 & 5.24 & - & - & 141 \\
\hline Pt reference & $\mathrm{T}_{2} / \mathrm{T}^{-}$ & N719 & 12.23 & 0.63 & 48 & 3.70 & - & - & 141 \\
\hline $\mathrm{MoS}_{2}$ (porous sheets) & $\mathrm{I}^{-} / \mathrm{I}_{3}^{-}$ & N719 & 15.40 & 0.763 & 53 & 6.35 & 7.95 & 1.73 & 143 \\
\hline $\mathrm{MoS}_{2}$ (flower-shaped) & $\mathrm{I}^{-} / \mathrm{I}_{3}^{-}$ & N719 & 13.73 & 0.700 & 52 & 5.23 & 7.89 & 2.67 & 143 \\
\hline Pt reference & $\mathrm{I}^{-} / \mathrm{I}_{3}^{-}$ & N719 & 16.34 & 0.745 & 51 & 6.19 & 8.06 & 1.82 & 143 \\
\hline $\operatorname{MoS}_{2}$ (sputtering, 5 min) & $\mathrm{I}^{-} / \mathrm{I}_{3}^{-}$ & N719 & 13.17 & 0.71 & 64 & 6.6 & 30.1 & 2.2 & 145 \\
\hline Pt reference & $\mathrm{I}^{-} / \mathrm{I}_{3}^{-}$ & N719 & 14.70 & 0.71 & 66 & 6.0 & 3.1 & 1.5 & 145 \\
\hline $\mathrm{MoS}_{2}$ (as-prepared) & $\mathrm{I}^{-} / \mathrm{I}_{3}^{-}$ & N719 & 11.92 & 0.656 & 35 & 2.74 & - & $1.01 \times 10^{4}$ & 146 \\
\hline $\operatorname{MoS}_{2}$ (heat-sintered) & $\mathrm{I}^{-} / \mathrm{I}_{3}^{-}$ & N719 & 13.01 & 0.705 & 65 & 5.96 & - & 18.50 & 146 \\
\hline $\mathrm{MoS}_{2}$ (laser-sintered) & $\mathrm{I}^{-} / \mathrm{I}_{3}^{-}$ & N719 & 14.94 & 0.718 & 67 & 7.19 & - & 15.29 & 146 \\
\hline Pt reference & $\mathrm{I}^{-} / \mathrm{I}_{3}^{-}$ & N719 & 14.30 & 0.741 & 70 & 7.42 & - & 3.99 & 146 \\
\hline $\mathrm{MoS}_{2}$ (growth time, $5 \mathrm{~h}$ ) & $\mathrm{I}^{-} / \mathrm{I}_{3}^{-}$ & N719 & 15.15 & 0.76 & 52 & 5.96 & 50.9 & 118.8 & 147 \\
\hline $\mathrm{MoS}_{2}$ (growth time, $10 \mathrm{~h}$ ) & $\mathrm{I}^{-} / \mathrm{I}_{3}^{-}$ & N719 & 15.94 & 0.71 & 63 & 7.14 & 50.4 & 21.2 & 147 \\
\hline $\mathrm{MoS}_{2}$ (growth time, $15 \mathrm{~h}$ ) & $\mathrm{I}^{-} / \mathrm{I}_{3}^{-}$ & N719 & 16.96 & 0.74 & 66 & 8.28 & 38.8 & 12.9 & 147 \\
\hline Pt reference & $\mathrm{I}^{-} / \mathrm{I}_{3}^{-}$ & N719 & 13.77 & 0.74 & 74 & 7.53 & 36.3 & 13.1 & 147 \\
\hline $\mathrm{MoS}_{2}$ (exfoliated) & $\mathrm{I}^{-} / \mathrm{I}_{3}^{-}$ & N719 & 11.54 & 0.80 & 65 & 6.0 & 29.60 & 19.60 & 148 \\
\hline $\mathrm{MoS}_{2}$ (annealed) & $\mathrm{I}^{-} / \mathrm{I}_{3}^{-}$ & N719 & 10.92 & 0.80 & 58 & 5.1 & 28.10 & 121.10 & 148 \\
\hline Pt reference & $\mathrm{I}^{-} / \mathrm{I}_{3}^{-}$ & N719 & - & & & & & & 148 \\
\hline $\mathrm{MoS}_{2}$ & $\mathrm{I}^{-} / \mathrm{I}_{3}^{-}$ & N719 & 12.92 & 0.701 & 46 & 4.15 & 11.69 & 3.65 & 151 \\
\hline Graphene nanosheet & $\mathrm{I}^{-} / \mathrm{I}_{3}^{-}$ & N719 & 11.99 & 0.754 & 30 & 2.68 & 9.31 & 6.24 & 151 \\
\hline $\mathrm{MoS}_{2}$-graphene nanosheet & $\mathrm{I}^{-} / \mathrm{I}_{3}^{-}$ & N719 & 12.79 & 0.773 & 59 & 5.81 & 9.52 & 2.34 & 151 \\
\hline Pt reference & $\mathrm{I}^{-} / \mathrm{I}_{3}^{-}$ & N719 & 13.12 & 0.763 & 62 & 6.24 & 9.11 & 1.79 & 151 \\
\hline $\mathrm{MoS}_{2}$ /graphene & $\mathrm{I}^{-} / \mathrm{I}_{3}^{-}$ & N719 & 12.41 & 0.71 & 68 & 5.98 & 24.42 & 4.94 & 152 \\
\hline Pt reference & $\mathrm{I}^{-} / \mathrm{I}_{3}^{-}$ & N719 & 12.43 & 0.73 & 67 & 6.23 & 24.72 & 4.74 & 152 \\
\hline $\mathrm{MoS}_{2}(\mathrm{CVD})$ & $\mathrm{I}^{-} / \mathrm{I}_{3}^{-}$ & N719 & 14.0 & 0.62 & 65 & 5.6 & 1.5 & 2.3 & 153 \\
\hline $\mathrm{MoS}_{2} /$ graphene (CVD) & $\mathrm{I}^{-} / \mathrm{I}_{3}^{-}$ & N719 & 16.1 & 0.66 & 67 & 7.1 & 1.7 & 1.6 & 153 \\
\hline Graphene & $\mathrm{I}^{-} / \mathrm{I}_{3}^{-}$ & N719 & 16.9 & 0.68 & 24 & 2.8 & 1.7 & 2.8 & 153 \\
\hline Pt reference & $\mathrm{I}^{-} / \mathrm{I}_{3}^{-}$ & N719 & 17.2 & 0.72 & 60 & 7.4 & 2.1 & 1.8 & 153 \\
\hline $\mathrm{MoS}_{2}$ & $\mathrm{I}^{-} / \mathrm{I}_{3}^{-}$ & N719 & 9.14 & 0.589 & 47 & 2.53 & - & - & 154 \\
\hline Graphene & $\mathrm{I}^{-} / \mathrm{I}_{3}^{-}$ & N719 & 10.7 & 0.652 & 51.9 & 3.62 & - & - & 154 \\
\hline $\operatorname{MoS}_{2}:$ graphene $(10: 90)$ & $\mathrm{I}^{-} / \mathrm{I}_{3}^{-}$ & N719 & 11.91 & 0.646 & 56.5 & 4.35 & - & - & 154 \\
\hline Pt reference & $\mathrm{I}^{-} / \mathrm{I}_{3}^{-}$ & N719 & 13.39 & 0.657 & 50 & 4.40 & - & - & 154 \\
\hline
\end{tabular}


Table 2 (Contd.)

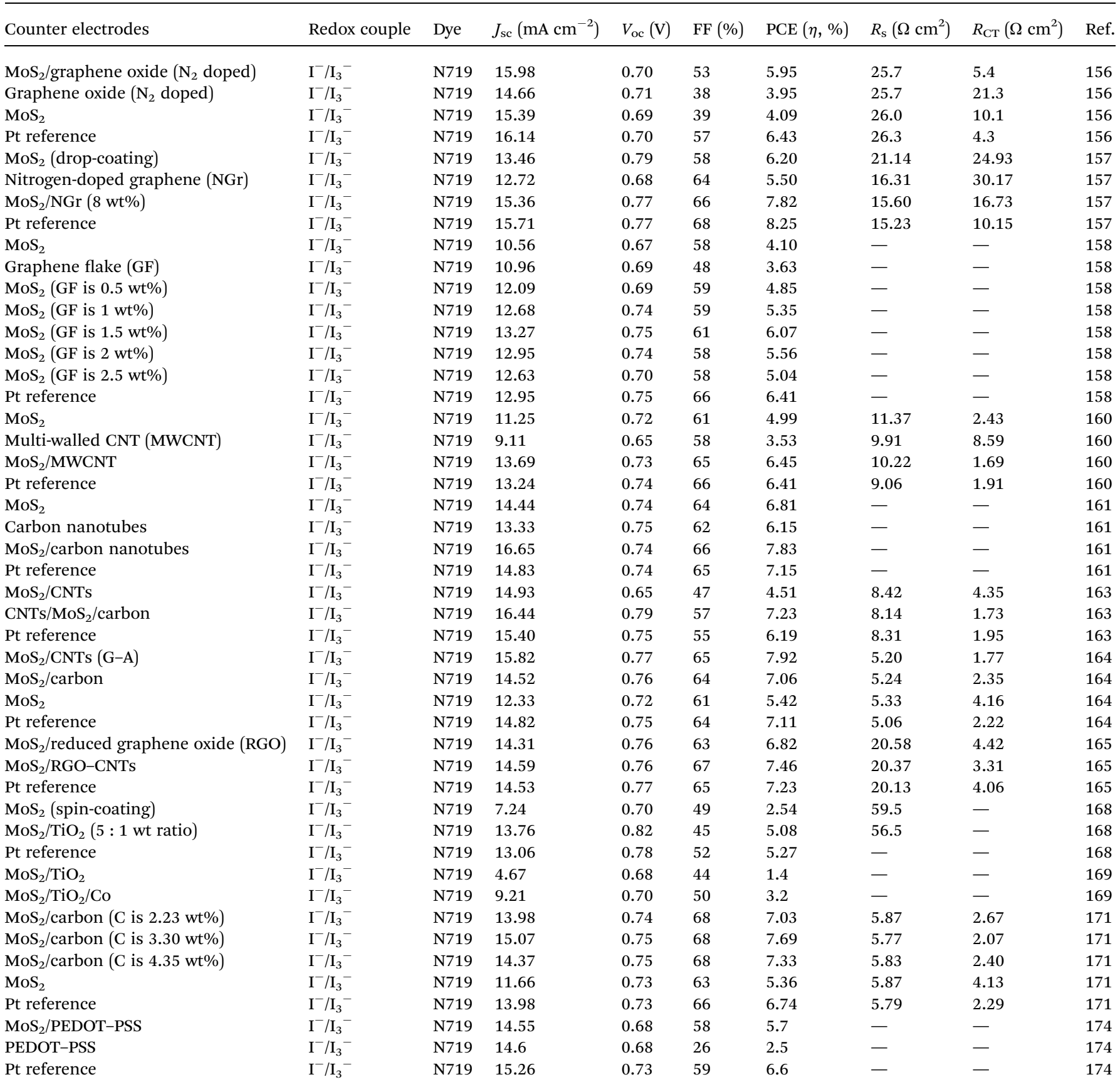

${ }^{a}$ Disulfide/thiolate $\left(\mathrm{T}_{2} / \mathrm{T}^{-}\right)$redox couple. In the case of $R_{\mathrm{S}}$ and $R_{\mathrm{CT}}$ : some of the authors used $\Omega$ instead of $\Omega \mathrm{cm}^{2}$ for the resistances without mentioning the size of the electrode.

found to vary as a function of the thickness of $\mathrm{MoS}_{2} /$ carbon CE. PCE values of $5.10,6.89,7.69,7.01$ and $4.85 \%$ were measured for the CE thicknesses of 4, 8, 12, 16 and $20 \mu \mathrm{m}$ for the $\mathrm{MoS}_{2}$ / carbon CE. EIS, CV, and Tafel curve analysis showed low $R_{\mathrm{CT}}$, high electrocatalytic activity, and faster reduction of triiodide $\left(\mathrm{I}_{3}{ }^{-}\right)$to iodide $\left(\mathrm{I}^{-}\right)$for the $\mathrm{MoS}_{2} /$ carbon CE compared to that of the Pt CE.

In yet another study, $\mathrm{MoS}_{2}$ /carbon fibers were used as CEs for DSSCs. ${ }^{172}$ Both electrocatalytic activity and the PCE $(3.26 \%)$ of the $\mathrm{MoS}_{2}$ /carbon fiber based CE was found be better than that of $\mathrm{Pt} /$ carbon fiber CE $(\eta=2.93 \%)$. In another study, composites of flower-like $\mathrm{MoS}_{2}$ microspheres and carbon materials such as vulcan carbon, acetylene black, MWCNTs, carbon nanofibers (CNFs), and rice husk ash were studied as cost-effective Pt-free CEs for DSSCs. ${ }^{173}$ The electrolyte used in the DSSC was a phthaloylchitosan-based polymer. The carbon materials/ $\mathrm{MoS}_{2}$ CEs showed low $R_{\mathrm{CT}}$ at the $\mathrm{CE} /$ electrolyte interface and high electro-catalytic activity for $\mathrm{I}_{3}{ }^{-}$reduction. The DSSC with $\mathrm{MoS}_{2}$ / 
CNF CE showed a PCE of $3.17 \%$, compared to a PCE of $1.04 \%$ for the pure $\mathrm{MoS}_{2} \mathrm{CE}$.

Another study used $\mathrm{MoS}_{2}$ and PEDOT:PSS composites as CEs for DSSCs. ${ }^{174}$ The $\mathrm{MoS}_{2} / \mathrm{PEDOT}$ :PSS composite CE exhibits a PCE of $5.7 \%$ and FF of $58 \%$, comparable to the Pt CE. The high PCE of the $\mathrm{MoS}_{2} / \mathrm{PEDOT}$ :PSS CE originated from high electrocatalytic activity of the $\mathrm{MoS}_{2}$ active sites for triiodide $\left(\mathrm{I}_{3}{ }^{-}\right)$ reduction and high conductivity of PEDOT:PSS. The inorganic/ organic $\mathrm{MoS}_{2}$ /PEDOT:PSS composite may be useful as a low-cost Pt-free CEs for DSSCs. Another study used $\mathrm{Bi}_{5} \mathrm{FeTi}_{3} \mathrm{O}_{15}$ (BFTO) nanofibers of 40-100 $\mathrm{nm}$ diameter developed by a sol-gel aided electrospinning method. ${ }^{175}$ The $\mathrm{MoS}_{2} / \mathrm{BFTO}$ nanocompositebased CE for DSSCs was prepared by uniformly dispersing $\mathrm{MoS}_{2}$ nanoparticles into the BFTO matrix. The optical bandgap of the $\mathrm{MoS}_{2} / \mathrm{BFTO}$ nanocomposites was found to decrease with increasing $\mathrm{MoS}_{2}$ contents. The DSSC with a $\mathrm{MoS}_{2} / \mathrm{BFTO}$ nanocomposite-based CE showed a PCE of 5.20\%, 24 times higher than that of the pure BFTO nanofiber based CE. Table 2 summarizes the electrochemical and photovoltaic properties of all types of $\mathrm{MoS}_{2}$ based CEs discussed in this section above, and a comparison is made with conventional Pt CEs for DSSCs.

\section{2 $\mathrm{WS}_{2}$ counter electrodes}

Tungsten disulfide $\left(\mathrm{WS}_{2}\right)$, traditionally used as a lubricant, is a semiconductor having van der Waals bonding which forms $2 \mathrm{D}$ layered-structures similar to other TMDs. $\mathrm{WS}_{2}$ can form atomically thin nanosheets, ${ }^{176,177}$ nanorods, ${ }^{178}$ and nanotubes, ${ }^{179,180}$ which have been actively studied for potential applications.

Carbon-coated $\mathrm{WS}_{2}$ CEs have been fabricated for DSSCs at low temperature and characterized using FESEM, XRD, and Raman spectroscopy. ${ }^{181}$ The electrocatalytic activity of the $\mathrm{WS}_{2}$ CEs was studied using CV and EIS. The DSSCs with carboncoated $\mathrm{WS}_{2}$ CEs show a PCE of 5.5\%, comparable to that of $\mathrm{Pt}$ CE based DSSCs $(\eta=5.6 \%)$. A DSSC having plastic $\mathrm{WS}_{2}$ CEs exhibited a PCE of $5.0 \%$. Carbon-coated $\mathrm{WS}_{2}$ seems promising to develop low cost Pt-free CEs for DSSCs. The $\mathrm{WS}_{2}$ films were deposited by radio frequency (RF) sputtering and a sulfurization process as CE for DSSCs. ${ }^{182}$ The $\mathrm{WS}_{2}$ films were characterized using XRD, FESEM, Raman spectroscopy, and XPS techniques. The transparent $\mathrm{WS}_{2}$ CEs demonstrated high electrocatalytic activity and fast reduction of triiodide, $\left(\mathrm{I}_{3}{ }^{-}\right)$as characterized using CV, EIS, and Tafel polarization curve. $\mathrm{WS}_{2}$ CE sputtered for 10 minutes showed a PCE of $6.3 \%$, slightly lower than the Ptbased CE $(\eta=6.64 \%)$ used in the DSSC. The $J-V$ characteristics as a function of sputtering time used to prepare $\mathrm{WS}_{2}$ films as a CE were also studied. $\mathrm{WS}_{2}$ film CEs prepared at sputtering time of 5, 10 and 15 minutes showed PCEs of 5.4\%, 6.3\% and $5.8 \%$, respectively.

Another research team ${ }^{183}$ used edge-oriented $\mathrm{WS}_{2}$ based CEs for DSSCs. Edge-oriented $\mathrm{WS}_{2}$ was obtained from mesoporous interconnected $\mathrm{WO}_{3}$ structures using a high temperature sulfurization process. The DSSCs with edge-oriented $\mathrm{WS}_{2} \mathrm{CEs}$ show a PCE of $8.85 \%$, higher compared to the Pt CE $(\eta=7.20 \%)$. The large number of active edge sites in edge-oriented $\mathrm{WS}_{2}$ is responsible for high electrocatalytic activity for the reduction of triiodide $\left(\mathrm{I}_{3}{ }^{-}\right)$in the DSSCs. The $\mathrm{WS}_{2}$ films were fabricated by the doctor-blade method (or tape casting method; a method removing excessive liquid material using a moving blade for uniform coating) to use as CEs for DSSCs. ${ }^{184} \mathrm{The}^{\mathrm{TiO}_{2}}$ (P25) and carbon nanoparticles were introduced into $\mathrm{WS}_{2}$ films to increase electrical conductivity and bonding strength. The electrochemical catalytic activity of $\mathrm{WS}_{2} / \mathrm{P} 25 / \mathrm{C}$ CEs was compared with $\mathrm{Pt}$ for the triiodide $\left(\mathrm{I}_{3}{ }^{-}\right)$to iodide $\left(\mathrm{I}^{-}\right)$electrolyte system using CV and EIS measurements. The DSSC developed with $\mathrm{WS}_{2} / \mathrm{P} 25 / \mathrm{C} \mathrm{CE}$ was shown to yield a PCE of $4.56 \%$.

Yue et al. ${ }^{185}$ prepared $\mathrm{WS}_{2}$ decorated multi-walled carbon nanotubes (MWCNTs) by applying a hydrothermal method, for use as a low-cost Pt-free CE for DSSCs. The contents of MWCNTs in MWCNTs-WS $\mathrm{S}_{2}$ CEs varied from 1 to $10 \mathrm{wt} \%$. PCE values of $5.20,5.45,6.41,5.53$ and $5.22 \%$ were measured in the DSSCs for CEs having 1, 3, 5, 7 and 10 wt $\%$ contents of MWCNTs, respectively. $\mathrm{CV}$ and EIS showed high electrocatalytic activity for the MWCNTs- $\mathrm{WS}_{2} \mathrm{CE}$ for the triiodide $\left(\mathrm{I}_{3}{ }^{-}\right.$) reduction. The $R_{\mathrm{CT}}$
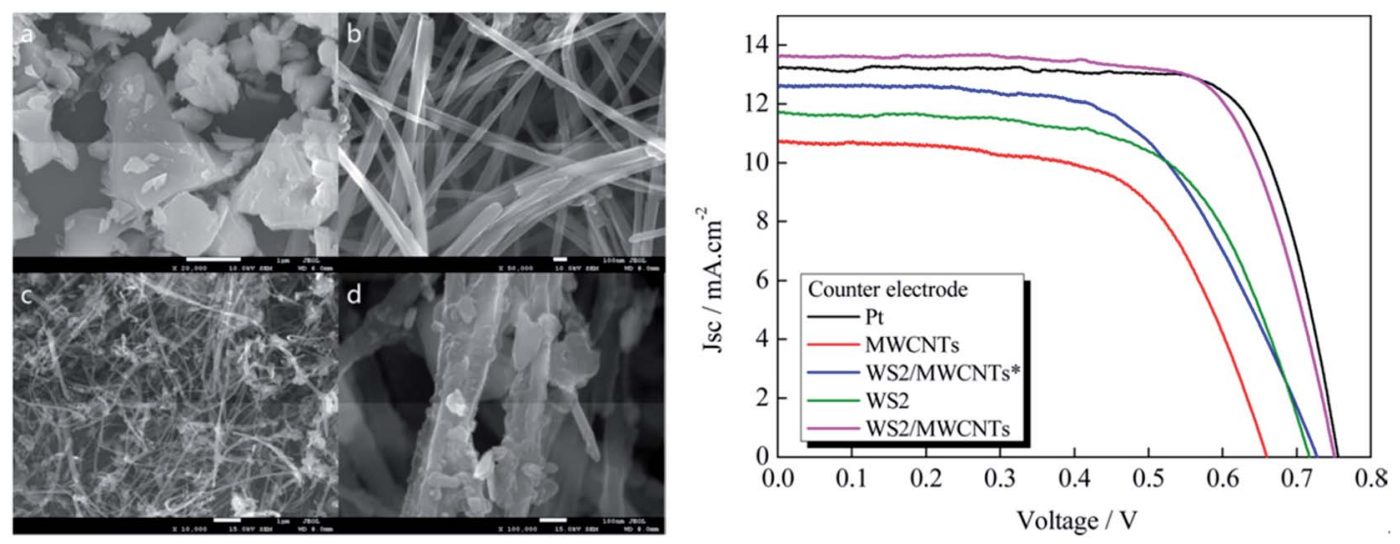

Fig. 11 (Left) SEM images of (a) WS $S_{2}$ (b) MWCNTs, and (c and d) $W_{2} / M W C N T s$ composites. (Right) photocurrent-voltage (J-V) curves of the DSSCs with Pt, WS $2, M W C N T s, W_{2} / M W C N T s *$ (prepared without glucose aid), and (G-A)WS $/$ MWCNTs counter electrodes under a simulated solar illumination of $100 \mathrm{~mW} \mathrm{~cm}{ }^{-2}$. Reprinted with permission from ref. 186, J. Wu, G. Yue, Y. Xiao, M. Huang, J. Lin, L. Fan, Z., Lan and J. Y. Lin, glucose aided preparation of tungsten sulfide/multi-wall carbon nanotube hybrid and use as counter electrode in dye-sensitized solar cells. ACS Appl. Mater. Interfaces, 2012, 4, 6530-6536. Copyright@ American Chemical Society. 
of MWCNTs-WS ${ }_{2}$ CEs having 1, 3, 7, and $10 \mathrm{wt} \%$ contents of MWCNTs were $4.54,3.47,3.24$, and $4.59 \Omega \mathrm{cm}^{2}$, respectively. The $R_{\mathrm{CT}}$ of the MWCNTs-WS 2 CE with $5 \mathrm{wt} \%$ contents of MWCNTs shows $2.53 \Omega \mathrm{cm}^{2}$, comparable to the $R_{\mathrm{CT}}$ of $2.74 \Omega$ $\mathrm{cm}^{2}$ for a Pt CE. The DSSCs based on $\mathrm{WS}_{2} /$ MWCNTs CEs showed a PCE of $6.41 \%$ for $5 \mathrm{wt} \%$ MWCNTs, comparable to the PCE of $6.56 \%$ for Pt CE under a simulated AM 1.5 solar illumination $\left(100 \mathrm{~mW} \mathrm{~cm}^{-2}\right)$. The low $R_{\mathrm{CT}}$ of $\mathrm{WS}_{2} /$ MWCNTs CEs at the electrolyte/electrode interface contributed to the higher PCEs.

The $\mathrm{WS}_{2}$ based CEs prepared by a hydrothermal method was also used for DSSC by Wu et al., ${ }^{141}$ which exhibited a PCE of $7.73 \%$. The same research team ${ }^{186}$ also synthesized $\mathrm{WS}_{2} /$ MWCNTs hybrids by a glucose-aided (G-A) hydrothermal route, which is discussed here in detail. Fig. 11 presents the SEM images of $\mathrm{WS}_{2}$, MWCNTs, and (G-A)WS 2 /MWCNTs composites, and $J-V$ curves of the DSSCs with $\mathrm{WS}_{2}$, MWCNTs, $\mathrm{WS}_{2} /$ MWCNTs* (prepared without the aid of glucose), $\mathrm{WS}_{2} /$ MWCNTs, and Pt CEs, under a simulated solar illumination of $100 \mathrm{~mW} \mathrm{~cm}{ }^{-2}$. The $\mathrm{WS}_{2}$ exhibits graphene-like lamellar structure, whereas the MWCNTs have a fiber-like structure, indicating both materials have a large specific surface area. The specific surface area of the (G-A)WS $\mathrm{W}_{2}$ MWCNTs composite was estimated to be $230 \mathrm{~m}^{2} \mathrm{~g}^{-1}$ by the Brunauer-Emmett-Teller (BET) technique, indicating high electrochemical activity as well as photovoltaic efficiency for CEs. The cathodic peak potentials of the $\mathrm{WS}_{2}, \mathrm{WS}_{2} / \mathrm{MWCNTs}$, and $\mathrm{WS}_{2} /$ MWCNTs* CEs showed cathodic peak potentials of $-0.14,-0.13$ and $-01.7 \mathrm{~V}$, respectively, which implies that the MWCNTs help in improving the electrocatalytic activity, and a lower cathodic peak potential observed for (G-A)WS $\mathrm{WWCNTs}_{2}$ as opposed to $\mathrm{WS}_{2} / \mathrm{MWCNTs}$ * results from the large specific surface area generated by glucose aided preparation. The EIS measurements yielded an $R_{\mathrm{CT}}$ of $2.49 \Omega \mathrm{cm}^{2}$ and $R_{\mathrm{S}}$ of $2.54 \Omega \mathrm{cm}^{2}$ for the $\mathrm{WS}_{2} /$ MWCNTs hybrid $\mathrm{CE}$, which is smaller compared with $\mathrm{WS}_{2} \mathrm{CE}$, and indicates the synergistic effect between $\mathrm{WS}_{2}$ and MWCNTs that enhanced the electrical conductivity of the hybrid. The (G-A) $\mathrm{WS}_{2} / \mathrm{MWCNT}$ CE based DSSC resulted in a PCE of 7.36\%, comparable to $\mathrm{WS}_{2} \mathrm{CE}$ (5.32\%), MWCNTs CE (4.34\%), and the Pt CE (7.54\%). The $J_{\text {sc }}$ and PCE values increased with increasing content of MWCNTs, up to $5 \mathrm{wt} \%$ in the $\mathrm{WS}_{2} / \mathrm{MWCNT}$ hybrid CEs, and thereafter started decreasing with further increases in MWCNTs content. The (G-A)WS $\mathrm{WWCNT}_{2}$ (M $\mathrm{wt} \%$ ) film also exhibits a smaller transmission between 320 to $800 \mathrm{~nm}$ than Pt film, therefore the $\mathrm{WS}_{2} /$ MWCNT film absorbs more incident light, which also further improves photovoltaic performance. The glucose aided (G-A)WS ${ }_{2} /$ MWCNTs (5 wt\%) CE in the DSSC had low $R_{\mathrm{CT}}$ and high electrocatalytic activity for the reduction of triiodide $\left(\mathrm{I}_{3}{ }^{-}\right)$, due to the synergistic effects induced by glucose.

\section{3 $\quad \mathrm{TiS}_{2}$ counter electrodes}

Titanium disulfide $\left(\mathrm{TiS}_{2}\right)$ is a metallic thermoelectric material which attains unique morphologies such as nanotubes, nanoclusters and nanodisks, and exhibits interesting physical properties. ${ }^{187-198}$ Meng et al. ${ }^{199}$ has prepared 2D TiS 2 nanosheets decorated on graphene using a ball milling method and followed by high-temperature annealing. The electroactive surface

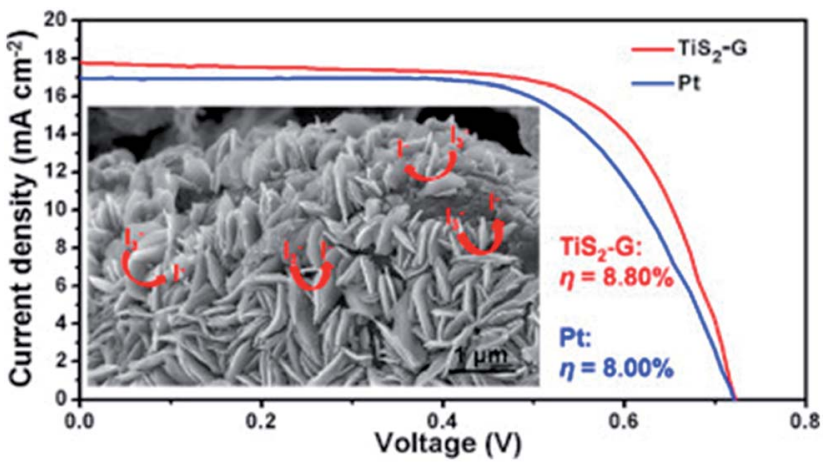

Fig. 12 A comparison of photocurrent density-voltage ( $J-V$ curves of DSSCs having $\mathrm{TiS}_{2}-$ graphene hybrid and Pt counter electrodes. Reprinted with permission from ref. 199, X. Meng, C. Yu, B. Lu, J. Yang and J. Qiu, dual integration system endowing two-dimensional titanium disulfide with enhanced triiodide reduction performance in dyesensitized solar cells. Nano Energy, 2016, 22, 59-69. Copyright@ Elsevier.

areas of $1.70 \mathrm{~cm}^{2}$ for $\mathrm{TiS}_{2}$-graphene and $0.232 \mathrm{~cm}^{2}$ for Pt electrodes, measured by $\mathrm{CV}$, indicate more active sites for the hybrid. Fig. 12 compares $J-V$ curves of DSSCs having TiS $_{2}-$ graphene and Pt/FTO CEs. The CEs based on $\mathrm{TiS}_{2}$-graphene hybrids exhibited higher electrocatalytic activity for the reduction of triiodide $\left(\mathrm{I}_{3}{ }^{-}\right)$to iodide $\left(\mathrm{I}^{-}\right)$in electrolyte with a PCE of $8.80 \%$, which is higher than the Pt CE $(\eta=8.00 \%)$. The $R_{\mathrm{S}}$ of TiS $_{2}$-graphene CEs $\left(2.32 \Omega \mathrm{cm}^{2}\right)$ was found to be smaller compared to the Pt CEs $\left(6.90 \Omega \mathrm{cm}^{2}\right)$, showing better contact between the hybrid CE and FTO glass. Furthermore, the $R_{\mathrm{CT}}$ of $\mathrm{TiS}_{2}$-graphene CE $\left(0.63 \Omega \mathrm{cm}^{2}\right)$ was also lower than the Pt CE (1.32 $\Omega \mathrm{cm}^{2}$ ), which again indicates a higher electrocatalytic activity for the reduction of triiodide $\left(\mathrm{I}_{3}{ }^{-}\right)$. Also, the $Z_{\mathrm{N}}$ of $\mathrm{TiS}_{2}{ }^{-}$ graphene CE $\left(10.52 \Omega \mathrm{cm}^{2}\right)$ was found to be higher than the Pt CE $\left(6.89 \Omega \mathrm{cm}^{2}\right)$. The high electrocatalytic activity of the $\mathrm{TiS}_{2}-$ graphene hybrids is attributed to the highly electroactivity of $\mathrm{TiS}_{2}$ and enhanced transport facilitated by the graphene conductive network.

Li et al. ${ }^{200}$ deposited composite films of $\mathrm{TiS}_{2} / \mathrm{PEDOT}: \mathrm{PSS}$ on ITO substrates by drop coating, to study CEs of DSSCs. The wt $\%$ of $\mathrm{TiS}_{2}$ particles in $\mathrm{TiS}_{2} / \mathrm{PEDOT}$ :PSS composite films varied from 5 to $15 \mathrm{wt} \%$. TiS $_{2}$ particles were dispersed in a PEDOT:PSS matrix to be used as an electrocatalyst for the $\mathrm{I}^{-} / \mathrm{I}_{3}{ }^{-}$redox reaction. In the composite, conducing polymer PEDOT:PSS plays the role of a binder for the $\mathrm{TiS}_{2}$ nanoparticles, as well as a linking agent between $\mathrm{TiS}_{2}$ particles and the ITO substrate, and also facilitates electron transfer. The $\mathrm{TiO}_{2}$ photoanode for a DSSC was prepared by immersing it in N719 dye solution for 24 hours at room temperature. Fig. 13 shows the photocurrent density-voltage curves and IPCE curves of the DSSCs with Pt, bare $\mathrm{TiS}_{2}$, bare PEDOT:PSS, and $10 \mathrm{wt} \% \mathrm{TiS}_{2} /$ PEDOT:PSS composite CEs. The $\mathrm{TiS}_{2} / \mathrm{PEDOT}$ :PSS composite CE offered a large surface area, yielding a high PCE of 7.04\%. The CEs of bare $\mathrm{TiS}_{2}$, bare PEDOT:PSS, the $\mathrm{TiS}_{2} / \mathrm{PEDOT}$ PSS composite, and Pt were characterized by AFM, SEM, and EDX. AFM images indicated a roughness of $45 \mathrm{~nm}$ for PEDOT:PSS and of $378 \mathrm{~nm}$ for $\mathrm{TiS}_{2} /$ PEDOT:PSS composite film; therefore, the higher 

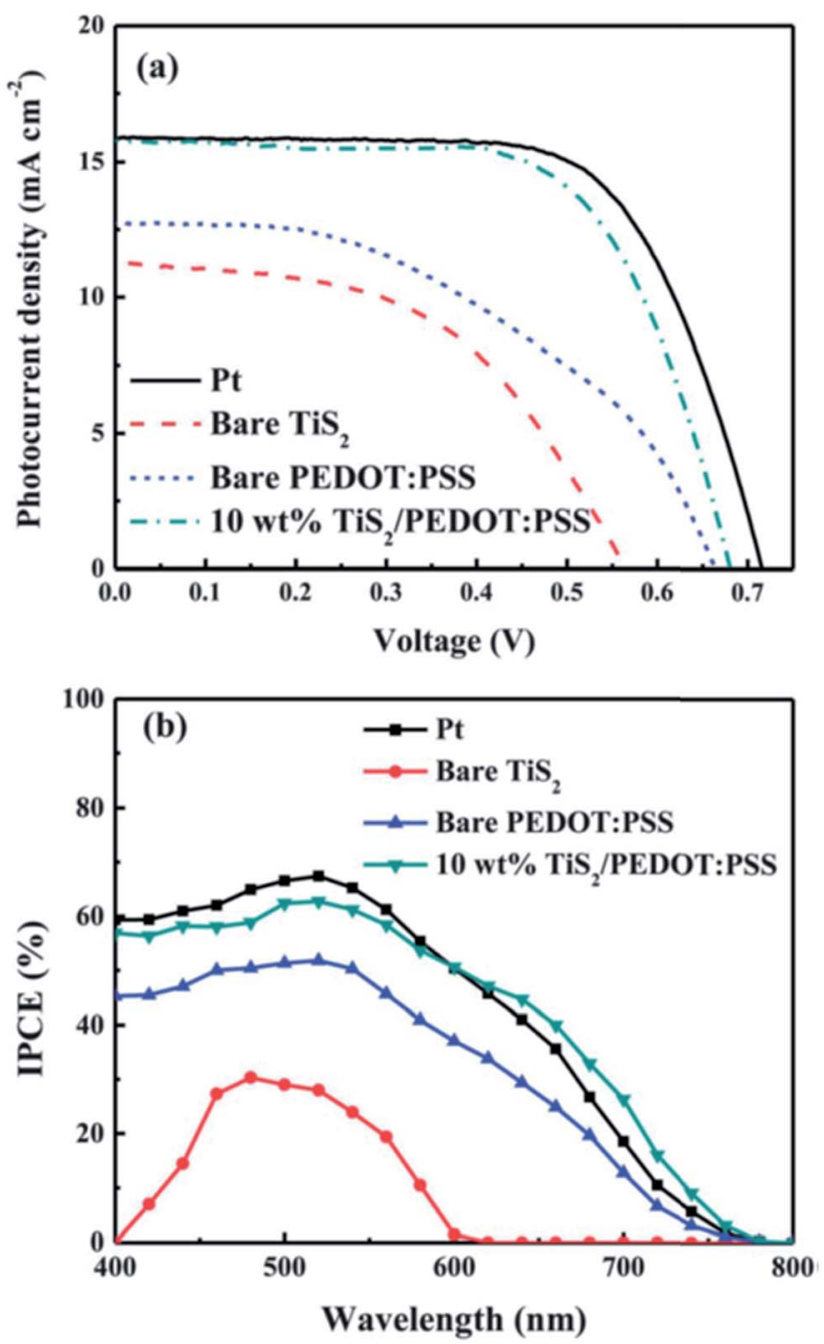

Fig. 13 (a) Photocurrent density-voltage curves of DSSCs with Pt bare $\mathrm{TiS}_{2}$, bare PEDOT:PSS, and $10 \mathrm{wt} \% \mathrm{TiS}_{2} /$ PEDOT:PSS composite based CEs recorded under light illumination of $100 \mathrm{~mW} \mathrm{~cm}^{-2}$ (AM 1.5). (b) Incident photon-to-current conversion efficiency (IPCE) curves of the DSSCs with similar CEs. Reprinted with permission from ref. 200, C. T. Li, C. P. Lee, Y. Y. Li, M. H. Yeh and K. C. Ho, a composite film of $\mathrm{TiS}_{2} /$ PEDOT:PSS as the electrocatalyst for the counter electrode in dyesensitized solar cells. J. Mater. Chem. A, 2013, 1, 14888-14896. Copyright $\odot$ Royal Society of Chemistry.

roughness could lead to a larger active surface area and consequently to the higher electrocatalytic activity for the $\mathrm{TiS}_{2} /$ PEDOT:PSS composite thin. The electrocatalytic properties of the DSSCs using the CEs of bare $\mathrm{TiS}_{2}$, bare PEDOT:PSS, the $\mathrm{TiS}_{2} /$ PEDOT:PSS composite, and Pt were evaluated by CV, RDE, EIS, and Tafel polarization measurements. The high PCE of the $\mathrm{TiS}_{2} /$ PEDOT:PSS composite CE based DSSC was also measured by IPCE curves. The maximum of the IPCE spectra at $520 \mathrm{~nm}$ increased from $52 \%$ to $63 \%$ as the content of $\mathrm{TiS}_{2}$ particles increased from 0 to $10 \mathrm{wt} \%$, respectively, and similar characteristics were observed for the $J_{\mathrm{sc}}$ values from the $J-V$ curves of the DSSCs. The $10 \mathrm{wt} \% \mathrm{TiS}_{2} /$ PEDOT:PSS composite film based CE shows a higher redox current density compared with bare $\mathrm{TiS}_{2}$ and PEDOT:PSS CEs, therefore, it possesses high electrocatalytic activity for triiodide $\left(\mathrm{I}_{3}{ }^{-}\right)$reduction, and it also exhibits high electrochemical stability after 100 consecutive cycles in the $\mathrm{I}^{-} / \mathrm{I}_{3}{ }^{-}$redox electrolyte.

\section{4 $\mathrm{NiS}_{2}$ counter electrodes}

Nickel disulfide $\left(\mathrm{NiS}_{2}\right)$ is a semiconducting material with pyrite structure which acquires unique morphologies such as hollow prisms, nano/microspheres, nanocubes, nanosheets, nanoparticles, and also exhibits interesting electrical, optical, magnetic, and catalytic properties. ${ }^{201-205}$ Depending upon the synthesis procedures, the stoichiometric composition of nickel sulfide varies to a great extent (NiS, $\mathrm{NiS}_{2}, \mathrm{Ni}_{3} \mathrm{~S}_{2}, \mathrm{Ni}_{3} \mathrm{~S}_{4}, \mathrm{Ni}_{6} \mathrm{~S}_{5}$, $\mathrm{Ni}_{7} \mathrm{~S}_{6}, \mathrm{Ni}_{9} \mathrm{~S}_{8}$, etc. $)$.

In one study, hierarchical $\mathrm{NiS}_{2}$ hollow microspheres on a FTO substrate were prepared by a hydrothermal method to use as a CE for a DSSC. ${ }^{206}$ The $\mathrm{NiS}_{2}$ hollow microspheres were partially broken, offering more active sites for electrocatalysis and electrolyte adsorptions. The IPCE values of $81.3 \%$ for the $\mathrm{NiS}_{2}$ microspheres CE and 76.6\% for the Pt CEs at $500 \mathrm{~nm}$ were observed. The peak current density of the $\mathrm{NiS}_{2}$ microspheres CE was found to be higher than the Pt CE, whereas the peak-to-peak separation $\left(E_{\mathrm{pp}}\right)$ value was lower by $10 \mathrm{mV}$ compared to Pt $\mathrm{CE}$, which suggests a high electrocatalytic activity for the $\mathrm{NiS}_{2}$ microspheres $\mathrm{CE}$ in the reduction of triiodide $\left(\mathrm{I}_{3}{ }^{-}\right)$in the electrolyte. The $\mathrm{NiS}_{2}$ hollow microspheres CE based DSSC showed a PCE of $7.84 \%$, equal to the Pt CE (7.89\%), indicating their potential as low-cost CEs for DSSCs. The NiS/NiS $\mathrm{N}_{2}$ composite hollow spheres prepared by a solvothermal method exhibited a low $R_{\mathrm{CT}}$ of $0.34 \Omega \mathrm{cm}^{-2}$ at the CE/electrolyte interface, and a PCE of $7.66 \%$, outperforming the Pt CE (7.01\%), and showed high electrocatalytic activity for $\mathrm{I}_{3}{ }^{-}$reduction, and also better electrochemical stability. ${ }^{207}$ The NiS and $\mathrm{NiS}_{2}$ hollow spheres were synthesized through a solvothermal process. ${ }^{208}$ The Ni/S molar ratio controlled the different stoichiometric ratios of nickel sulfides. The $\mathrm{NiS}_{2} \mathrm{CE}$ based DSSC showed a higher electrocatalytic activity than that of the NiS CE for $\mathrm{I}_{3}{ }^{-}$reduction. The DSSC with $\mathrm{NiS}_{2}$ CE yielded a PCE value of $7.13 \%$ in comparison to $6.49 \%$ for NiS CE.

$\mathrm{NiS}_{2}$ polyhedrons were studied as CEs for DSSCs by Zheng et al. $^{209}$ Fig. 14 shows SEM, TEM, and selected area electron diffraction (SAED) images of $\mathrm{NiS}_{2}$ octahedrons and $\mathrm{NiS}_{2}$ cubes, and electrochemical characteristics of DSSCs having $\mathrm{NiS}_{2}$ octahedrons, $\mathrm{NiS}_{2}$ cubes and Pt CEs, under simulated AM1.5G solar light. The average size of $\mathrm{NiS}_{2}$ octahedrons and cubes were about $250 \mathrm{~nm}$. The electrochemical performance of $\mathrm{NiS}_{2}$ octahedron and cube based CEs were evaluated using $\mathrm{CV}, J-V$ characteristics, EIS, and the Tafel polarization method. The $\mathrm{NiS}_{2}$ octahedron CEs showed peak current density of $1.40 \mathrm{~mA}$ $\mathrm{cm}^{-2}$, compared to $1.22 \mathrm{~mA} \mathrm{~cm}{ }^{-2}$ for the $\mathrm{NiS}_{2}$ cubes, indicating better electrocatalytic activity. The $\mathrm{NiS}_{2}$ octahedron CEs also exhibited a higher $J_{\mathrm{sc}}$ of $13.55 \mathrm{~mA} \mathrm{~cm}^{-2}$ and $\mathrm{FF}$ of $62 \%$, higher than that of the $\mathrm{NiS}_{2}$ cube $\mathrm{CE}\left(J_{\mathrm{sc}}\right.$ of $12.62 \mathrm{~mA} \mathrm{~cm}^{-2}$ and $\mathrm{FF}$ of $60 \%$ ), giving rise to a higher PCE. Octahedral $\mathrm{NiS}_{2}$ nanocrystals based CEs incorporated into DSSCs exhibited a PCE of 5.98\%, slightly higher than that of the $\mathrm{NiS}_{2}$ cube nanocrystals $(\eta=$ $5.43 \%$ ). The $\mathrm{NiS}_{2}$ octahedron CE had a PCE of up to $91 \%$ of the 

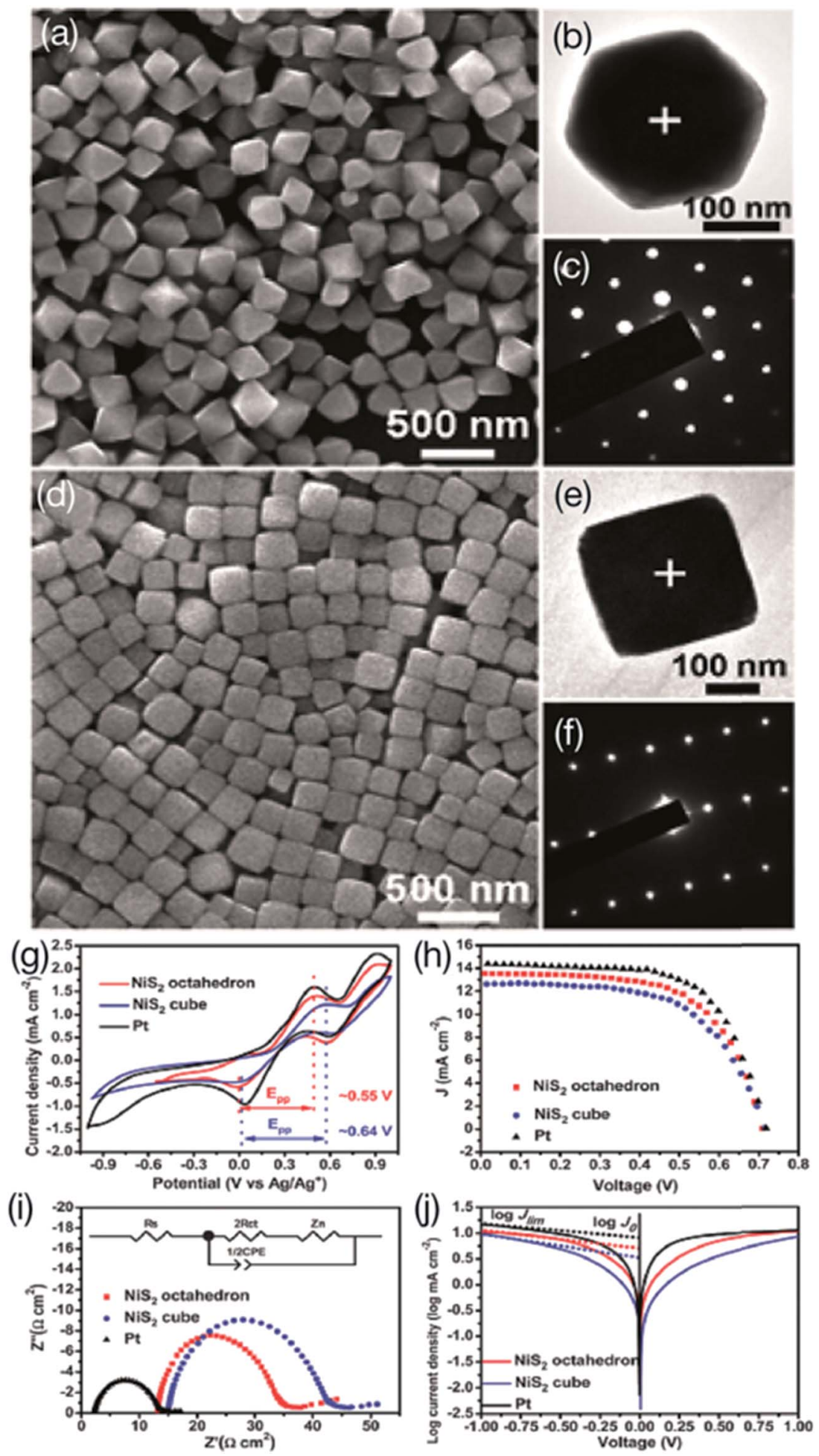

Fig. 14 SEM, TEM, and SAED images of $\mathrm{NiS}_{2}$ octahedrons $(\mathrm{a}-\mathrm{c})$ and $\mathrm{NiS}_{2}$ cubes (d-f). SAED patterns of $\mathrm{NiS}_{2}$ octahedrons (c) and $\mathrm{NiS}_{2}$ cubes (f) were recorded from the corresponding particles depicted (b) and (e), respectively. (g) $C-V$ curves of DSSCs having counter electrodes of NiS 2 octahedrons, $\mathrm{NiS}_{2}$ cubes and Pt for the reduction of tri-iodide (h) J-V curves of DSSCs with $\mathrm{NiS}_{2}$ octahedrons, $\mathrm{NiS}_{2}$ cubes and Pt CEs under simulated AM1.5G solar light. Nyquist plots (i) and Tafel polarization curves (j) of DSSCs having $\mathrm{NiS}_{2}$ octahedrons, NiS $\mathrm{C}_{2}$ cubes and Pt CEs. Reprinted with permission from ref. 209, J. Zheng, W. Zhou, Y. Ma, W. Cao, C. Wang and L. Guo, facet-dependent NiS 2 polyhedrons on counter electrodes for dye-sensitized solar cells. Chem. Commun., 2015, 51, 12863-12866. Copyright@ Royal Society of Chemistry.

conventional Pt CE in DSSCs $(\eta=6.55 \%)$. The $R_{\mathrm{S}}$ of the $\mathrm{NiS}_{2}$ octahedron based CE was $13.14 \Omega \mathrm{cm}^{2}$, somewhat lower than that of the $\mathrm{NiS}_{2}$ cube $\mathrm{CE}\left(R_{\mathrm{S}}\right.$ of $\left.14.98 \Omega \mathrm{cm}^{2}\right)$, indicating higher electrical conductivity of the $\mathrm{NiS}_{2}$ octahedron based CE. The $R_{\mathrm{CT}}$ of the $\mathrm{NiS}_{2}$ octahedron CE was measured as $9.86 \Omega \mathrm{cm}^{2}$, also lower than that of the $\mathrm{NiS}_{2}$ cube $\mathrm{CE}\left(R_{\mathrm{CT}}\right.$ of $\left.13.17 \Omega \mathrm{cm}^{2}\right)$, which 


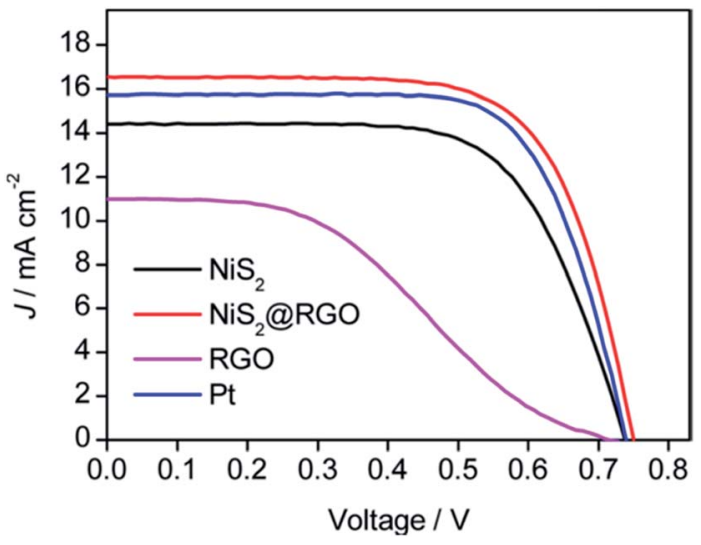

Fig. 15 (a) Photocurrent density-voltage $(J-V)$ curves of DSSCs with bare $\mathrm{NiS}_{2}, \mathrm{NiS}_{2} @ \mathrm{RGO}$ nanocomposites, bare RGO, and Pt CEs measured under light illumination of $100 \mathrm{~mW} \mathrm{~cm}^{-2}$ (AM 1.5). Reprinted with permission from ref. 210, Z. Li, F. Gong, G. Zhou and Z. S. Wang, $\mathrm{NiS}_{2}$ /reduced graphene oxide nanocomposites for efficient dyesensitized solar cells. J. Phys. Chem. C, 2013, 117, 6561-6566. Copyright $\odot$ American Chemical Society.

demonstrates that the $\mathrm{NiS}_{2}$ octahedrons with $\{111\}$ facets possesses better electrocatalytic activity than the $\mathrm{NiS}_{2}$ cubes with $\{100\}$ facets.

The electrocatalytic performance of $\mathrm{NiS}_{2}$ nanoparticles and their nanocomposites with RGO were compared by Li et al. ${ }^{210}$ In a hydrothermal process, graphene oxide was transformed to RGO, and then $\mathrm{NiS}_{2} @ R G O$ nanocomposites were formed by depositing $\mathrm{NiS}_{2}$ nanoparticles on the surface of RGO. CEs for DSSCs were fabricated by drop-casting solutions of $\mathrm{NiS}_{2}$, $\mathrm{NiS}_{2} @$ RGO, and RGO nanocomposites on FTO-coated glass substrate. The surface areas measured by the BET method were 11.4, 9.4, and 8.6, and $5.8 \mathrm{~m}^{2} \mathrm{~g}^{-1}$ for $\mathrm{NiS}_{2} @ \mathrm{RGO}, \mathrm{NiS}_{2}$, and RGO, respectively. Fig. 15 shows $J-V$ curves of DSSCs with bare $\mathrm{NiS}_{2}$, $\mathrm{NiS}_{2} @$ RGO nanocomposites, bare RGO, and Pt CEs. The $\mathrm{NiS}_{2} @$ RGO nanocomposites based CE showed a PCE of 8.55\% $\left(J_{\mathrm{sc}}=16.55 \mathrm{~mA} \mathrm{~cm}{ }^{-2}, V_{\mathrm{oc}}=0.749 \mathrm{~V}\right.$, and $\left.\mathrm{FF}=0.69\right)$, much higher than that of the $\mathrm{NiS}_{2} \mathrm{CE}(\eta=7.02 \%)$, RGO CE $(\eta=$ $3.14 \%)$, or standard Pt CE $(\eta=8.15 \%)$ for the DSSCs under the same experimental conditions. The larger $R_{\mathrm{CT}}$ values of $100.2 \Omega$ $\mathrm{cm}^{2}$ for RGO and $8.8 \Omega \mathrm{cm}^{2}$ for $\mathrm{NiS}_{2}$ also suggest the low electrocatalytic activity. On the other hand, the smaller $R_{\mathrm{CT}}$ value of $2.9 \Omega \mathrm{cm}^{2}$ for the $\mathrm{NiS}_{2} @ \mathrm{RGO}$ nanocomposite indicates much higher electrocatalytic activity for the reduction of triiodide $\left(\mathrm{I}_{3}{ }^{-}\right)$ in electrolyte due the cooperative synergetic effect and the increased conductivity from the RGO nanosheets. This study demonstrates that $\mathrm{NiS}_{2} @ \mathrm{RGO}$ nanocomposites are a promising alternate CE to conventional Pt CE for DSSC devices.

\section{5 $\mathrm{FeS}_{2}$ based counter electrodes}

Pyrite iron disulfide $\left(\mathrm{NiS}_{2}\right)$ acquires unique morphological structures including nanocrystals, nanowires, nanosheets, nanocubes, and exhibits interesting electrical, photovoltaic, and catalytic properties. ${ }^{211-220}$ An interesting comparative study was done by Shukla et al. ${ }^{221}$ on pyrite iron disulfide $\left(\mathrm{FeS}_{2}\right)$ as a CE material in comparison with Pt and PEDOT CEs in DSSCs.
The $\mathrm{FeS}_{2}$ film CEs were fabricated on a FTO glass substrate by a spray pyrolysis method and used in $\mathrm{I}_{3}{ }^{-} / \mathrm{I}^{-}$and $\mathrm{Co}(\mathrm{III}) / \mathrm{Co}$ (II) electrolyte-mediated DSSCs. N719 dye was used for the DSSC with $\mathrm{I}_{3}{ }^{-} / \mathrm{I}^{-}$redox electrolyte and $\mathrm{C} 128$ dye for the $\left[\mathrm{Co}(\mathrm{bpy})_{3}\right]^{2+/ 3+}$ redox electrolyte. The $\mathrm{I}_{3}{ }^{-} / \mathrm{I}^{-}$redox electrolyte contained $1.0 \mathrm{mM}$ of 1,3-dimethylimidazolium iodide, $50 \mathrm{mM}$ of LiI, $30 \mathrm{mM}$ of $\mathrm{I}_{2}$, $0.5 \mathrm{mM}$ of tert-butylpyridine, and $0.1 \mathrm{mM}$ of guanidinium thiocyanate in a acetonitrile and valeronitrile $(\mathrm{v} / \mathrm{v}, 85 / 15)$ mixed solution. The cobalt electrolyte was made up of $0.22 \mathrm{M}$ of $\mathrm{Co}(\mathrm{bpy})_{3}(\mathrm{TFSI})_{2}, \quad\left(\right.$ bpy $=2,2^{\prime}$-bipyridine and TFSI $=[b i s($ trifluoromethane)-sulfonimide]), $\quad 0.05 \mathrm{M}$ of $\mathrm{Co}(\mathrm{bpy})_{3}(\mathrm{TFSI})_{3}$, $0.1 \mathrm{M}$ of lithium bis(trifluoromethanesulfonyl)imide (LiTFSI), and $0.2 \mathrm{M}$ of tert-butylpyridine $(t \mathrm{BP})$ in acetonitrile. Fig. 16 shows the $J-V$ curves and IPCE of the DSSCs with $\mathrm{FeS}_{2}$ and Pt CEs in $\mathrm{I}_{3}^{-} / \mathrm{I}^{-}$electrolyte, and DSSCs with $\mathrm{FeS}_{2}$ and PEDOT CEs in the $\mathrm{Co}\left(\mathrm{III} / \mathrm{Co}\right.$ (II) electrolyte. The catalytic activity of the $\mathrm{FeS}_{2}$ film CEs was found to be comparable to the Pt and PEDOT CEs, which were both in $\mathrm{I}_{3}^{-} / \mathrm{I}^{-}$and $\mathrm{Co}^{2+} / \mathrm{Co}^{3+}$ electrolytes, respectively. With the $\mathrm{I}_{3}{ }^{-} / \mathrm{I}^{-}$electrolyte, a PCE of $7.97 \%$ was observed for the $\mathrm{FeS}_{2}$ film CE and a PCE of $7.54 \%$ for the Pt CE in the $\mathrm{I}_{3}{ }^{-} /$ $\mathrm{I}^{-}$electrolyte, whereas the PCEs were almost the same (6.3\%) for the $\mathrm{FeS}_{2}$ film and PEDOT CEs in the $\left[\mathrm{Co}(\mathrm{bpy})_{3}\right]^{2+/ 3+}$ redoxmediated DSSCs. The performance of the DSSCs with $\mathrm{FeS}_{2}$ and Pt CEs was studied by varying solar light illumination intensities between 1 Sun and 0.1 Sun. The current density was observed to be higher for the $\mathrm{FeS}_{2} \mathrm{CE}\left(15.20 \mathrm{~mA} \mathrm{~cm}^{-2}\right)$ than for the Pt CE $\left(14.77 \mathrm{~mA} \mathrm{~cm}^{-2}\right)$ at 1 Sun light intensity. When the solar light intensity was reduced to 0.5 and 0.1 Sun, the difference in current density between the $\mathrm{FeS}_{2}$ and Pt CEs was not noticeable, with the $J_{\mathrm{sc}}$ values being 8.97 and $8.91 \mathrm{~mA} \mathrm{~cm}^{-2}$ at 0.5 Sun, and 1.75 and $1.74 \mathrm{~mA} \mathrm{~cm}^{-2}$ at 0.1 Sun for the Fe and Pt CEs, respectively. The PCE values for the $\mathrm{FeS}_{2}$ and Pt CEs were $9.27 \%$ and $8.92 \%$ at 0.5 Sun, and $8.68 \%$ and $8.32 \%$ at 0.1 Sun, respectively. The excellent performance of $\mathrm{FeS}_{2}$ film in both electrolyte systems makes it very interesting for applications in DSSCs.

In an interesting study, $\mathrm{FeS}_{2}$ nanorod arrays were fabricated on a FTO substrate after sulfurizing $\mathrm{FeO}(\mathrm{OH})$ nanorods, and used as a CE for DSSCs. ${ }^{222}$ The $\mathrm{FeS}_{2}$ nanorods exhibited better electrocatalytic activity than $\mathrm{FeS}_{2}$ films and Pt-based CEs due to more active sites, which resulted in high $J_{\mathrm{sc}}$ value of the DSSCs. The $\mathrm{FeS}_{2}$ nanorods-based CEs showed lower interface resistance compared with $\mathrm{FeS}_{2}$ thin films, which leads to a higher $\mathrm{FF}$ and hence a higher PCE comparable to Pt CE based DSSCs. The electrochemical stability of the $\mathrm{FeS}_{2}$ nanorod arrays-based $\mathrm{CE}$ measured in $\mathrm{I}_{3}^{-} / \mathrm{I}^{-}$electrolyte showed a slight change in $\mathrm{CV}$ plots up to 10 consecutive days of aging time. In another study, $\mathrm{FeS}_{2}$ powder prepared through a hydrothermal method was used as a CE for fabricating DSSCs. ${ }^{223}$ The effect of $\mathrm{NaOH}$ addition on $\mathrm{FeS}_{2}$ crystal size and electrocatalytic activities was then studied. It was observed that the size of $\mathrm{FeS}_{2}$ nanoparticles decreased after adding $\mathrm{NaOH}$, and the resulting photovoltaic performance and electrocatalytic activity of DSSC with $\mathrm{FeS}_{2}$ powder significantly increased, achieving a PCE of $5.78 \%$ under simulated sunlight irradiation of 1 Sun.

A chemically prepared $\mathrm{FeS}_{2}$ nanocrystal ink was used to fabricate a CE for a DSSC, which showed a PCE of $7.31 \%$ after 

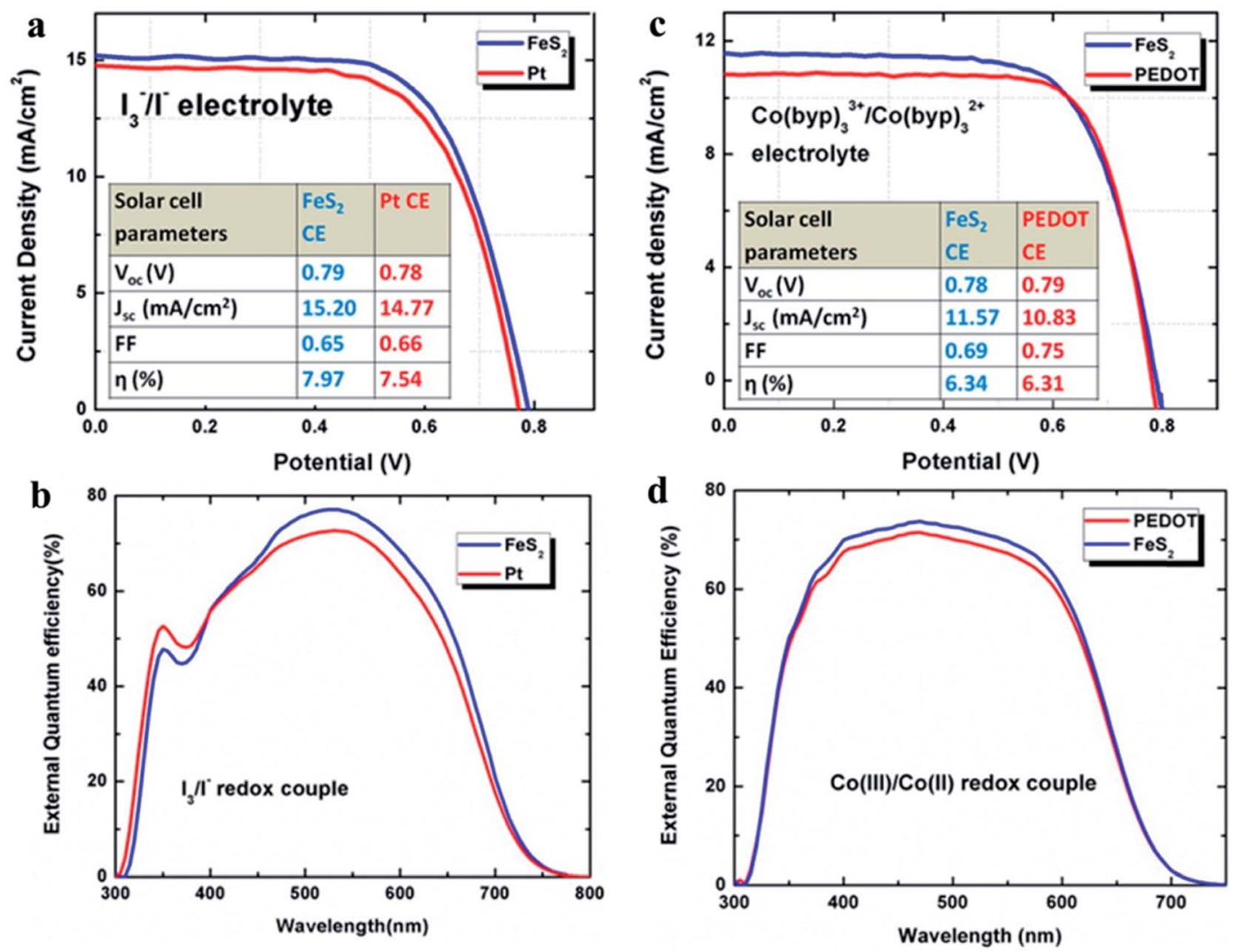

Fig. 16 (a) Photocurrent density-voltage $\left(J-V\right.$ curves and (b) IPCE of the DSSCs with $\mathrm{FeS}_{2}$ and Pt counter electrodes using N719 dye in $\mathrm{I}_{3}{ }^{-} \mathrm{I}^{-}$ electrolyte. (c) J-V curve and (d) IPCE of the DSSCs with $\mathrm{FeS}_{2}$ and PEDOT counter electrodes suing C128 dye in $\mathrm{Co}^{3+} / \mathrm{Co}^{2+}$ electrolyte. Reprinted with permission from ref. 221, S. Shukla, N. H. Loc, P. P. Boix, T. M. Koh, R. R. Prabhakar, H. K. Mulmudi, J. Zhang, S. Chen, C. F. Ng, C. H. A. Huan and N. Mathews, iron pyrite thin film counter electrodes for dye-sensitized solar cells: high efficiency for iodine and cobalt redox electrolyte cells. ACS Nano, 2014, 8, 10597-10605. Copyright@ American Chemical Society.

ethanedithiol (EDT) treatment. ${ }^{224} \mathrm{FeS}_{2}$ nanocrystal ink casted on a flexible ITO/PET substrate exhibited a $J_{\mathrm{sc}}$ of $14.93 \mathrm{~mA} \mathrm{~cm}{ }^{-2}$, $V_{\text {oc }}$ of $0.71 \mathrm{~V}, \mathrm{FF}$ of 0.60 , and a PCE of $6.36 \%$. The semitransparent $\mathrm{FeS}_{2}$ nanocrystal/ITO glass $\mathrm{CE}$ has an optical transmittance of $50-70 \%$ between 300 to $800 \mathrm{~nm}$ in comparison to $15 \%$ transmittance for the reference Pt/ITO glass CE. When the DSSC with the $\mathrm{FeS}_{2}$ nanocrystal CE was illuminated from the rear side, it showed a PCE of $4.17 \%$, which was $57 \%$ of the front illumination value, whereas opaque Pt CE had a PCE of 1.06\% from the rear side. Semi-transparent $\mathrm{FeS}_{2}$ nanocrystal CEs offer bifacial DSSCs utilizing incident light from both front and rear sides, and thus could be cost-effective for energy production. The $\mathrm{FeS}_{2}$ nanocrystal ink also demonstrated high electrocatalytic activity and electrochemical stability. Additionally, MWCNT/TiO ${ }_{2}$ hybrid and pure $\mathrm{TiO}_{2}$ mesoporous photoanodes with $\mathrm{FeS}_{2}$ thin films as CEs were studied for DSSCs by Kilic et al. ${ }^{225}$ In the MWCNT/ $/ \mathrm{TiO}_{2}$ hybrid photoanode, CNT played an important role of increasing the optical absorption and shifting it toward a longer wavelength region, where the bandgap of $3.15 \mathrm{eV}$ for mesoporous $\mathrm{TiO}_{2}$ shifted to $2.5 \mathrm{eV}$ for the MWCNT/ $\mathrm{TiO}_{2}$ hybrid. The DSSC with the MWCNT/TiO 2 hybrid photoanode and the Pt CE showed values of $J_{\mathrm{sc}}$ of $15.96 \mathrm{~mA} \mathrm{~cm}^{-2}, V_{\mathrm{oc}}$ of $0.77 \mathrm{~V}, \mathrm{FF}$ of 0.57 and a PCE of $7.0 \%$. The DSSC with the pure mesoporous $\mathrm{TiO}_{2}$ photoanode and the Pt CE both resulted in
PCEs of $6.51 \%$. The enhancement in PCE value of the hybrid photoanode is associated with MWCNTs, which offer an electrical conduction pathway for speedy electron transport. The MWCNT/ $/ \mathrm{TiO}_{2}$ hybrid photoanode also showed an increase in IPCE in the $350-600 \mathrm{~nm}$ wavelength range compared to the mesoporous $\mathrm{TiO}_{2}$ photoanode. When $\mathrm{FeS}_{2}$ thin films were used as a $\mathrm{CE}$ with a MWCNT/TiO ${ }_{2}$ hybrid photoanode, the PCE of the DSSC increased to $7.27 \%$ under 1 Sun. The DSSC with a $\mathrm{FeS}_{2} \mathrm{CE}$ and a pure $\mathrm{TiO}_{2}$ photoanode both yielded a PCE of $6.65 \%$. The $\mathrm{FeS}_{2}$ thin films showed an optical bandgap of $1.27 \mathrm{eV}$ and large effective surface area, which contribute to more light absorption and increased electrocatalytic activity for the reduction of triiodide $\left(\mathrm{I}_{3}{ }^{-}\right)$.

\section{6 $\mathrm{CoS}_{2}$ counter electrodes}

Cobalt disulfide $\left(\mathrm{CoS}_{2}\right)$ is a semiconducting material that exhibits interesting magnetic, electrical, and catalytic properties for energy storage applications. ${ }^{226-231}$ The properties of $\mathrm{CoS}_{2}$ nanocrystalline thin films prepared by a hydrothermal method were reported by Jin et al. ${ }^{232} \mathrm{CoS}_{2}$ powder was dispersed in ethanol in order to prepare a nanoink $\left(40 \mathrm{mg} \mathrm{m} \mathrm{L}^{-1}\right)$ for fabricating a CE. The $\mathrm{CoS}_{2}$ nanoink $(10 \mu \mathrm{L})$ was drop-cast on an FTO glass or flexible ITO/PET substrate, followed by ethanol 
evaporation. The self-assembled $\mathrm{CoS}_{2}$ film CE has a thickness of $2.5 \mu \mathrm{m}$ which can be controlled by the nanoink content. DSSCs were assembled by using a N719 dye-sensitized $\mathrm{TiO}_{2}$ photoanode as the working electrode, a $\mathrm{CoS}_{2}$ nanocrystal film or a $\mathrm{Pt}$ as the $\mathrm{CE}$, and an electrolyte solution containing LiI (0.1 M), I2 (0.05 M) I2, 1,2-dimethyl-3- $n$-propylimidazolium iodide (DMPII, $0.6 \mathrm{M}$ ), and 4-tert-butylpyridine (TBP, $0.5 \mathrm{M}$ ) in acetonitrile. The morphology and structure of the $\mathrm{CoS}_{2}$ self-assemblies were studied by SEM and TEM techniques. Fig. 17 shows an SEM image of a self-assembled $\mathrm{CoS}_{2}$ nanocrystal film, a photographic image of $\mathrm{CoS}_{2}$ nanoink, a self-assembled $\mathrm{CoS}_{2} \mathrm{CE}$, and $J-V$ curves of the DSSCs, fabricated with the $\mathrm{CoS}_{2}$ nanocrystal thin film and a Pt CE on the FTO and flexible ITO/polyethylene terephthalate (PET) substrate. The $\mathrm{CoS}_{2}$ nanoparticles were stabilized with poly(vinylpyrrolidone) (PVP) to form an oriented structure. The DSSC with self-assembled $\operatorname{CoS}_{2} \mathrm{CE}$ shows a $J_{\mathrm{sc}}$ of $14.62 \mathrm{~mA} \mathrm{~cm}^{-2}, V_{\text {oc }}$ of $0.71 \mathrm{~V}$, and a FF of 0.64 , resulting in a PCE of $6.78 \%$, which is comparable to a Pt CE with a value of $7.38 \%$. The PCE was found to decrease when the thickness of the selfassembled $\mathrm{CoS}_{2}$ film was either higher or lower than $2.5 \mu \mathrm{m}$. The $\mathrm{CoS}_{2}$ shows a $R_{\mathrm{s}}$ value of $34.20 \Omega \mathrm{cm}^{2}$, slightly higher compared to Pt (27.13 $\left.\Omega \mathrm{cm}^{2}\right)$, indicating comparable electrical conductivity. The $R_{\mathrm{CT}}$ value of $7.21 \Omega \mathrm{cm}^{2}$ for the $\mathrm{CoS}_{2} \mathrm{CE}$ indicates higher electrocatalytic activity for the reduction of triiodide $\left(\mathrm{I}_{3}{ }^{-}\right)$. The $\mathrm{CoS}_{2} \mathrm{CE}$ has a high chemical capacitance $(\mathrm{C} \mu)$ of $27.57 \mu \mathrm{F}$, compared to $2.76 \mu \mathrm{F}$ for the Pt CE, which also is evidence of a high surface area for $\mathrm{CoS}_{2} \mathrm{CE}$ which is beneficial to electrocatalysis. The DSSCs with $\mathrm{CoS}_{2}$ deposited on a flexible ITO/PET substrate showed a $J_{\mathrm{sc}}$ of $13.17 \mathrm{~mA} \mathrm{~cm}{ }^{-2}, V_{\text {oc }}$ of $0.70 \mathrm{~V}$,
FF of 0.68 and a PCE of $6.40 \%$. The fabrication of a $\mathrm{CoS}_{2} \mathrm{CE}$ is low-cost and solution processable at room temperature, which could make it an alternative to Pt CEs for flexible DSSCs.

Another study used mesoporous $\mathrm{CoS}_{2}$ nanotube arrays deposited on an FTO glass substrate and used as a CE for a DSSC. ${ }^{233}$ The $\mathrm{CoS}_{2}$ nanotube arrays were characterized by SEM, TEM, and XRD techniques for their morphology and crystal structures. The electrocatalytic properties of the $\mathrm{CoS}_{2}$ nanotube arrays were measured using $\mathrm{CV}$ and Tafel polarization curve measurements. The DSSCs having $\operatorname{CoS}_{2}$ CEs achieved a PCE of $6.13 \%$, comparable to that of sputtered Pt CE (6.04\%). The $R_{\mathrm{CT}}$ of the mesoporous $\mathrm{CoS}_{2}$ nanotube array CE was found to be 3.51 $\Omega \mathrm{cm}^{2}$ and comparable to the Pt CE $\left(5.78 \Omega \mathrm{cm}^{2}\right)$. The $\operatorname{CoS}_{2}$ nanotube array based CEs have large active surface area due to the mesoporous nanotube structure. The $\mathrm{CoS}_{2}$ nanotube array $\mathrm{CE}$ also exhibits electrocatalytic activities comparable to Pt CE. Tsai et al. ${ }^{234}$ also prepared $\mathrm{CoS}_{2}$ nanoflake arrays from $\mathrm{Co}(\mathrm{OH})_{2}$ nanoflake arrays through an ion exchange reaction to develop CEs for DSSCs. The $\mathrm{CoS}_{2}$ nanoflakes were found to be composed of $\mathrm{CoS}_{2}$ single crystals as well as their aggregates. The DSSC with $\mathrm{CoS}_{2}$ nanoflake arrays as a CE showed a PCE of $5.20 \%$, comparable to a sputtered Pt CE (5.34\%).

Different types of cobalt sulfide (CoS) have been used as CEs for DSSCs. The CoS nanoparticles deposited onto FTO glass substrates showed good transparency and high electrocatalytic activity for the $\mathrm{I}^{-} / \mathrm{I}^{-}{ }_{3}$ redox couple for a DSSC. ${ }^{235}$ CoS nanoparticle CEs showed a low $R_{\mathrm{CT}}$ value of $1.3 \Omega \mathrm{cm}^{2}$, less than that of Pt on FTO glass $\left(R_{\mathrm{CT}}\right.$ of $\left.2.3 \Omega \mathrm{cm}^{2}\right)$ and achieved a PCE of $6.6 \%$. An optimized $\mathrm{CoS}$ nanoparticle $\mathrm{CE}$ was also studied for
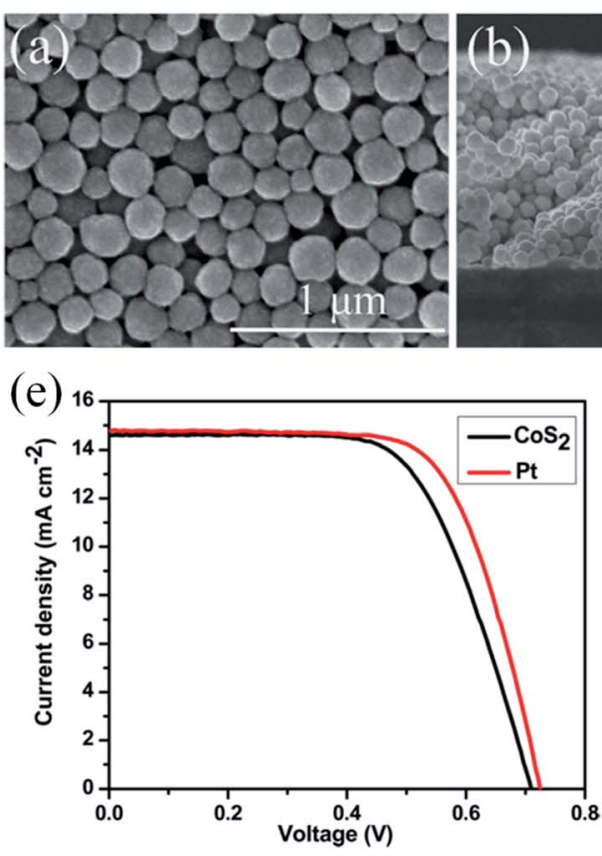

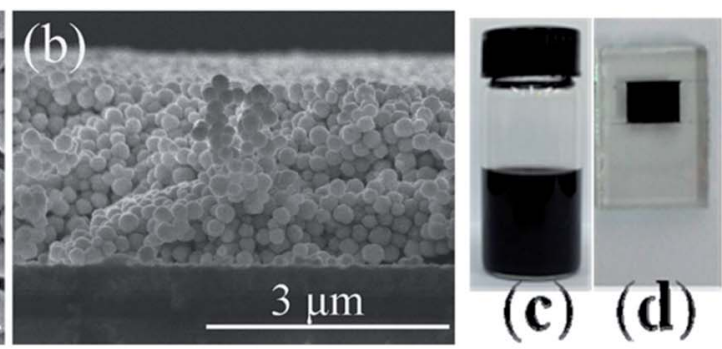

(f)

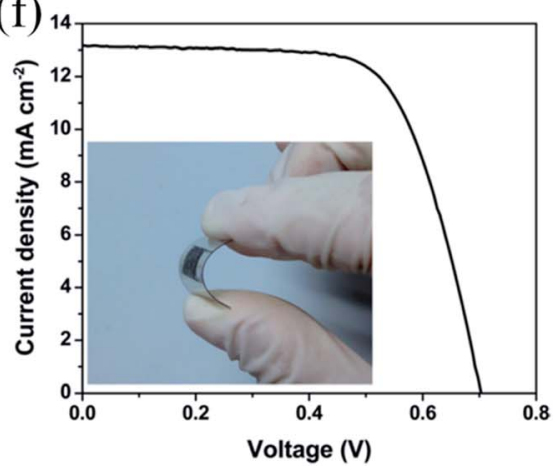

Fig. 17 (a) SEM image of a self-assembled $\mathrm{COS}_{2}$ nanocrystal film on FTO glass substrate, (b) cross-sectional SEM image of the CoS 2 counter electrode (CE), (c) photographic image of $\mathrm{CoS}_{2}$ nanoink, and (d) self-assembled $\mathrm{CoS}_{2} \mathrm{CE}$. (e) Photocurrent density-voltage ( $J-V$ ) curves of the DSSCs with $\mathrm{COS}_{2}$ nanocrystal thin film and Pt CEs. (f) J-V curves of the DSSCs with $\mathrm{CoS}_{2}$ deposited on a flexible ITO/PET substrate. Reprinted with permission from ref. 232, J. Jin, X. Zhang and T. He, self-assembled $\mathrm{CoS}_{2}$ nanocrystal film as an efficient counter electrode for dyesensitized solar cells. J. Phys. Chem. C, 2014, 118, 24877-24883. Copyright@ American Chemical Society. 

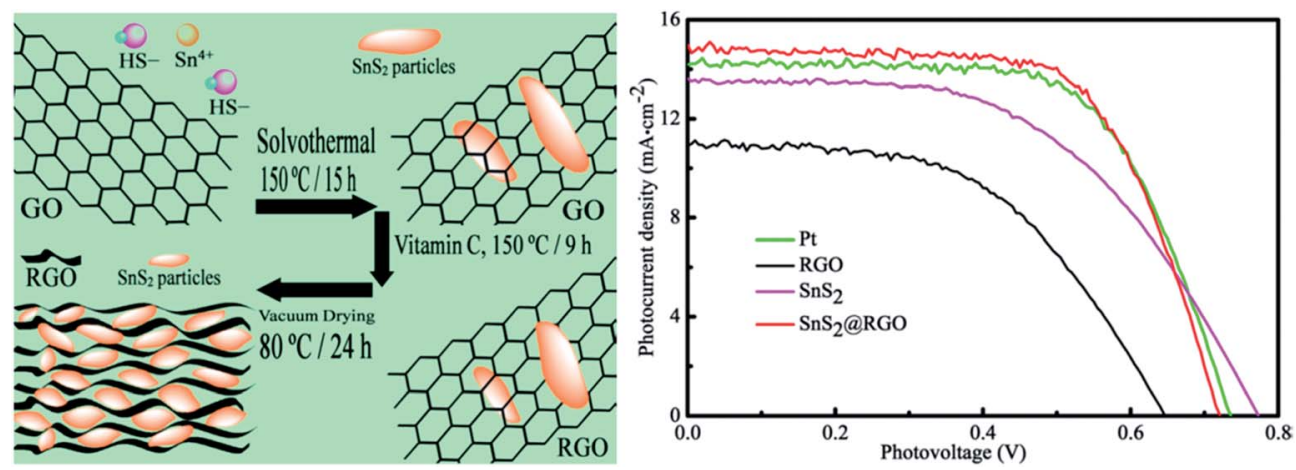

Fig. 18 (Left) illustration depicting preparation of tin sulfide nanoparticles/reduced graphene oxide (SnS 2 @RGO) nanocomposites. (Right) photocurrent density-photovoltage $\left(\mathrm{J}-\mathrm{V}\right.$ ) curves for DSSCs having Pt, RGO, SnS 2 , and $\mathrm{SnS}_{2} \mathrm{aRGO}$ composite CEs. Reprinted with permission from ref. 250, B. Yang, X. Zuo, P. Chen, L. Zhou, X. Yang, H. Zhang, G. Li, M. Wu, Y. Ma, S. Jin and X. Chen, nanocomposite of tin sulfide nanoparticles with reduced graphene oxide in high-efficiency dye-sensitized solar cells. ACS Appl. Mater. Interfaces, 2015, 7, 137-143. Copyright@ American Chemical Society.

a ferrocene-based liquid electrolyte. The rose-petal like $\mathrm{CoS}_{2}$ was deposited on an FTO as CE using a chemical bath deposition method. ${ }^{236}$ The DSSC assembled with a $\mathrm{CoS}_{2} \mathrm{CE}$ achieved a PCE of $5.32 \%$, higher than that of a Pt CE (5.02\%). The PCEs of $\mathrm{CoS}_{2}$ CEs depend on the deposition parameters including the concentrations of urea and thioacetamide, and the deposition time of the CEs. Also, $\mathrm{CoS}_{2}$ embedded carbon nanocages were fabricated as CEs for DSSCs through a zeolitic imidazolate framework-67, $\operatorname{Co}(2 \text {-methylimidolate })_{2}$ template. ${ }^{237}$ The performance of the $\operatorname{CoS}_{2}$ CE in a DSSC was optimized via a sulfurization process, where $\mathrm{CoS}_{2}$ nanoparticles with embedded carbon nanocages were sulfurized for a period of 4 hours, and showed the highest PCE of $8.20 \%$, even higher than Pt-based CE $(7.88 \%)$. The synergic effect of $\mathrm{CoS}_{2}$ nanoparticles and the carbon matrix resulted in the $\mathrm{CE}$ having high electrical conductivity and catalytic activity. Kim et al. ${ }^{238}$ deposited $\mathrm{CoS}_{2}$, nickel sulfide (NiS), and Ni-doped $\mathrm{CoS}_{2}$ nanoparticles on a FTO substrate as CEs for DSSCs via a chemical bath deposition method. The surface morphology of the thin films was analyzed by SEM. Electrochemical properties of Ni-doped $\mathrm{CoS}_{2}$ thin films evaluated by EIS, CV, and Tafel polarization curves indicated increased electrocatalytic activity for the reduction of $\mathrm{I}_{3}{ }^{-}$in the DSSCs compared to Pt CEs. The Ni-doped $\mathrm{CoS}_{2}$ CE (15\% Ni) showed a PCE of $5.50 \%$ under 1 Sun illumination, exceeding the PCE of the Pt CE ( $\eta=5.21 \%)$. PCE and $R_{\mathrm{CT}}$ values of the DSSCs were found to depend on the amount of Ni-doping of the $\mathrm{CoS}_{2}$ nanoparticles. These yielded PCEs of 4.81, 5.17, 5.50, and $4.12 \%$, for $R_{\mathrm{CT}}$ values of $279.7,36.63,8.53$ and $82.72 \Omega \mathrm{cm}^{2}$, at 5 , 10,15 and $20 \% \mathrm{Ni}$ contents in the $\mathrm{CoS}_{2} \mathrm{CE}$, respectively. Comparatively, DSSCs with bare $\mathrm{CoS}_{2}$ and NiS CEs showed poor electrocatalytic activity of $\mathrm{I}_{3}{ }^{-}$reduction.

In another study, $\mathrm{CoS}_{2} /$ graphene composites were prepared via a hydrothermal method using Co ions with thiourea in the presence of graphene oxide (GO). ${ }^{239}$ The distribution and size of the $\mathrm{CoS}_{2}$ nanoparticles deposited onto a flexible graphene sheet was controlled in order to optimize the electrocatalytic activity for $\mathrm{I}_{3}{ }^{-}$reduction. A $\mathrm{CoS}_{2}$ nanoparticles/graphene sheet $\left(\mathrm{CoS}_{2} /\right.$ $\mathrm{G}_{50}$ ) CE was prepared by incorporating $50 \mathrm{mg}$ graphene oxide, and exhibited the lowest electrolyte diffusion resistance and the highest electrocatalytic activity. The DSSC with $\operatorname{CoS}_{2} / \mathrm{G}_{50} \mathrm{CE}$ achieved a PCE of $6.55 \%$, higher than bare $\mathrm{CoS}_{2}$ or graphene CEs or a conventional Pt CE $(\eta=6.20 \%)$. Also, $\mathrm{CoS}_{2} / \mathrm{RGO}$ composite films for a CE of a DSSC were prepared using the layer-by-layer (LbL) assembly method, followed by thermal annealing. ${ }^{240}$ The photovoltaic parameters of the $\mathrm{CoS}_{2} / \mathrm{RGO} \mathrm{CE}$ based DSSCs were found to depend upon the deposition times of graphene oxide. PCE values of 2.6, 4.1, 5.4, 2.9 and $1.4 \%$ were measured for $2,4,6,8$ and 10 deposition times of graphene oxide, respectively. It appeared that the lowest $R_{\mathrm{CT}}$ of $4.8 \Omega \mathrm{cm}^{2}$ was observed for a $\mathrm{CoS}_{2} / \mathrm{RGO}$ CE prepared with 6 deposition times.

\section{7 $\mathrm{SnS}_{2}$ counter electrodes}

Tin disulfide $\left(\mathrm{SnS}_{2}\right)$ attains morphological structures which include nanocrystals, nanosheets, nanowires, nanobelts, and these show potential for field-effect transistors, gas sensors, photocatalysts, and solar cells. ${ }^{241-248}$ In one study, semitransparent $\mathrm{SnS}_{2}$ nanosheets were prepared as a CE to develop a Pt-free DSSC for the reduction of $\mathrm{I}_{3}{ }^{-}{ }^{249}$ The $\mathrm{SnS}_{2}$-based CE with $300 \mathrm{~nm}$ thickness showed high electrocatalytic activity, with a PCE of $7.64 \%$ compared to a PCE of $7.71 \%$ for a Pt CE based DSSC. When $\mathrm{SnS}_{2}$ nanosheets were functionalized with carbon nanoparticles, the CE exhibited a PCE of $8.06 \%$, a better electrocatalytic performance than a Pt CE. $\mathrm{SnS}_{2}$ nanosheets could therefore be used as a low cost electrocatalytic electrode material for DSSCs. Yang et al. ${ }^{250}$ prepared $\mathrm{SnS}_{2}$ nanoparticles and a RGO nanocomposite as a Pt-free CE for a DSSC. The $\mathrm{SnS}_{2}$ nanoparticles dispersed onto RGO sheets exhibited improved electrocatalytic activity for reducing $\mathrm{I}_{3}{ }^{-}$, and also increased conductivity. Fig. 18 illustrates the preparation of $\mathrm{SnS}_{2} @ \mathrm{RGO}$ nanocomposites and compares $J-V$ curves for DSSCs having Pt, RGO, $\mathrm{SnS}_{2}$, and $\mathrm{SnS}_{2} @ \mathrm{RGO}$ composite CEs. The DSSC with $\mathrm{SnS}_{2} @ \mathrm{RGO}$ nanocomposite CE showed a PCE of 7.12\%, much higher than that of the RGO sheet alone (3.73\%) and $\mathrm{SnS}_{2}$ nanoparticles (5.58\%), and a comparable PCE value to Pt CE $(6.79 \%)$. The $Z_{\mathrm{N}}$ values were $0.64,4.36,5.01$ and $0.95 \Omega$ for the 
Table 3 Photovoltaic parameters of $\mathrm{WS}_{2}, \mathrm{NiS}_{2}, \mathrm{TiS}_{2}, \mathrm{FeS}_{2}, \mathrm{CoS}_{2}$, and $\mathrm{SnS}_{2}$ based CEs used in DSSCs. FTO glass is the common substrate used in assembling DSSCs with different CE materials. The measurements were conducted at a simulated solar light intensity of $100 \mathrm{~mW} \mathrm{~cm}^{-2}$ (AM $1.5 \mathrm{G}$ ) unless specified. The photovoltaic parameters short-circuit photocurrent density $\left(J_{\mathrm{sc}}\right)$, open-circuit voltage $\left(V_{\text {oc }}\right)$, fill factor $(F F)$, and power conversion efficiency $(\eta)$, series resistance $\left(R_{\mathrm{s}}\right)$, charge-transfer resistance $\left(R_{\mathrm{CT}}\right)$, electrolyte and dye used for DSSCs are summarized and compared with standard Pt counter electrode ${ }^{a}$

\begin{tabular}{|c|c|c|c|c|c|c|c|c|c|}
\hline Counter electrodes & Redox couples & Dye & $J_{\mathrm{sc}}\left(\mathrm{mA} \mathrm{cm}^{-2}\right)$ & $V_{\mathrm{oc}}(\mathrm{V})$ & FF $(\%)$ & $\operatorname{PCE}(\eta, \%)$ & $R_{\mathrm{S}}\left(\Omega \mathrm{cm}^{2}\right)$ & $R_{\mathrm{CT}}\left(\Omega \mathrm{cm}^{2}\right)$ & Ref. \\
\hline $\mathrm{WS}_{2}$ & $\mathrm{I}^{-} / \mathrm{I}_{3}^{-}$ & N719 & 12.1 & 0.662 & 55 & 4.4 & - & - & 181 \\
\hline $\mathrm{WS}_{2}$ (glucose solution, $0.3 \mathrm{M}$ ) & $\mathrm{I}^{-} / \mathrm{I}_{3}^{-}$ & N719 & 12.8 & 0.658 & 63 & 5.3 & - & - & 181 \\
\hline $\mathrm{WS}_{2}$ (glucose solution, $1.2 \mathrm{M}$ ) & $\mathrm{I}^{-} / \mathrm{I}_{3}^{-}$ & N719 & 12.4 & 0.675 & 63 & 5.3 & - & - & 181 \\
\hline Pt reference & $\mathrm{I}^{-} / \mathrm{I}_{3}^{-}$ & N719 & 13.2 & 0.668 & 63 & 5.6 & - & - & 181 \\
\hline $\mathrm{WS}_{2}$ (sputtering time, $10 \mathrm{~min}$ ) & $\mathrm{I}^{-} / \mathrm{I}_{3}^{-}$ & N719 & 13.43 & 0.71 & 66 & 6.3 & - & - & 182 \\
\hline $\mathrm{WS}_{2}$ (hydrothermal method) & $\mathrm{I}^{-} / \mathrm{I}_{3}^{-}$ & N719 & 11.28 & 0.72 & 59 & 4.79 & 4.86 & 5.13 & 185 \\
\hline $\mathrm{WS}_{2} / \mathrm{MWCNTs}(3 \mathrm{wt} \%)$ & $\mathrm{I}^{-} / \mathrm{I}_{3}^{-}$ & N719 & 12.65 & 0.73 & 59 & 5.45 & 3.75 & 3.47 & 185 \\
\hline $\mathrm{WS}_{2} /$ MWCNTs (5 wt $\%$ ) & $\mathrm{I}^{-} / \mathrm{I}_{3}^{-}$ & N719 & 13.51 & 0.73 & 65 & 6.41 & 3.01 & 2.53 & 185 \\
\hline $\mathrm{WS}_{2} / \mathrm{MWCNTs}(10 \mathrm{wt} \%)$ & $\mathrm{I}^{-} / \mathrm{I}_{3}^{-}$ & N719 & 12.09 & 0.72 & 60 & 5.22 & 4.17 & 4.59 & 185 \\
\hline MWCNTs & $\mathrm{I}^{-} / \mathrm{I}_{3}^{-}$ & N719 & 10.77 & 0.66 & 61 & 4.34 & 6.52 & 6.60 & 185 \\
\hline Pt reference & $\mathrm{I}^{-} / \mathrm{I}_{3}^{-}$ & N719 & 13.23 & 0.74 & 67 & 6.56 & 2.26 & 2.74 & 185 \\
\hline $\mathrm{WS}_{2} /$ MWCNTs $(10 \mathrm{wt} \%)$ & $\mathrm{I}^{-} / \mathrm{I}_{3}^{-}$ & N719 & 12.47 & 0.74 & 68 & 6.27 & 2.78 & 3.46 & 186 \\
\hline $\mathrm{WS}_{2} / \mathrm{MWCNTs}^{*}$ & $\mathrm{I}^{-} / \mathrm{I}_{3}^{-}$ & N719 & 12.65 & 0.73 & 59 & 5.45 & 2.85 & 3.47 & 186 \\
\hline MWCNTs & $\mathrm{I}^{-} / \mathrm{I}_{3}^{-}$ & N719 & 10.77 & 0.66 & 61 & 4.34 & 2.95 & 6.60 & 186 \\
\hline Pt reference & $\mathrm{I}^{-} / \mathrm{I}_{3}^{-}$ & N719 & 13.23 & 0.76 & 75 & 7.54 & 2.27 & 2.74 & 186 \\
\hline $\mathrm{TiS}_{2}$ nanosheets & $\mathrm{I}^{-} / \mathrm{I}_{3}^{-}$ & N719 & 17.48 & 0.73 & 60.3 & 7.66 & - & - & 199 \\
\hline $\mathrm{TiS}_{2} /$ graphene hybrid & $\mathrm{I}^{-} / \mathrm{I}_{3}^{-}$ & N719 & 17.76 & 0.72 & 68.5 & 8.80 & 2.32 & 0.63 & 199 \\
\hline Graphene & $\mathrm{I}^{-} / \mathrm{I}_{3}^{-}$ & N719 & 15.41 & 0.71 & 48.4 & 5.33 & - & - & 199 \\
\hline Pt reference & $\mathrm{I}^{-} / \mathrm{I}_{3}^{-}$ & N719 & 16.93 & 0.72 & 65.6 & 8.00 & 6.90 & 1.32 & 199 \\
\hline $\mathrm{TiS}_{2}$ (drop coating method) & $\mathrm{I}^{-} / \mathrm{I}_{3}^{-}$ & N719 & 11.27 & 0.565 & 51 & 3.24 & 16.12 & - & 200 \\
\hline $\mathrm{TiS}_{2} /$ PEDOT:PSS (5 wt $\left.\%\right)$ & $\mathrm{I}^{-} / \mathrm{I}_{3}^{-}$ & N719 & 13.81 & 0.686 & 62 & 5.91 & - & - & 200 \\
\hline $\mathrm{TiS}_{2} /$ PEDOT:PSS (10 wt $\%$ ) & $\mathrm{I}^{-} / \mathrm{I}_{3}^{-}$ & N719 & 15.78 & 0.681 & 66 & 7.04 & 15.78 & 4.78 & 200 \\
\hline PEDOT:PSS & $\mathrm{I}^{-} / \mathrm{I}_{3}^{-}$ & N719 & 12.74 & 0.664 & 46 & 3.91 & 14.92 & 7.27 & 200 \\
\hline Reduced graphene oxide (RGO) & $\mathrm{I}^{-} / \mathrm{I}_{3}^{-}$ & N719 & 10.98 & 0.716 & 40 & 3.14 & 14.2 & 100.2 & 210 \\
\hline Pt reference & $\mathrm{I}^{-} / \mathrm{I}_{3}^{-}$ & N719 & 15.75 & 0.739 & 70 & 8.15 & 2.2 & 0.5 & 210 \\
\hline $\mathrm{FeS}_{2}$ (spray pyrolysis) & $\mathrm{I}^{-} / \mathrm{I}_{3}^{-}$ & N719 & 15.20 & 0.79 & 65 & 7.97 & - & - & 221 \\
\hline Pt reference & $\mathrm{I}^{-} / \mathrm{I}_{3}^{-}$ & N719 & 14.77 & 0.78 & 66 & 7.54 & - & - & 221 \\
\hline $\mathrm{FeS}_{2}$ & $\mathrm{Co}^{2+} / \mathrm{Co}^{3+}$ & $\mathrm{C} 128$ & 11.57 & 0.78 & 69 & 6.34 & 4.9 & 7.2 & 221 \\
\hline PEDOT & $\mathrm{Co}^{2+} / \mathrm{Co}^{3+}$ & $\mathrm{C} 128$ & 10.83 & 0.79 & 75 & 6.31 & 6.0 & 3.9 & 221 \\
\hline $\mathrm{FeS}_{2}$ films & $\mathrm{I}^{-} / \mathrm{I}_{3}^{-}$ & N719 & 12.56 & 0.658 & 57.8 & 4.78 & 9.60 & 213.1 & 222 \\
\hline $\mathrm{FeS}_{2}$ nanorods & $\mathrm{I}^{-} / \mathrm{I}_{3}^{-}$ & N719 & 13.68 & 0.653 & 65.7 & 5.88 & 9.61 & 11.0 & 222 \\
\hline Pt reference & $\mathrm{I}^{-} / \mathrm{I}_{3}^{-}$ & N719 & 13.36 & 0.685 & 68.2 & 6.23 & 5.62 & 9.2 & 222 \\
\hline $\mathrm{FeS}_{2}$ (without $\mathrm{NaOH}$ ) & $\mathrm{I}^{-} / \mathrm{I}_{3}^{-}$ & N719 & 10.20 & 0.70 & 66 & 4.76 & 3.73 & 13.6 & 223 \\
\hline $\mathrm{FeS}_{2}$ (with $\mathrm{NaOH}$ ) & $\mathrm{I}^{-} / \mathrm{I}_{3}^{-}$ & N719 & 12.08 & 0.74 & 64 & 5.78 & 2.91 & 5.99 & 223 \\
\hline Pt reference & $\mathrm{I}^{-} / \mathrm{I}_{3}^{-}$ & N719 & 11.58 & 0.74 & 69 & 5.93 & 3.09 & 1.16 & 223 \\
\hline $\mathrm{FeS}_{2}$ (with ethanedithiol) & $\mathrm{I}^{-} / \mathrm{I}_{3}^{-}$ & N719 & 15.14 & 0.71 & 68 & 7.31 & - & 1.60 & 224 \\
\hline $\mathrm{FeS}_{2}$ (without ethanedithiol) & $\mathrm{I}^{-} / \mathrm{I}_{3}^{-}$ & N719 & 12.63 & 0.71 & 64 & 5.74 & - & 4.45 & 224 \\
\hline Pt reference & $\mathrm{I}^{-} / \mathrm{I}_{3}^{-}$ & N719 & 15.37 & 0.71 & 69 & 7.52 & - & 1.47 & 224 \\
\hline $\mathrm{FeS}_{2}\left(\mathrm{MWCNT} / \mathrm{TiO}_{2}\right.$ photoanode) & $\mathrm{I}^{-} / \mathrm{I}_{3}^{-}$ & N719 & 16.86 & 0.77 & 56 & 7.27 & - & - & 225 \\
\hline $\mathrm{FeS}_{2}\left(\mathrm{TiO}_{2}\right.$ photoanode $)$ & $\mathrm{I}^{-} / \mathrm{I}_{3}^{-}$ & N719 & 15.16 & 0.77 & 57 & 6.65 & - & - & 225 \\
\hline Pt (MWCNT/TiO 2 photoanode) & $\mathrm{I}^{-} / \mathrm{I}_{3}^{-}$ & N719 & 15.96 & 0.77 & 57 & 7.00 & - & - & 225 \\
\hline $\mathrm{Pt}\left(\mathrm{TiO}_{2}\right.$ photoanode $)$ & $\mathrm{I}^{-} / \mathrm{I}_{3}^{-}$ & N719 & 15.68 & 0.77 & 54 & 6.51 & - & - & 225 \\
\hline $\mathrm{CoS}_{2}$ nanocrystals & $\mathrm{I}^{-} / \mathrm{I}_{3}^{-}$ & N719 & 14.62 & 0.71 & 64 & 6.78 & 34.20 & 7.21 & 232 \\
\hline Pt reference & $\mathrm{I}^{-} / \mathrm{I}_{3}^{-}$ & N719 & 14.78 & 0.72 & 68 & 7.38 & 27.13 & 4.57 & 232 \\
\hline
\end{tabular}


Table 3 (Contd.)

\begin{tabular}{|c|c|c|c|c|c|c|c|c|c|}
\hline Counter electrodes & Redox couples & Dye & $J_{\mathrm{sc}}\left(\mathrm{mA} \mathrm{cm}^{-2}\right)$ & $V_{\mathrm{oc}}(\mathrm{V})$ & $\mathrm{FF}(\%)$ & $\operatorname{PCE}(\eta, \%)$ & $R_{\mathrm{s}}\left(\Omega \mathrm{cm}^{2}\right)$ & $R_{\mathrm{CT}}\left(\Omega \mathrm{cm}^{2}\right)$ & Ref. \\
\hline $\mathrm{CoS}_{2}$ nanotube (NT1) & $\mathrm{I}^{-} / \mathrm{I}_{3}^{-}$ & N719 & 5.26 & 0.765 & 52.5 & 2.13 & - & - & 233 \\
\hline $\mathrm{CoS}_{2}$ nanotube (NT2) & $\mathrm{I}^{-} / \mathrm{I}_{3}^{-}$ & N719 & 10.68 & 0.794 & 64.6 & 5.48 & - & - & 233 \\
\hline $\mathrm{CoS}_{2}$ nanotube (NT4) & $\mathrm{I}^{-} / \mathrm{I}_{3}^{-}$ & N719 & 11.58 & 0.804 & 65.8 & 6.13 & - & - & 233 \\
\hline Pt reference & $\mathrm{I}^{-} / \mathrm{I}_{3}^{-}$ & N719 & 12.28 & 0.770 & 63.9 & 6.04 & - & - & 233 \\
\hline $\mathrm{CoS}_{2}$ nanoflakes & $\mathrm{I}^{-} / \mathrm{I}_{3}^{-}$ & N719 & 10.13 & 0.747 & 68.8 & 5.20 & - & - & 234 \\
\hline $\operatorname{CoS}(25)$ (chloroform, $25 \mathrm{mM}$ ) & $\mathrm{I}^{-} / \mathrm{I}_{3}^{-}$ & N3 & 9.23 & 0.700 & 51.3 & 3.5 & - & - & 235 \\
\hline $\operatorname{CoS}(25) \mathrm{A}$ (annealed for $240 \mathrm{~min})$ & $\mathrm{I}^{-} / \mathrm{I}_{3}^{-}$ & N3 & 3.86 & 0.560 & 23.2 & 0.5 & - & - & 235 \\
\hline $\operatorname{CoS}(12.5)$ (chloroform, $12.5 \mathrm{mM}$ ) & $\mathrm{I}^{-} / \mathrm{I}_{3}^{-}$ & N3 & 6.08 & 0.701 & 54.1 & 2.3 & - & - & 235 \\
\hline $\operatorname{CoS}(2.5)$ (chloroform, $2.5 \mathrm{mM})$ & $\mathrm{I}^{-} / \mathrm{I}_{3}^{-}$ & N3 & 4.32 & 0.700 & 47.9 & 1.4 & - & - & 235 \\
\hline Pt reference & $\mathrm{I}^{-} / \mathrm{I}_{3}^{-}$ & N3 & 9.05 & 0.702 & 56.4 & 3.6 & - & - & 235 \\
\hline $\operatorname{CoS}(25)$ (chloroform, $25 \mathrm{mM}$ ) & $\mathrm{I}^{-} / \mathrm{I}_{3}^{-}$ & N719 & 14.15 & 0.703 & 66.7 & 6.6 & - & - & 235 \\
\hline $\mathrm{CoS}_{2}(\mathrm{Ni}$-doped, $15 \%)$ & $\mathrm{I}^{-} / \mathrm{I}_{3}^{-}$ & N719 & 12.12 & 0.649 & 69.8 & 5.50 & 9.21 & 8.53 & 238 \\
\hline NiS nanoparticles & $\mathrm{I}^{-} / \mathrm{I}_{3}^{-}$ & N719 & 9.54 & 0.592 & 67.8 & 3.83 & - & - & 238 \\
\hline Pt reference & $\mathrm{I}^{-} / \mathrm{I}_{3}^{-}$ & N719 & 12.33 & 0.649 & 65.0 & 5.21 & 10.4 & 14.18 & 238 \\
\hline $\mathrm{CoS}_{2}$ & $\mathrm{I}^{-} / \mathrm{I}_{3}^{-}$ & N719 & 6.25 & 0.58 & 51 & 1.86 & 9.7 & 3.4 & 239 \\
\hline $\mathrm{CoS}_{2}-\mathrm{G}_{20}(\mathrm{GO}$ powder, $20 \mathrm{mg})$ & $\mathrm{I}^{-} / \mathrm{I}_{3}^{-}$ & N719 & 14.38 & 0.71 & 57 & 5.86 & 7.7 & 2.3 & 239 \\
\hline $\mathrm{CoS}_{2}-\mathrm{G}_{50}$ (GO powder, $50 \mathrm{mg}$ ) & $\mathrm{I}^{-} / \mathrm{I}_{3}^{-}$ & N719 & 15.12 & 0.73 & 60 & 6.55 & 7.6 & 1.3 & 239 \\
\hline $\mathrm{CoS}_{2}-\mathrm{G}_{80}$ (GO powder, $80 \mathrm{mg}$ ) & $\mathrm{I}^{-} / \mathrm{I}_{3}^{-}$ & N719 & 13.11 & 0.71 & 52 & 4.83 & 7.9 & 2.7 & 239 \\
\hline Graphene & $\mathrm{I}^{-} / \mathrm{I}_{3}^{-}$ & N719 & 3.68 & 0.65 & 58 & 1.37 & 7.6 & 4.0 & 239 \\
\hline Pt reference & $\mathrm{I}^{-} / \mathrm{I}_{3}^{-}$ & N719 & 14.69 & 0.73 & 58 & 6.20 & 7.2 & 1.9 & 239 \\
\hline $\mathrm{CoS}_{2} /$ reduced graphene oxide & $\mathrm{I}^{-} / \mathrm{I}_{3}^{-}$ & Z907 & 12.87 & 0.67 & 63 & 5.4 & 22.5 & 4.8 & 240 \\
\hline $\mathrm{SnS}_{2}\left(350^{\circ} \mathrm{C}, 30 \mathrm{~min}\right)$ & $\mathrm{I}^{-} / \mathrm{I}_{3}^{-}$ & N719 & 15.63 & 0.725 & 55.3 & 6.27 & 21.5 & 8.3 & 249 \\
\hline $\mathrm{SnS}_{2}\left(400{ }^{\circ} \mathrm{C}, 30 \mathrm{~min}\right)$ & $\mathrm{I}^{-} / \mathrm{I}_{3}^{-}$ & N719 & 16.96 & 0.743 & 60.7 & 7.64 & 18.6 & 5.6 & 249 \\
\hline
\end{tabular}

${ }^{a} \mathrm{WS}_{2} /$ MWCNTs* prepared without glucose aid. In the case of $R_{\mathrm{S}}$ and $R_{\mathrm{CT}}$ : some of the authors used $\Omega$ instead of $\Omega \mathrm{cm}^{2}$ for the resistances without mentioning the size of the electrode.

$\mathrm{SnS}_{2} @ \mathrm{RGO}$ nanocomposite, $\mathrm{SnS}_{2}$, RGO and Pt CEs, respectively. The RGO and $\mathrm{SnS}_{2}$ CEs have larger $R_{\mathrm{CT}}$ values, hence lower electrocatalytic ability among these CEs, whereas the $\mathrm{SnS}_{2}$ @RGO composite has a lower $R_{\mathrm{CT}}$ value, leading to a higher electrocatalytic activity. The role of the RGO sheets is to facilitate the conduction pathway. The $E_{\mathrm{pp}}$ of the $\mathrm{SnS}_{2} @ \mathrm{RGO}$ nanocomposite CE is $593 \mathrm{mV}$, similar to a Pt CE ( $E_{\mathrm{pp}}$ of $\left.605 \mathrm{mV}\right)$. This indicates that the electrocatalytic activity of the $\mathrm{SnS}_{2} @ \mathrm{RGO}$ nanocomposite $\mathrm{CE}$ is similar to that of a conventional Pt CE. The electrochemical stability of the $\mathrm{SnS}_{2} @ \mathrm{RGO}$ nanocomposite CE was analyzed up to 25 cycles of CV curves, where no drastic change was noticed in peak current density, confirming that $\mathrm{SnS}_{2} @ \mathrm{RGO}$ nanocomposite CEs are stable for electrocatalysis of $\mathrm{I}_{3}{ }^{-}$in the electrolyte. The $\mathrm{SnS}_{2} @$ @RO nanocomposite CEs are as promising as Pt CEs in DSSCs. Table 3 lists a summary of the photovoltaic parameters of $\mathrm{WS}_{2}, \mathrm{NiS}_{2}, \mathrm{TiS}_{2}, \mathrm{FeS}_{2}, \mathrm{CoS}_{2}$, and $\mathrm{SnS}_{2}$ based CEs for DSSCs and their comparison with a standard Pt CE.

\section{Transition-metal diselenides based counter electrodes}

\section{1 $\mathrm{MoSe}_{2}$ counter electrodes}

Molybdenum dichalcogenides, such as $\mathrm{MoS}_{2}, \mathrm{MoSe}_{2}$, and $\mathrm{MoTe}_{2}$, are a very interesting class of materials that has attracted a great attention because of their unique properties. ${ }^{251-257}$ Molybdenum diselenide $\left(\mathrm{MoSe}_{2}\right)$ is a semiconductor that has been studied for device applications..$^{\mathbf{9 2 , 2 5 8 , 2 5 9}}$ The nanosheets of $\mathrm{MoSe}_{2}$ have weak van der Waals forces, therefore, poorly adhere to the surface of substrates. To resolve this problem, Lee et al. ${ }^{\mathbf{2 6 0}}$ and Chen et al. ${ }^{\mathbf{2} 1}$ applied a CVD technique to grow catalytic $\mathrm{MoSe}_{2}$ films on Mo foils. Lee et al. ${ }^{260}$ used few-layer $\mathrm{MoSe}_{2}$ in a DSSC as CE for the reduction of $\mathrm{I}_{3}{ }^{-}$to $\mathrm{I}^{-}$. Fig. 19 shows a schematic representation for the preparation of few-layer $\mathrm{MoSe}_{2}$, and their SEM and TEM images. The few-layer $\mathrm{MoSe}_{2}$ on Mo film was developed by selenizing the Mo-coated sodalime glass in a tube furnace. X-ray diffraction analysis exhibits 

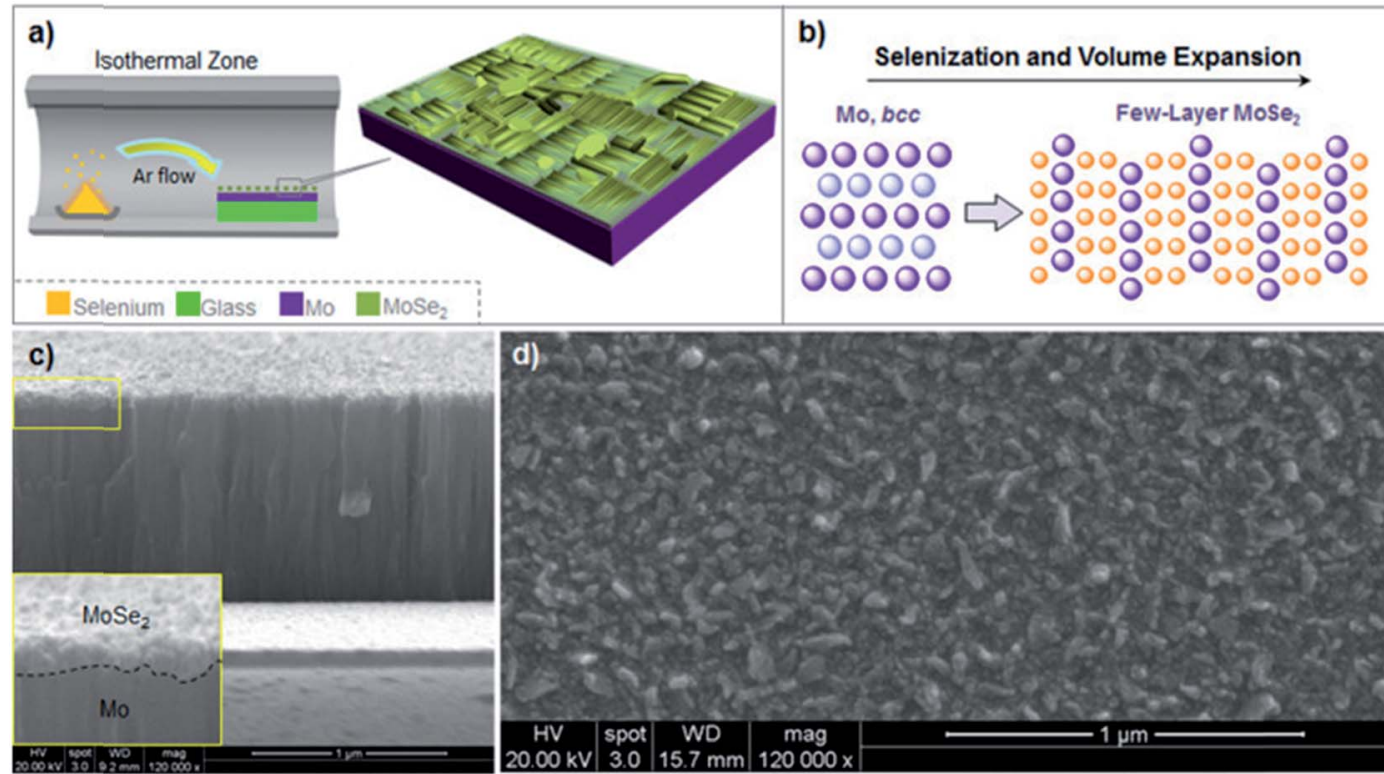

e)
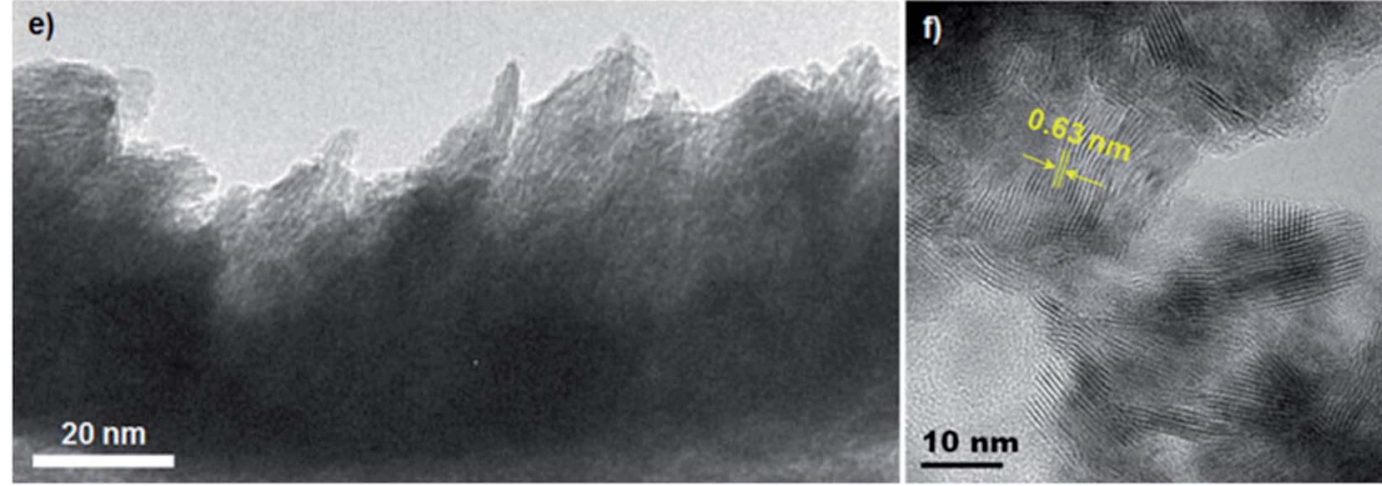

Fig. 19 (a) Schematic representation for the selenization of Mo-coated soda-lime glass in a tube furnace for few-layer MoSe ${ }_{2}$ (b) schematic illustration showing the formation of few-layer MoSe $\mathrm{f}_{2}$ from body-centered cubic (bcc) crystal structures of Mo (c) cross-sectional SEM image of the $\mathrm{MoSe}_{2}$ on Mo surface, inset shows the borderline between MoSe $\mathrm{S}_{2}$ and Mo substrate; (d) SEM image of the as-synthesized MoSe 2 nanostructures; (e) HRTEM image of the few-layer MoSe $e_{2}$ (f) high magnification HRTEM image of the few-layer MoSe $e_{2}$ with interlayer spacing of 0.63-0.64 nm. Reprinted with permission from ref. 260, L. T. L. Lee, J. He, B. Wang, Y. Ma, K. Y. Wong, Q. Li, X. Xiao and T. Chen, few-layer MoSe 2 possessing high catalytic activity towards iodide/tri-iodide redox shuttles. Sci. Rep., 2014, 4, 4063-4069. Copyright@ Nature Publishing Group.

body-centered cubic (bcc) crystal structures of the Mo film. The Mo film thickness was $1 \mu \mathrm{m}$ and selenization was performed at $550{ }^{\circ} \mathrm{C}$ for 5 minutes, and produced the best performance for the DSSC. The $\mathrm{MoSe}_{2}$ layer was about $70 \mathrm{~nm}$ as confirmed by the cross-sectional SEM image. The surface of the selenized Mo/ glass contains nanoparticles, and the HRTEM image shows the few-layer structures. The interlayer spacing was measured as 0.63-0.64 nm. The few-layer $\mathrm{MoSe}_{2}$ was prepared by surface selenization of Mo-coated soda-lime glass, which yielded a PCE of $9.0 \%$, compared to a PCE of $8.68 \%$ for the Pt/FTO-based photoanode, thus showing the Pt/FTO free $\mathrm{MoSe}_{2} \mathrm{CE}$ outperformed the conventional CE. An $\mathrm{MoS}_{2} / \mathrm{Mo}$ combination as a CE in a DSSC shows a PCE of $8.69 \%$. Fig. 20 shows a comparison of $J-V$ curves of the DSSCs having $\mathrm{MoSe}_{2} / \mathrm{Mo}$ and $\mathrm{MoS}_{2} /$ Mo CEs with different temperatures and times of selenization and sulfurization, and the Pt/FTO CE. The PCE of the DSSCs decreased from $7.14 \%$ for $\mathrm{MoSe}_{2}$ CEs selenized at $580{ }^{\circ} \mathrm{C}$ for 60 minutes, to a PCE of $4.26 \%$ for 120 minutes. The edge sites were also found to be important for the high catalytic activity. The Mo substrate plays an important role in significantly reducing the sheet resistance of the $\mathrm{CE}$, which eventually leads to a high DSSC performance. The low sheet resistance of $0.29 \Omega \mathrm{sq}^{-1}$ for $\mathrm{MoSe}_{2} / \mathrm{Mo}$, compared to $12.60 \Omega \mathrm{sq}^{-1}$ for Pt/FTO, indicates that $\mathrm{MoSe}_{2} / \mathrm{Mo}$ is better as a CE in a DSSC than a Pt/ FTO. The $R_{\mathrm{CT}}$ of $0.87 \Omega \mathrm{cm}^{2}$ for $\mathrm{MoSe}_{2}$ and $0.61 \Omega \mathrm{cm}^{2}$ for $\mathrm{MoS}_{2}$ is lower compared to Pt $\left(6.26 \Omega \mathrm{cm}^{2}\right)$ due to high conductivity of the Mo substrate, therefore the Mo substrate seems superior to the FTO substrate. Chen et $a .^{261}$ also used a $\mathrm{MoSe}_{2} / \mathrm{Mo}$ based CE in a DSSC to develop a Pt/FTO-free CE, which showed a PCE of $8.13 \%$, slightly higher than the Pt/FTO CE (PCE of 8.06\%). The $R_{\mathrm{S}}$ and $R_{\mathrm{CT}}$ values of the $\mathrm{MoSe}_{2} / \mathrm{Mo}$ CEs were found to be $16.5 \%$ and $3.35 \%$ of the Pt/FTO CE, indicating a higher electrocatalytic activity of the $\mathrm{MoSe}_{2} / \mathrm{Mo}$. 


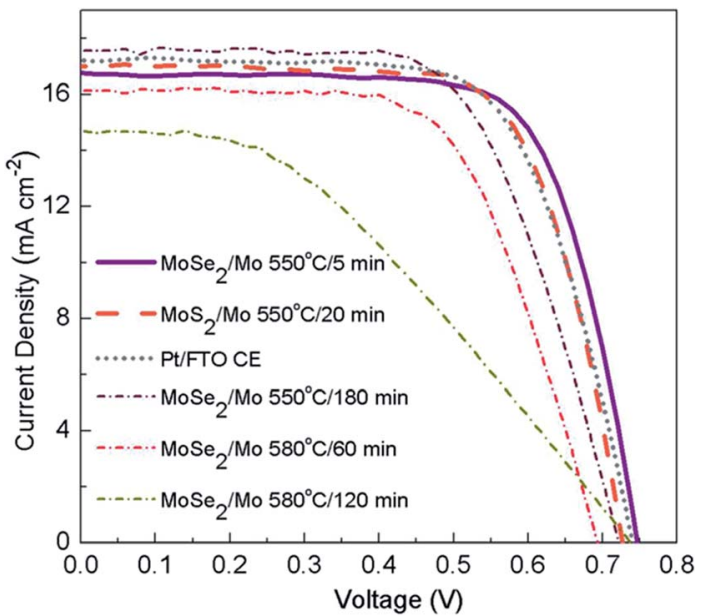

Fig. 20 Photocurrent density-voltage $(J-V)$ curves of DSSCs having $\mathrm{MoSe}_{2} / \mathrm{Mo}$ and $\mathrm{MoS}_{2} / \mathrm{Mo}$ counter electrodes with different temperatures and time of selenization and sulfurization and a comparison with conventional Pt/FTO counter electrodes. Reprinted with permission from ref. 260, L. T. L. Lee, J. He, B. Wang, Y. Ma, K. Y. Wong, Q. Li, X. $\mathrm{XiaO}$ and $\mathrm{T}$. Chen, few-layer MoSe $\mathrm{M}_{2}$ possessing high catalytic activity towards iodide/tri-iodide redox shuttles. Sci. Rep., 2014, 4, 40634069. Copyright@ Nature Publishing Group.

Thin films of the metal selenides $\mathrm{NiSe}_{2}, \mathrm{CoSe}_{2}$, and $\mathrm{MoSe}_{2}$ were used as CEs for DSSCs for $\mathrm{I}_{3}{ }^{-}$reduction by Ji et al. ${ }^{262} \mathrm{NiSe}_{2}$ was found to be equally efficient to conventional Pt CEs. In comparison, $\mathrm{NiSe}_{2}$ also showed a higher PCE than its sulfide analog $\left(\mathrm{NiS}_{2}\right)$ due to lower resistance to charge transfer. Fig. 21 shows SEM images of $\mathrm{NiSe}_{2}, \mathrm{CoSe}_{2}$, and $\mathrm{MoSe}_{2}$, and Tafel polarization curves and $J-V$ curves of the metal selenides $\mathrm{NiSe}_{2}$, $\mathrm{CoSe}_{2}, \mathrm{MoSe}_{2}, \mathrm{WSe}_{2}, \mathrm{Bi}_{2} \mathrm{Se}_{3}, \mathrm{MnSe}, \mathrm{PbSe}$, as well as Pt based CEs used in DSSCs. The metal selenides were deposited on FTO glass. The $\mathrm{NiSe}_{2}, \mathrm{CoSe}_{2}$, and $\mathrm{MoSe}_{2}$ showed higher exchange current densities compared to other selenides. The $J-V$ curve measurements of the DSSCs indicated better performance of the $\mathrm{NiSe}_{2} \mathrm{CE}$ than that of the Pt CE, however the performance of DSSCs having $\mathrm{CoSe}_{2}$ and $\mathrm{MoSe}_{2}$ CEs was lower compared to the Pt CE.

In another study, $\mathrm{MoSe}_{2}$ nanosheets were prepared using a solvothermal method which shows microsphere hierarchical architecture. ${ }^{263} \mathrm{MoSe}_{2}$ nanosheets used as CE in fabricating a DSSC device showed a PCE of $9.80 \%$, exceeding the PCE of a Pt CE based DSSC $(\eta=8.17 \%)$ for the triiodide/iodide $\left(\mathrm{I}_{3}{ }^{-} / \mathrm{I}^{-}\right)$ redox reaction. Bi et al. ${ }^{264}$ anchored fullerene-structured $\mathrm{MoSe}_{2}$ hollow spheres on highly nitrogen-doped graphene (HNG) as a CE for a DSSC. Diethylenetriamine (DETA) was used as a dopant for nitrogen of graphene. The hollow spheres consisted of 12-15 layers of $\mathrm{MoSe}_{2}$ which formed the conductive network for facilitating rapid electron transfer in the DSCC. The $\mathrm{MoSe}_{2}$ hollow spheres of 60-100 nm diameter and 8-12 nm thickness were dispersed on a HNG surface. The HNG-MoSe hybrid has $52.4 \mathrm{wt} \%$ of $\mathrm{MoSe}_{2}$ content. The $\mathrm{N}$ content increased from $2.5 \%$ in $\mathrm{MoSe}_{2}$ /graphene hybrid to $12.5 \%$ in the $\mathrm{HNG}-$ $\mathrm{MoSe}_{2}$ hybrid, which also showed high stability after 200 consecutive cycles of $\mathrm{CV}$ measurements. The $\mathrm{HNG}-\mathrm{MoSe}_{2}$ hybrid CE showed a PCE of $10.01 \%$, slightly lower than a Pt CE $(\eta=10.55 \%)$ under similar conditions, while the $\mathrm{MoSe}_{2}$ /graphene hybrid CE had a PCE of $7.34 \%$ arising from a poor fill factor of 0.60 .

Composites of $\mathrm{MoSe}_{2}$ nanosheets (NS) and poly(3,4 ethylenedioxythiophene):poly(styrenesulfonate) were investigated as the CE of a DSSC by Huang et al. ${ }^{265} \mathrm{MoSe}_{2}$ NS acts as an electrocatalyst, while the PEDOT:PSS plays a role of a conductive binder to facilitate electron transfer between the $\mathrm{MoSe}_{2}$ and the substrate. The weight ratios of $\mathrm{MoSe}_{2}$ and PEDOT:PSS (MP) in the composites varied from 0.25 to 2.00. Each composite film contained $50 \mathrm{mg}$ of $\mathrm{MoSe}_{2}$ powder and $200 \mathrm{mg}$, $100 \mathrm{mg}, 50 \mathrm{mg}$, and $25 \mathrm{mg}$ of PEDOT:PSS, which are respectively referred to as MP-0.25, MP-0.50, MP-1.00, and MP-2.00, as per the ratios. The DSSC with a MP-1.00 composite film (equal weights of $\mathrm{MoSe}_{2}$ and PEDOT:PSS) CE exhibits the highest electrocatalytic activity for the reduction of $\mathrm{I}_{3}{ }^{-}$. The DSSC containing the $\mathrm{MoSe}_{2}$ NS/PEDOT:PSS composite film based CE shows a PCE of $7.58 \%$, compared to the Pt CE exhibiting a PCE of $7.81 \%$ under similar experimental conditions. When $\mathrm{MoSe}_{2}$ NS/PEDOT:PSS composite films coated on a titanium (Ti) foil flexible substrate was used as CE, the DSSC showed a PCE of $8.51 \%$, compared to a PCE of $8.21 \%$ for the Ptcoated Ti foil CE. The CEs in the DSSCs show the relative order of the electrocatalytic activity as Pt $>\mathrm{MP}-1.00>$ bare $\mathrm{MoSe}_{2}>$ bare PEDOT:PSS, which is the same as observed by the IPCE spectra. The MP-1.00 composite film shows larger values of the heterogeneous rate constant, and the effective catalytic surface area as compared to bare $\mathrm{MoSe}_{2}$ and bare PEDOT:PSS, because of $\mathrm{MoSe}_{2}$ NS contents. The $R_{\mathrm{CT}-\mathrm{Tafel}}$ values of $3.23 \Omega \mathrm{cm}^{2}$ for Pt, $181.46 \Omega \mathrm{cm}^{2}$ for bare PEDOT:PSS, $3.77 \Omega \mathrm{cm}^{2}$ for MP-1.00, and $3.11 \Omega \mathrm{cm}^{2}$ for bare $\mathrm{MoSe}_{2}$ were observed. The electrocatalytic ability of the CEs follow a trend seen in the $R_{\mathrm{CT}}$ values measured from Tafel polarization curves and EIS. The $\mathrm{MoSe}_{2}$ NS/PEDOT:PSS composite film based CEs thus show potential to replace a costly $\mathrm{Pt}$ electrode.

A cobalt selenide $\left(\mathrm{Co}_{0.85} \mathrm{Se}\right) / \mathrm{MoSe}_{2} /$ molybdenum oxide $\left(\mathrm{MoO}_{3}\right)$ ternary hybrid was evaluated as a CE for DSSCs. ${ }^{266}$ $\mathrm{Co}_{0.85} \mathrm{Se} / \mathrm{MoSe}_{2} / \mathrm{MoO}_{3}$ ternary hybrids consist of nanorods, nanosheets, and nanoparticles, as confirmed by FESEM. CV showed larger current density for the $\mathrm{Co}_{0.85} \mathrm{Se} / \mathrm{MoSe}_{2} / \mathrm{MoO}_{3}$ hybrid compared with a sputtered Pt CE. The $\mathrm{Co}_{0.85} \mathrm{Se} / \mathrm{MoSe}_{2} /$ $\mathrm{MoO}_{3} \mathrm{CE}$ based DSSCs showed a PCE of 7.10\%, much higher than that of a DSSC with a Pt CE $(\eta=6.03 \%)$. For comparison, the $\mathrm{Co}_{0.85}$ Se hollow nanoparticles as a CE for DSSCs showed a PCE of $6.03 \%$, lower compared to the Pt CE based DSSC $(\eta=$ $6.45 \%) .{ }^{267}$ The transparent CEs using metal selenides alloys (M-Se; $\mathrm{M}=\mathrm{Co}, \mathrm{Ni}, \mathrm{Cu}, \mathrm{Fe}, \mathrm{Ru}$ ) were studied for the electrocatalytic activity for DSSCs and triiodide $\left(\mathrm{I}_{3}{ }^{-}\right)$reduction. ${ }^{268}$ The DSSCs containing CEs consisting of a metal selenide alloy showed PCEs of $8.30 \%$ for $\mathrm{Co}_{0.85} \mathrm{Se}, 7.85 \%$ for $\mathrm{Ni}_{0.85} \mathrm{Se}, 6.43 \%$ for $\mathrm{Cu}_{0.50} \mathrm{Se}, 7.64 \%$ for FeSe, and $9.22 \%$ for $\mathrm{Ru}_{0.33} \mathrm{Se}$. A Pt CE based DSSC exhibited PCE of 6.18\%. Also, a nickel cobalt sulfide $\left(\mathrm{NiCo}_{2} \mathrm{~S}_{4}\right)$ nanoneedle array ${ }^{269}$ used as a CE for a DSSC showed a PCE value of $6.9 \%$, which is comparable to a Pt CE ( $\eta$ $=7.7 \%)$. 

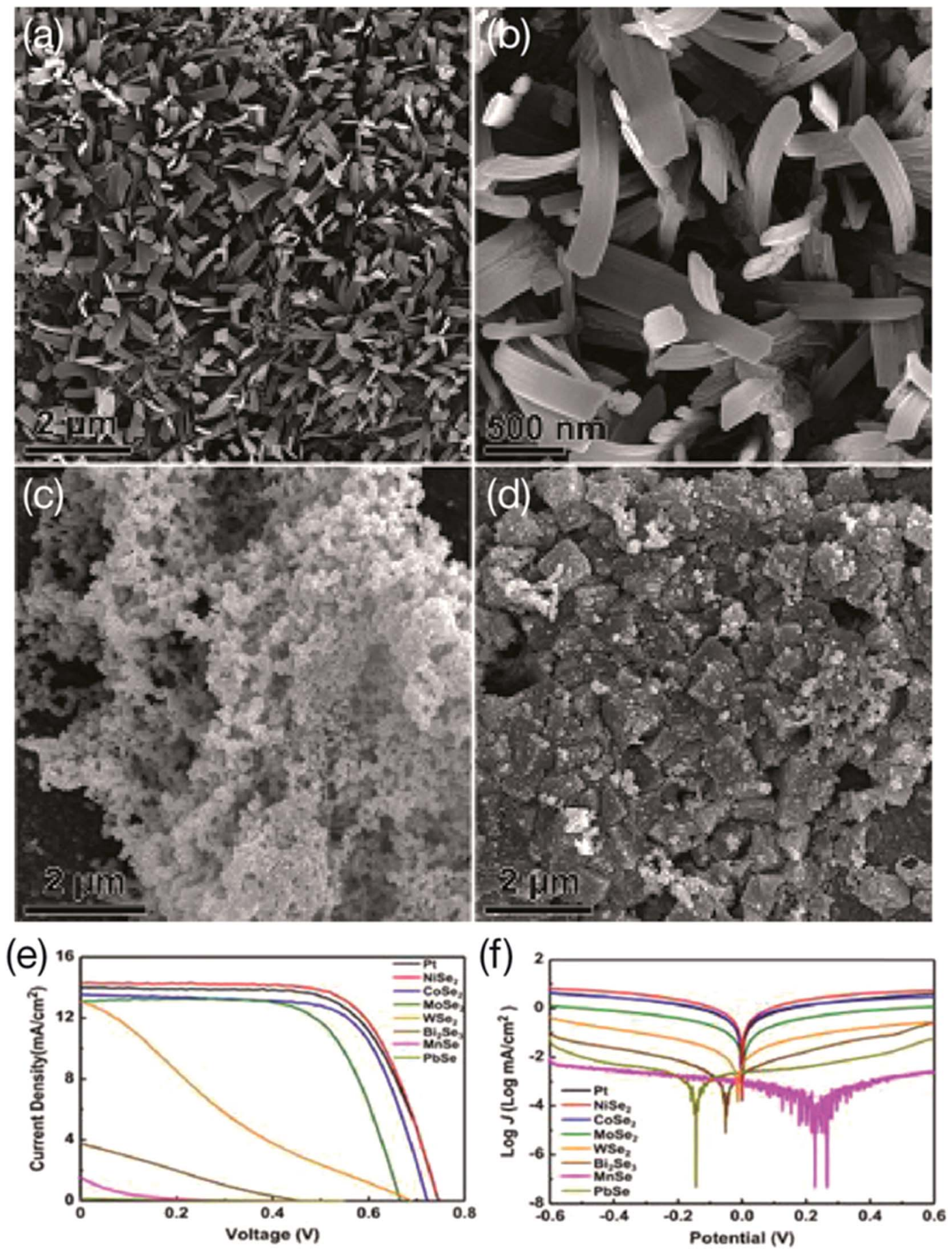

Fig. 21 SEM images of $\mathrm{NiSe}_{2}(\mathrm{a}, \mathrm{b})$ and SEM images of $\mathrm{CoSe}_{2}$ (c) and MoSe $\mathrm{M}_{2}$ (d). J-V characteristic curves (e) and Tafel polarization curves (f) of DSSCs based on CEs of made of metal selenides; $\mathrm{NiSe}_{2}, \mathrm{CoSe}_{2}, \mathrm{MoSe}_{2}, \mathrm{WSe}_{2}, \mathrm{Bi}_{2} \mathrm{Se}_{3}, \mathrm{MnSe}, \mathrm{PbSe}$, and Pt. Reprinted with permission from ref. 262 , I. A. Ji, H. M. Choi and J. H. Bang, metal selenide films as the counter electrode in dye-sensitized solar cell. Mater. Lett., 2014, 123, 51-54. Copyright@ Elsevier.

\section{2 $\mathrm{NbSe}_{2}$ counter electrodes}

Niobium diselenide $\left(\mathrm{NbSe}_{2}\right)$ has attracted attention due to its superconducting properties ${ }^{270-275}$ and can be easily processed into nanosheets, nanoflakes, nanowires and nanotubes usable for applications in field-effect transistors, ${ }^{99 a}$ light-emitting diodes, ${ }^{276}$ superconductors, ${ }^{277}$ and lithium batteries. ${ }^{278}$
$\mathrm{NbSe}_{2}$ nanosheets, nanorods, and $\mathrm{NbSe}_{2} / \mathrm{C}$ composites were used as CEs for DSSCs. ${ }^{279}$ The morphology and structure of the $\mathrm{NbSe}_{2}$ materials were characterized by SEM, TEM, and XRD while their electrochemical properties were evaluated by $\mathrm{CV}$, EIS, and Tafel polarization curve measurements. The CEs based on $\mathrm{NbSe}_{2}$ nanorods and $\mathrm{NbSe}_{2}$ nanosheets showed lower charge 


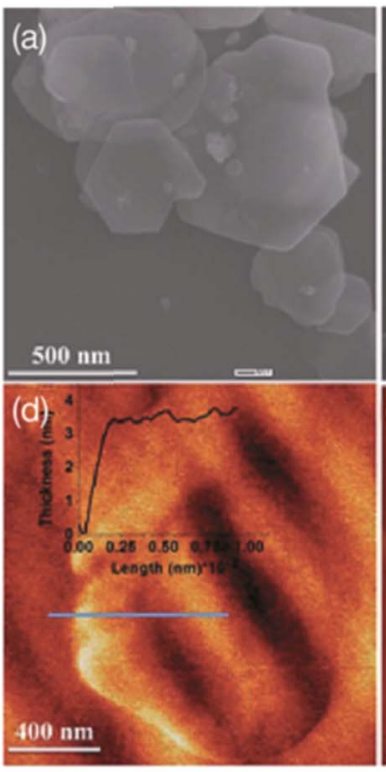

(g)

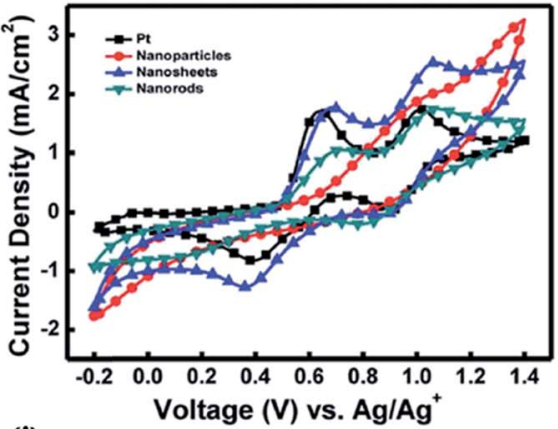

(i)

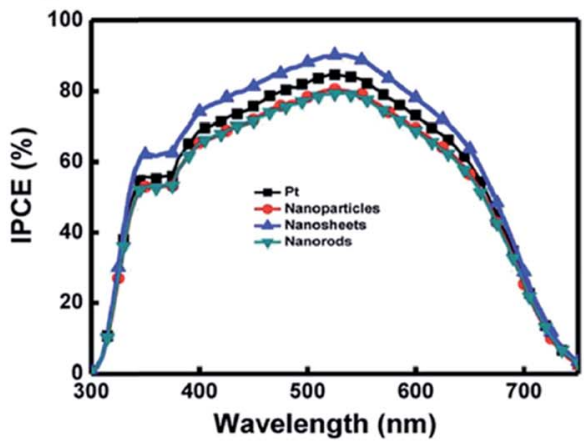

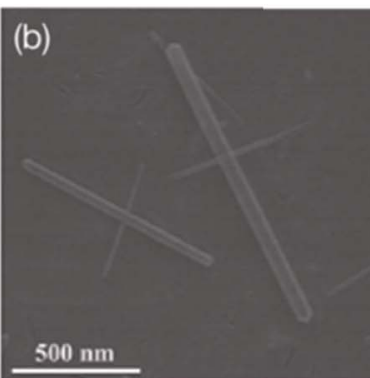
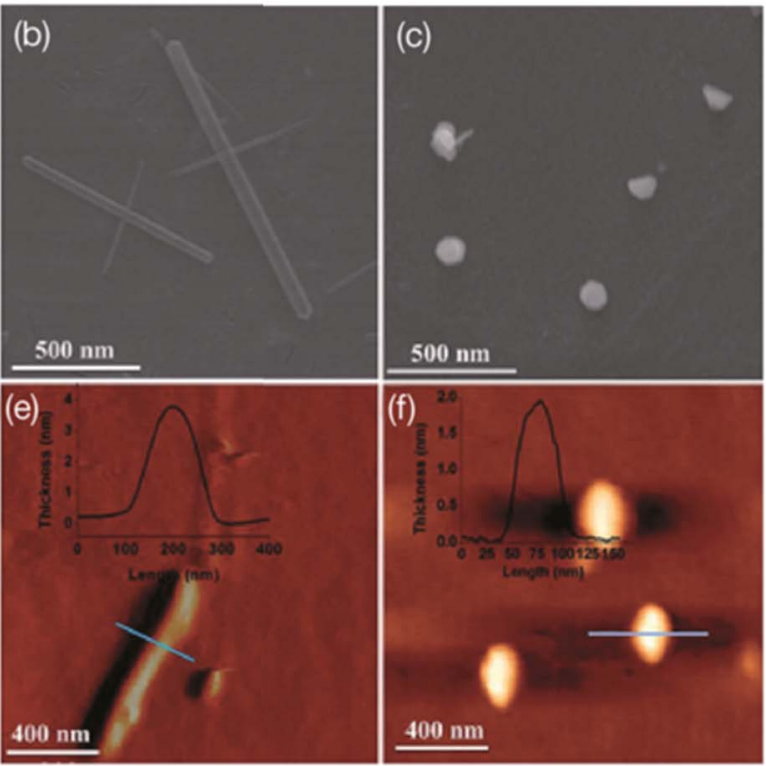

(h)

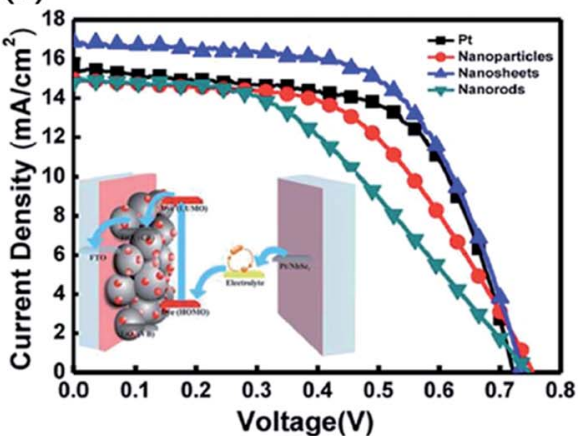

(j)

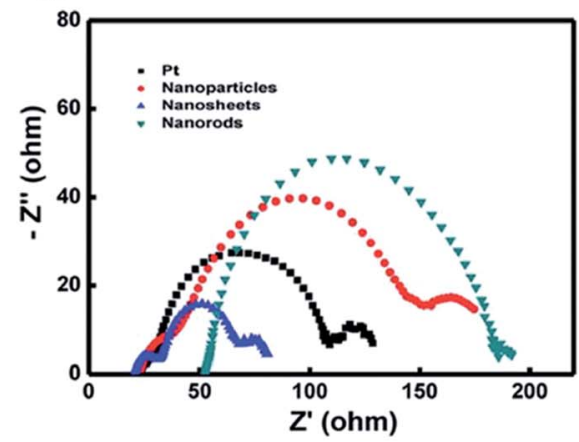

Fig. 22 SEM images of $\mathrm{NbSe}_{2}$ nanostructures that include nanosheets (a), nanorods (b), and nanoparticles (c), (d-f) AFM height images of NbSe 2 nanosheets (d), nanorods (e), and nanoparticles (f). The insets show height profiles measured by AFM images. (g) Cyclic voltammograms (CV) of Pt $\mathrm{CE}$ and $\mathrm{NbSe}_{2}$ nanostructures based CEs. (h) $J-V$ curves of $\mathrm{Pt}$ and $\mathrm{NbSe}_{2}$ nanostructures. The inset represents DSSC structure with an energy level diagram of the materials. (i) Photon-to-current conversion efficiency (IPCE) curves of Pt and $\mathrm{NbSe}_{2}$ nanostructures, and (j) EIS Nyquist plots of Pt and $\mathrm{NbSe}_{2}$ nanostructures based CEs used in DSSCs. Reprinted with permission from ref. 280, M. A. Ibrahem, W. C. Huang, T. W. Lan, K. M. Boopathi, Y. C. Hsiao, C. H. Chen, W. Budiawan, Y. Y. Chen, C. S. Chang, L. J. Li, C. H. Tsai, C. C. Chu, controlled mechanical cleavage of bulk niobium diselenide to nanoscaled sheet, rod, and particle structures for Pt-free dye-sensitized solar cells. J. Mater. Chem. A, 2014, 2, 1138211390. Copyright $\odot$ Royal Society of Chemistry.

transfer resistance and ionic diffusion. DSSCs having $\mathrm{NbSe}_{2}$ nanosheet-based CEs achieved a PCE of 7.34\%, which further increased to $7.80 \%$ for the $\mathrm{NbSe}_{2} / \mathrm{C}$ composite-based CEs due to reduced series resistance, which is a PCE of $98.7 \%$ of the conventional Pt-based CEs $(\eta=7.90 \%)$. Also, $\mathrm{NbSe}_{2}$ nanostructures deposited via spray-coating were used to develop Pt-free CEs for DSSCs by Ibrahem et al. ${ }^{280}$ Fig. 22 shows SEM images and AFM height profiles of $\mathrm{NbSe}_{2}$ nanosheets, nanorods, and nanoparticles, CV, $J-V$ curves, IPCE spectra, and EIS (presented in Nyquist plots) of Pt and $\mathrm{NbSe}_{2}$ nanostructures 
based CEs used in DSSCs. The morphology of the synthesized $\mathrm{NbSe}_{2}$ nanostructures was analyzed by SEM and AFM techniques. SEM analysis indicated the pristine $\mathrm{NbSe}_{2} 2 \mathrm{D}$ sheets were $100 \mu \mathrm{m}$ thick. The separate $\mathrm{NbSe}_{2}$ nanosheets were between 100-500 $\mathrm{nm}$ in lateral dimension. The length of $\mathrm{NbSe}_{2}$ nanorods were up to $1.2 \mu \mathrm{m}$ with diameters ranging between 20 to $100 \mathrm{~nm}$. The average size of the $\mathrm{NbSe}_{2}$ nanoparticles was between 50-100 $\mathrm{nm}$. The AFM images revealed an average thickness of $<8 \mathrm{~nm}$ for the $\mathrm{NbSe}_{2}$ nanosheets, $<5 \mathrm{~nm}$ for the $\mathrm{NbSe}_{2}$ nanorods, and $<3 \mathrm{~nm}$ for the $\mathrm{NbSe}_{2}$ nanoparticles. HRTEM of the $\mathrm{NbSe}_{2}$ nanosheets on their edge showed a spacing of $6.3 \AA$. HRTEM revealed the crystalline nature of individual $\mathrm{NbSe}_{2}$ nanorods and nanoparticles. The $\mathrm{NbSe}_{2}$ nanosheets, nanorods and nanoparticles were studied as CEs in DSSCs as a replacement to a conventional Pt CE. The dyeabsorbed $\mathrm{TiO}_{2}$ electrodes were prepared by dipping electrodes into ruthenium dye 719 solution for 24 hours at room temperature. The dye solution contained $0.5 \mathrm{mM}$ dye N719, [cisdi(thiocyanato)- $N$-N0-bis(2,20-bipyridyl-4-carboxylic acid-40tetrabutyl-ammonium carboxylate) ruthenium(II)], and $0.5 \mathrm{mM}$ chenodeoxycholic acid in a 1:1 mixture of tert-butanol and acetonitrile. The electrolyte solution was composed of 1-butyl-3methylimidazolium iodide (BMII, 0.6 M), 4-tert-butylpyridine $(0.5 \mathrm{M})$, iodine $(0.03 \mathrm{M})$, and guanidinium thiocyanate $(0.1 \mathrm{M})$ in a acetonitrile-valeronitrile mixture. The $\mathrm{NbSe}_{2}$ nanosheet CEs achieved a PCE of $7.73 \%$, compared to a PCE of $7.01 \%$ for
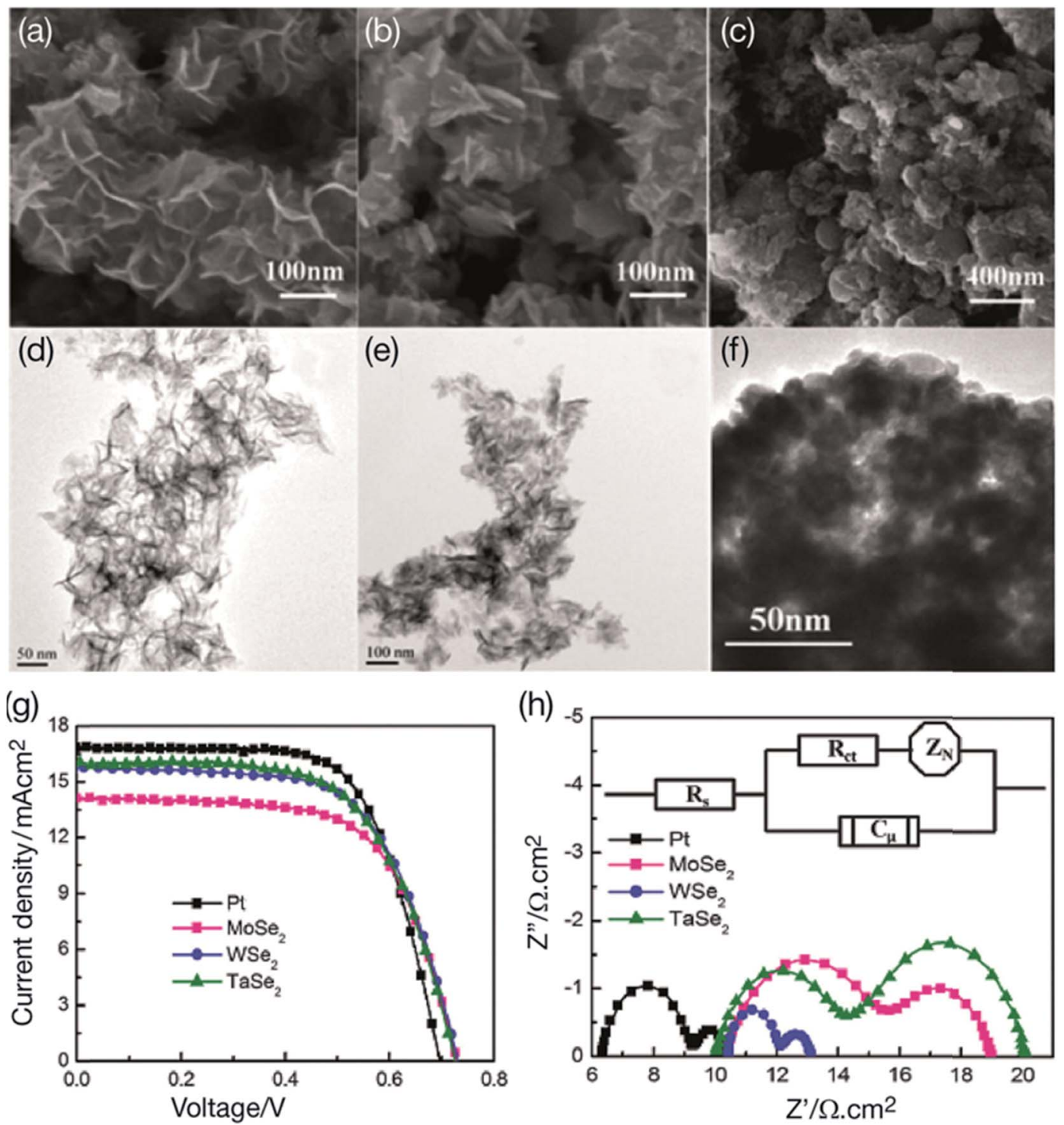

Fig. 23 SEM and TEM images of $\mathrm{MoSe}_{2}$ ( $a$ and d), WSe $\left(b\right.$ and e), and $\mathrm{TaSe}_{2}$ ( $c$ and $\mathrm{f}$ ). (g) Photocurrent-voltage ( $J-V$ curves of the DSSCs based on $\mathrm{MoSe}_{2}, \mathrm{WSe}_{2}$, and Pt CEs, measured under simulated sunlight illumination (100 mW cm ${ }^{-2}, 1.5 \mathrm{AM}$ G). (h) Nyquist plots of electrochemical impedance spectroscopy (EIS) measurements for DSSCs fabricated with two identical electrodes in the triiodide/iodide $\left(I_{3}{ }^{-} / I^{-}\right)$redox couple in the electrolyte. The inset represents equivalent circuit of DSSCs for fitting Nyquist plots. Reprinted with permission from ref. 281, J. Guo, S. Liang, Y. Shi, C. Hao, X. Wang and T. Ma, transition metal selenides as efficient counter-electrode materials for dye-sensitized solar cells. Phys. Chem. Chem. Phys., 2015, 17, 28985-28992. Copyright@ Royal Society of Chemistry/Owner Societies. 
Pt-based CEs for DSSCs. The DSSCs with $\mathrm{NbSe}_{2}$ nanoparticles and nanorods based CEs show PCE values of $6.27 \%$ and $5.05 \%$, respectively, due to low FF arising from relatively smaller surface areas, as well as low exposure on the FTO glass substrates. DSSCs having $\mathrm{NbSe}_{2}$ nanosheets based CE show the best IPCE spectral response, where the peak increases from $84 \%$ for a Pt CE to $89 \%$ for a $\mathrm{NbSe}_{2}$ nanosheets based CE. On the other hand, lower IPCE peak values were observed for $\mathrm{NbSe}_{2}$ nanoparticles and nanorods based CEs. The charge-transfer processes at the interface of $\mathrm{TiO}_{2} /$ dye/electrolyte were analyzed by EIS. The $\mathrm{NbSe}_{2}$ nanosheet based CEs for the DSSCs shows a middle-frequency semicircle, implying it had the highest electro-catalytic activity for the reduction of triiodide ions $\left(\mathrm{I}_{3}{ }^{-}\right)$, and efficient generation of electrons, therefore, occurring of larger electrons at the $\mathrm{TiO}_{2} /$ dye/electrolyte interface. This study suggests that $\mathrm{NbSe}_{2}$ nanosheets could be used as alternative CEs to conventional Pt CEs in DSSCs because of their large surface area.

\section{3 $\mathrm{TaSe}_{2}$ counter electrodes}

Three transition-metal selenides $\left(\mathrm{MoSe}_{2}, \mathrm{WSe}_{2}\right.$, and $\left.\mathrm{TaSe}_{2}\right)$ were prepared by Guo et al. ${ }^{281}$ and compared as potential CEs for fabricating DSSC devices using a solvothermal method. These transition-metal selenides show high electrocatalytic activity for the reduction of triiodide $\left(\mathrm{I}_{3}{ }^{-}\right)$, except for $\mathrm{MoSe}_{2}$, due to low adsorption and charge-transfer. Fig. 23 shows SEM and TEM images of $\mathrm{MoSe}_{2}$ (a and d), WSe Nyquist plots of EIS measurements recorded at $-0.75 \mathrm{~V}$ bias of the DSSCs based on $\mathrm{MoSe}_{2}, \mathrm{WSe}_{2}$, and Pt CEs for the triiodide/ iodide $\left(\mathrm{I}_{3}{ }^{-} / \mathrm{I}^{-}\right)$redox couple in the electrolyte; and their $J-V$ curves measured under simulated sunlight illumination. The $\mathrm{MoSe}_{2}$ nanosheets had thickness of about $10 \mathrm{~nm}$ with lateral dimensions ranging 100-150 $\mathrm{nm}$. WSe ${ }_{2}$ consists of interlaced nanoplates with $15 \mathrm{~nm}$ average thickness and a width varying between 60 and $100 \mathrm{~nm}$. The SEM image of $\mathrm{TaSe}_{2}$ shows fluffy nanoparticles with a wide size distribution. The HRTEM images of $\mathrm{MoSe}_{2}, \mathrm{WSe}_{2}$, and $\mathrm{TaSe}_{2}$ indicated spacings of $0.282 \mathrm{~nm}$, $0.283 \mathrm{~nm}$, and $0.291 \mathrm{~nm}$, respectively. The $\mathrm{WSe}_{2}$ shows a pore size distribution (PSD) curve at about $43 \mathrm{~nm}, \mathrm{MoSe}_{2}$ at $30 \mathrm{~nm}$, and $\mathrm{TaSe}_{2}$ at $10 \mathrm{~nm}$. The mesoporous structure of $\mathrm{WSe}_{2}$ facilitates the adsorption of triiodide $\left(\mathrm{I}_{3}{ }^{-}\right)$and transport during the electrocatalytic activity. The BET surface areas were 95.6, 104.4 and $78.8 \mathrm{~m}^{2} \mathrm{~g}^{-1}$, and the total pore volumes were $0.32 \mathrm{~cm}^{3} \mathrm{~g}^{-1}$, $0.41 \mathrm{~cm}^{3} \mathrm{~g}^{-1}$ and $0.14 \mathrm{~cm}^{3} \mathrm{~g}^{-1}$, for $\mathrm{WSe}_{2}, \mathrm{MoSe}_{2}, \mathrm{TaSe}_{2}$, respectively. The significant difference in BET surface area and the pore size distribution led to different adsorption properties and electrocatalytic activity of the DSSCs. The $R_{\mathrm{CT}}$ of the transition-metal selenides at the electrolyte/electrode interface indicates the level of electrocatalytic activity. The $R_{\mathrm{CT}}$ value of $0.78 \Omega \mathrm{cm}^{2}$ for the $\mathrm{WSe}_{2} \mathrm{CE}$ is smaller compared with a Pt CE $\left(1.32 \Omega \mathrm{cm}^{2}\right)$ and a TaSe $2\left(1.89 \Omega \mathrm{cm}^{2}\right) \mathrm{CE}$, while the $R_{\mathrm{CT}}$ value of the $\mathrm{MoSe}_{2}\left(2.43 \Omega \mathrm{cm}^{2}\right)$ CE was larger than that of the Pt CE. Therefore, $\mathrm{WSe}_{2}$ shows better electrocatalytic activity for triiodide $\left(\mathrm{I}_{3}{ }^{-}\right)$reduction. The ionic $Z_{\mathrm{N}}$ value of $\mathrm{WSe}_{2}$ is $1.15 \Omega \mathrm{cm}^{2}$, lower than that of the $\mathrm{MoSe}_{2}$, and TaSe 2 CEs, and comparable to the Pt CE, which demonstrates a larger diffusion coefficient for triiodide $\left(\mathrm{I}_{3}{ }^{-}\right)$within the CEs. The conductivities measured by linear sweep voltammetry decrease in the relative order $\mathrm{TaSe}_{2}>$ $\mathrm{MoSe}_{2}>\mathrm{WSe}_{2}$. The DSSCs based on $\mathrm{TaSe}_{2}$ and $\mathrm{WSe}_{2}$ CES showed larger $J_{\mathrm{sc}}$ than that of $\mathrm{MoSe}_{2} \mathrm{CE}$. WSe $\mathrm{W}_{2}$ has larger pores and high electrocatalytic activity suitable for fast regeneration and transfer of triiodide $\left(\mathrm{I}_{3}{ }^{-}\right)$. PCE values of $7.32 \%$ for $\mathrm{TaSe}_{2}$ and $7.48 \%$ for $\mathrm{Wse}_{2}$ were measured, which are comparable to a sputtered Pt CE $(\eta=7.91 \%)$. The lower PCE value of $6.70 \%$ for $\mathrm{MoSe}_{2}$ arises from a lower $V_{\mathrm{oc}}$ and $J_{\text {sc }}$ for the DSSC.

\section{4 $\mathrm{NiSe}_{2}$ counter electrodes}

Nickel diselenide $\left(\mathrm{NiSe}_{2}\right)$ has been studied as a CE of DSSCs for the reduction of $\mathrm{I}_{3}{ }^{-}$, which yielded higher PCE of $8.69 \%$ than that of a conventional Pt CE (8.04\%) under the same experimental conditions. ${ }^{282}$ Zhang et al. ${ }^{283}$ developed two types of $\mathrm{NiSe}_{2}$ CEs on RGO; namely, microsphere $\mathrm{NiSe}_{2} / \mathrm{RGO}$, and octahedron $\mathrm{NiSe}_{2} / \mathrm{RGO}$ through a hydrothermal process. The microsphere $\mathrm{NiSe}_{2} / \mathrm{RGO} \mathrm{CE}$ exhibited higher electrocatalytic performance than a Pt CE for the reduction of triiodide $\left(\mathrm{I}_{3}{ }^{-}\right)$ because of better carrier transfer induced by graphene nanosheets.

CEs of ternary Ni-Co compounds having different morphological structures such as nanoparticles, nanotubes, nanowires, nanoflakes, follower-like, and urchin-like have been studied for DSSCs. ${ }^{284,285}$ For example, the CE made of flower-like $\mathrm{NiCo}_{2} \mathrm{~S}_{4} /$ NiS microspheres ${ }^{286}$ exhibited a PCE of $8.8 \%$, much higher than a standard Pt CE $(\eta=8.1 \%)$. A similar concept was employed by Qian et al. ${ }^{287}$ for developing a very interesting class of CEs for DSSCs from nickel cobalt (Ni-Co) selenides having different morphological structures, due to the tuning of the Ni/Co molar ratios. The morphological structure and electrocatalytic performance of ternary $\mathrm{Ni}-\mathrm{Co}$ selenides was optimized by using different Ni/Co molar ratios. Fig. 24 shows the SEM images of $\mathrm{Co}_{3} \mathrm{Se}_{4}, \mathrm{Ni}_{0.33} \mathrm{Co}_{0.67} \mathrm{Se}$ precursor, $\mathrm{Ni}_{0.33} \mathrm{Co}_{0.67} \mathrm{Se}, \mathrm{Ni}_{0.5} \mathrm{Co}_{0.5} \mathrm{Se}$, $\mathrm{Ni}_{0.67} \mathrm{Co}_{0.33} \mathrm{Se}$, and NiSe, and also shows $\mathrm{CV}$ and $J-V$ curves of their DSSCs. The different morphological structures were obtained by tuning the $\mathrm{Ni} / \mathrm{Co}$ molar ratio, $\mathrm{Ni}_{x} \mathrm{Co}_{1-x} \mathrm{Se}$, where, $x$ was $0,0.33,0.5,0.67$, and 1.0 . The $3 \mathrm{D}$ dandelion-like precursor of $\mathrm{Ni}_{0.33} \mathrm{Co}_{0.67} \mathrm{Se}$ assembled into nanotubes having about $100 \mathrm{~nm}$ diameter, $\mathrm{Ni}_{0.5} \mathrm{Co}_{0.5} \mathrm{Se}$ into a floccus-like microsphere structure with a diameter of 4 microns, $\mathrm{Ni}_{0.67} \mathrm{Co}_{0.33} \mathrm{Se}$ microspheres compiled into nanosheets, and $\mathrm{Co}_{3} \mathrm{Se}_{4}$ built up roughsurface nanotubes. The specific surface areas determined from the BET method were 5.0, 10.1, 26.1, 28.9, and $35.6 \mathrm{~m}^{2} \mathrm{~g}^{-1}$, for NiSe, $\mathrm{Co}_{3} \mathrm{Se}_{4}, \mathrm{Ni}_{0.5} \mathrm{Co}_{0.5} \mathrm{Se}, \mathrm{Ni}_{0.67} \mathrm{Co}_{0.33} \mathrm{Se}$ and $\mathrm{Ni}_{0.33} \mathrm{Co}_{0.67} \mathrm{Se}$, respectively. Among all metal selenides, $\mathrm{Ni}_{0.33} \mathrm{Co}_{0.67} \mathrm{Se}$ has the highest specific surface area, which is favorable for providing more active sites for catalysis and increasing the contact area between its $\mathrm{CE}$ and the electrolyte, which results in better electrochemical and photovoltaic properties of its DSSCs. The $R_{\mathrm{CT}}$ values of CEs follows the relative order of $\mathrm{NiSe}>\mathrm{Co}_{3} \mathrm{Se}_{4}>\mathrm{Pt}$ $>\mathrm{Ni}_{0.67} \mathrm{Co}_{0.33} \mathrm{Se}>\mathrm{Ni}_{0.5} \mathrm{Co}_{0.5} \mathrm{Se}>\mathrm{Ni}_{0.33} \mathrm{Co}_{0.67} \mathrm{Se}$, which implies that the electrocatalytic activity increases in a reverse order. Thus, NiSe was of the lowest activity and $\mathrm{Ni}_{0.33} \mathrm{Co}_{0.67} \mathrm{Se}$ was of the highest catalytic activity for the reduction of triiodide $\left(\mathrm{I}_{3}{ }^{-}\right)$. Therefore, higher contents of $\mathrm{Ni}$ in the Ni-Co selenides CEs are 

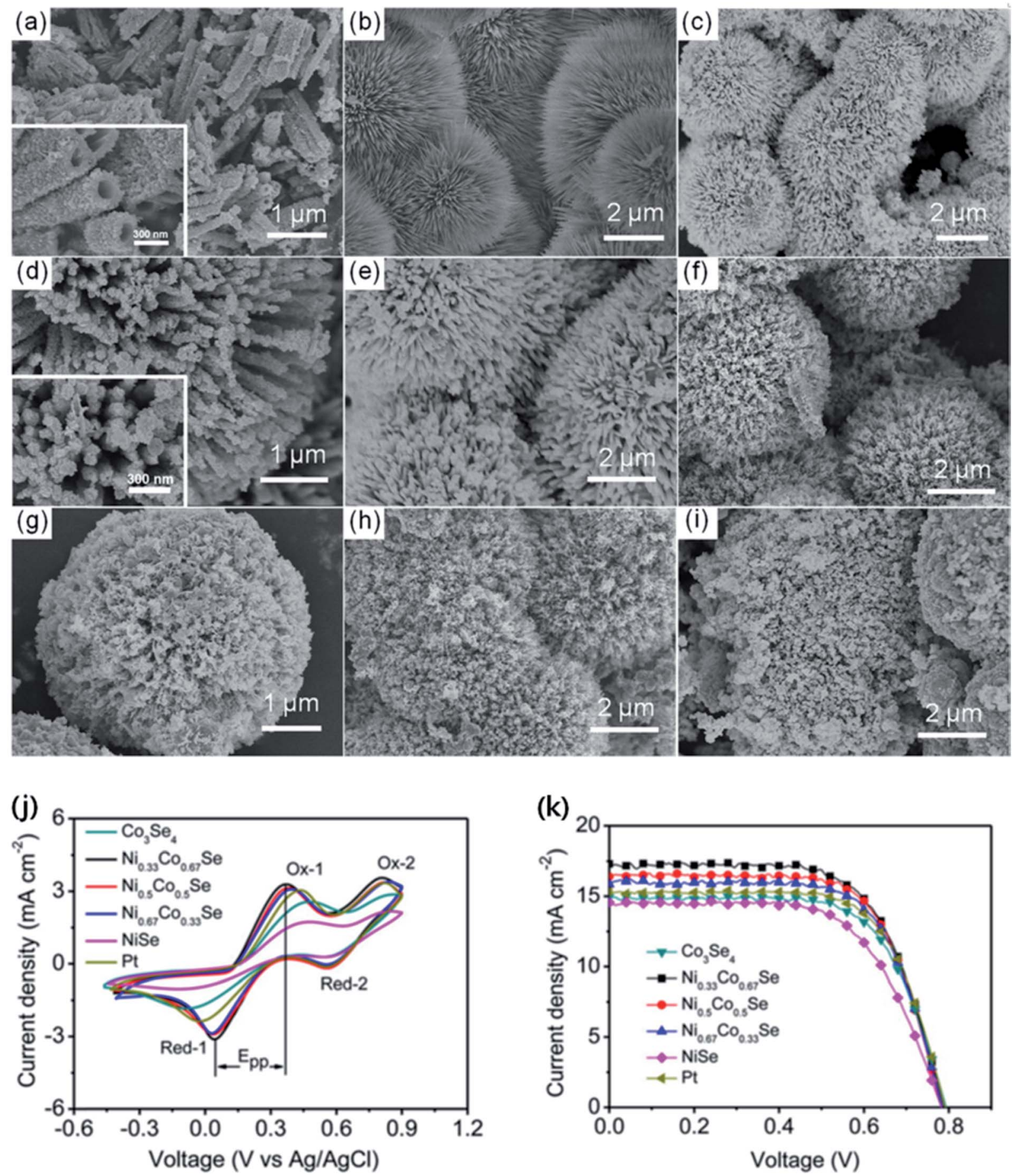

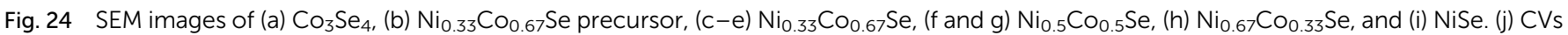
of DSSCs with $\mathrm{CO}_{3} \mathrm{Se}_{4}, \mathrm{Ni}_{0.33} \mathrm{CO}_{0.67} \mathrm{Se}, \mathrm{Ni}_{0.5} \mathrm{Co}_{0.5} \mathrm{Se}, \mathrm{Ni}_{0.67} \mathrm{Co}_{0.33} \mathrm{Se}, \mathrm{NiSe}$, and Pt-based CEs at a scan rate of $50 \mathrm{mV} \mathrm{s}{ }^{-1}$. (k) Photocurrent densityvoltage $\left(\mathrm{J}-\mathrm{V}\right.$ ) curves of DSSCs with $\mathrm{CO}_{3} \mathrm{Se}_{4}, \mathrm{Ni}_{0.33} \mathrm{CO}_{0.67} \mathrm{Se}, \mathrm{Ni}_{0.5} \mathrm{CO}_{0.5} \mathrm{Se}, \mathrm{Ni}_{0.67} \mathrm{Co}_{0.33} \mathrm{Se}$, NiSe, and Pt CEs under AM 1.5G illumination. Reprinted with permission from ref. 287, X. Qian, H. Li, L. Shao, X. Jiang and L. Hou, morphology-tuned synthesis of nickel cobalt selenides as highly efficient Pt-free counter electrode catalysts for dye-sensitized solar cells. ACS Appl. Mater. Interfaces, 2016, 8, 29486-29495. Copyright@ American Chemical Society.

not favorable for electrocatalytic activity. The values of cathodic peak current density (red-1) and the $E_{\mathrm{pp}}$ can also help understand the electrocatalytic activities of these CEs. The authors noted the following relative order of cathodic peak current density: NiSe $\left(1.044 \mathrm{~mA} \mathrm{~cm}{ }^{-2}\right)<\mathrm{Co}_{3} \mathrm{Se}_{4}\left(1.849 \mathrm{~mA} \mathrm{~cm}{ }^{-2}\right)<\mathrm{Pt}$ $\left(2.373 \mathrm{~mA} \mathrm{~cm}^{-2}\right)<\mathrm{Ni}_{0.67} \mathrm{Co}_{0.33} \mathrm{Se}\left(2.878 \mathrm{~mA} \mathrm{~cm}^{-2}\right)<\mathrm{Ni}_{0.5} \mathrm{Co}_{0.5} \mathrm{Se}$ $\left(2.917 \mathrm{~mA} \mathrm{~cm}^{-2}\right)<\mathrm{Ni}_{0.33} \mathrm{Co}_{0.67} \mathrm{Se}\left(3.120 \mathrm{~mA} \mathrm{~cm}^{-2}\right)$. They also noted $E_{\mathrm{pp}}$ values of NiSe $(602 \mathrm{mV})>\mathrm{Co}_{3} \mathrm{Se}_{4}(565 \mathrm{mV})>\mathrm{Pt}(460$ 
$\mathrm{mV})>\mathrm{Ni}_{0.67} \mathrm{Co}_{0.33} \mathrm{Se}(365 \mathrm{mV})>\mathrm{Ni}_{0.5} \mathrm{Co}_{0.5} \mathrm{Se}(349 \mathrm{mV})>\mathrm{Ni}_{0.33^{-}}$ $\mathrm{Co}_{0.67} \mathrm{Se}(329 \mathrm{mV})$, which were in an agreement with EIS measurements of the CEs. The $3 \mathrm{D}$ dandelion-like $\mathrm{Ni}_{0.33} \mathrm{~S}_{0.67} \mathrm{Se}$ microspheres based CEs exhibited the highest PCE of 9.01\%, exceeding that of the Pt CE $(\eta=8.30 \%)$. The DSSC with a $\mathrm{Co}_{3} \mathrm{Se}_{4}$ CE showed a PCE of $7.95 \%$, higher than that of NiSe CE $(\eta=$ $7.23 \%$ ). These results support the notion that the ternary Ni-Co selenides possess higher electrocatalytic activities and photovoltaic properties than those of binary selenides NiSe and $\mathrm{Co}_{3} \mathrm{Se}_{4}$ as well as Pt CEs for the triiodide $\left(\mathrm{I}_{3}{ }^{-}\right)$reduction, due to their unique morphology and chemical composition.

\section{5 $\quad \mathrm{FeSe}_{2}$ counter electrodes}

Iron diselenide $\left(\mathrm{FeSe}_{2}\right)$ can be processed into nanosheets, nanocubes, flower-like structures, and nanorods, rod clusters, and microspheres, ${ }^{288-294}$ and has applications in catalysis, ${ }^{295}$ batteries, ${ }^{296,297}$ and photovoltaic devices. ${ }^{298}$ The first-row (3d) transition metal dichalcogenides $\left(\mathrm{MX}_{2}\right)$ with pyrite structure (where, $\mathrm{M}=\mathrm{Fe}, \mathrm{Co}, \mathrm{Ni}$, and $\mathrm{X}=\mathrm{S}, \mathrm{Se}$ ) also exhibit electronic, optoelectronic, and magnetic properties comparable to other TMDs. ${ }^{299-302}$ Huang et al. ${ }^{302}$ used 2D FeSe 2 nanosheets with $7 \mathrm{~nm}$ average thickness as a CE for a DSSC. Fig. 25 shows the SEM and TEM images of the synthesized $\mathrm{FeSe}_{2}$ nanosheets. The thickness of $\mathrm{FeSe}_{2}$ nanosheets was found to be in the 4-7 nm range, as evaluated by TEM images. High-resolution TEM (HRTEM) indicated the crystalline nature of the nanosheets, having $0.168 \mathrm{~nm}$ interplanar spacing. The $\mathrm{FeSe}_{2}$ nanosheets had specific surface area of $35.02 \mathrm{~m}^{2} \mathrm{~g}^{-1}$ as calculated by the BET analysis. The $\mathrm{FeSe}_{2}$ nanosheets exhibit a low charge-transfer resistance $\left(R_{\mathrm{CT}}\right)$ and a high electrocatalytic activity for triiodide $\left(\mathrm{I}_{3}{ }^{-}\right)$reduction in DSSCs. The $\mathrm{FeSe}_{2}$ nanosheets $\mathrm{CE}$ based DSSC showed a PCE of $7.53 \%$, comparable to a Pt CE, while the PCE of $\mathrm{FeSe}_{2}$ microparticles CE based DSSC was slightly lower $(\eta$

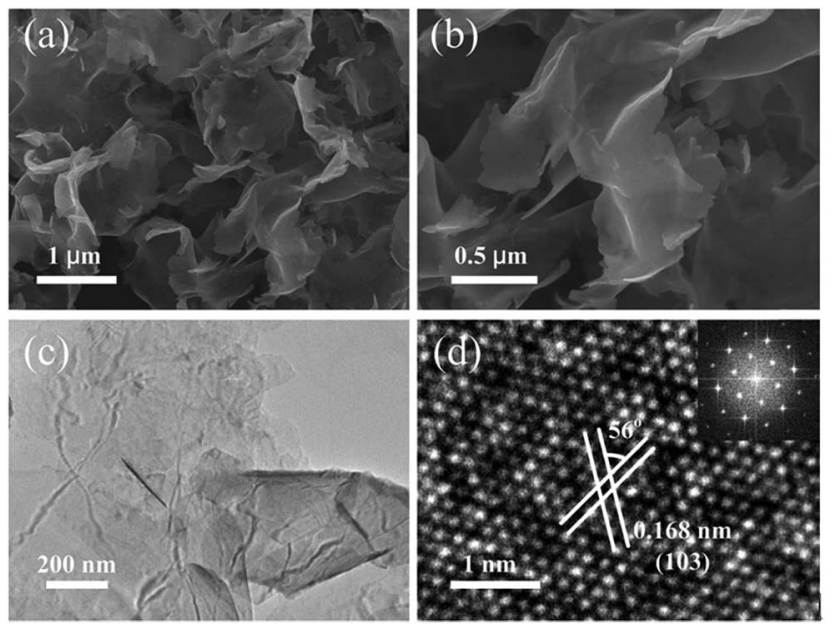

Fig. 25 (a, b) SEM images and (c) TEM image of the as-synthesized $\mathrm{FeSe}_{2}$ nanosheets, and (d) HRTEM image of a small portion of $\mathrm{FeSe}_{2}$ nanosheet (inset shows SAED pattern of the $\mathrm{FeSe}_{2}$ nanosheets). Reprinted with permission from ref. 302, S. Huang, Q. He, W. Chen, Q. Qiao, J. Zai and X. Qian, ultrathin $\mathrm{FeSe}_{2}$ nanosheets: controlled synthesis and application as a heterogeneous catalyst in dye-sensitized solar cells. Chem.-Eur. J., 2015, 21, 4085-4091. Copyright $\odot$ Wiley$\mathrm{VCH}$.
$=6.88 \%$ ). The large surface area of the $\mathrm{FeSe}_{2}$ nanosheets contributed to a higher PCE by providing more active sites for electrocatalytic activity, as well as a larger electrode/electrolyte interface that of the $\mathrm{FeSe}_{2}$ microparticles. The electrochemical stability of the CEs of $\mathrm{FeSe}_{2}$ nanosheets and Pt were investigated with sequential CV scanning. The current densities of the $\mathrm{FeSe}_{2}$ CE showed no change after 1000 cycles, confirming corrosion resistance to the electrolyte. The PCEs of $\mathrm{FeSe}_{2}$ nanosheets under nitrogen protection $\left(\mathrm{N}-\mathrm{FeSe}_{2}\right)$ and exposure to air for one week $\left(\mathrm{O}-\mathrm{FeSe}_{2}\right)$ were also studied. The $R_{\mathrm{CT}}$ of the $\mathrm{N}-\mathrm{FeSe}_{2} \mathrm{CE}$ $\left(0.53 \Omega \mathrm{cm}^{2}\right)$ was much lower that the $\mathrm{O}-\mathrm{FeSe}_{2} \mathrm{CE}\left(10.13 \Omega \mathrm{cm}^{2}\right)$ and a Pt CE $\left(1.68 \Omega \mathrm{cm}^{2}\right)$, indicating poorer electrocatalytic activity of the $\mathrm{O}-\mathrm{FeSe}_{2} \mathrm{CE}$ compared to the $\mathrm{N}-\mathrm{FeSe}_{2}$ and Pt CEs. The Tafel polarization curves decreased in the order $\mathrm{N}-\mathrm{FeSe}_{2}>$ $\mathrm{Pt}>\mathrm{O}-\mathrm{FeSe}_{2}$, having the same order as of exchange current density, $\mathrm{CV}$ and EIS measurements. The $\mathrm{O}-\mathrm{FeSe}_{2}$ nanosheets $\mathrm{CE}$ based DSSC has a PCE of 6.15\%, much lower than that of the NFeSe $_{2}(\eta=7.53 \%) \mathrm{CE}$ and Pt CE $(\eta=7.47 \%)$ under similar conditions.

3D hierarchical $\mathrm{FeSe}_{2}$ microspheres using a hot-injection method were prepared and studied by Huang et al. ${ }^{303}$ The morphologies of the $\mathrm{FeSe}_{2}$ nanomaterials was controlled by the use of alkyl thiols; 1-dodecanethiol (1-DDT) or tert-dodecanethiol ( $t$-DDT) and their contents were used in synthesis, which varied from irregular $\mathrm{FeSe}_{2}$ micro/nanoparticles to $3 \mathrm{D}$ hierarchical $\mathrm{FeSe}_{2}$ microspheres and consisted of ultrathin $\mathrm{FeSe}_{2}$ nanosheets or urchin-like microspheres made of crystalline $\mathrm{FeSe}_{2}$ nanorods having an average diameter of $650 \mathrm{~nm}$. The $\mathrm{FeSe}_{2}$ nanomaterials were used as CEs for DSSCs. 3D hierarchical $\mathrm{FeSe}_{2}$ microspheres made of ultrathin $\mathrm{FeSe}_{2}$ nanosheets showed the lowest $R_{\mathrm{CT}}$ of $0.49 \Omega \mathrm{cm}^{2}$ at the electrolyte/electrode interface, a lower $Z_{\mathrm{N}}$ value of $0.39 \Omega \mathrm{cm}^{2}$, and faster reaction kinetics for the reduction of $\mathrm{I}_{3}{ }^{-}$to $\mathrm{I}^{-}$than that of a Pt CE $\left(R_{\mathrm{CT}}\right.$ of $1.15 \Omega \mathrm{cm}^{2}$ and $Z_{\mathrm{N}}$ value of $0.91 \Omega \mathrm{cm}^{2}$ ). $R_{\mathrm{CT}}$ values followed the relative order of $\mathrm{FeSe}_{2}$ microparticles $<\mathrm{FeSe}_{2}$ nanorods $<\mathrm{Pt}<$ $\mathrm{FeSe}_{2}$ nanosheets, as supported by EIS measurements. A DSSC with a $\mathrm{FeSe}_{2}$ nanosheets CE exhibited a PCE of $8.39 \%$, slightly better than that of a Pt CE $(8.20 \%)$ under simulated solar illumination of $100 \mathrm{~mW} \mathrm{~cm} \mathrm{~cm}^{-2}$ (AM 1.5). $\mathrm{FeSe}_{2}$ nanorods showed a PCE value of $8.03 \%$, higher than that of $\mathrm{FeSe}_{2}$ microparticles (7.68\%). The PCE value of DSSCs is morphology dependent, where the $\mathrm{FeSe}_{2}$ nanosheets $\mathrm{CE}$ has a high electrocatalytic activity and a larger specific surface area $\left(30.03 \mathrm{~m}^{2} \mathrm{~g}^{-1}\right)$ than that of $\mathrm{FeSe}_{2}$ nanorods $\left(19.82 \mathrm{~m}^{2} \mathrm{~g}^{-1}\right)$. The FeSe 2 nanosheets CE based DSSC retained $99.5 \%$ of its initial photocurrent density, compared to $98.3 \%$ retained by the Pt CE, after simulated solar illumination of $100 \mathrm{~mW} \mathrm{~cm} \mathrm{~cm}^{-2}$ for 1 hour, and this indicates better stability of the $\mathrm{FeSe}_{2}$ nanosheets $\mathrm{CE}$ than that of standard Pt CE. Also, the 3D flower-like and sphere-shaped $\mathrm{FeSe}_{2}$ films were used as CEs for DSSCs. ${ }^{304}$ The 3D flower-like $\mathrm{FeSe}_{2}$-based CE exhibited a comparable PCE to a Pt CE $(\eta=8.00 \%$ versus $7.87 \%)$.

\section{6 $\mathrm{CoSe}_{2}$ counter electrodes}

Cobalt diselenide $\left(\mathrm{CoSe}_{2}\right)$ has been extensively studied as a catalyst for oxygen reduction reactions. ${ }^{305-308}$ The $\mathrm{CoSe}_{2}$ 
(a)

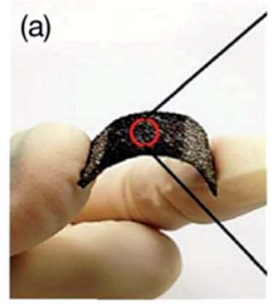

(e)

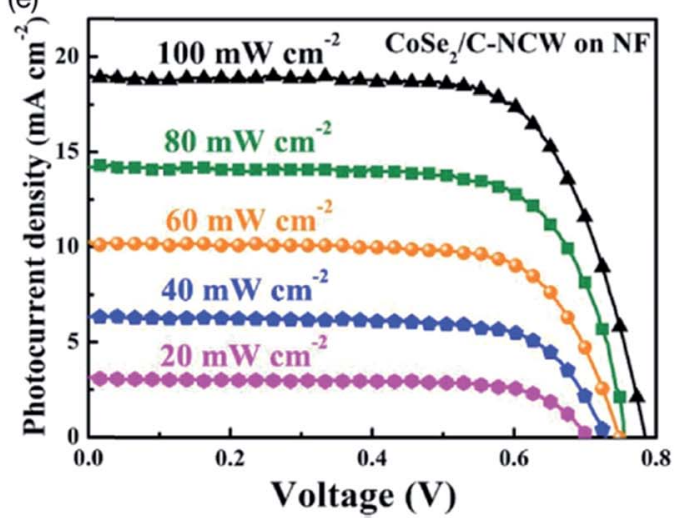

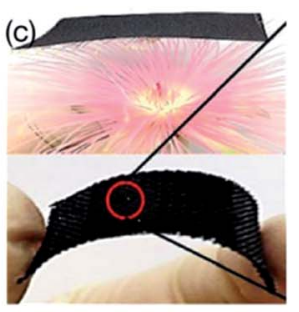

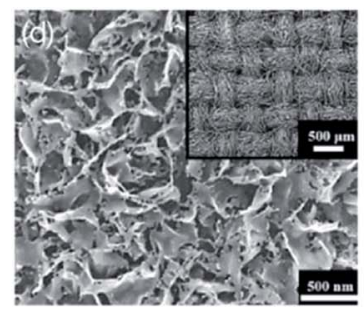

(f)

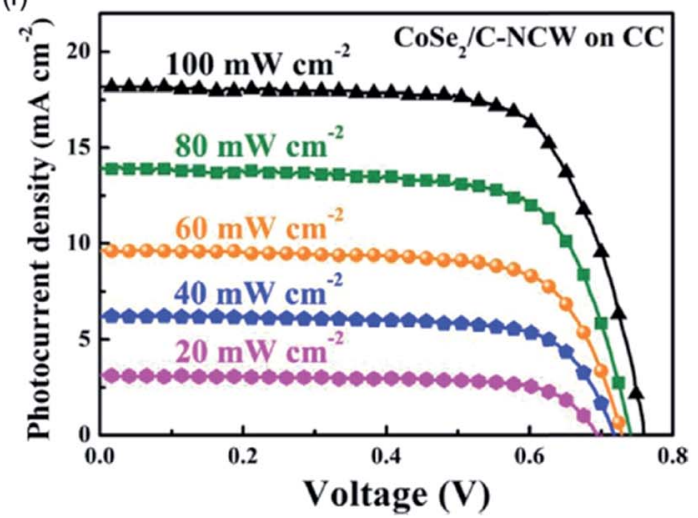

Fig. 26 (a) Photograph of the nickel foam (NF) and (b) SEM image of $\mathrm{CoSe}_{2} / \mathrm{C}-\mathrm{NCW}$ film on the nickel foam (NF). (c) Photograph of the carbon cloth (CC) and thin CC substrate on a soft flower having needle-like petals and (d) SEM image of CoSe $2 / C-N C W$ film on carbon cloth (CC). Inset shows field-emission scanning electron microscopy (FE-SEM) images in a magnified version. (e) Photocurrent-voltage ( $J-V$ ) curves of the DSSCs with $\mathrm{CoSe}_{2} / \mathrm{C}-\mathrm{NCW}$ on flexible nickel foam (NF) CE, measured at light intensities varying from $20 \mathrm{~mW} \mathrm{~cm}^{-2}$ (0.2 Sun) to $100 \mathrm{~mW} \mathrm{~cm}{ }^{-2}$ (1 Sun). (f) Photocurrent-voltage $(J-V)$ curves of the DSSCs with $\mathrm{CoSe}_{2} / \mathrm{C}-\mathrm{NCW}$ on flexible carbon cloth (CC) CE, under similar light intensities. Reprinted with permission from ref. 310, I. T. Chiu, C. T. Li, C. P. Lee, P. Y. Chen, Y. H. Tseng, R. Vittal and K. C. Ho, nanoclimbing-wall-like CoSe 2 /carbon composite film for the counter electrode of a highly efficient dye-sensitized solar cell: a study on the morphology control. Nano Energy, 2016, 22, 594-606. Copyright@ Elsevier.

nanorods synthesized by a hydrothermal method was studied as CEs for DSSCs. ${ }^{309}$ FESEM revealed a $\mathrm{CoSe}_{2}$ nanorod morphology of the $\mathrm{CoSe}_{2}$, which supports carrier transport from the surface of the nanorods to the redox electrolyte. The $\mathrm{CoSe}_{2} \mathrm{CE}$ also exhibited larger current density compared with a Pt $\mathrm{CE}$, as measured by CV. EIS shows an $R_{\mathrm{S}}$ of $8.034 \Omega \mathrm{cm}^{2}$ and a low $R_{\mathrm{CT}}$ of $0.097 \Omega \mathrm{cm}^{2}$ for the $\mathrm{CoSe}_{2}$ CE. The DSSC with a $\mathrm{CoSe}_{2}$ CE showed a PCE value of $8.38 \%$, higher than the DSSC based on a Pt CE ( $\eta=7.83 \%)$, under simulated sunlight illumination of $100 \mathrm{~mW} \mathrm{~cm} \mathrm{~cm}^{-2}$ (AM 1.5G).

A comprehensive and detailed study was conducted by Chiu et al. ${ }^{310}$ on composite films of $\mathrm{CoSe}_{2} /$ carbon $\left(\mathrm{CoSe}_{2} / \mathrm{C}\right)$ deposited on FTO substrates having three different morphologies, developed using electro-deposition, followed by an annealing process at $500{ }^{\circ} \mathrm{C}$ for 30 minutes in vacuum. In the first stage, three types of $\mathrm{CoSe}_{2} /$ carbon films containing nanowalls were deposited with an electro-deposition process employing different $\mathrm{pH}$ baths, while in the second stage, the morphology of the films was transformed after the annealing. The N719 dye-adsorbed $\mathrm{TiO}_{2}$ film was used as a photoanode for DSSCs. CoSe $/$ C films had three different morphologies, including nanograin (NG), nanorock (NR), and nanoclimbing-wall (NCW), which were used as CEs for DSSCs. The electrocatalytic activity of these three CEs was analyzed by CV, RDE, Tafel polarization curves, and EIS, which showed a relative order of $\mathrm{CoSe}_{2} / \mathrm{C}-\mathrm{NCW}>\mathrm{CoSe}_{2} / \mathrm{C}-\mathrm{NG}>$ $\mathrm{Pt}>\mathrm{CoSe}_{2} / \mathrm{C}-\mathrm{NR}$ as CEs in the DSSCs, a similar order as was observed for the $R_{\mathrm{CT}}$ values obtained by EIS and Tafel measurements. The $\mathrm{CoSe}_{2} / \mathrm{C}-\mathrm{NCW}$ showed higher electrical conductivity and a large effective surface area and, therefore, the best electrocatalytic ability for triiodide $\left(\mathrm{I}_{3}{ }^{-}\right)$reduction. The DSSCs with $\mathrm{CoSe}_{2} / \mathrm{C}-\mathrm{NG}, \mathrm{CoSe}_{2} / \mathrm{C}-\mathrm{NCR}, \mathrm{CoSe}_{2} / \mathrm{C}-\mathrm{NCW}$, and Pt CEs exhibited IPCE values between $80-95 \%$ in the 400 to $600 \mathrm{~nm}$ wavelength region, where the highest IPCE value of 95\% was observed for the $\mathrm{CoSe}_{2} / \mathrm{C}-\mathrm{NCW}$ CE. The DSSC having a $\mathrm{CoSe}_{2} / \mathrm{C}-\mathrm{NCW}$ CE showed the highest PCE value of $8.92 \%$, even higher than compared with the Pt CE (8.25\%). The $\mathrm{CoSe}_{2} /$ C-NCW CEs were electro-deposited onto low-cost, flexible, and highly porous substrates, such as carbon cloth (CC, sheet resistance $=0.63 \Omega \mathrm{sq}^{-1}$ ) and nickel foam (NF, porosity $=95 \%$, sheet resistance $\left.=0.45 \Omega \mathrm{sq}^{-1}\right)$. Fig. 26 shows photographs of the flexible nickel foam (NF) and carbon cloth (CC), SEM images of $\mathrm{CoSe}_{2} / \mathrm{C}-\mathrm{NCW}$ film on the flexible NF and CC substrates, and $J-V$ curves of the DSSCs, with $\mathrm{CoSe}_{2} / \mathrm{C}-\mathrm{NCW}$ on NF and CC CEs measured at different light intensities $\left(20-100 \mathrm{~mW} \mathrm{~cm}^{-2}\right)$. The $\mathrm{CoSe}_{2} /$ carbon-NCW CEs shell covered all the minute parts of the carbon cloth and nickel foam core shell structures. The DSSC containing the $\mathrm{CE}$ with $\mathrm{CoSe}_{2} / \mathrm{C}-\mathrm{NCW}$ deposited on nickel foam exhibited the highest PCE of $10.46 \%$ at $100 \mathrm{~mW} \mathrm{~cm}^{-2}(1$ Sun) and $7.90 \%$ at $20 \mathrm{~mW} \mathrm{~cm}^{-2}$ (0.2 Sun). The DSSC with the CE of $\mathrm{CoSe}_{2} / \mathrm{C}-\mathrm{NCW}$ deposited on low-weight carbon cloth showed a PCE of $9.87 \%$ at 1 Sun and $7.83 \%$ at 0.2 Sun. The low cost and flexible $\mathrm{CoSe}_{2} / \mathrm{C}-\mathrm{NCW}$ CEs seem to be promising materials to 
Table 4 Photovoltaic parameters of $\mathrm{MoSe}_{2}, \mathrm{WSe}_{2}, \mathrm{TaSe}_{2}, \mathrm{NbSe}_{2}, \mathrm{FeSe}_{2}, \mathrm{CoSe}_{2}$ and $\mathrm{Bi}_{2} \mathrm{Se}_{3}$ based CEs for DSSCs. FTO glass is the common substrate used in assembling the DSSCs with different CE materials. The measurements were conducted at a simulated solar light intensity of 100 $\mathrm{mW} \mathrm{cm}{ }^{-2}$ (AM 1.5G) unless specified. The photovoltaic parameters short-circuit photocurrent density $\left(J_{\mathrm{sc}}\right)$, open-circuit voltage $\left(V_{\mathrm{oc}}\right)$, fill factor $(\mathrm{FF})$, and power conversion efficiency $(\eta)$, series resistance $\left(R_{\mathrm{S}}\right)$, charge-transfer resistance $\left(R_{\mathrm{CT}}\right)$, electrolyte and dye used for DSSCs are summarized and compared with a standard $\mathrm{Pt} \mathrm{CE}^{a}$

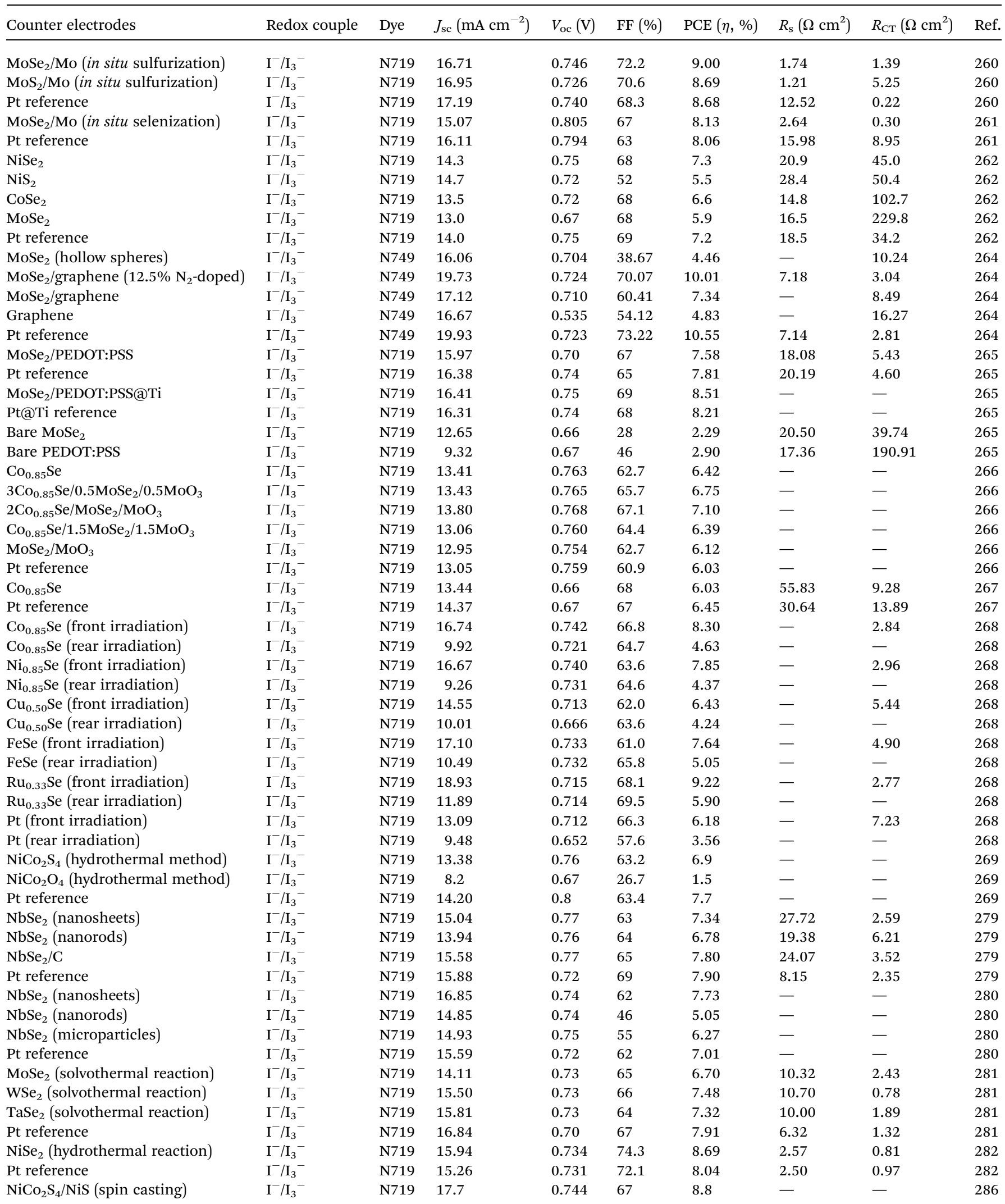


Table 4 (Contd.)

\begin{tabular}{|c|c|c|c|c|c|c|c|c|c|}
\hline Counter electrodes & Redox couple & Dye & $J_{\mathrm{sc}}\left(\mathrm{mA} \mathrm{cm}{ }^{-2}\right)$ & $V_{\mathrm{oc}}(\mathrm{V})$ & $\mathrm{FF}(\%)$ & $\operatorname{PCE}(\eta, \%)$ & $R_{\mathrm{s}}\left(\Omega \mathrm{cm}^{2}\right)$ & $R_{\mathrm{CT}}\left(\Omega \mathrm{cm}^{2}\right)$ & Ref. \\
\hline $\mathrm{NiCo}_{2} \mathrm{~S}_{4}$ (spin casting) & $\mathrm{I}^{-} / \mathrm{I}_{3}^{-}$ & N719 & 17.4 & 0.743 & 66 & 8.5 & - & - & 286 \\
\hline $\mathrm{Co}_{9} \mathrm{~S}_{8}$ (spin casting) & $\mathrm{I}^{-} / \mathrm{I}_{3}^{-}$ & N719 & 16.2 & 0.741 & 64 & 7.7 & - & - & 286 \\
\hline Pt reference & $\mathrm{I}^{-} / \mathrm{I}_{3}^{-}$ & N719 & 16.5 & 0.736 & 67 & 8.1 & - & - & 286 \\
\hline $\mathrm{Ni}_{0.33} \mathrm{Co}_{0.67} \mathrm{Se}$ & $\mathrm{I}^{-} / \mathrm{I}_{3}^{-}$ & N719 & 17.29 & 0.789 & 67 & 9.01 & 30.40 & 1.11 & 287 \\
\hline $\mathrm{Ni}_{0.5} \mathrm{Co}_{0.5} \mathrm{Se}$ & $\mathrm{I}^{-} / \mathrm{I}_{3}^{-}$ & N719 & 16.42 & 0.783 & 69 & 8.80 & 30.38 & 1.50 & 287 \\
\hline NiSe & $\mathrm{I}^{-} / \mathrm{I}_{3}^{-}$ & N719 & 14.54 & 0.783 & 64 & 7.23 & 29.87 & 13.88 & 287 \\
\hline Pt reference & $\mathrm{I}^{-} / \mathrm{I}_{3}^{-}$ & N719 & 15.33 & 0.791 & 69 & 8.30 & 30.30 & 2.88 & 287 \\
\hline $\mathrm{FeSe}_{2}$ (nanosheets, under $\mathrm{N}_{2}$ ) & $\mathrm{I}^{-} / \mathrm{I}_{3}^{-}$ & N719 & 17.49 & 0.718 & 60 & 7.53 & 8.07 & 0.53 & 302 \\
\hline $\mathrm{FeSe}_{2}$ (nanosheets, air exposed) & $\mathrm{I}^{-} / \mathrm{I}_{3}^{-}$ & N719 & 15.51 & 0.708 & 56 & 6.15 & 10.13 & 6.26 & 302 \\
\hline $\mathrm{FeSe}_{2}$ (microparticles) & $\mathrm{I}^{-} / \mathrm{I}_{3}^{-}$ & N719 & 16.32 & 0.715 & 59 & 6.88 & 8.51 & 4.10 & 302 \\
\hline Pt reference & $\mathrm{I}^{-} / \mathrm{I}_{3}^{-}$ & N719 & 17.77 & 0.725 & 58 & 7.47 & 7.94 & 1.68 & 302 \\
\hline $\mathrm{FeSe}_{2}$ (3D flower-like) & $\mathrm{I}^{-} / \mathrm{I}_{3}^{-}$ & N719 & 14.93 & 0.744 & 72.1 & 8.00 & 16.82 & 0.53 & 304 \\
\hline $\mathrm{FeSe}_{2}$ (sphere-shaped) & $\mathrm{I}^{-} / \mathrm{I}_{3}^{-}$ & N719 & 14.60 & 0.724 & 69.8 & 7.38 & 27.05 & 0.96 & 304 \\
\hline Pt reference & $\mathrm{I}^{-} / \mathrm{I}_{3}^{-}$ & N719 & 15.13 & 0.741 & 70.2 & 7.87 & 17.01 & 0.78 & 304 \\
\hline $\mathrm{CoSe}_{2}$ (hydrothermal, $140^{\circ} \mathrm{C}$ ) & $\mathrm{I}^{-} / \mathrm{I}_{3}^{-}$ & N719 & 16.65 & 0.750 & 64.4 & 8.04 & 8.783 & 0.132 & 309 \\
\hline $\mathrm{CoSe}_{2}$ (hydrothermal, $160^{\circ} \mathrm{C}$ ) & $\mathrm{I}^{-} / \mathrm{I}_{3}^{-}$ & N719 & 17.04 & 0.743 & 66.2 & 8.38 & 8.034 & 0.097 & 309 \\
\hline $\mathrm{CoSe}_{2}$ (hydrothermal, $180^{\circ} \mathrm{C}$ ) & $\mathrm{I}^{-} / \mathrm{I}_{3}^{-}$ & N719 & 15.44 & 0.750 & 63.9 & 7.40 & 15.17 & 0.932 & 309 \\
\hline Pt reference & $\mathrm{I}^{-} / \mathrm{I}_{3}^{-}$ & N719 & 16.88 & 0.743 & 62.4 & 7.83 & 12.86 & 1.923 & 309 \\
\hline $\mathrm{CoSe}_{2} / \mathrm{C}-\mathrm{NG}$ & $\mathrm{I}^{-} / \mathrm{I}_{3}^{-}$ & N719 & 17.51 & 0.73 & 67 & 8.41 & 20.6 & 0.85 & 310 \\
\hline $\mathrm{CoSe}_{2} / \mathrm{C}-\mathrm{NR}$ & $\mathrm{I}^{-} / \mathrm{I}_{3}^{-}$ & N719 & 15.98 & 0.73 & 67 & 7.83 & 20.6 & 1.16 & 310 \\
\hline $\mathrm{CoSe}_{2} / \mathrm{C}-\mathrm{NCW}$ & $\mathrm{I}^{-} / \mathrm{I}_{3}^{-}$ & N719 & 18.03 & 0.73 & 67 & 8.92 & 20.6 & 0.52 & 310 \\
\hline $\mathrm{CoSe}_{2} / \mathrm{C}-\mathrm{NCW}$ on nickel foam & $\mathrm{I}^{-} / \mathrm{I}_{3}^{-}$ & N719 & 18.86 & 0.78 & 71 & 10.46 & - & - & 310 \\
\hline $\mathrm{CoSe}_{2} / \mathrm{C}-\mathrm{NCW}$ on carbon cloth & $\mathrm{I}^{-} / \mathrm{I}_{3}^{-}$ & N719 & 18.16 & 0.76 & 71 & 9.87 & - & - & 310 \\
\hline $\mathrm{Bi}_{2} \mathrm{Se}_{3}$ nanoparticles & $\mathrm{I}^{-} / \mathrm{I}_{3}^{-}$ & N719 & 7.02 & 0.55 & 46 & 1.86 & - & - & 325 \\
\hline $\mathrm{Bi}_{2} \mathrm{Se}_{3} /$ graphene (40 mg) & $\mathrm{I}^{-} / \mathrm{I}_{3}^{-}$ & N719 & 15.42 & 0.78 & 50 & 6.35 & - & - & 325 \\
\hline $\mathrm{Bi}_{2} \mathrm{Se}_{3} /$ graphene ( $\left.60 \mathrm{mg}\right)$ & $\mathrm{I}^{-} / \mathrm{I}_{3}^{-}$ & N719 & 16.36 & 0.75 & 57 & 7.09 & - & - & 325 \\
\hline $\mathrm{Bi}_{2} \mathrm{Se}_{3} /$ graphene $(80 \mathrm{mg})$ & $\mathrm{I}^{-} / \mathrm{I}_{3}^{-}$ & N719 & 16.01 & 0.76 & 53 & 6.66 & - & - & 325 \\
\hline Pt reference & $\mathrm{I}^{-} / \mathrm{I}_{3}^{-}$ & N719 & 15.65 & 0.68 & 59 & 6.47 & - & - & 325 \\
\hline $\mathrm{ZnO}$ (photoanode) & $\mathrm{I}^{-} / \mathrm{I}_{3}^{-}$ & N719 & 8.189 & 0.656 & 55.2 & 2.96 & 16.6 & 7.23 & 335 \\
\hline $\mathrm{Bi}_{2} \mathrm{Te}_{3} / \mathrm{ZnO}$ (photoanode) & $\mathrm{I}^{-} / \mathrm{I}_{3}^{-}$ & N719 & 11.767 & 0.637 & 57.0 & 4.27 & 15.8 & 3.75 & 335 \\
\hline
\end{tabular}

${ }^{a}$ Nanograin (NG), nanorock (NR), nanoclimbing-wall (NCW), nickel foam (NF), carbon cloth (CC), rGO = reduced graphene oxide. In the case of $R_{\mathrm{S}}$ and $R_{\mathrm{CT}}$ : some of the authors used $\Omega$ instead of $\Omega \mathrm{cm}^{2}$ for the resistances without mentioning the size of the electrode.

replace expensive Pt CEs for DSSCs for indoor, outdoor or wearable applications.

$\mathrm{CoSe}_{2}$ and RGO composites were also explored as CEs in DSSCs, which showed a PCE of $7.01 \%$ versus a Pt CE $(\eta=$ $6.77 \%) .{ }^{311} \mathrm{Co}_{0.85} \mathrm{Se}$ and $\mathrm{Ni}_{0.85} \mathrm{Se}$ was deposited on FTO glass substrate by a low-temperature hydrothermal process and were used as CEs for DSSCs by Gong et al. ${ }^{312} \mathrm{Co}_{0.85}$ Se has a graphenelike nanostructure and possesses a large surface area, while $\mathrm{Ni}_{0.85} \mathrm{Se}$ is composed of aggregated particles. The graphene-like $\mathrm{Co}_{0.85} \mathrm{Se} \mathrm{CE}$ showed higher electrocatalytic activity than that of the Pt CE for the reduction of triiodide $\left(\mathrm{I}_{3}{ }^{-}\right)$. DSSCs with $\mathrm{Co}_{0.85}$ Se CEs showed a PCE of $9.40 \%$, significantly higher than that of a Pt CE (8.64\%), under simulated solar light of $100 \mathrm{~mW}$ $\mathrm{cm}^{-2}$ (AM 1.5G). In the case of the $\mathrm{Ni}_{0.85} \mathrm{Se} \mathrm{CE}$, the PCE of $8.32 \%$ was slightly lower than a Pt CE. Both $J_{\text {sc }}$ and PCE values showed a relative order of $\mathrm{Ni}_{0.85} \mathrm{Se}<\mathrm{Pt}<\mathrm{Co}_{0.85} \mathrm{Se}$. The $R_{\mathrm{CT}}$ value was found to increase in the relative order $\mathrm{Co}_{0.85} \mathrm{Se}\left(0.6 \Omega \mathrm{cm}^{2}\right)<\mathrm{Pt}$ $\left(1.1 \Omega \mathrm{cm}^{2}\right)<\mathrm{Ni}_{0.85} \mathrm{Se}\left(1.8 \Omega \mathrm{cm}^{2}\right)$, suggesting an inverse order of electrocatalytic activity of these CEs in the DSSCs. Table 4 summarizes the photovoltaic parameters of $\mathrm{MoSe}_{2}, \mathrm{WSe}_{2}$, 
$\mathrm{TaSe}_{2}, \mathrm{NbSe}_{2}, \mathrm{FeSe}_{2}, \mathrm{CoSe}_{2}$ and $\mathrm{Bi}_{2} \mathrm{Se}_{3}$ based CEs for DSSCs, and their comparison with a standard Pt CE.

\section{7 $\quad \mathrm{Bi}_{2} \mathrm{Se}_{3}$ counter electrodes}

Bismuth selenide $\left(\mathrm{Bi}_{2} \mathrm{Se}_{3}\right)$ and bismuth telluride $\left(\mathrm{Bi}_{2} \mathrm{Te}_{3}\right)$ have been previously studied as topological insulators. ${ }^{313,314} \mathrm{Bi}_{2} \mathrm{Se}_{3}$, a semiconducting and thermoelectric material, can be processed into single layers, nanosheets, nanotubes, nanoribbons, and nanowires ${ }^{315-318}$ and has applications in field-effect transistors, ${ }^{319}$ sensors, ${ }^{320}$ non-volatile memory devices, ${ }^{321}$ photovoltaic devices, ${ }^{322}$ and drug delivery and anti-cancer therapy. ${ }^{323,324}$ $\mathrm{Bi}_{2} \mathrm{Se}_{3} / \mathrm{RGO}$ nanocomposites were prepared by a microwaveassisted hydrothermal method as a CE for a DSSC by Zhu et $a l .{ }^{325}$ Fig. 27 shows the TEM images of the graphene nanosheets, $\mathrm{Bi}_{2} \mathrm{Se}_{3}$ nanospheres and $\mathrm{Bi}_{2} \mathrm{Se}_{3}$ /graphene nanocomposites containing $60 \mathrm{mg}$ graphene contents. The TEM images showed that $10-15 \mathrm{~nm} \mathrm{Bi}_{2} \mathrm{Se}_{3}$ nanoparticles were attached onto graphene nanosheets. SEM images showed that the graphene had a flake-like structure while the $\mathrm{Bi}_{2} \mathrm{Se}_{3}$ nanoparticles were large size spheres. Furthermore, the surface of the graphene oxide was found to be very smooth in comparison with graphene nanosheets doped with $\mathrm{Bi}_{2} \mathrm{Se}_{3}$ nanoparticles. The inclusion of $\mathrm{Bi}_{2} \mathrm{Se}_{3}$ nanoparticles onto graphene nanosheets was controlled to achieve high electrocatalytic activity of the $\mathrm{CE}$ for the reduction of triiodide $\left(\mathrm{I}_{3}{ }^{-}\right)$. The DSSC with a $\mathrm{Bi}_{2} \mathrm{Se}_{3} /$ graphene $(60 \mathrm{mg}) \mathrm{CE}$ yielded a high PCE of $7.09 \%$, which is comparable to a Pt CE $(\eta=6.23 \%)$. The $\mathrm{Bi}_{2} \mathrm{Se}_{3}$ /graphene nanocomposite CEs with $40 \mathrm{mg}$ and $80 \mathrm{mg}$ graphene content showed PCE values of $6.35 \%$ and $6.66 \%$ for the DSSCs, respectively, which was much higher than that of pure $\mathrm{Bi}_{2} \mathrm{Se}_{3} \mathrm{CE}$ $(\eta=1.86 \%)$, but still comparable to a Pt CE.

\section{5. $\mathrm{Bi}_{2} \mathrm{Te}_{3}$ based photoanodes}

Bismuth telluride $\left(\mathrm{Bi}_{2} \mathrm{Te}_{3}\right)$ has been studied for thermoelectric applications and can be processed into nanowires arrays, ${ }^{\text {326-329 }}$ nanotubes, ${ }^{330}$ nanoplates, ${ }^{331}$ nanosheets, ${ }^{332,333}$ and thin films. ${ }^{334}$ Dou et al. ${ }^{335}$ developed hybrid photoanodes by dispersing $\mathrm{Bi}_{2} \mathrm{Te}_{3}$ nanotubes into $\mathrm{ZnO}$ nanoparticles. The $0.5,1.0,1.5,2.0$, and $2.5 \mathrm{wt} \%$ of highly crystalline $\mathrm{Bi}_{2} \mathrm{Te}_{3}$ nanotubes were mixed with $\mathrm{ZnO}$ nanoparticles to fabricate photoanodes for DSSCs. Pt films deposited on FTO glass was used as a CE. The electrolyte consisted of $0.05 \mathrm{M} \mathrm{I}_{2}, 0.5 \mathrm{M} \mathrm{LiI}$, and $0.1 \mathrm{M}$ 4-tert-butylpyridine in acetonitrile-propylene carbonate $(1: 1)$ solution. In the $\mathrm{Bi}_{2} \mathrm{Te}_{3} / \mathrm{ZnO}$ hybrid, $\mathrm{Bi}_{2} \mathrm{Te}_{3}$ nanotubes provided a conduction pathway which facilitated electron transfer. The $J_{\text {sc }}$ value increased gradually with increasing $\mathrm{Bi}_{2} \mathrm{Te}_{3}$ nanotubes content up to $1.5 \mathrm{wt} \%$ (11.767 $\mathrm{mA} \mathrm{cm}{ }^{-2}$ ) and then started decreasing as the $\mathrm{Bi}_{2} \mathrm{Te}_{3}$ nanotubes content exceeded $2.0 \mathrm{wt} \%\left(9.957 \mathrm{~mA} \mathrm{~cm}^{-2}\right)$, due to the low dye loading on the surface of $\mathrm{ZnO}$ nanoparticles. A similar trend was observed for the PCE values. The DSSCs with

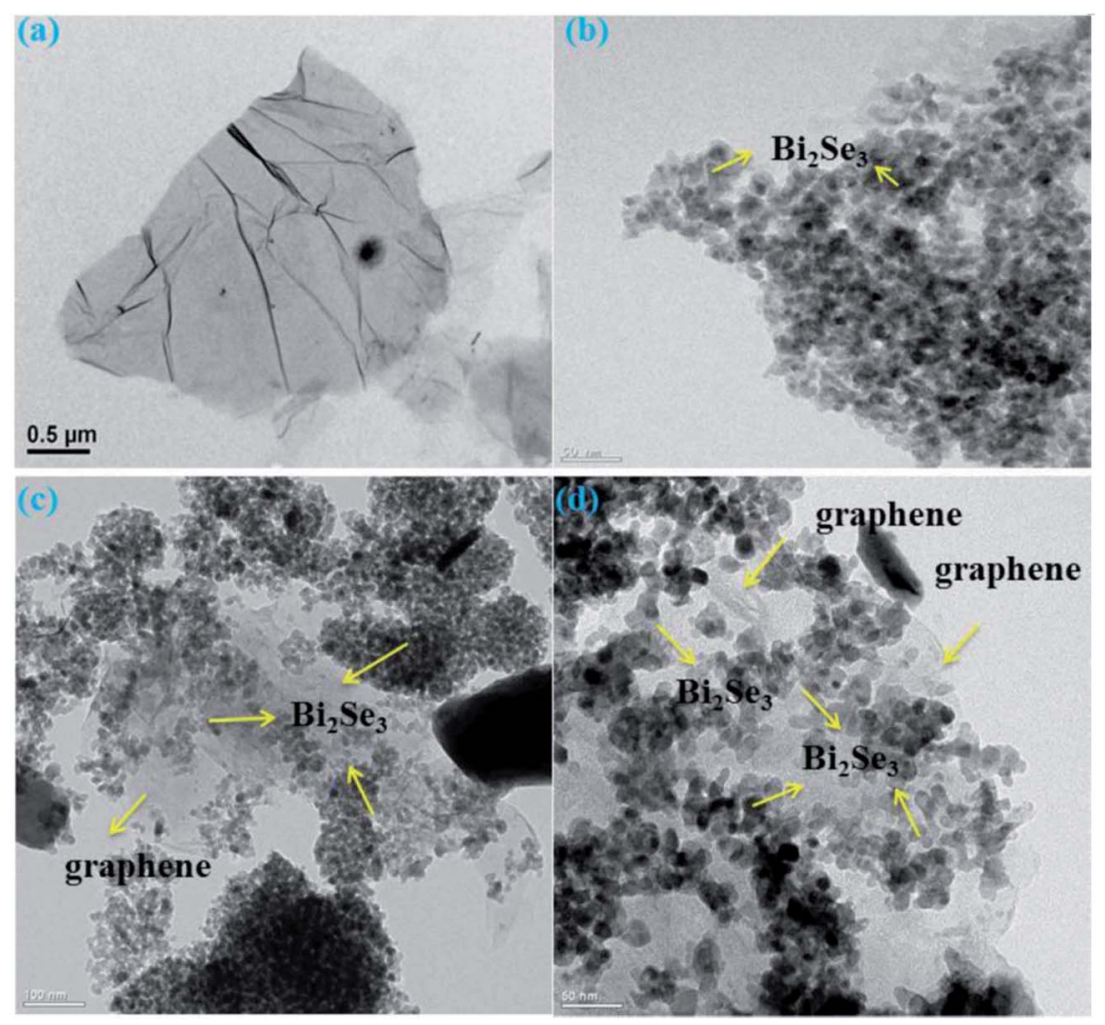

Fig. 27 TEM images of (a) graphene nanosheet, (b) $\mathrm{Bi}_{2} \mathrm{Se}_{3}$ nanospheres (c) and (d) $\mathrm{Bi}_{2} \mathrm{Se}_{3} /$ graphene nanocomposite (60 mg graphene). Reprinted with permission from ref. 325, L. Zhu, K. Y. Cho and W. C. Oh, microwave-assisted synthesis of $\mathrm{Bi}_{2} \mathrm{Se}_{3} /$ reduced graphene oxide nanocomposite as efficient catalytic counter electrode for dye-sensitized solar cell, Fullerenes, Nanotubes, Carbon Nanostruct., 2016, 24, 622-629. Copyright $\odot$ Taylor \& Francis Group. 
a $\mathrm{Bi}_{2} \mathrm{Te}_{3} / \mathrm{ZnO}$ composite photoanode containing $1.5 \mathrm{wt} \%$ $\mathrm{Bi}_{2} \mathrm{Te}_{3}$ nanotubes in the $\mathrm{ZnO}$ photoanode showed a PCE of $4.27 \%$, which is $44.3 \%$ higher compared with a pure $\mathrm{ZnO}$ photoanode. The PCE values were $2.96 \%$ for the bare $\mathrm{ZnO}$ photoanode, and 3.74, 3.96, 4.27, 3.41 and $3.01 \%$ for the 0.5 , 1.0, 1.5, 2.0 and $2.5 \mathrm{wt} \% \mathrm{Bi}_{2} \mathrm{Te}_{3}$ nanotubes content photoanodes, respectively. This study indicated that loading of thermoelectric $\mathrm{Bi}_{2} \mathrm{Te}_{3}$ in a $\mathrm{ZnO}$ photoanode improves the photovoltaic performance of DSSCs. Wan et al. ${ }^{336}$ prepared hexagonal $\mathrm{Bi}_{2} \mathrm{Te}_{3}$ nanosheets of 300-400 nm length by a hydrothermal method. The nanocomposites of the $\mathrm{Bi}_{2} \mathrm{Te}_{3}$ nanosheets and $\mathrm{ZnO}$ nanoparticles were used as photoanodes for DSSCs, where the $\mathrm{Bi}_{2} \mathrm{Te}_{3}$ nanosheet concentration was varied from 0 to $0.25 \mathrm{wt} \%$. The DSSCs with $0.15 \mathrm{wt} \%$ of $\mathrm{Bi}_{2} \mathrm{Te}_{3}$ nanosheets in the $\mathrm{Bi}_{2} \mathrm{Te}_{3}$ nanosheet/ZnO nanoparticle composite photoanode showed a PCE of $4.10 \%$, which was improved by $46.95 \%$ compared with the bare $\mathrm{ZnO}$ photoanode. The thermoelectric $\mathrm{Bi}_{2} \mathrm{Te}_{3}$ nanosheets in the composite photoanode helped in enhancing the electron density and reducing the temperature of the DSSCs. The $\mathrm{Bi}_{2} \mathrm{Te}_{3}$ nanosheet/ZnO nanoparticles composite photoanode significantly improved the DSSC performance. A thermoelectric $\mathrm{Bi}_{2} \mathrm{Te}_{3} / \mathrm{TiO}_{2}$ composite based photoanode was also used for DSSCs, where $\mathrm{Bi}_{2} \mathrm{Te}_{3}$ nanoplates help in converting heat into electricity and enhanced the rate of charge transfer. ${ }^{337}$ This resulted in a $28 \%$ increase of the PCE of the DSSC. The $\mathrm{Bi}_{2} \mathrm{Te}_{3}$ nanoplates have also been used for doping $\mathrm{TiO}_{2}$ photoanodes. ${ }^{338}$ The effect of $\mathrm{Bi}_{2} \mathrm{Te}_{3}$ nanoplates size was evaluated for DSSCs, where a decrease in the size of the $\mathrm{Bi}_{2} \mathrm{Te}_{3}$ nanoplates led to and higher PCE. The performance of DSSCs with a $\mathrm{Bi}_{2} \mathrm{Te}_{3} / \mathrm{TiO}_{2}$ photoanode increased by $15.3 \%$ compared to the undoped $\mathrm{TiO}_{2}$ photoanode.

\section{Long-term stability of TMDs based DSSCs}

The long-term stability of DSSCs is one of the most important parameters for commercial applications. The stability of DSSC devices depends upon a number of factors and the components used in their fabrication. The decrease in power conversion efficiency of a DSSC can be associated with the stability of different electrolyte components, photosensitizing dyes, aging of the $\mathrm{TiO}_{2}$ photoanode, degradation of the CE (cathode), corrosion of components by electrolytes, sealant, leakage, exposure to solar irradiation, high humidity, and elevated temperature..$^{339-349}$

A few research reports have been published on the long-term stability of TMDs based DSSCs which are briefly discussed here. Infant et al. ${ }^{131}$ studied the stability of CVD-deposited vertically oriented $\mathrm{MoS}_{2}$ thin films on an FTO surface used as a CE in a DSSC. The electrochemical stability of a $\mathrm{MoS}_{2} \mathrm{CE}$ based DSSC was analyzed by CV measurements, where electrodes were repeatedly subjected to 20 cycles at a $10 \mathrm{mV} \mathrm{s}^{-1}$ scan rate for the $\mathrm{I}^{-} / \mathrm{I}_{3}{ }^{-}$redox couple in the electrolyte. The $\mathrm{MoS}_{2}$ based CE showed no significant change up to 20th consecutive cycle, whereas the Pt CE exhibited some changes between the cycles (Fig. 28). This confirms that CVD deposited $\mathrm{MoS}_{2}$ strongly adhered onto the surface of the FTO substrate. The stability of $\mathrm{MoS}_{2}$ CEs was measured under ambient conditions by storing them for 15 days, where the PCE remained at 94\% of its initial efficiency value, which was much higher than that of the Pt CE.

For preparing Pt-free dye-sensitized solar cells, Liu et al. ${ }^{\mathbf{3 5 0}}$ fabricated DSSCs using $\mathrm{MoS}_{2}$ and RGO composite as a CE for the reduction of triiodide $\left(\mathrm{I}_{3}{ }^{-}\right)$to iodide $\left(\mathrm{I}^{-}\right)$. AFM, XPS, and XRD confirmed the deposition of $\mathrm{MoS}_{2}$ nanoparticles onto the RGO surface. The CV measurement showed a higher current density for the $\mathrm{MoS}_{2} / \mathrm{RGO}$ nanocomposite based CE compared to RGO, $\mathrm{MoS}_{2}$, and Pt-sputtered CEs due to an increased surface area. The $\mathrm{MoS}_{2} / \mathrm{RGO} \mathrm{CE}$ also exhibited a low $R_{\mathrm{CT}}$ of $0.57 \Omega \mathrm{cm}^{2}$ for the reduction of triiodide $\left(\mathrm{I}_{3}{ }^{-}\right)$to iodide $\left(\mathrm{I}^{-}\right)$. The $\mathrm{MoS}_{2} / \mathrm{RGO}$ nanocomposite CE based DSSC showed a PCE of $6.04 \%$, comparable to a PCE of $6.38 \%$ for the conventional Pt CE. $\mathrm{MoS}_{2} /$ RGO nanocomposites based CEs also have better electrochemical stability, as no degradation in current densities was observed up to 100 repeated CV tests. The stability test conducted on a DSSC having $\mathrm{MoS}_{2} / \mathrm{RGO}$ nanocomposites as CES showed over $10 \%$ degradation in PCE over a period of 20 days, as depicted in (Fig. 29a). Therefore, $\mathrm{MoS}_{2} / \mathrm{RGO}$ nanocomposites based CEs were found to be stable both for environmental and consecutive electrochemical tests. $\mathrm{Li}$ et al. ${ }^{\mathbf{2 0 0}}$ prepared a composite film of $\mathrm{TiS}_{2} / \mathrm{PEDOT}$ :PSS on an ITO substrate as a CE
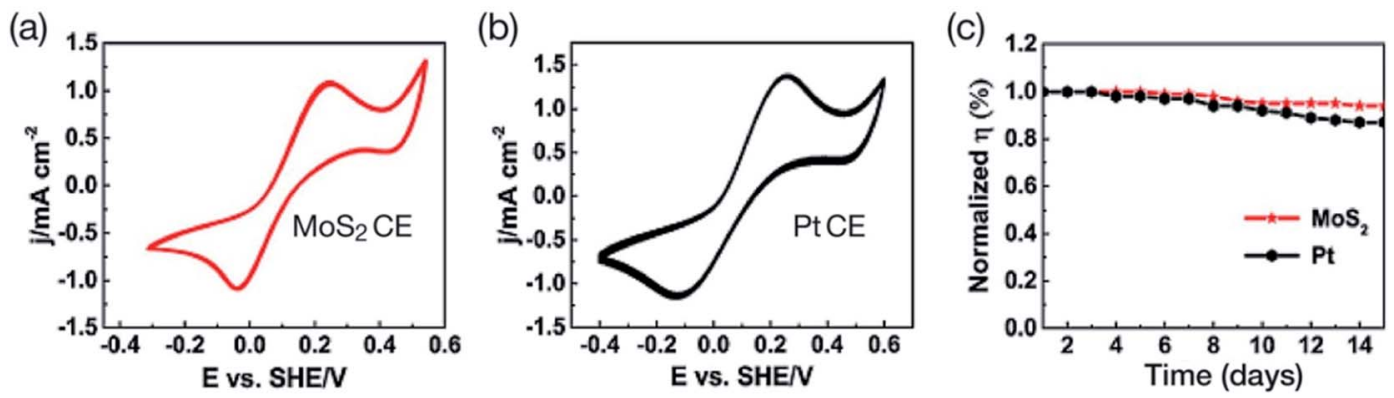

Fig. 28 Electrochemical properties of thin films of $\mathrm{MoS}_{2}$ prepared at $600{ }^{\circ} \mathrm{C}$ for 15 minutes. 20 consecutive cyclic voltammogram (CV) curve of $\mathrm{MoS}_{2}$ (a) and Pt (b) counter electrodes recorded at the scan rate of $10 \mathrm{mV} \mathrm{s}^{-1}$ and (c) PCE of MoS and Pt CEs based DSSCs measured for 15 days under ambient conditions. Reprinted with permission from ref. 131, R. S. Infant, X. Xu, W. Yang, F. Yang, L. Hou and Y. Li, highly active and reflective $\mathrm{MoS}_{2}$ counter electrode for enhancement of photovoltaic efficiency of dye sensitized solar cells. Electrochim. Acta, 2016, 212, 614-620. Copyright $\odot$ Elsevier. 

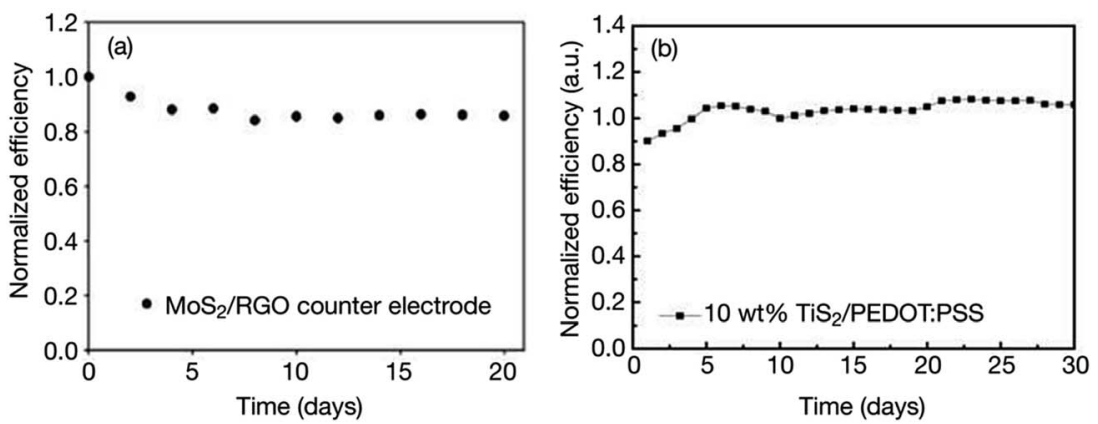

Fig. 29 (a) Stability of a DSSC with $\mathrm{MOS}_{2} /$ RGO based counter electrode recorded for 20 days. Reprinted with permission from ref. 350, C. J. Liu, S. Y. Tai, S. W. Chou, Y. C. Yu, K. D. Chang, S. Wang, F. S. S. Chien, J. Y. Lin and T. W. Lin, facile synthesis of MoS $2 /$ graphene nanocomposite with high catalytic activity toward triiodide reduction in dye-sensitized solar cells. J. Mater. Chem., 2015, 22, 21057-21064. Copyright@ Royal Society of Chemistry. (b) The long-term stability of the DSSCs with 10 wt\% TiS 2 /PEDOT:PSS composite CE. Reprinted with permission from ref. 200, C. T. Li, C. P. Lee, Y. Y. Li, M. H. Yeh and K. C. Ho, a composite film of TiS 2 /PEDOT:PSS as the electrocatalyst for the counter electrode in dye-sensitized solar cells. J. Mater. Chem. A, 2013, 1, 14888-14896. Copyright@ Royal Society of Chemistry.

of DSSCs for the $\mathrm{I}^{-} / \mathrm{I}_{3}{ }^{-}$redox system, which exhibited a PCE as high as $7.04 \%$ and is comparable to a Pt CE. Fig. 29b shows dark current density-voltage curves of DSSCs with Pt, bare $\mathrm{TiS}_{2}$, bare PEDOT:PSS, and $10 \mathrm{wt} \% \mathrm{TiS}_{2} / \mathrm{PEDOT}$ :PSS composite CEs, and also the long-term stability of a $10 \mathrm{wt} \% \mathrm{TiS}_{2} / \mathrm{PEDOT}$ :PSS composite CE based DSSC. This another example of long-term stability of DSSCs based on $\mathrm{TiS}_{2} / \mathrm{PEDOT}$ :PSS CEs.

The stability of DSSCs with a $\mathrm{TiS}_{2}$ /graphene hybrid CE was studied by Meng et al. ${ }^{199}$ (Fig. 30). The TiS $_{2}$-graphene hybrid CE maintained $96 \%$ of its initial PCE value after 500 hours in air, also exhibiting higher electrochemical stability. The $R_{\mathrm{S}}$ and $Z_{\mathrm{N}}$ values for the $\mathrm{TiS}_{2}$-graphene hybrid CE based DSSC did not change after 10 cyclic measurements. The $R_{\mathrm{CT}}$ value of a DSSC with Pt CE significantly increased with increasing cycling number, while there was no change in the $R_{\mathrm{CT}}$ value of the $\mathrm{TiS}_{2}-$ graphene hybrid after 10 cycles. This indicates better electrochemical stability of the $\mathrm{TiS}_{2}$-graphene hybrid CE than the Pt CE. The stability of photovoltaic parameters of DSSCs having

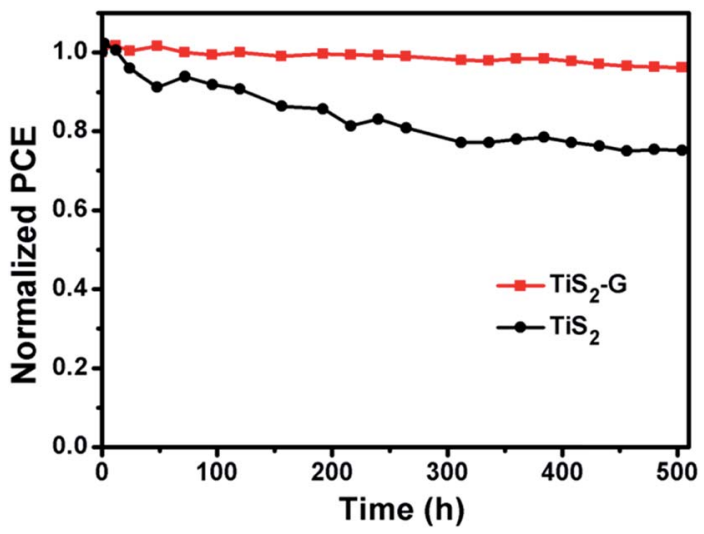

Fig. 30 Stability of DSSCs with $\mathrm{TiS}_{2}$-graphene hybrid and Pt CEs Reprinted with permission from ref. 199, X. Meng, C. Yu, B. Lu, J. Yang and J. Qiu, dual integration system endowing two-dimensional titanium disulfide with enhanced triiodide reduction performance in dyesensitized solar cells. Nano Energy, 2016, 22, 59-69. Copyright $\odot$ Elsevier. mesoporous $\operatorname{CoS}_{2}$ nanotube arrays as CEs was recorded for 10 days by Tsai et al. ${ }^{233}$ a slight drop in the $V_{\mathrm{oc}}$ and $\mathrm{FF}$ values were observed, which resulted in a $2.2 \%$ decrease in the PCE of the $\mathrm{CoS}_{2}$ nanotube array CEs. The photovoltaic parameters of the DSSC were quite stable up to 10 days, indicating good stability of DSSCs with mesoporous $\mathrm{CoS}_{2}$ nanotube array CEs (Fig. 31).

The electrochemical stability of DSSCs with $\mathrm{FeSe}_{2}$ nanosheets and Pt CEs in an iodine-based electrolyte was studied by Huang et al. ${ }^{302}$ Both CEs were subjected to consecutively CV scanning. The $\mathrm{FeSe}_{2}$ nanosheets-based CE showed no change in the current densities and $E_{\mathrm{pp}}$ values up to 1000 cycles, whereas the $E_{\mathrm{pp}}$ value for the Pt-based CE was observed to increase after 1000 consecutive cycles (Fig. 32). This study confirmed a better corrosion resistance of $\mathrm{FeSe}_{2}$ nanosheets $\mathrm{CE}$ to the iodine-based electrolyte than a Pt CE. Both CEs were also subjected to sequential EIS scanning, where negligible changes in $R_{\mathrm{CT}}$ were noticed after 10 cycles, again indicating an excellent electrochemical stability of both CEs. Furthermore, $R_{\mathrm{S}}$ and $Z_{\mathrm{N}}$ values also showed no change upon repeated scanning cycles.

The stability of a $\mathrm{FeS}_{2}$ nanorod based $\mathrm{CE}$ was also measured in an iodide $\left(\mathrm{I}^{-}\right)$electrolyte up to 10 days, and $\mathrm{CV}$ plots showed slight change at different times of aging. ${ }^{222}$ The hydrothermally synthesized $\mathrm{CoSe}_{2}$ nanorods were used as an electrocatalyst for a DSSC for the reduction of $\mathrm{I}_{3}{ }^{-}$using N719 dye by Sun et al. ${ }^{351}$ The single crystalline $\mathrm{CoSe}_{2}$ nanorods based CE showed a PCE of $10.20 \%$, compared with a PCE of $8.17 \%$ for a Pt CE, under 1 Sun illumination. The DSSCs having $\mathrm{CoSe}_{2}$ CEs were stored in daylight and their photovoltaic properties were measured every day, and showed long-term stability. These studies show an excellent electrochemical stability of TMDs-based CEs for DSSCs in iodine-based electrolyte, with no corrosion. The TMDs CEs are also quite stable when stored under ambient conditions of up to 2-3 weeks, as no significant changes were observed in the PCEs of the DSSC devices. Furthermore, TMDs based CEs should be further investigated to exhibit better electrochemical stability and environmental stability than that of standard Pt CEs, and endurance tests should be carried out to study the their stability. The DSSS devices should have a service life of at least 20 years under ambient conditions as pointed out by 

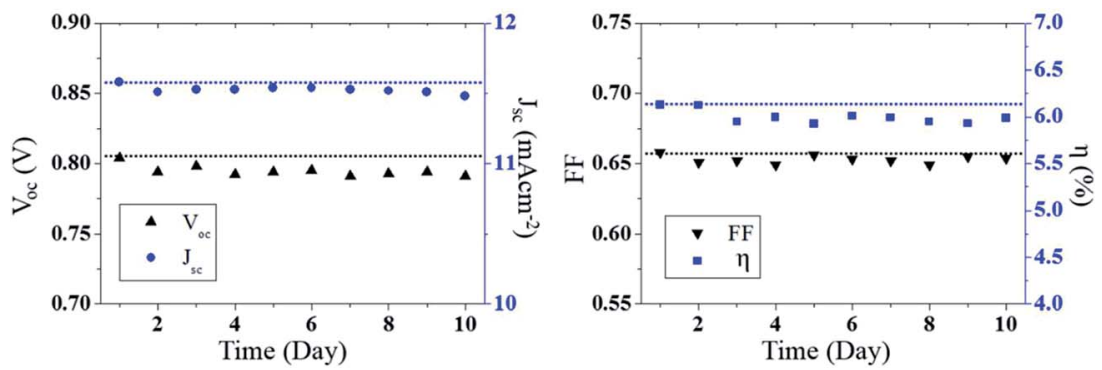

Fig. 31 Stability of photovoltaic parameters; open-circuit voltage $\left(V_{\mathrm{oc}}\right)$, short-circuit photocurrent density $\left(J_{\mathrm{sc}}\right)$, fill factor $(\mathrm{FF})$, and power conversion efficiency $(\eta)$ of DSSCs with mesoporous $\mathrm{CoS}_{2}$ nanotube array CE as a function of time. Reprinted with permission from ref. 233, J. C. Tsai, M. H. Hon and I. C. Leu, fabrication of mesoporous $\mathrm{CoS}_{2}$ nanotube arrays as the counter electrodes of dye-sensitized solar cells. Chem.Asian J., 2015, 10, 1932-1939. Copyright@ Wiley-VCH.
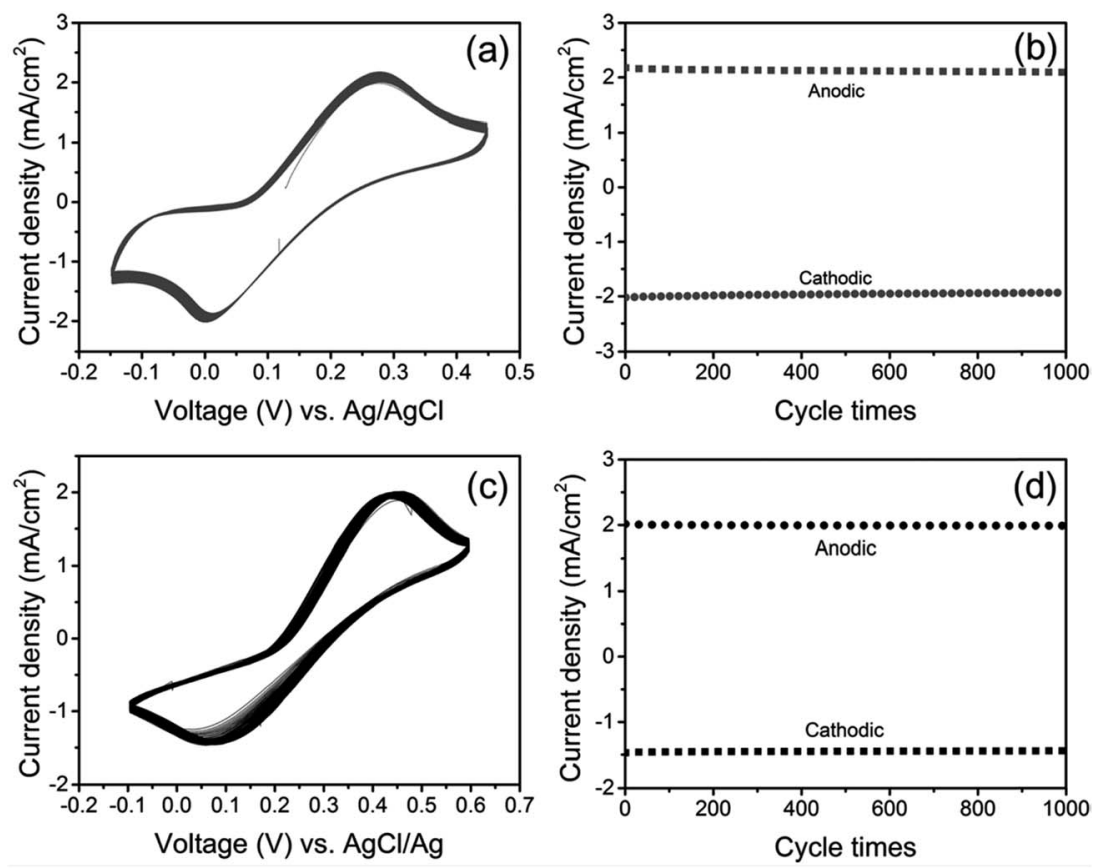

Fig. 321000 consecutive cycles of CVs of FeSe 2 nanosheets-based CE (a) and Pt-based CE (c) at a scan rate of $50 \mathrm{mV} \mathrm{s}^{-1}$ and the anodic as well as cathodic peak current densities up to 1000 cycles for $\mathrm{FeSe}_{2}-$ (b) and Pt-based CEs (d), respectively. Reprinted with permission from ref. 302, S. Huang, Q. He, W. Chen, Q. Qiao, J. Zai and X. Qian, ultrathin $\mathrm{FeSe}_{2}$ nanosheets: controlled synthesis and application as a heterogeneous catalyst in dye-sensitized solar cells. Chem.-Eur. J., 2015, 21, 4085-4091. Copyright@ Wiley-VCH.

Grätzel. ${ }^{342}$ The long-term stability of DSSCs is feasible by carefully selecting components and solar cell structure. The TMDs based CEs may overcome the concerns associated with scarcity, high production cost, and corrosion of Pt CEs in electrolyte solutions. Researchers in this field should address the stability for of TMDs based CEs to evaluate the performance of Pt-free DSSCs.

Some achievements and strategies to overcome the longterm stability of Pt-free DSSCs are summarized in the following section. Kato et al. ${ }^{352}$ used Raman spectroscopy and EIS to evaluate the durability of DSSCs for 2.5 years in outdoor conditions. Both N719 dye-adsorbed $\mathrm{TiO}_{2}$ CEs and carbon CEs were found to be stable. The $V_{\text {oc }}$ and FF values were slightly decreased because of increased $Z_{\mathrm{N}}$ of triiodide $\left(\mathrm{I}_{3}{ }^{-}\right)$, arising from the change in electrolyte components. Matsui et al. ${ }^{353}$ achieved stability over 1000 hours for DSSCs at $85{ }^{\circ} \mathrm{C}$ and under $85 \%$ relative humidity, and recorded no degradation of the photovoltaic performance between -40 and $90{ }^{\circ} \mathrm{C}$ for 200 cycles. Xue et al..$^{354}$ measured thermal stability of DSSCs between -20 to $25^{\circ} \mathrm{C}$ temperature range for 1080 hours. DSSCs with N719 dye absorbed on the $\mathrm{TiO}_{2}$ photoanode retained $80 \%$ of their initial PCE values after aging for 1080 hours. The deterioration of the N719 dye was found to be the main cause for a decrease the PCE and degradation of DSSC devices. Harikisun and Desilvestro ${ }^{355}$ evaluated photovoltaic performance of Z907-based DSSCs after continuous light-soaking at 55-60 ${ }^{\circ} \mathrm{C}$ for 25600 hours, where a slight degradation was observed. The accelerated aging tests predicted a life time of 40 years for Middle European conditions 
while 25 years for Southern European conditions. The $10 \%$ and $20 \%$ decrease of photovoltaic performance was measured for ionic liquid and solvent based electrolytes over 1000 hours at $180{ }^{\circ} \mathrm{C}$, respectively.

Strategies to improve the long-term stability of DSSCs include developing new photosensitizing dyes, new non-volatile electrolytes, encapsulation, and of course new photoanodes and CEs. Like the heterojunction solar cells, ${ }^{27}$ several strategies for improving electrochemical and thermal stability of DSSC devices have been proposed. The role of photosensitizing dyes containing $\pi$-conjugated organic systems have been studied for the stability of DSSCs. Wu et al. ${ }^{356}$ suggested a novel concept of molecular engineering of donor-acceptor- $\pi$-acceptor (D-A- $\pi-$ A) based photosensitizers, not only to improve the stability of DSSCs but also to enhance the photovoltaic performance. Katoh et $a l .^{357}$ compared the stability of five sensitizing dyes in DSSCs with and without $\pi$-conjugated oligothiophene moiety, which indicated that dyes with $\pi$-conjugated oligothiophene exhibit higher stability than those of without oligothiophene moiety. Joly et $a l .{ }^{358}$ fabricated DSSCs with a new organic sensitizer (RK1) which showed a $J_{\mathrm{sc}}$ of $18.26 \mathrm{~mA} \mathrm{~cm}^{-2}, V_{\mathrm{oc}}$ of $0.76 \mathrm{~V}$, and $\mathrm{FF}$ of 0.74 , resulting in a PCE value of $10.2 \%$ under 1 Sun illumination for the triiodide/iodide $\left(\mathrm{I}_{3}{ }^{-} / \mathrm{I}^{-}\right)$redox couple. A similar PCE of $10.19 \%$ was achieved for the ruthenium N719 dye. When RK1 dye was used with a viscous ionic liquid electrolyte, the DSSC yielded a $J_{\mathrm{sc}}$ of $15.40 \mathrm{~mA} \mathrm{~cm} \mathrm{~cm}^{-2}, V_{\text {oc }}$ of $0.665 \mathrm{~V}$, FF of 0.69 , and a PCE of $7.36 \%$, with outstanding stability. The DSSC exhibited no degradation of photovoltaic performance after visible-light soaking at $65{ }^{\circ} \mathrm{C}$ for 2200 hours, but, thereafter, DSSC started degrading and retained $75 \%$ of its initial PCE at $65{ }^{\circ} \mathrm{C}$ after 5000 hours.

A new coumarin dye, namely 2-cyano- $3-\left\{5^{\prime}-[1\right.$-cyano-2(1,1,6,6-tetramethyl-10-oxo-2,3,5,6-tetrahydro- $1 \mathrm{H}, 4 \mathrm{H}, 10 \mathrm{H}-11$ oxa-3a-aza-benzo[de]anthracen-9-yl)-vinyl]-[2,2']bithiophenyl-5yl\}-acrylic acid (NKX-2883) was developed by Wang et al. ${ }^{359}$ to examine the stability of DSSCs in a nonvolatile electrolyte made of $0.1 \mathrm{M} \mathrm{I}_{2}, 0.6 \mathrm{M}$ 1,2-dimethyl-3- $n$-propylimidazolium iodide (DMPImI), and $0.1 \mathrm{M} \mathrm{N}$-methylbenzimidazole (NMBI) in 3methoxypropionitrile. The NKX-2883 dye-based DSSC showed a $J_{\mathrm{sc}}$ value of $18.8 \mathrm{~mA} \mathrm{~cm} \mathrm{~cm}^{-2}$ and a PCE of $6.5 \%$ with 6 micron thick $\mathrm{TiO}_{2}$ film. The DSSCs maintained a PCE of $6 \%$ under continuous light soaking of $100 \mathrm{~mW} \mathrm{~cm}^{-2}$ (1 Sun illumination) at $50-55{ }^{\circ} \mathrm{C}$ for 1000 hours. Organic photosensitizing dyes having long alkyl chains were also proposed to improve longterm stability for both liquid and quasi-solid-state DSSCs. ${ }^{360}$ In another study, quinoxaline based metal-free organic sensitizing dyes were utilized to introduce long-term stability in DSSCs. ${ }^{361}$ The length of the alkyl chains on the donor unit was found to affect the performance of DSSC devices. The quasisolid-state DSSCs with a quinoxaline-based organic dye showed a PCE of $7.14 \%$, and maintained $100 \%$ of its initial PCE value after continuous sunlight irradiation for 1000 hours, indicating that molecular engineering of dye molecules can lead to both high PCE and long-term stability of DSSC devices.

The electrochemical stability of CEs in corrosive triiodide/ iodide $\left(\mathrm{I}_{3}{ }^{-} / \mathrm{I}^{-}\right)$electrolyte is of significant concern because it restricts commercial applications of DSSCs. To overcome this disadvantage of the $\mathrm{I}^{-} / \mathrm{I}_{3}{ }^{-}$redox couple, research activities have been focused on finding alternative iodine-free non-corrosive redox electrolytes. ${ }^{19,362-366}$ Cell-sealing conditions are also important when using liquid electrolytes. The DSSCs can be made suitable for outdoor applications by using encapsulation. The role of electrolytes has been studied in the stability of DSSCs by Sauvage et al. ${ }^{367}$ suggesting a new electrolyte based on butyronitrile solvent with low volatility, along with thiophenebased sensitizer $\mathrm{Na}-\mathrm{Ru}\left(4,4^{\prime}\right.$-bis(5-(hexylthio)thiophen-2-yl)2,2'-bipyridine)(4-carboxylic acid-4'-carboxylate-2,2'-bipyridine)(thiocyanate)2, coded C106, for DSSCs which showed $>95 \%$ retention of PCE value after 1000 hours at $60{ }^{\circ} \mathrm{C}$ for an exposure to $100 \mathrm{~mW} \mathrm{~cm}{ }^{-2}$ light illumination. Yoon et al. ${ }^{368}$ fabricated DSSCs with 1-propyl-3-methyl imidazolium iodide (PMII) ion-gel electrolyte with a poly(styrene-blockethyleneoxide-block-styrene) (SEOS) triblock copolymer. The DSSC with ion-gel electrolyte retained $92 \%$ of its initial PCE up to 1440 hours, compared to $78 \%$ for the ionic liquid electrolyte. Lee et $a{ }^{369}$ reported long-term stability of DSSCs with organic tetrabutylammonium iodide (TBAI) or 1-methyl 3-propyl imidazolium iodide (PMII) in methoxypropionitrile-based electrolytes. The DSSCs having TBAI retained $96.9 \%$ of their initial efficiency after being stored for 1000 hours under 1 Sun light irradiation at $60{ }^{\circ} \mathrm{C}$. Yang et al. ${ }^{370}$ proposed the use of poly(ethylene oxide)-poly(vinylidene fluoride) (PEO-PVDF) polymerblend electrolytes with water and ethanol for improving stability of DSSCs. The electrical conductivity was found to increase after adding water and ethanol to the PEO-PVDF polymer-blend electrolytes. The cross-linking capability of hydroxyl-rich additives for modified electrolytes was found to have a positive impact. Chen et al. ${ }^{371}$ demonstrated the long-time durability of DSSCs by using a succinonitrile, silica nanoparticles and 1butyl-3-methylimidazolium tetrafluoroborate $\left(\mathrm{BMI} \cdot \mathrm{BF}_{4}\right)$ gel system which maintained $93 \%$ of its initial PCE after aging at $60{ }^{\circ} \mathrm{C}$ for 1000 hours. Dembele et al. ${ }^{372}$ also demonstrated that adding $1.0 \mathrm{wt} \%$ concentration of MWCNTs to $\mathrm{TiO}_{2}$ photoanodes can improve both PCE and stability of a DSSC, where the PCE value increased to $4.1 \%$ compared with $3.7 \%$ for pure $\mathrm{TiO}_{2}$ photoanodes. The performance of the DSSC devices was measured for 10 consecutive days under ambient light exposure. The PCE decreased about $10 \%$ for the $\mathrm{MWCNTs} / \mathrm{TiO}_{2}$ photoanodes, compared to $35 \%$ decrease in pure $\mathrm{TiO}_{2}$ photoanodes.

The long-term stability of Pt-free DSSCs is of significant importance for both indoor and outdoor applications and different approaches can be examined to improve environmental stability. ${ }^{356-361,367-377}$ These studies show that long-term stability may be introduced in TMDs based DSSCs by similar strategies of using long alkyl chain organic dyes, ion-gel and polymer-based electrolytes, silica nanoparticles, or modifying $\mathrm{TiO}_{2}$ photoanodes. Similar electrochemical and thermal stability studies should be conducted for TMD CEs for DSSC devices.

\section{Conclusion and perspective}

The electrochemical and photovoltaic properties of DSSC devices employing CEs (CEs) of 2D layered transition metal 
dichalcogenides $\left(\mathrm{MoS}_{2}, \mathrm{MoSe}_{2}, \mathrm{WS}_{2}, \mathrm{TiS}_{2}, \mathrm{NbSe}_{2}, \mathrm{TaSe}_{2}, \mathrm{NiSe}_{2}\right.$, $\mathrm{FeSe}_{2}, \mathrm{CoSe}_{2}, \mathrm{SnS}_{2}, \mathrm{Bi}_{2} \mathrm{Se}_{3}$ and their based composites) have been summarized and discussed. This data indicates that the PCEs of TMDs-based CEs surpasses conventional Pt CEs in dyesensitized solar cell (DSSC) devices. The composites of TMDs with graphene, CNTs, carbon, carbon nanofibers (CNFs), and PEDOT:PSS also show a great potential as CEs for DSSCs. The DSSCs having CEs made of chemical vapor deposition (CVD)grown vertically inclined $\mathrm{MoS}_{2}$ films, ${ }^{\mathbf{1 3 1}}$ hydrothermally prepared $\mathrm{MoS}_{2}$ films, ${ }^{\mathbf{1 3 5 , 1 4 1}} \mathrm{MoS}_{2}$ and $\mathrm{MoSe}_{2}$ thin films deposited on Mo foil, ${ }^{260,261} \mathrm{MoS}_{2} /$ graphene, $\mathrm{MoS}_{2} / \mathrm{CNTs},{ }^{164} \mathrm{MoS}_{2} /$ carbon, ${ }^{171}$ and $\mathrm{MoSe}_{2}$ /PEDOT:PSS composites exhibit higher PCE values than that of Pt CEs for the reduction of triiodide $\left(\mathrm{I}_{3}{ }^{-}\right)$to iodide $\left(\mathrm{I}^{-}\right)$. Furthermore, the CEs of $\mathrm{TiS}_{2} /$ graphene hybrids, ${ }^{199} \mathrm{NiS}_{2} /$ reduced graphene oxide (RGO) composites, ${ }^{210} \mathrm{FeS}_{2},{ }^{221} \mathrm{NbSe}_{2},{ }^{280}$ and $\mathrm{FeSe}_{2}$ nanosheets ${ }^{302}$ also show a better photovoltaic performance than that of Pt CEs in DSSCs. The low cost and flexible $\mathrm{CoSe}_{2}$ /carbon-nanoclimbing-wall $\mathrm{CE}$ deposited on nickel foam shows the highest PCE of $10.46 \%$ versus a Pt CE $(\eta=$ $8.25 \%)$ at 1 Sun illumination $\left(100 \mathrm{~mW} \mathrm{~cm}^{-2}\right.$ (AM 1.5G)). ${ }^{310}$ It has been observed that the morphology of CEs also plays an important role in determining the electrocatalytic activity of DSSC devices, where CEs with large surface area nanostructures tend to show larger PCE values and a higher electrocatalytic activity of the DSSCs. ${ }^{282}$ The DSSCs with $\mathrm{TiS}_{2} /$ graphene hybrids $^{199}$ and TiS $_{2} /$ PEDOT:PSS composites ${ }^{200}$ based CEs showed environmental stability of up to 20 and 30 days, respectively, with no degradation in the photovoltaic performance. Interestingly, thermoelectric $\mathrm{Bi}_{2} \mathrm{Te}_{3}$ nanosheet/ZnO nanoparticles composite based photoanodes ${ }^{335}$ exhibited a $46.95 \%$ increase in PCE value compared with a bare $\mathrm{ZnO}$ photoanode based DSSC. Also, the DSSC with the $\mathrm{Bi}_{2} \mathrm{Te}_{3} / \mathrm{TiO}_{2}$ composite based photoanode ${ }^{336}$ showed a $28 \%$ increase in PCE than that of pure $\mathrm{TiO}_{2}$ photoanode.

Transition metal dichalcogenides (TMDs) based materials which are analogues of $2 \mathrm{D}$ graphene are emerging as a great alternative to fabricating low-cost Pt-free DSSC devices. TMDsbased CEs have demonstrated better electrochemical stability than that of standard Pt CEs in iodine-based electrolyte and also under ambient conditions. In addition to long-term stability, TMDs may also cause cytotoxicity to humans, as has been observed for other nanostructured materials, ${ }^{378-383}$ therefore, aspects of toxicity should be investigated in studies with DSSC devices.

2D TMDs based CEs are a cheap alternative to Pt CEs for DSSCs. In this review, we have summarized recent developments of TMDs used as CE materials for DSSCs which are still in their infancy. The low-cost 2D TMDs are abundantly available in nature, and can easily be processed into thin films and hybridized with other inorganic and organic materials for fabricating DSSC devices. The vast majority of 2D TMDs have yet to be studied, even as $2 \mathrm{D}$ graphene-based materials, but at this early stage they offer a low-cost alternative and outperform their Pt counterparts. Tremendous possibilities exist for developing new TMDs based CEs for $\mathrm{I}_{3}{ }^{-} / \mathrm{I}^{-}, \mathrm{Co}^{2+} \mathrm{Co}^{3+}$ and $\mathrm{T}_{2} / \mathrm{T}^{-}$redox couples. The important requirements for commercial applications are ease of processing, low-cost manufacturing, high PCE value, and long-term electrochemical stability. Like graphenebased materials, more edge active sites can be created in TMDs-based CEs to facilitate more dye adsorption. Research on the use of TMDs CEs are in very early stage of developing Pt-free DSSCs. TMDs based CEs offer increased charge transfer capability and fast reaction kinetics for the reduction of triiodide $\left(\mathrm{I}_{3}{ }^{-}\right)$to iodide $\left(\mathrm{I}^{-}\right)$in electrolyte for DSSCs and their potential can be realized in parallel to graphene. The large family of TMDs, such as $\mathrm{MoS}_{2}, \mathrm{MoSe}_{2}, \mathrm{MoTe}_{2}, \mathrm{WS}_{2}, \mathrm{WSe}{ }_{2}, \mathrm{WTe}_{2}, \mathrm{FeSe}_{2}$, $\mathrm{TaS}_{2}, \mathrm{NbSe}_{2}$, etc., should also be explored with other inorganic and organic materials, as the family of $2 \mathrm{D}$ materials is enormously large and are expected to play an important role in developing low-cost highly efficient DSSCs for commercial applications.

\section{Disclaimer}

The authors cannot accept liability for any kind of scientific data contained in this review article whatsoever for the accuracy of contents or any omissions or any errors or a claim of completeness.

\section{Acknowledgements}

Eric Singh is thankful to Prof. Dr G. Y. Yeom for offering him a summer research internship in his group at the School of Advanced Materials Science and Engineering, Sungkyunkwan University (SKKU), South Korea. This work was supported by the Nano Material Technology Development Program through the National Research Foundation of Korea (NRF), funded by the Ministry of Education, Science and Technology (2016M3A7B4910429).

\section{References}

1 B. O'Regan and M. Grätzel, A low-cost, high-efficiency solar cell based on dye-sensitized, Nature, 1991, 353, 737-740.

2 M. K. Nazeeruddin, A. Kay, I. Rodicio, R. Humphry-Baker, E. Müller, P. Liska, N. Vlachopoulos and M. Grätzel, Conversion of light to electricity by cis- $\mathrm{X}_{2}$ bis $\left(2,2^{\prime}\right.$ bipyridyl-4,4'-dicarboxylate) ruthenium(II) charge-transfer sensitizers ( $\mathrm{X}=\mathrm{Cl}-, \mathrm{Br}-, \mathrm{I}-, \mathrm{CN}-$, and $\mathrm{SCN}-$ ) on nanocrystalline titanium dioxide electrodes, J. Am. Chem. Soc., 1993, 115, 6382-6390.

3 M. K. Nazeeruddin, P. Pechy and M. Grätzel, Efficient panchromatic sensitization of nanocrystalline $\mathrm{TiO}_{2}$ films by a black dye based on a trithiocyanato-ruthenium complex, Chem. Commun., 1997, 1705-1706.

4 S. Mathew, A. Yella, P. Gao, R. Humphry-Baker, B. F. Curchod, N. Ashari-Astani, I. Tavernelli, U. Rothlisberger, M. K. Nazeeruddin and M. Grätzel, Dyesensitized solar cells with $13 \%$ efficiency achieved through the molecular engineering of porphyrin sensitizers, Nat. Chem., 2014, 6, 242-247.

5 M. Grätzel, Perspectives for dye-sensitized nanocrystalline solar cells, Prog. Photovoltaics, 2000, 8, 171-185. 
6 M. K. Hara and H. Arakawa, Dye-sensitized solar cells, Handbook of Photovoltaic Science and Engineering, ed. A. Luque and S. Hegedus, Wiley, New York, 2003, pp. 663-700.

7 M. Grätzel, Dye-sensitized solar cells, J. Photochem. Photobiol., C, 2003, 4, 145-153.

8 B. E. Hardin, H. J. Snaith and M. D. McGehee, The renaissance of dye-sensitized solar cells, Nat. Photonics, 2012, 6, 162-169.

9 J. H. Yum, E. Baranoff, S. Wenger, M. K. Nazeeruddin and M. Grätzel, Panchromatic engineering for dye-sensitized solar cells, Energy Environ. Sci., 2011, 4, 842-857.

10 T. Prakash, Review on nanostructured semiconductors for dye sensitized solar cells, Electron. Mater. Lett., 2012, 8, 231-243.

11 G. Boschloo and A. Hagfeldt, Characteristics of the iodide/ triiodide redox mediator in dye-sensitized solar cells, Acc. Chem. Res., 2009, 42, 1819-1826.

12 A. Hagfeldt, G. Boschloo, L. Sun, L. Kloo and H. Pettersson, Dye-sensitized solar cells, Chem. Rev., 2010, 110, 6595-6663.

13 Q. Zhang and G. Cao, Nanostructured photoelectrodes for dye-sensitized solar cells, Nano Today, 2011, 6, 91-109.

14 S. Zhang, X. Yang, Y. Numata and L. Han, Highly efficient dye-sensitized solar cells: progress and future challenges, Energy Environ. Sci., 2013, 6, 1443-1464.

15 N. Tétreault and M. Grätzel, Novel nanostructures for next generation dye-sensitized solar cells, Energy Environ. Sci., 2012, 5, 8506-8516.

16 A. Listorti, B. O'Regan and J. R. Durrant, Electron transfer dynamics in dye-sensitized solar cells, Chem. Mater., 2011, 23, 3381-3399.

17 M. Ye, X. Wen, M. Wang, J. Iocozzia, N. Zhang, C. Lin and Z. Lin, Recent advances in dye-sensitized solar cells: from photoanodes, sensitizers and electrolytes to counter electrodes, Mater. Today, 2015, 18, 155-162.

18 (a) M. Wu, X. Lin, Y. Wang, L. Wang, W. Guo, D. Qi, X. Peng, A. Hagfeldt, M. Grätzel and T. Ma, Economical Pt-free catalysts for counter electrodes of dye-sensitized solar cells, J. Am. Chem. Soc., 2012, 134, 3419-3428; (b) F. Hao, P. Dong, Q. Luo, J. Li, J. Lou and H. Lin, Recent advances in alternative cathode materials for iodine-free dyesensitized solar cells, Energy Environ. Sci., 2013, 6, 20032019.

19 (a) A. C. Cakir and S. Erten-Ela, Comparison between synthesis techniques to obtain $\mathrm{ZnO}$ nanorods and its effect on dye sensitized solar cells, Adv. Powder Technol., 2012, 23, 655-660; (b) Y. Çakmak, S. Kolemen, M. Buyuktemiz, Y. Dede and S. Erten-Ela, Synthesis and dye sensitized solar cell applications of Bodipy derivatives with bis-dimethylfluorenyl amine donor groups, New J. Chem., 2015, 39, 4086-4092.

20 (a) S. Erten-Ela, S. Cogal, G. C. Cogal and A. U. Oksuz, Highly conductive polymer materials based multi-walled carbon nanotubes as counter electrodes for dye-sensitized solar cells, Fullerenes, Nanotubes, Carbon Nanostruct., 2016, 24, 380-384; (b) M. Wu and T. Ma, Recent progress of counter electrode catalysts in dye-sensitized solar cells, J. Phys. Chem. C, 2014, 118, 16727-16742.
21 S. Thomas, T. G. Deepak, G. S. Anjusree, T. A. Arun, S. V. Nair and A. S. Nair, A review on counter electrode materials in dye-sensitized solar cells, J. Mater. Chem. A, 2014, 2, 4474-4490.

22 (a) Encyclopedia of Nanoscience and Nanotechnology; 10volume set, ed. $\mathrm{H}$. S. Nalwa, American Scientific Publishers, Los Angeles, 2004; (b) Handbook of Nanostructured Materials and Nanotechnology; 5-volume set, ed. H. S. Nalwa, Academic Press, San Diego, 2000; (c) Nanomaterials for Energy Storage Applications, ed. H. S. Nalwa, American Scientific Publishers, Los Angeles, 2009.

23 T. E. Graedel, E. M. Harper, N. T. Nassar, P. Nuss and B. K. Reck, Criticality of metals and metalloids, Proc. Natl. Acad. Sci. U. S. A., 2015, 112, 4257-4262, DOI: 10.1073/ pnas.1500415112.

24 Minerals, Critical Minerals, and the U.S. Economy, National Research Council, National Academies Press, Washington D.C., U.S., 2008; Assessments of Criticality, National Research Council (US) Chemical Sciences Roundtable, 2012.

25 E. Singh and H. S. Nalwa, Graphene-based dye-sensitized solar cells: a review, Sci. Adv. Mater., 2015, 7, 1863-1912.

26 E. Singh and H. S. Nalwa, Graphene-based bulkheterojunction solar cells: a review, J. Nanosci. Nanotechnol., 2015, 15, 6237-6278.

27 E. Singh and H. S. Nalwa, Stability of graphene-based heterojunction solar cells, RSC Adv., 2015, 5, 73575-73600.

$28 \mathrm{~J}$. A. Wilson and A. D. Yoffe, The transition metal dichalcogenides discussion and interpretation of the observed optical, electrical and structural properties, Adv. Phys., 1969, 18, 193-335.

29 X. Huang, Z. Zeng and H. Zhang, Metal dichalcogenide nanosheets: preparation, properties and applications, Chem. Soc. Rev., 2013, 42, 1934-1946.

30 M. Chhowalla, H. S. Shin, G. Eda, L. J. Li, K. P. Loh and H. Zhang, The chemistry of two-dimensional layered transition metal dichalcogenide nanosheets, Nat. Chem., 2013, 5, 263-275.

31 C. Ataca, H. Sahin and S. Ciraci, Stable, single-layer $\mathrm{MX}_{2}$ transition-metal oxides and dichalcogenides in a honeycomb-like structure, J. Phys. Chem. C, 2012, 116, 8983-8999.

32 A. K. Geim and I. V. Grigorieva, van der Waals heterostructures, Nature, 2013, 499, 419-425.

33 B. Radisavljevic, A. Radenovic, J. Brivio, V. Giacometti and A. Kis, Single-layer $\mathrm{MoS}_{2}$ transistors, Nat. Nanotechnol., 2011, 6, 147-150.

34 W. S. Yun, S. W. Han, S. C. Hong, I. G. Kim and J. D. Lee, Thickness and strain effects on electronic structures of transition metal dichalcogenides: 2H-MX semiconductors $(\mathrm{M}=\mathrm{Mo}, \mathrm{W} ; \mathrm{X}=\mathrm{S}, \mathrm{Se}, \mathrm{Te})$, Phys. Rev. $B$ : Condens. Matter Mater. Phys., 2012, 85, 033305.

35 G. Eda and S. A. Maier, Two-Dimensional Crystals: Managing Light for Optoelectronics, ACS Nano, 2013, 7, 5660-5665.

36 S. Tongay, J. Suh, C. Ataca, W. Fan, A. Luce, J. S. Kang, J. Liu, C. Ko, R. Raghunathanan, J. Zhou, F. Ogletree, J. Li, 
J. C. Grossman and J. Wu, Defects activated photoluminescence in two-dimensional semiconductors: interplay between bound, charged, and free excitons, Sci. Rep., 2013, 3, 2657.

37 P. Tonndorf, R. Schmidt, P. Böttger, X. Zhang, J. Borner, A. Liebig, M. Albrecht, C. Kloc, O. Gorgan, D. R. T. Zahn, S. M. de Vasconcellos and R. Bratschitsch, Photoluminescence Emission and Raman Response of Monolayer $\mathrm{MoS}_{2}, \mathrm{MoSe}_{2}$, and $\mathrm{WSe}_{2}$, Opt. Express, 2013, 21, 4908-4916.

38 K. M. McCreary, A. T. Hanbicki, G. G. Jernigan, J. C. Culbertson and B. T. Jonker, Synthesis of large-area $\mathrm{WS}_{2}$ monolayers with exceptional photoluminescence, $\mathrm{Sci}$. Rep., 2016, 6, 19159.

39 K. Ueno, K. Saiki, T. Shimada and A. Koma, Epitaxial growth of transition metal dichalcogenides on cleaved faces of mica, J. Vac. Sci. Technol., A, 1990, 8, 68-72.

40 K. S. Novoselov, D. Jiang, F. Schedin, T. J. Booth, V. V. Khotkevich, S. V. Morozov and A. K. Geim, Twodimensional atomic crystals, Proc. Natl. Acad. Sci. U. S. A., 2005, 102, 10451-10453.

41 H. Li, G. Lu, Y. Wang, Z. Yin, C. Cong, Q. He, L. Wang, F. Ding, T. Yu and H. Zhang, Mechanical Exfoliation and Characterization of Single-and Few-Layer Nanosheets of $\mathrm{WSe}_{2}, \mathrm{TaS}_{2}$, and $\mathrm{TaSe}_{2}$, Small, 2013, 9, 1974-1981.

42 A. A. Al-Hilli and B. L. Evans, The preparation and properties of transition metal dichalcogenide single crystals, J. Cryst. Growth, 1972, 15, 93-101.

43 Y. H. Lee, L. Yu, H. Wang, W. Fang, X. Ling, Y. Shi, C. T. Lin, J. K. Huang, M. T. Chang, C. S. Chang, M. Dresselhaus, T. Palacios, L. J. Li and J. Kong, Synthesis and transfer of single-layer transition metal disulfides on diverse surfaces, Nano Lett., 2013, 13, 1852-1857.

44 Y. Shi, H. Li and L. J. Li, Recent advances in controlled synthesis of two-dimensional transition metal dichalcogenides via vapour deposition techniques, Chem. Soc. Rev., 2015, 44, 2744-2756.

45 R. Gatensby, N. McEvoy, K. Lee, T. Hallam, N. C. Berner, E. Rezvani, S. Winters, M. O'Brien and G. S. Duesberg, Controlled synthesis of transition metal dichalcogenide thin films for electronic applications, Appl. Surf. Sci., 2015, 297, 139-146.

46 S. Jeong, D. Yoo, J. T. Jang, M. Kim and J. Cheon, Welldefined colloidal 2-D layered transition-metal chalcogenide nanocrystals via generalized synthetic protocols, J. Am. Chem. Soc., 2012, 134, 18233-18236.

47 M. S. Whittingham and F. R. Gamble, The lithium intercalates of the transition metal dichalcogenides, Mater. Res. Bull., 1975, 10, 363-371.

48 Z. Zeng, T. Sun, J. Zhu, X. Huang, Z. Yin, G. Lu, Z. Fan, Q. Yan, H. H. Hng and H. Zhang, An Effective Method for the Fabrication of Few-Layer-Thick Inorganic Nanosheets, Angew. Chem., Int. Ed., 2012, 51, 9052-9056.

49 A. Y. S. Eng, A. Ambrosi, Z. Sofer, P. Simek and M. Pumera, Electrochemistry of transition metal dichalcogenides: strong dependence on the metal-to-chalcogen composition and exfoliation method, ACS Nano, 2014, 8, 12185-12198.

50 R. A. Gordon, D. Yang, E. D. Crozier, D. T. Jiang and R. F. Frindt, Structures of exfoliated single layers of $\mathrm{WS}_{2}$, $\mathrm{MoS}_{2}$, and $\mathrm{MoSe}_{2}$ in aqueous suspension, Phys. Rev. B: Condens. Matter Mater. Phys., 2002, 65, 125407.

51 G. Cunningham, M. Lotya, C. S. Cucinotta, S. Sanvito, S. D. Bergin, R. Menzel, M. S. Shaffer and J. N. Coleman, Solvent exfoliation of transition metal dichalcogenides: dispersibility of exfoliated nanosheets varies only weakly between compounds, ACS Nano, 2012, 6, 3468-3480.

52 R. J. Smith, P. J. King, M. Lotya, C. Wirtz, U. Khan, S. De, A. O'Neill, G. S. Duesberg, J. C. Grunlan, G. Moriarty and J. Chen, Large-scale exfoliation of inorganic layered compounds in aqueous surfactant solutions, Adv. Mater., 2011, 23, 3944-3948.

53 V. Nicolosi, M. Chhowalla, M. G. Kanatzidis, M. S. Strano and J. N. Coleman, Liquid exfoliation of layered materials, Science, 2013, 340, 1226419.

54 J. N. Coleman, M. Lotya, A. O'Neill, S. D. Bergin, P. J. King, U. Khan, K. Young, A. Gaucher, S. De, R. J. Smith, I. V. Shvets, S. K. Arora, G. Stanton, H. Y. Kim, K. Lee, G. Kim, G. S. Duesberg, T. Hallam, J. J. Boland, J. J. Wang, J. F. Donegan, J. C. Grunlan, G. Moriarty, A. Shmeliov, R. J. Nicholls, J. M. Perkins, E. M. Grieveson, K. Theuwissen, D. W. McComb, P. D. Nellist and V. Nicolosi, Two-dimensional nanosheets produced by liquid exfoliation of layered materials, Science, 2011, 331, 568-571.

55 L. Niu, K. Li, H. Zhen, Y. S. Chui, W. Zhang, F. Yan and Z. Zheng, Salt-Assisted High-Throughput Synthesis of Single-and Few-Layer Transition Metal Dichalcogenides and Their Application in Organic Solar Cells, Small, 2014, 10, 4651-4657.

56 X. Zhang, X. F. Qiao, W. Shi, J. B. Wu, D. S. Jiang and P. H. Tan, Phonon and Raman scattering of twodimensional transition metal dichalcogenides from monolayer, multilayer to bulk material, Chem. Soc. Rev., 2015, 44, 2757-2785.

57 A. S. Pawbake, M. S. Pawar, S. R. Jadkar and D. J. Late, Large area chemical vapor deposition of monolayer transition metal dichalcogenides and their temperature dependent Raman spectroscopy studies, Nanoscale, 2016, 8, 30083018.

58 J. L. Verble and T. J. Wieting, Lattice Mode Degeneracy in $\mathrm{MoS}_{2}$ and Other Layer Compounds, Phys. Rev. Lett., 1970, 25, 362 .

59 G. Frey, R. Tenne, M. Matthews, M. Dresselhaus and G. Dresselhaus, Raman and resonance Raman investigation of $\mathrm{MoS}_{2}$ nanoparticles, Phys. Rev. B: Condens. Matter Mater. Phys., 1999, 60, 2883-2892.

60 A. Castellanos-Gomez, J. Quereda, H. P. van der Meulen, N. Agraït and G. Rubio-Bollinger, Spatially resolved optical absorption spectroscopy of single-and few-layer $\mathrm{MoS}_{2}$ by hyperspectral imaging, Nanotechnology, 2016, 27, 115705. 
61 S. K. Balasingam, J. S. Lee and Y. Jun, Few-layered $\mathrm{MoSe}_{2}$ nanosheets as an advanced electrode material for supercapacitors, Dalton Trans., 2015, 44, 15491-15498.

62 W. Zhao, Z. Ghorannevis, K. K. Amara, J. R. Pang, M. Toh, X. Zhang, C. Kloc, P. H. Tan and G. Eda, Lattice dynamics in mono-and few-layer sheets of $\mathrm{WS}_{2}$ and $\mathrm{WSe}_{2}$, Nanoscale, 2013, 5, 9677-9683.

63 C. Lee, H. Yan, L. E. Brus, T. F. Heinz, J. Hone and S. Ryu, Anomalous Lattice Vibrations of Single- and Few-Layer $\mathrm{MoS}_{2}$, ACS Nano, 2010, 4, 2695-2700.

64 A. Molina-Sanchez and L. Wirtz, Phonons in single-layer and few-layer $\mathrm{MoS}_{2}$ and $\mathrm{WS}_{2}$, Phys. Rev. B: Condens. Matter Mater. Phys., 2011, 84, 155413.

65 S. Tongay, J. Zhou, C. Ataca, K. Lo, T. S. Matthews, J. Li, J. C. Grossman and J. Wu, Thermally Driven Crossover from Indirect toward Direct Bandgap in 2D Semiconductors: $\mathrm{MoSe}_{2}$ versus $\mathrm{MoS}_{2}$, Nano Lett., 2012, 12, 5576-5580.

66 H. Li, Q. Zhang, C. C. R. Yap, B. K. Tay, T. H. T. Edwin, A. Olivier and D. Baillargeat, From Bulk to Monolayer $\mathrm{MoS}_{2}$ : Evolution of Raman Scattering, Adv. Funct. Mater., 2012, 22, 1385-1390.

67 A. Berkdemir, H. R. Gutierrez, A. R. Botello-Mendez, N. Perea-Lopez, A. L. Elias, C. I. Chia, B. Wang, V. H. Crespi, F. Lopez-Urias, J. C. Charlier, H. Terrones and M. Terrones, Identification of individual and few layers of $\mathrm{WS}_{2}$ using Raman Spectroscopy, Sci. Rep., 2013, 3, 1755, DOI: 10.1038/srep01755.

68 H. Sahin, S. Tongay, S. Horzum, W. Fan, J. Zhou, J. Li, J. Wu and F. M. Peeters, Anomalous Raman spectra and thickness-dependent electronic properties of $\mathrm{WSe}_{2}$, Phys. Rev. B: Condens. Matter Mater. Phys., 2013, 87, 165409.

69 R. Saito, Y. Tatsumi, S. Huang, X. Ling and M. S. Dresselhaus, Raman spectroscopy of transition metal dichalcogenides, J. Phys.: Condens. Matter, 2016, 28, 353002 .

70 H. Terrones, E. Del Corro, S. Feng, J. M. Poumirol, D. Rhodes, D. Smirnov, N. R. Pradhan, Z. Lin, M. A. T. Nguyen, A. L. Elias and T. E. Mallouk, New first order Raman-active modes in few layered transition metal dichalcogenides, Sci. Rep., 2014, 4, 4215.

71 S. Y. Chen, C. Zheng, M. S. Fuhrer and J. Yan, Helicityresolved Raman scattering of $\mathrm{MoS}_{2}, \mathrm{MoSe}_{2}, \mathrm{WS}_{2}$, and $\mathrm{WSe}_{2}$ atomic layers, Nano Lett., 2015, 15, 2526-2532.

72 P. D. Fleischauer and R. Bauer, Chemical and structural effects on the lubrication properties of sputtered $\mathrm{MoS}_{2}$ films, Tribol. Trans., 1988, 31, 239-250.

73 T. Spalvins, Lubrication with sputtered $\mathrm{MoS}_{2}$ films: principles, operation, and limitations, J. Mater. Eng. Perform., 1992, 1, 347-351.

74 M. R. Hilton, R. Bauer, S. V. Didziulis, M. T. Dugger, J. M. Keem and J. Scholhamer, Structural and tribological studies of $\mathrm{MoS}_{2}$ solid lubricant films having tailored metal-multilayer nanostructures, Surf. Coat. Technol., 1992, 53, 13-23.

75 A. Savan, E. Pflüger, P. Voumard, A. Schröer and M. Simmonds, Modern solid lubrication: recent developments and applications of $\mathrm{MoS}_{2}$, Lubr. Sci., 2000, 12, 185-203.

76 L. Rapoport, Y. Bilik, Y. Feldman, M. Homyonfer, S. R. Cohen and R. Tenne, Hollow nanoparticles of $\mathrm{WS}_{2}$ as potential solid-state lubricants, Nature, 1997, 387, 791793.

77 L. Rapoport, N. Fleischer and R. Tenne, Fullerene-like $\mathrm{WS}_{2}$ Nanoparticles: Superior Lubricants for Harsh Conditions, Adv. Mater., 2003, 15, 651-655.

78 Y. Q. Liu, C. S. Li, J. H. Yang, Y. M. Yu and X. K. Li, Synthesis and tribological properties of tubular $\mathrm{NbS}_{2}$ and $\mathrm{TaS}_{2}$ nanostructures, Chin. J. Chem. Phys., 2007, 20, 768-772.

79 T. Polcar and A. Cavaleiro, Review on self-lubricant transition metal dichalcogenide nanocomposite coatings alloyed with carbon, Surf. Coat. Technol., 2011, 206, 686695.

80 J. F. Yang, B. Parakash, J. Hardell and Q. F. Fang, Tribological properties of transition metal dichalcogenide based lubricant coatings, Front. Mater. Sci., 2012, 6, 116-127.

81 D. Krasnozhon, D. Lembke, C. Nyffeler, Y. Leblebici and A. Kis, $\mathrm{MoS}_{2}$ transistors operating at gigahertz frequencies, Nano Lett., 2014, 14, 5905-5911.

82 H. Fang, S. Chuang, T. C. Chang, K. Takei, T. Takahashi and A. Javey, High-performance single layered $\mathrm{WSe}_{2}$ p-FETs with chemically doped contacts, Nano Lett., 2012, 12, 3788-3792.

83 H. Wang, L. Yu, Y. H. Lee, Y. Shi, A. Hsu, M. L. Chin, L. J. Li, M. Dubey, J. Kong and T. Palacios, Integrated circuits based on bilayer $\mathrm{MoS}_{2}$ transistors, Nano Lett., 2012, 12, 46744680 .

$84 \mathrm{H}$. Li, J. Wu, Z. Yin and H. Zhang, Preparation and applications of mechanically exfoliated single-layer and multilayer $\mathrm{MoS}_{2}$ and $\mathrm{WSe}_{2}$ nanosheets, Acc. Chem. Res., 2014, 47, 1067-1075.

85 C. Gong, H. Zhang, W. Wang, L. Colombo, R. M. Wallace and K. Cho, Band alignment of two-dimensional transition metal dichalcogenides: application in tunnel field effect transistors, Appl. Phys. Lett., 2013, 103, 053513.

86 D. Jariwala, V. K. Sangwan, L. J. Lauhon, T. J. Marks and M. C. Hersam, Emerging device applications for semiconducting two-dimensional transition metal dichalcogenides, ACS Nano, 2014, 8, 1102-1120.

87 F. Schwierz, J. Pezoldt and R. Granzner, Two-dimensional materials and their prospects in transistor electronics, Nanoscale, 2015, 7, 8261-8283.

88 H. Y. Chang, S. Yang, J. Lee, L. Tao, W. S. Hwang, D. Jena, $\mathrm{N}$. $\mathrm{Lu}$ and D. Akinwande, High-performance, highly bendable $\mathrm{MoS}_{2}$ transistors with high-k dielectrics for flexible low-power systems, ACS Nano, 2013, 7, 5446-5452.

89 R. Cheng, S. Jiang, Y. Chen, Y. Liu, N. Weiss, H. C. Cheng, H. Wu, Y. Huang and X. Duan, Few-layer molybdenum disulfide transistors and circuits for high-speed flexible electronics, Nat. Commun., 2014, 5, 5143.

90 W. S. Hwang, M. Remskar, R. Yan, V. Protasenko, K. Tahy, S. D. Chae, P. Zhao, A. Konar, H. G. Xing, A. Seabaugh and D. Jena, Transistors with chemically synthesized layered semiconductor $\mathrm{WS}_{2}$ exhibiting $10^{5}$ room temperature 
modulation and ambipolar behavior, Appl. Phys. Lett., 2012, 101, 013107.

91 M. Tosun, S. Chuang, H. Fang, A. B. Sachid, M. Hettick, Y. Lin, Y. Zeng and A. Javey, High-gain inverters based on $\mathrm{WSe}_{2}$ complementary field-effect transistors, ACS Nano, 2014, 8, 4948-4953.

92 S. Larentis, B. Fallahazad and E. Tutuc, Field-effect transistors and intrinsic mobility in ultra-thin $\mathrm{MoSe}_{2}$ layers, Appl. Phys. Lett., 2012, 101, 223104.

93 B. Chamlagain, Q. Li, N. J. Ghimire, H. J. Chuang, M. M. Perera, H. Tu, Y. Xu, M. Pan, D. Xaio, J. Yan and D. Mandrus, Mobility improvement and temperature dependence in $\mathrm{MoSe}_{2}$ field-effect transistors on paryleneC substrate, ACS Nano, 2014, 8, 5079-5088.

94 S. Fathipour, N. Ma, W. S. Hwang, V. Protasenko, S. Vishwanath, H. G. Xing, H. Xu, D. Jena, J. Appenzeller and A. Seabaugh, Exfoliated multilayer $\mathrm{MoTe}_{2}$ field-effect transistors, Appl. Phys. Lett., 2014, 105, 192101.

95 Y. F. Lin, Y. Xu, S. T. Wang, S. L. Li, M. Yamamoto, A. Aparecido-Ferreira, W. Li, H. Sun, S. Nakaharai, W. B. Jian and K. Ueno, Ambipolar $\mathrm{MoTe}_{2}$ transistors and their applications in logic circuits, Adv. Mater., 2014, 26, 3263-3269.

96 E. Liu, Y. Fu, Y. Wang, Y. Feng, H. Liu, X. Wan, W. Zhou, B. Wang, L. Shao, C. H. Ho and Y. S. Huang, Integrated digital inverters based on two-dimensional anisotropic $\mathrm{ReS}_{2}$ field-effect transistors, Nat. Commun., 2015, 6, 6991.

97 D. Gao, Q. Xue, X. Mao, W. Wang, Q. Xu and D. Xue, Ferromagnetism in ultrathin $\mathrm{VS}_{2}$ nanosheets, J. Mater. Chem. C, 2013, 1, 5909-5916.

98 T. Kanazawa, T. Amemiya, A. Ishikawa, V. Upadhyaya, K. Tsuruta, T. Tanaka and Y. Miyamoto, Few-layer $\mathrm{HfS}_{2}$ transistors, Sci. Rep., 2016, 6, 22277.

99 (a) M. S. El-Bana, D. Wolverson, S. Russo, G. Balakrishnan, D. M. Paul and S. J. Bending, Superconductivity in twodimensional $\mathrm{NbSe}_{2}$ field effect transistors, Supercond. Sci. Technol., 2013, 26, 125020; (b) S. Yang, Q. Yue, H. Cai, K. Wu, C. Jiang and S. Tongay, Highly efficient gas molecule-tunable few-layer GaSe phototransistors, $J$. Mater. Chem. C, 2016, 4, 248-253.

100 X. Geng, Y. Yu, X. Zhou, C. Wang, K. Xu, Y. Zhang, C. Wu, L. Wang, Y. Jiang and Q. Yang, Design and construction of ultra-thin $\mathrm{MoSe}_{2}$ nanosheet-based heterojunction for highspeed and low-noise photodetection, Nano Res., 2016, 9, 2641-2651.

101 E. Zhang, Y. Jin, X. Yuan, W. Wang, C. Zhang, L. Tang, S. Liu, P. Zhou, W. Hu and F. Xiu, $\mathrm{ReS}_{2}$-Based Field-Effect Transistors and Photodetectors, Adv. Funct. Mater., 2015, 25, 4076-4082.

102 S. Yang, C. Wang, C. Ataca, Y. Li, H. Chen, H. Cai, A. Suslu, J. C. Grossman, C. Jiang, Q. Liu and S. Tongay, Self-Driven Photodetector and Ambipolar Transistor in Atomically Thin GaTe- $\mathrm{MoS}_{2}$ p-n vdW Heterostructure, ACS Appl. Mater. Interfaces, 2016, 8, 2533-2539.

103 J. S. Ross, P. Klement, A. M. Jones, N. J. Ghimire, J. Yan, D. G. Mandrus, T. Taniguchi, K. Watanabe, K. Kitamura, W. Yao and D. H. Cobden, Electrically tunable excitonic light-emitting diodes based on monolayer $\mathrm{WSe}_{2} \mathrm{pn}$ junctions, Nat. Nanotechnol., 2014, 9, 268-272.

104 Z. Yin, X. Zhang, Y. Cai, J. Chen, J. I. Wong, Y. Y. Tay, J. Chai, J. Wu, Z. Zeng, B. Zheng and H. Y. Yang, Preparation of $\mathrm{MoS}_{2}-\mathrm{MoO}_{3}$ Hybrid Nanomaterials for Light-Emitting Diodes, Angew. Chem., Int. Ed., 2014, 53, 12560-12565.

105 A. Lipatov, P. Sharma, A. Gruverman and A. Sinitskii, Optoelectrical Molybdenum Disulfide $\left(\mathrm{MoS}_{2}\right)$-Ferroelectric Memories, ACS Nano, 2015, 9, 8089-8098.

106 J. Lee, Z. Wang, K. He, J. Shan and P. X. L. Feng, High frequency $\mathrm{MoS}_{2}$ nanomechanical resonators, ACS Nano, 2013, 7, 6086-6091.

107 F. Clerici, M. Fontana, S. Bianco, M. Serrapede, F. Perrucci, S. Ferrero, E. Tresso and A. Lamberti, In situ $\mathrm{MoS}_{2}$ Decoration of Laser-Induced Graphene as Flexible Supercapacitor Electrodes, ACS Appl. Mater. Interfaces, 2016, 8, 10459-10465.

108 X. Zhou, B. Xu, Z. Lin, D. Shu and L. Ma, Hydrothermal Synthesis of Flower-Like $\mathrm{MoS}_{2}$ Nanospheres for Electrochemical Supercapacitors, J. Nanosci. Nanotechnol., 2014, 14, 7250-7254.

109 G. Du, Z. Guo, S. Wang, R. Zeng, Z. Chen and H. Liu, Superior Stability and High Capacity of Restacked Molybdenum Disulfide as Anode Material for Lithium Ion Batteries, Chem. Commun., 2010, 46, 1106-1108.

110 Z. Zhang, X. Shi, X. Yang, Y. Fu, K. Zhang, Y. Lai and J. Li, Nanooctahedra particles assembled $\mathrm{FeSe}_{2}$ microspheres embedded into sulfur-doped reduced graphene oxide sheets as a promising anode for sodium ion batteries, ACS Appl. Mater. Interfaces, 2016, 8, 13849-13856.

111 X. Xu, C. S. Rout, J. Yang, R. Cao, P. Oh, H. S. Shin and J. Cho, Freeze-dried $\mathrm{WS}_{2}$ composites with low content of graphene as high-rate lithium storage materials, J. Mater. Chem. A, 2013, 1, 14548-14554.

112 O. Lopez-Sanchez, E. Alarcon Llado, V. Koman, A. Fontcuberta i Morral, A. Radenovic and A. Kis, Light Generation and Harvesting in a van der Waals Heterostructure, ACS Nano, 2014, 8, 3042-3048.

113 F. K. Perkins, A. L. Friedman, E. Cobas, P. M. Campbell, G. G. Jernigan and B. T. Jonker, Chemical vapor sensing with monolayer $\mathrm{MoS}_{2}$, Nano Lett., 2013, 13, 668-673.

114 D. J. Late, T. Doneux and M. Bougouma, Single-layer $\mathrm{MoSe}_{2}$ based $\mathrm{NH}_{3}$ gas sensor, Appl. Phys. Lett., 2014, 105, 233103.

115 T. Wang, R. Zhu, J. Zhuo, Z. Zhu, Y. Shao and M. Li, Direct detection of DNA below ppb level based on thioninfunctionalized layered $\mathrm{MoS}_{2}$ electrochemical sensors, Anal. Chem., 2014, 86, 12064-12069.

116 M. Pumera and A. H. Loo, Layered transition-metal dichalcogenides $\left(\mathrm{MoS}_{2}\right.$ and $\left.\mathrm{WS}_{2}\right)$ for sensing and biosensing, TrAC, Trends Anal. Chem., 2014, 61, 49-53.

117 Z. Li and S. L. Wong, Functionalization of 2D transition metal dichalcogenides for biomedical applications, Mater. Sci. Eng., C, 2016, 70, 1095-1106.

118 E. Singh, K. S. Kim, G. Y. Yeom and H. S. Nalwa, Atomically thin-layered molybdenum disulfide $\left(\mathrm{MoS}_{2}\right)$ for bulk- 
heterojunction solar cells, ACS Appl. Mater. Interfaces, 2017, 9, 3223-3245.

119 (a) K. S. Kim, K. H. Kim, Y. Nam, J. Jeon, S. Yim, E. Singh, J. Y. Lee, S. Lee, Y. S. Jung, G. Y. Yeom and D. W. Kim, Atomic Layer Etching Mechanism of $\mathrm{MoS}_{2}$ for Nanodevices, ACS Appl. Mater. Interfaces, 2017, 9, 1196711976; (b) Q. H. Wang, K. Kalantar-Zadeh, A. Kis, J. N. Coleman and M. S. Strano, Electronics and optoelectronics of two-dimensional transition metal dichalcogenides, Nat. Nanotechnol., 2012, 7, 699-712.

120 K. F. Mak and J. Shan, Photonics and optoelectronics of 2D semiconductor transition metal dichalcogenides, Nat. Photonics, 2016, 10, 216-226.

121 J. U. Lee, K. Kim, S. Han, G. H. Ryu, Z. Lee and H. Cheong, Raman Signatures of Polytypism in Molybdenum Disulfide, ACS Nano, 2016, 10, 1948-1953.

122 A. R. Beal, J. C. Knights and W. Y. Liang, Transmission spectra of some transition metal dichalcogenides II. Group VIA: trigonal prismatic coordination, J. Phys. C: Solid State Phys., 1972, 5, 3540.

123 J. A. Woollam and R. B. Somoano, Superconducting critical fields of alkali and alkaline-earth intercalates of $\mathrm{MoS}_{2}$, Phys. Rev. B: Solid State, 1976, 13, 3843.

124 F. Wypych and R. Schöllhorn, 1T- $\mathrm{MoS}_{2}$, a new metallic modification of molybdenum disulfide, J. Chem. Soc., Chem. Commun., 1992, 1386-1388.

125 L. Wang, Z. Xu, W. Wang and X. Bai, Atomic mechanism of dynamic electrochemical lithiation processes of $\mathrm{MoS}_{2}$ nanosheets, J. Am. Chem. Soc., 2014, 136, 6693-6697.

126 S. N. Shirodkar and U. V. Waghmare, Emergence of Ferroelectricity at a Metal-Semiconductor Transition in a 1T Monolayer of $\mathrm{MoS}_{2}$, Phys. Rev. Lett., 2014, 112, 157601.

127 M. Acerce, D. Voiry and M. Chhowalla, Metallic 1T phase $\mathrm{MoS}_{2}$ nanosheets as supercapacitor electrode materials, Nat. Nanotechnol., 2015, 10, 313-318.

128 P. Cheng, K. Sun and Y. H. Hu, Memristive Behavior and Ideal Memristor of $1 \mathrm{~T}$ Phase $\mathrm{MoS}_{2}$ Nanosheets, Nano Lett., 2015, 16, 572-576.

129 R. Kappera, D. Voiry, S. E. Yalcin, B. Branch, G. Gupta, A. D. Mohite and M. Chhowalla, Phase-engineered lowresistance contacts for ultrathin $\mathrm{MoS}_{2}$ transistors, Nat. Mater., 2014, 13, 1128-1134.

130 W. Wei, K. Sun and Y. H. Hu, An efficient counter electrode material for dye-sensitized solar cells-flower-structured $1 \mathrm{~T}$ metallic phase $\mathrm{MoS}_{2}$, J. Mater. Chem. A, 2016, 4, 12398-12401.

131 R. S. Infant, X. Xu, W. Yang, F. Yang, L. Hou and Y. Li, Highly active and reflective $\mathrm{MoS}_{2}$ counter electrode for enhancement of photovoltaic efficiency of dye sensitized solar cells, Electrochim. Acta, 2016, 212, 614-620.

132 S. Jiang, X. Yin, J. Zhang, X. Zhu, J. Li and M. He, Vertical ultrathin $\mathrm{MoS}_{2}$ nanosheets on a flexible substrate as an efficient counter electrode for dye-sensitized solar cells, Nanoscale, 2015, 7, 10459-10464.

133 B. Lei, G. R. Li and X. P. Gao, Morphology dependence of molybdenum disulfide transparent counter electrode in dye-sensitized solar cells, J. Mater. Chem. A, 2014, 2, 39193925.

134 J. Zhang, S. Najmaei, H. Lin and J. Lou, $\mathrm{MoS}_{2}$ atomic layers with artificial active edge sites as transparent counter electrodes for improved performance of dye-sensitized solar cells, Nanoscale, 2014, 6, 5279-5283.

135 M. Al-Mamun, H. Zhang, P. Liu, Y. Wang, J. Cao and H. Zhao, Directly hydrothermal growth of ultrathin $\mathrm{MoS}_{2}$ nanostructured films as high performance counter electrodes for dye-sensitised solar cells, RSC Adv., 2014, 4, 21277-21283.

136 C. K. Cheng and C. K. Hsieh, Electrochemical deposition of molybdenum sulfide thin films on conductive plastic substrates as platinum-free flexible counter electrodes for dye-sensitized solar cells, Thin Solid Films, 2015, 584, 52-60.

137 C. H. Lin, C. H. Tsai, F. G. Tseng, Y. Y. Yu, H. C. Wu and C. K. Hsieh, Low-Temperature Thermally Reduced Molybdenum Disulfide as a Pt-Free Counter Electrode for Dye-Sensitized Solar Cells, Nanoscale Res. Lett., 2015, 10, 1-10.

138 S. A. Patil, P. Y. Kalode, R. S. Mane, D. V. Shinde, A. Doyoung, C. Keumnam, M. M. Sung, S. B. Ambade and S. H. Han, Highly efficient and stable DSSCs of wetchemically synthesized $\mathrm{MoS}_{2}$ counter electrode, Dalton Trans., 2014, 43, 5256-5259.

139 W. H. Jhang and Y. J. Lin, Overpotential modification at the $\mathrm{MoS}_{2}$ counter electrode/electrolyte interfaces by thermal annealing resulting improvement in photovoltaic performance of dye-sensitized solar cells, J. Mater. Sci.: Mater. Electron., 2015, 26, 3739-3743.

140 A. Antonelou, G. Syrrokostas, L. Sygellou, G. Leftheriotis, V. Dracopoulos and S. N. Yannopoulos, Facile, substratescale growth of mono-and few-layer homogeneous $\mathrm{MoS}_{2}$ films on Mo foils with enhanced catalytic activity as counter electrodes in DSSCs, Nanotechnology, 2015, 27, 045404.

$141 \mathrm{M} . \mathrm{Wu}$, Y. Wang, X. Lin, N. Yu, L. Wang, L. Wang, A. Hagfeldt and T. Ma, Economical and effective sulfide catalysts for dye-sensitized solar cells as counter electrodes, Phys. Chem. Chem. Phys., 2011, 13, 19298-19301.

142 H. Zhang, J. Choi, A. Ramani, D. Voiry, S. N. Natoli, M. Chhowalla, D. R. McMillin and J. H. Choi, Engineering Chemically Exfoliated Large-Area TwoDimensional $\mathrm{MoS}_{2}$ Nanolayers with Porphyrins for Improved Light Harvesting, ChemPhysChem, 2016, 17, 2854-2862.

143 W. Liu, S. He, T. Yang, Y. Feng, G. Qian, J. Xu and S. Miao, TEOS-assisted synthesis of porous $\mathrm{MoS}_{2}$ with ultra-small exfoliated sheets and applications in dye-sensitized solar cells, Appl. Surf. Sci., 2014, 313, 498-503.

144 S. S. Kim, J. W. Lee, J. M. Yun and S. I. Na, 2-Dimensional $\mathrm{MoS}_{2}$ nanosheets as transparent and highly electrocatalytic counter electrode in dye-sensitized solar cells: effect of thermal treatments, J. Ind. Eng. Chem., 2015, 29, 71-77.

145 S. Hussain, S. F. Shaikh, D. Vikraman, R. S. Mane, O. S. Joo, M. Naushad and J. Jung, High-Performance Platinum-Free 
Dye-Sensitized Solar Cells with Molybdenum Disulfide Films as Counter Electrodes, ChemPhysChem, 2015, 16, 3959-3965.

146 H. Jeong, J. Y. Kim, B. Koo, H. J. Son, D. Kim and M. J. Ko, Rapid sintering of $\mathrm{MoS}_{2}$ counter electrode using nearinfrared pulsed laser for use in highly efficient dyesensitized solar cells, J. Power Sources, 2016, 330, 104-110.

147 J. Liang, J. Li, H. Zhu, Y. Han, Y. Wang, C. Wang, Z. Jin, G. Zhang and J. Liu, One-step fabrication of large-area ultrathin $\mathrm{MoS}_{2}$ nanofilms with high catalytic activity for photovoltaic devices, Nanoscale, 2016, 8, 16017-16025.

148 C. Tan, W. Zhao, A. Chaturvedi, Z. Fei, Z. Zeng, J. Chen, Y. Huang, P. Ercius, Z. Luo, X. Qi and B. Chen, Preparation of Single-Layer $\operatorname{MoS}_{2} x \mathrm{Se}_{2}(1-x)$ and $\mathrm{Mo}_{x} \mathrm{~W}_{1-x} \mathrm{~S}_{2}$ Nanosheets with High-Concentration Metallic 1T Phase, Small, 2016, 12, 1866-1874.

149 O. Eksik, J. Gao, S. A. Shojaee, A. Thomas, P. Chow, S. F. Bartolucci, D. A. Lucca and N. Koratkar, Epoxy nanocomposites with two-dimensional transition metal dichalcogenide additives, ACS Nano, 2014, 8, 5282-5289.

150 C. Tan and H. Zhang, Two-dimensional transition metal dichalcogenide nanosheet-based composites, Chem. Soc. Rev., 2015, 44, 2713-2731.

151 J. Y. Lin, C. Y. Chan and S. W. Chou, Electrophoretic deposition of transparent $\mathrm{MoS}_{2}$-graphene nanosheet composite films as counter electrodes in dye-sensitized solar cells, Chem. Commun., 2013, 49, 1440-1442.

152 G. Yue, J. Y. Lin, S. Y. Tai, Y. Xiao and J. Wu, A catalytic composite film of $\mathrm{MoS}_{2}$ /graphene flake as a counter electrode for Pt-free dye-sensitized solar cells, Electrochim. Acta, 2012, 85, 162-168.

153 C. Yu, X. Meng, X. Song, S. Liang, Q. Dong, G. Wang, C. Hao, X. Yang, T. Ma, P. M. Ajayan and J. Qiu, Graphene-mediated highly-dispersed $\mathrm{MoS}_{2}$ nanosheets with enhanced triiodide reduction activity for dyesensitized solar cells, Carbon, 2016, 100, 474-483.

154 P. Lynch, U. Khan, A. Harvey, I. Ahmed and J. N. Coleman, Graphene- $\mathrm{MoS}_{2}$ nanosheet composites as electrodes for dye sensitised solar cells, Mater. Res. Express, 2016, 3, 035007.

155 S. Li, H. Min, F. Xu, L. Tong, J. Chen, C. Zhu and L. Sun, All electrochemical fabrication of $\mathrm{MoS}_{2}$ /graphene counter electrodes for efficient dye-sensitized solar cells, RSC Adv., 2016, 6, 34546-34552.

156 C. K. Cheng, C. H. Lin, H. C. Wu, C. C. M. Ma, T. K. Yeh, H. Y. Chou, C. H. Tsai and C. K. Hsieh, The TwoDimensional Nanocomposite of Molybdenum Disulfide and Nitrogen-Doped Graphene Oxide for Efficient Counter Electrode of Dye-Sensitized Solar Cells, Nanoscale Res. Lett., 2016, 11, 1-9.

157 M. S. Fan, C. P. Lee, C. T. Li, Y. J. Huang, R. Vittal and K. C. Ho, Nitrogen-doped graphene/molybdenum disulfide composite as the electrocatalytic film for dyesensitized solar cells, Electrochim. Acta, 2016, 211, 164-172.

158 J. Y. Lin, G. Yue, S. Y. Tai, Y. Xiao, H. M. Cheng, F. M. Wang and $\mathrm{J} . \mathrm{Wu}$, Hydrothermal synthesis of graphene flake embedded nanosheet-like molybdenum sulfide hybrids as counter electrode catalysts for dye-sensitized solar cells, Mater. Chem. Phys., 2013, 143, 53-59.

159 G. Yue, X. Ma, Q. Jiang, F. Tan, J. Wu, C. Chen, F. Li and Q. Li, PEDOT:PSS and glucose assisted preparation of molybdenum disulfide/single-wall carbon nanotubes counter electrode and served in dye-sensitized solar cells, Electrochim. Acta, 2014, 142, 68-75.

160 S. Y. Tai, C. J. Liu, S. W. Chou, F. S. S. Chien, J. Y. Lin and T. W. Lin, Few-layer $\mathrm{MoS}_{2}$ nanosheets coated onto multiwalled carbon nanotubes as a low-cost and highly electrocatalytic counter electrode for dye-sensitized solar cells, J. Mater. Chem., 2012, 22, 24753-24759.

161 C. H. Lin, C. H. Tsai, F. G. Tseng, C. C. M. Ma, H. C. Wu and C. K. Hsieh, Three-dimensional vertically aligned hybrid nanoarchitecture of two-dimensional molybdenum disulfide nanosheets anchored on directly grown onedimensional carbon nanotubes for use as a counter electrode in dye-sensitized solar cells, J. Alloys Compd., 2017, 692, 941-949.

162 M. Zheng, J. Huo, Y. Tu, J. Wu, L. Hu and S. Dai, Flowerlike molybdenum sulfide/multi-walled carbon nanotube hybrid as Pt-free counter electrode used in dye-sensitized solar cells, Electrochim. Acta, 2015, 173, 252-259.

163 W. Liu, S. He, Y. Wang, Y. Dou, D. Pan, Y. Feng, G. Qian, J. $\mathrm{Xu}$ and $\mathrm{S}$. Miao, PEG-assisted synthesis of homogeneous carbon nanotubes- $\mathrm{MoS}_{2}$-carbon as a counter electrode for dye-sensitized solar cells, Electrochim. Acta, 2014, 144, 119-126.

164 G. Yue, W. Zhang, J. Wu and Q. Jiang, Glucose aided synthesis of molybdenum sulfide/carbon nanotubes composites as counter electrode for high performance dye-sensitized solar cells, Electrochim. Acta, 2013, 112, 655-662.

165 J. Y. Lin, A. L. Su, C. Y. Chang, K. C. Hung and T. W. Lin, Molybdenum Disulfide/Reduced Graphene Oxide-Carbon Nanotube Hybrids as Efficient Catalytic Materials in DyeSensitized Solar Cells, ChemElectroChem, 2015, 2, 720-725. 166 (a) S. Wang, X. Jiang, H. Zheng, H. Wu, S. J. Kim and C. Feng, Solvothermal synthesis of $\mathrm{MoS}_{2} /$ carbon nanotube composites with improved electrochemical performance for lithium ion batteries, Nanosci. Nanotechnol. Lett., 2012, 4, 378-383; (b) J. Z. Wang, L. Lu, M. Lotya, J. N. Coleman, S. L. Chou, H. K. Liu, A. I. Minett and J. Chen, Development of $\mathrm{MoS}_{2}-\mathrm{CNT}$ composite thin film from layered $\mathrm{MoS}_{2}$ for lithium batteries, Adv. Energy Mater., 2013, 3, 798-805.

167 T. Du, N. Wang, H. Chen, H. He, H. Lin and K. Liu, $\mathrm{TiO}_{2}-$ based solar cells sensitized by chemical-bath-deposited few-layer $\mathrm{MoS}_{2}$, J. Power Sources, 2015, 275, 943-949.

$168 \mathrm{~W}$. H. Jhang and Y. J. Lin, Interface modification of $\mathrm{MoS}_{2}$ counter electrode/electrolyte in dye-sensitized solar cells by incorporating $\mathrm{TiO}_{2}$ nanoparticles, Curr. Appl. Phys, 2015, 15, 906-909.

169 H. C. Hung, Y. J. Lin and Z. Y. Ke, Interface modification of $\mathrm{MoS}_{2}: \mathrm{TiO}_{2}$ counter electrode/electrolyte in dye-sensitized solar cells by doping with different Co contents, J. Mater. Sci.: Mater. Electron., 2016, 27, 5059-5063. 
170 Z. He, W. Que, Y. Xing and X. Liu, Reporting performance in $\mathrm{MoS}_{2}-\mathrm{TiO}_{2}$ bilayer and heterojunction films based dyesensitized photovoltaic devices, J. Alloys Compd., 2016, 672, 481-488.

171 G. Yue, J. Wu, Y. Xiao, M. Huang, J. Lin and J. Y. Lin, High performance platinum-free counter electrode of molybdenum sulfide-carbon used in dye-sensitized solar cells, J. Mater. Chem. A, 2013, 1, 1495-1501.

172 W. B. Li, M. X. Sun, J. He, S. F. Sun, Q. Zhang and Y. Y. Shi, Preparation of $\mathrm{MoS}_{2} /$ Carbon Fiber Counter Electrodes and Its Application in DSSCs, J. Mater. Sci. Eng., 2015, 3, 020.

173 J. Theerthagiri, R. A. Senthil, P. Arunachalam, J. Madhavan, M. H. Buraidah, A. Santhanam and A. K. Arof, Synthesis of various carbon incorporated flower-like $\mathrm{MoS}_{2}$ microspheres as counter electrode for dye-sensitized solar cells, J. Solid State Electrochem., 2016, 1-10.

174 D. Song, M. Li, Y. Jiang, Z. Chen, F. Bai, Y. Li and B. Jiang, Facile fabrication of $\mathrm{MoS}_{2}$ /PEDOT-PSS composites as lowcost and efficient counter electrodes for dye-sensitized solar cells, J. Photochem. Photobiol., A, 2014, 279, 47-51.

175 X. Liang, H. W. Zheng, X. J. Li, Y. H. Yu, G. T. Yue, W. Zhang, J. J. Tian and T. F. Li, Nanocomposites of $\mathrm{Bi}_{5} \mathrm{FeTi}_{3} \mathrm{O}_{15}$ with $\mathrm{MoS}_{2}$ as Novel Pt-free Counter Electrode in Dye-Sensitized Solar Cells, Ceram. Int., 2016, 42, 12888-12893.

176 J. G. Song, J. Park, W. Lee, T. Choi, H. Jung, C. W. Lee, S. H. Hwang, J. M. Myoung, J. H. Jung, S. H. Kim and C. Lansalot-Matras, Layer-controlled, wafer-scale, and conformal synthesis of tungsten disulfide nanosheets using atomic layer deposition, ACS Nano, 2013, 7, 1133311340.

177 A. L. Elias, N. Perea-López, A. Castro-Beltrán, A. Berkdemir, R. Lv, S. Feng, A. D. Long, T. Hayashi, Y. A. Kim, M. Endo and H. R. Gutiérrez, Controlled synthesis and transfer of large-area $\mathrm{WS}_{2}$ sheets: from single layer to few layers, $A C S$ Nano, 2013, 7, 5235-5242.

178 S. I. Nikitenko, Y. Koltypin, Y. Mastai, M. Koltypin and A. Gedanken, Sonochemical synthesis of tungsten sulfide nanorods, J. Mater. Chem., 2002, 12, 1450-1452.

179 Y. Q. Zhu, W. K. Hsu, H. Terrones, N. Grobert, B. H. Chang, M. Terrones, B. Q. Wei, H. W. Kroto, D. R. M. Walton, C. B. Boothroyd and I. Kinloch, Morphology, structure and growth of $\mathrm{WS}_{2}$ nanotubes, J. Mater. Chem., 2000, 10, 2570-2577.

180 R. Rosentsveig, A. Margolin, Y. Feldman, R. Popovitz-Biro and R. Tenne, $\mathrm{WS}_{2}$ nanotube bundles and foils, Chem. Mater., 2002, 14, 471-473.

181 Y. Wang, S. Li, Y. Bai, Z. Chen, Q. Jiang, T. Li and W. Zhang, Dye-sensitized solar cells based on low cost carbon-coated tungsten disulphide counter electrodes, Electrochim. Acta, 2013, 114, 30-34.

182 S. Hussain, S. F. Shaikh, D. Vikraman, R. S. Mane, O. S. Joo, M. Naushad and J. Jung, Sputtering and sulfurizationcombined synthesis of a transparent $\mathrm{WS}_{2}$ counter electrode and its application to dye-sensitized solar cells, RSC Adv., 2015, 5, 103567-103572.
183 S. H. Ahn and A. Manthiram, Edge-Oriented Tungsten Disulfide Catalyst Produced from Mesoporous $\mathrm{WO}_{3}$ for Highly Efficient Dye-Sensitized Solar Cells, Adv. Energy Mater., 2016, 6, 1501814, DOI: 10.1002/aenm.201501814.

184 S. Li, Z. Chen and W. Zhang, Dye-sensitized solar cells based on $\mathrm{WS}_{2}$ counter electrodes, Mater. Lett., 2012, 72, 22-24.

185 G. Yue, J. Wu, J. Y. Lin, Y. Xiao, S. Y. Tai, J. Lin, M. Huang and Z. Lan, A counter electrode of multi-wall carbon nanotubes decorated with tungsten sulfide used in dyesensitized solar cells, Carbon, 2013, 55, 1-9.

186 J. Wu, G. Yue, Y. Xiao, M. Huang, J. Lin, L. Fan, Z. Lan and J. Y. Lin, Glucose aided preparation of tungsten sulfide/ multi-wall carbon nanotube hybrid and use as counter electrode in dye-sensitized solar cells, ACS Appl. Mater. Interfaces, 2012, 4, 6530-6536.

187 J. A. Wilson, Concerning the semimetallic characters of $\mathrm{TiS}_{2}$ and $\mathrm{TiSe}_{2}$, Solid State Commun., 1977, 22, 551-553.

188 G. A. Benesh, A. M. Woolley and C. Umrigar, The pressure dependences of $\mathrm{TiS}_{2}$ and $\mathrm{TiSe}_{2}$ band structures, J. Phys. C: Solid State Phys., 1985, 18(8), 1595.

189 C. Bourgès, T. Barbier, G. Guélou, P. Vaqueiro, A. V. Powell, O. I. Lebedev, N. Barrier, Y. Kinemuchi and E. Guilmeau, Thermoelectric properties of $\mathrm{TiS}_{2}$ mechanically alloyed compounds, J. Eur. Ceram. Soc., 2016, 36, 1183-1189.

190 M. Inoue, H. P. Hughes and A. D. Yoffe, The electronic and magnetic properties of the $3 \mathrm{~d}$ transition metal intercalates of $\mathrm{TiS}_{2}$, Adv. Phys., 1989, 38, 565-604.

191 C. Wan, X. Gu, F. Dang, T. Itoh, Y. Wang, H. Sasaki, M. Kondo, K. Koga, K. Yabuki, G. J. Snyder and R. Yang, Flexible n-type thermoelectric materials by organic intercalation of layered transition metal dichalcogenide $\mathrm{TiS}_{2}$, Nat. Mater., 2015, 14, 622-627.

192 C. S. Cucinotta, K. Dolui, H. Pettersson, Q. M. Ramasse, E. Long, S. E. O'Brian, V. Nicolosi and S. Sanvito, Electronic Properties and Chemical Reactivity of $\mathrm{TiS}_{2}$ Nanoflakes, J. Phys. Chem. C, 2015, 119, 15707-15715.

193 J. Chen, S. L. Li, Z. L. Tao, Y. T. Shen and C. X. Cui, Titanium disulfide nanotubes as hydrogen-storage materials, J. Am. Chem. Soc., 2003, 125, 5284-5285.

194 S. Prabakar, C. W. Bumby and R. D. Tilley, Liquid-phase synthesis of flower-like and flake-like titanium disulfide nanostructures, Chem. Mater., 2009, 21, 1725-1730.

195 A. Margolin, R. Popovitz-Biro, A. Albu-Yaron, A. Moshkovich, L. Rapoport and R. Tenne, Fullerene-like nanoparticles of titanium disulfide, Curr. Nanosci., 2005, 1, 253-262.

196 K. H. Park, J. Choi, H. J. Kim, D. H. Oh, J. R. Ahn and S. U. Son, Unstable Single-Layered Colloidal $\mathrm{TiS}_{2}$ Nanodisks, Small, 2008, 4, 945-950.

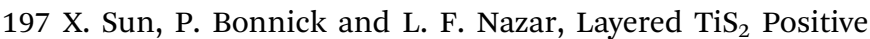
Electrode for $\mathrm{Mg}$ Batteries, ACS Energy Lett., 2016, 1, 297301.

198 C. Lin, X. Zhu, J. Feng, C. Wu, S. Hu, J. Peng, Y. Guo, L. Peng, J. Zhao, J. Huang and J. Yang, Hydrogenincorporated $\mathrm{TiS}_{2}$ ultrathin nanosheets with ultrahigh 
conductivity for stamp-transferrable electrodes, J. Am. Chem. Soc., 2013, 135, 5144-5151.

199 X. Meng, C. Yu, B. Lu, J. Yang and J. Qiu, Dual integration system endowing two-dimensional titanium disulfide with enhanced triiodide reduction performance in dyesensitized solar cells, Nano Energy, 2016, 22, 59-69.

200 C. T. Li, C. P. Lee, Y. Y. Li, M. H. Yeh and K. C. Ho, A composite film of $\mathrm{TiS}_{2} / \mathrm{PEDOT}$ :PSS as the electrocatalyst for the counter electrode in dye-sensitized solar cells, $J$. Mater. Chem. A, 2013, 1, 14888-14896.

201 S. L. Yang, H. B. Yao, M. R. Gao and S. H. Yu, Monodisperse cubic pyrite $\mathrm{NiS}_{2}$ dodecahedrons and microspheres synthesized by a solvothermal process in a mixed solvent: thermal stability and magnetic properties, CrystEngComm, 2009, 11, 1383-1390.

202 X. Song, W. Shen, Z. Sun, C. Yang, P. Zhang and L. Gao, Size-engineerable $\mathrm{NiS}_{2}$ hollow spheres photo co-catalysts from supermolecular precursor for $\mathrm{H}_{2}$ production from water splitting, Chem. Eng. J., 2016, 290, 74-81.

203 C. Tang, Z. Pu, Q. Liu, A. M. Asiri and X. Sun, $\mathrm{NiS}_{2}$ nanosheets array grown on carbon cloth as an efficient 3D hydrogen evolution cathode, Electrochim. Acta, 2015, 153, 508-514.

204 F. Gautier, G. Krill, M. F. Lapierre and C. Robert, Influence of non-stoichiometry on the electrical and magnetic properties of $\mathrm{NiS}_{2}$, Solid State Commun., 1972, 11, 12011203.

205 A. Jamil, S. S. Batool, F. Sher and M. A. Rafiq, Determination of density of states, conduction mechanisms and dielectric properties of nickel disulfide nanoparticles, AIP Adv., 2016, 6, 055120.

206 Z. Wan, C. Jia and Y. Wang, In situ growth of hierarchical $\mathrm{NiS}_{2}$ hollow microspheres as efficient counter electrode for dye-sensitized solar cell, Nanoscale, 2015, 7, 1273712742.

207 X. Zuo, S. Yan, B. Yang, G. Li, M. Wu, Y. Ma, S. Jin and K. Zhu, Hollow spherical NiS/NiS ${ }_{2}, J$. Mater. Sci.: Mater. Electron., 2016, 27, 7974.

208 X. Zuo, S. Yan, B. Yang, G. Li, H. Zhang, H. Tang, M. Wu, Y. Ma, S. Jin and K. Zhu, Template-free synthesis of nickel sulfides hollow spheres and their application in dye-sensitized solar cells, Sol. Energy, 2016, 132, 503-510.

209 J. Zheng, W. Zhou, Y. Ma, W. Cao, C. Wang and L. Guo, Facet-dependent $\mathrm{NiS}_{2}$ polyhedrons on counter electrodes for dye-sensitized solar cells, Chem. Commun., 2015, 51, 12863-12866.

210 Z. Li, F. Gong, G. Zhou and Z. S. Wang, $\mathrm{NiS}_{2} /$ reduced graphene oxide nanocomposites for efficient dyesensitized solar cells, J. Phys. Chem. C, 2013, 117, 65616566.

211 L. Zhu, B. J. Richardson and Q. Yu, Anisotropic growth of iron pyrite $\mathrm{FeS}_{2}$ nanocrystals via oriented attachment, Chem. Mater., 2015, 27, 3516-3525.

212 J. Puthussery, S. Seefeld, N. Berry, M. Gibbs and M. Law, Colloidal iron pyrite $\left(\mathrm{FeS}_{2}\right)$ nanocrystal inks for thin-film photovoltaics, J. Am. Chem. Soc., 2010, 133, 716-719.
213 Y. Bi, Y. Yuan, C. L. Exstrom, S. A. Darveau and J. Huang, Air stable, photosensitive, phase pure iron pyrite nanocrystal thin films for photovoltaic application, Nano Lett., 2011, 11, 4953-4957.

214 M. Cabaán-Acevedo, M. S. Faber, Y. Tan, R. J. Hamers and S. Jin, Synthesis and properties of semiconducting iron pyrite $\left(\mathrm{FeS}_{2}\right)$ nanowires, Nano Lett., 2012, 12, 1977-1982.

215 S. Shukla, G. Xing, H. Ge, R. R. Prabhakar, S. Mathew, Z. Su, V. Nalla, T. Venkatesan, N. Mathews, T. Sritharan and T. C. Sum, Origin of photocarrier losses in iron pyrite $\left(\mathrm{FeS}_{2}\right)$ nanocubes, ACS Nano, 2016, 10, 4431-4440.

216 M. Barawi, I. J. Ferrer, E. Flores, S. Yoda, J. R. Ares and C. Sánchez, Hydrogen photoassisted generation by visible light and an earth abundant photocatalyst: pyrite $\left(\mathrm{FeS}_{2}\right)$, J. Phys. Chem. C, 2016, 120, 9547-9552.

217 I. G. Orletskii, P. D. Mar'yanchuk, E. V. Maistruk, M. N. Solovan and V. V. Brus, Low-temperature spraypyrolysis of $\mathrm{FeS}_{2}$ films and their electrical and optical properties, Phys. Solid State, 2016, 58, 37-41.

218 F. Jiang, L. T. Peckler and A. J. Muscat, Phase pure pyrite $\mathrm{FeS}_{2}$ nanocubes synthesized using oleylamine as ligand, solvent, and reductant, Cryst. Growth Des., 2015, 15, 35653572.

219 X. Zhang, T. Scott, T. Socha, D. Nielsen, M. Manno, M. Johnson, Y. Yan, Y. Losovyj, P. Dowben, E. S. Aydil and C. Leighton, Phase stability and stoichiometry in thin film iron pyrite: impact on electronic transport properties, ACS Appl. Mater. Interfaces, 2015, 7, 1413014139.

220 L. Xu, Y. Hu, H. Zhang, H. Jiang and C. Li, Confined synthesis of $\mathrm{FeS}_{2}$ nanoparticles encapsulated in carbon nanotube hybrids for ultrastable lithium-ion batteries, ACS Sustainable Chem. Eng., 2016, 4, 4251-4255.

221 S. Shukla, N. H. Loc, P. P. Boix, T. M. Koh, R. R. Prabhakar, H. K. Mulmudi, J. Zhang, S. Chen, C. F. Ng, C. H. A. Huan and N. Mathews, Iron pyrite thin film counter electrodes for dye-sensitized solar cells: high efficiency for iodine and cobalt redox electrolyte cells, ACS Nano, 2014, 8, 1059710605.

222 Q. H. Huang, T. Ling, S. Z. Qiao and X. W. Du, Pyrite nanorod arrays as an efficient counter electrode for dyesensitized solar cells, J. Mater. Chem. A, 2013, 1, 1182811833.

223 C. Song, S. Wang, W. Dong, X. Fang, J. Shao, J. Zhu and X. Pan, Hydrothermal synthesis of iron pyrite $\left(\mathrm{FeS}_{2}\right)$ as efficient counter electrodes for dye-sensitized solar cells, Sol. Energy, 2016, 133, 429-436.

224 Y. C. Wang, D. Y. Wang, Y. T. Jiang, H. A. Chen, C. C. Chen, K. C. Ho, H. L. Chou and C. W. Chen, $\mathrm{FeS}_{2}$ Nanocrystal Ink as a Catalytic Electrode for Dye-Sensitized Solar Cells, Angew. Chem., Int. Ed., 2013, 52, 6694-6698.

225 B. Kilic, S. Turkdogan, A. Astam, O. C. Ozer, M. Asgin, H. Cebeci, D. Urk and S. P. Mucur, Preparation of Carbon Nanotube/ $/ \mathrm{TiO}_{2}$ Mesoporous Hybrid Photoanode with Iron Pyrite $\left(\mathrm{FeS}_{2}\right)$ Thin Films Counter Electrodes for DyeSensitized Solar Cell., Sci. Rep., 2016, 6, 27052. 
226 S. Miyahara and T. Teranishi, Magnetic properties of $\mathrm{FeS}_{2}$ and $\mathrm{CoS}_{2}$, J. Appl. Phys., 1968, 39, 896-897.

227 N. Wu, Y. B. Losovyj, D. Wisbey, K. Belashchenko, M. Manno, L. Wang, C. Leighton and P. A. Dowben, The electronic band structure of $\mathrm{CoS}_{2}$, J. Phys.: Condens. Matter, 2007, 19, 156224.

228 W. Fang, D. Liu, Q. Lu, X. Sun and A. M. Asiri, Nickel promoted cobalt disulfide nanowire array supported on carbon cloth: an efficient and stable bifunctional electrocatalyst for full water splitting, Electrochem. Commun., 2016, 63, 60-64.

229 Q. Wang, L. Jiao, Y. Han, H. Du, W. Peng, Q. Huan, D. Song, Y. Si, Y. Wang and H. Yuan, $\mathrm{CoS}_{2}$ hollow spheres: fabrication and their application in lithium-ion batteries, J. Phys. Chem. C, 2011, 115, 8300-8304.

230 L. Yu, J. F. Yang and X. W. D. Lou, Formation of $\mathrm{CoS}_{2}$ nanobubble hollow prisms for highly reversible lithium storage, Angew. Chem., Int. Ed., 2016, 55, 13422-13426.

231 D. Zhang, H. Liu, J. Zhang, X. Wang, R. Zhang, J. Zhou, J. Zhong and B. Yuan, Synthesis of novel $\mathrm{CoS}_{2}$ nanodendrites with high performance supercapacitors, Int. J. Electrochem. Sci., 2016, 11, 6791-6798.

232 J. Jin, X. Zhang and T. He, Self-assembled $\mathrm{CoS}_{2}$ nanocrystal film as an efficient counter electrode for dye-sensitized solar cells, J. Phys. Chem. C, 2014, 118, 24877-24883.

233 J. C. Tsai, M. H. Hon and I. C. Leu, Fabrication of mesoporous $\mathrm{CoS}_{2}$ nanotube arrays as the counter electrodes of dye-sensitized solar cells, Chem.-Asian J., 2015, 10, 1932-1939.

234 J. C. Tsai, M. H. Hon and C. Leu, Preparation of $\mathrm{CoS}_{2}$ nanoflake arrays through ion exchange reaction of $\mathrm{Co}(\mathrm{OH})_{2}$ and their application as counter electrodes for dye-sensitized solar cells, $R S C$ Adv., 2015, 5, 4328-4333.

235 M. Congiu, L. G. S. Albano, F. Decker and C. F. O. Graeff, Single precursor route to efficient cobalt sulphide counter electrodes for dye sensitized solar cells, Electrochim. Acta, 2015, 151, 517-524.

236 S. S. Rao, C. V. Gopi, S. K. Kim, M. K. Son, M. S. Jeong, A. D. Savariraj, K. Prabakar and H. J. Kim, Cobalt sulfide thin film as an efficient counter electrode for dyesensitized solar cells, Electrochim. Acta, 2014, 133, 174-179.

237 X. Cui, Z. Xie and Y. Wang, Novel $\mathrm{CoS}_{2}$ embedded carbon nanocages by direct sulfurizing metal-organic frameworks for dye-sensitized solar cells, Nanoscale, 2016, 8, 11984-11992.

238 H. J. Kim, C. W. Kim, D. Punnoose, C. V. Gopi, S. K. Kim, K. Prabakar and S. S. Rao, Nickel doped cobalt sulfide as a high performance counter electrode for dye-sensitized solar cells, Appl. Surf. Sci., 2015, 328, 78-85.

239 X. Duan, Z. Gao, J. Chang, D. Wu, P. Ma, J. He, F. Xu, S. Gao and K. Jiang, $\mathrm{CoS}_{2}$-graphene composite as efficient catalytic counter electrode for dye-sensitized solar cell, Electrochim. Acta, 2013, 114, 173-179.

240 L. Sun, Y. Bai, N. Zhang and K. Sun, The facile preparation of a cobalt disulfide-reduced graphene oxide composite film as an efficient counter electrode for dye-sensitized solar cells, Chem. Commun., 2015, 51, 1846-1849.
241 B. Hai, K. Tang, C. Wang, C. An, Q. Yang, G. Shen and Y. Qian, Synthesis of $\mathrm{SnS}_{2}$ nanocrystals via a solvothermal process, J. Cryst. Growth, 2001, 225, 92-95.

242 C. Zhai, N. Du and H. Z. D. Yang, Large-scale synthesis of ultrathin hexagonal tin disulfide nanosheets with highly reversible lithium storage, Chem. Commun., 2011, 47, 1270-1272.

243 Y. T. Lin, J. B. Shi, Y. C. Chen, C. J. Chen and P. F. Wu, Synthesis and characterization of tin disulfide $\left(\mathrm{SnS}_{2}\right)$ nanowires, Nanoscale Res. Lett., 2009, 4, 694.

244 J. Wang, J. Liu, H. Xu, S. Ji, J. Wang, Y. Zhou, P. Hodgson and Y. Li, Gram-scale and template-free synthesis of ultralong tin disulfide nanobelts and their lithium ion storage performances, J. Mater. Chem. A, 2013, 1, 11171122.

245 Y. Huang, H. Zang, J. S. Chen, E. A. Sutter, P. W. Sutter, C. Y. Nam and M. Cotlet, Hybrid quantum dot-tin disulfide field-effect transistors with improved photocurrent and spectral responsivity, Appl. Phys. Lett., 2016, 108, 123502.

246 A. Giberti, A. Gaiardo, B. Fabbri, S. Gherardi, V. Guidi, C. Malagù, P. Bellutti, G. Zonta, D. Casotti and G. Cruciani, Tin(Iv) sulfide nanorods as a new gas sensing material, Sens. Actuators, B, 2016, 223, 827-833.

247 W. Du, D. Deng, Z. Han, W. Xiao, C. Bian and X. Qian, Hexagonal tin disulfide nanoplatelets: a new photocatalyst driven by solar light, CrystEngComm, 2011, 13, 2071-2076.

248 N. T. N. Truong and C. Park, Synthesis and characterization of tin disulfide nanocrystals for hybrid bulk hetero-junction solar cell applications, Electron. Mater. Lett., 2016, 12, 308314.

249 Y. Bai, X. Zong, H. Yu, Z. G. Chen and L. Wang, Scalable low-cost $\mathrm{SnS}_{2}$ nanosheets as counter electrode building blocks for dye-sensitized solar cells, Chem.-Eur. J., 2014, 20, 8670-8676.

250 B. Yang, X. Zuo, P. Chen, L. Zhou, X. Yang, H. Zhang, G. Li, M. Wu, Y. Ma, S. Jin and X. Chen, Nanocomposite of tin sulfide nanoparticles with reduced graphene oxide in high-efficiency dye-sensitized solar cells, ACS Appl. Mater. Interfaces, 2015, 7, 137-143.

251 S. Sugai and T. Ueda, High-pressure Raman spectroscopy in the layered materials $2 \mathrm{H}-\mathrm{MoS}_{2}, 2 \mathrm{HMoTe}_{2}$, and $2 \mathrm{H}-\mathrm{MoTe}_{2}$, Phys. Rev. B: Condens. Matter Mater. Phys., 1982, 26, 6554.

252 T. Böker, R. Severin, A. Müller, C. Janowitz, R. Manzke, D. Voß, P. Krüger, A. Mazur and J. Pollmann, Band structure of $\mathrm{MoS}_{2}, \mathrm{MoSe}_{2}$, and $\alpha-\mathrm{MoTe}_{2}$ : angle-resolved photoelectron spectroscopy and $a b$ initio calculations, Phys. Rev. B: Condens. Matter Mater. Phys., 2001, 64, 235305.

253 N. L. Heda, A. Dashora, A. Marwal, Y. Sharma, S. K. Srivastava, G. Ahmed, R. Jain and B. L. Ahuja, Electronic properties and Compton profiles of molybdenum dichalcogenides, J. Phys. Chem. Solids, 2010, 71, 187-193.

254 S. H. Rhim, Y. S. Kim and A. J. Freeman, Strain-induced giant second-harmonic generation in monolayered $2 \mathrm{H}-$ $\mathrm{MoX}_{2}$ (X = S, Se, Te), Appl. Phys. Lett., 2015, 107, 241908. 
255 S. Caramazza, C. Marini, L. Simonelli, P. Dore and P. Postorino, Temperature dependent EXAFS study on transition metal dichalcogenides $\mathrm{MoX}_{2}(\mathrm{X}=\mathrm{S}$, Se, Te), $J$. Phys.: Condens. Matter, 2016, 28, 325401.

$256 \mathrm{H}$. Jiang, Electronic band structures of molybdenum and tungsten dichalcogenides by the GW approach, J. Phys. Chem. C, 2012, 116, 7664-7671.

257 U. Ahuja, R. Joshi, D. C. Kothari, H. Tiwari and K. Venugopalan, Optical response of mixed molybdenum dichalcogenides for solar cell applications using the modified becke-johnson potential, Z. Naturforsch., A: Phys. Sci., 2016, 71, 213-223.

258 A. Abderrahmane, P. J. Ko, T. V. Thu, S. Ishizawa, T. Takamura and A. Sandhu, High photosensitivity fewlayered $\mathrm{MoSe}_{2}$ back-gated field-effect phototransistors, Nanotechnology, 2014, 25, 365202.

259 H. J. Chuang, B. Chamlagain, M. Koehler, M. M. Perera, J. Yan, D. Mandrus, D. Tomaánek and Z. Zhou, Lowresistance $2 \mathrm{D} / 2 \mathrm{D}$ ohmic contacts: a universal approach to high-performance $\mathrm{WSe}_{2}, \mathrm{MoS}_{2}$, and $\mathrm{MoSe}_{2}$ transistors, Nano Lett., 2016, 16, 1896-1902.

260 L. T. L. Lee, J. He, B. Wang, Y. Ma, K. Y. Wong, Q. Li, X. Xiao and $\mathrm{T}$. Chen, Few-layer $\mathrm{MoSe}_{2}$ possessing high catalytic activity towards iodide/tri-iodide redox shuttles, Sci. Rep., 2014, 4, 4063-4069.

261 H. Chen, Y. Xie, H. Cui, W. Zhao, X. Zhu, Y. Wang, X. Lü and F. Huang, In situ growth of a $\mathrm{MoSe}_{2} / \mathrm{Mo}$ counter electrode for high efficiency dye-sensitized solar cells, Chem. Commun., 2014, 50, 4475-4477.

262 I. A. Ji, H. M. Choi and J. H. Bang, Metal selenide films as the counter electrode in dye-sensitized solar cell, Mater. Lett., 2014, 123, 51-54.

263 J. Jia, J. Wu, J. Dong, Y. Tu, Z. Lan, L. Fan and Y. Wei, Highperformance molybdenum diselenide electrodes used in dye-sensitized solar cells and supercapacitors, IEEE J. Photovoltaics, 2016, 6, 1196-1202.

264 E. Bi, H. Chen, X. Yang, F. Ye, M. Yin and L. Han, Fullerenestructured $\mathrm{MoSe}_{2}$ hollow spheres anchored on highly nitrogen-doped graphene as a conductive catalyst for photovoltaic applications, Sci. Rep., 2015, 5, 13214.

265 Y. J. Huang, M. S. Fan, C. T. Li, C. P. Lee, T. Y. Chen, R. Vittal and K. C. Ho, MoSe 2 nanosheet/poly(3,4ethylenedioxythiophene):poly

(styrenesulfonate) composite film as a Pt-free counter electrode for dyesensitized solar cells, Electrochim. Acta, 2016, 211, 794-803.

266 J. Dong, J. Wu, J. Jia, L. Hu and S. Dai, Cobalt/molybdenum ternary hybrid with hierarchical architecture used as high efficient counter electrode for dye-sensitized solar cells, Sol. Energy, 2015, 122, 326-333.

267 Q. Jiang and G. $\mathrm{Hu}, \mathrm{Co}_{0.85}$ Se hollow nanoparticles as Pt-free counter electrode materials for dye-sensitized solar cells, Mater. Lett., 2015, 153, 114-117.

268 Y. Duan, Q. Tang, J. Liu, B. He and L. Yu, Transparent metal selenide alloy counter electrodes for high-efficiency bifacial dye-sensitized solar cells, Angew. Chem., Int. Ed., 2014, 53, 14569-14574.
269 A. Banerjee, K. K. Upadhyay, S. Bhatnagar, M. Tathavadekar, U. Bansode, S. Agarkar and S. B. Ogale, Nickel cobalt sulfide nanoneedle array as an effective alternative to $\mathrm{Pt}$ as a counter electrode in dye sensitized solar cells, RSC Adv., 2014, 4, 8289-8294.

270 D. Jerome, A. J. Grant and A. D. Yoffe, Pressure enhanced superconductivity in $\mathrm{NbSe}_{2}$, Solid State Commun., 1971, 9, 2183-2185.

271 D. H. Galvan, J. H. Kim, M. B. Maple, M. Avalos-Borja and E. Adem, Formation of $\mathrm{NbSe}_{2}$ nanotubes by electron irradiation, Fullerene Sci. Technol., 2000, 8, 143-151.

272 N. E. Staley, J. Wu, P. Eklund, Y. Liu, L. Li and Z. Xu, Electric field effect on superconductivity in atomically thin flakes of $\mathrm{NbSe}_{2}$, Phys. Rev. B: Condens. Matter Mater. Phys., 2009, 80, 184505.

273 V. V. Ivanovskaya, A. N. Enyashin, N. I. Medvedeva and A. L. Ivanovskii, Electronic properties of superconducting $\mathrm{NbSe}_{2}$ nanotubes, Phys. Status Solidi B, 2003, 238, R1-R4.

274 T. Tsuneta, T. Toshima, K. Inagaki, T. Shibayama, S. Tanda, S. Uji, M. Ahlskog, P. Hakonen and M. Paalanen, Formation of metallic $\mathrm{NbSe}_{2}$ nanotubes and nanofibers, Curr. Appl. Phys., 2003, 3, 473-476.

275 E. Hitz, J. Wan, A. Patel, Y. Xu, L. Meshi, J. Dai, Y. Chen, A. Lu, A. V. Davydov and L. Hu, Electrochemical intercalation of lithium ions into $\mathrm{NbSe}_{2}$ nanosheets, ACS Appl. Mater. Interfaces, 2016, 8, 11390-11395.

276 K. J. Reynolds, G. L. Frey and R. H. Friend, Solutionprocessed niobium diselenide as conductor and anode for polymer light-emitting diodes, Appl. Phys. Lett., 2003, 82, 1123-1125.

277 (a) M. Yoshida, J. Ye, T. Nishizaki, N. Kobayashi and Y. Iwasa, Electrostatic and electrochemical tuning of superconductivity in two-dimensional $\mathrm{NbSe}_{2}$ crystals, Appl. Phys. Lett., 2016, 108, 202602; (b) X. Zhu, Y. Guo, H. Cheng, J. Dai, X. An, J. Zhao, K. Tian, S. Wei, X. C. Zeng, C. Wu and Y. Xie, Signature of coexistence of superconductivity and ferromagnetism in twodimensional $\mathrm{NbSe}_{2}$ triggered by surface molecular adsorption, Nat. Commun., 2016, 7, 11210.

278 D. W. Murphy, F. A. Trumbore and J. N. Carides, A new niobium selenide cathode for nonaqueous lithium batteries, J. Electrochem. Soc., 1977, 124, 325-329.

279 J. Guo, Y. Shi, C. Zhu, L. Wang, N. Wang and T. Ma, Costeffective and morphology-controllable niobium diselenides for highly efficient counter electrodes of dyesensitized solar cells, J. Mater. Chem. A, 2013, 1, 1187411879.

280 M. A. Ibrahem, W. C. Huang, T. W. Lan, K. M. Boopathi, Y. C. Hsiao, C. H. Chen, W. Budiawan, Y. Y. Chen, C. S. Chang, L. J. Li, C. H. Tsai and C. C. Chu, Controlled mechanical cleavage of bulk niobium diselenide to nanoscaled sheet, rod, and particle structures for Pt-free dye-sensitized solar cells, J. Mater. Chem. A, 2014, 2, 11382-11390.

281 J. Guo, S. Liang, Y. Shi, C. Hao, X. Wang and T. Ma, Transition metal selenides as efficient counter-electrode 
materials for dye-sensitized solar cells, Phys. Chem. Chem. Phys., 2015, 17, 28985-28992.

282 F. Gong, X. Xu, Z. Li, G. Zhou and Z. S. Wang, $\mathrm{NiSe}_{2}$ as an efficient electrocatalyst for a Pt-free counter electrode of dye-sensitized solar cells, Chem. Commun., 2013, 49, 1437-1439.

283 X. Zhang, T. Z. Jing, S. Q. Guo, G. D. Gao and L. Liu, Synthesis of $\mathrm{NiSe}_{2} /$ reduced graphene oxide crystalline materials and their efficient electrocatalytic activity in dye-sensitized solar cells, RSC Adv., 2014, 4, 50312-50317.

284 J. Xiao, L. Wan, S. Yang, F. Xiao and S. Wang, Design hierarchical electrodes with highly conductive $\mathrm{NiCo}_{2} \mathrm{~S}_{4}$ nanotube arrays grown on carbon fiber paper for highperformance pseudocapacitors, Nano Lett., 2014, 14, 831838.

285 Q. Wang, B. Liu, X. Wang, S. Ran, L. Wang, D. Chen and G. Shen, Morphology evolution of urchin-like $\mathrm{NiCo}_{2} \mathrm{O}_{4}$ nanostructures and their applications as psuedocapacitors and photoelectrochemical cells, $J$. Mater. Chem., 2012, 22, 21647-21653.

286 J. Huo, J. Wu, M. Zheng, Y. Tu and Z. Lan, Flower-like nickel cobalt sulfide microspheres modified with nickel sulfide as Pt-free counter electrode for dye-sensitized solar cells, $J$. Power Sources, 2016, 304, 266-272.

287 X. Qian, H. Li, L. Shao, X. Jiang and L. Hou, Morphologytuned synthesis of nickel cobalt selenides as highly efficient Pt-free counter electrode catalysts for dyesensitized solar cells, ACS Appl. Mater. Interfaces, 2016, 8, 29486-29495.

288 R. G. Coleman, New occurrences of ferroselite $\left(\mathrm{FeSe}_{2}\right)$, Geochim. Cosmochim. Acta, 1959, 16, 296-301.

289 H. D. Lutz and B. Müller, Lattice vibration spectra LXVIII. Single-crystal Raman spectra of marcasite-type iron chalcogenides and pnictides, $\mathrm{FeX}_{2}(\mathrm{X}=\mathrm{S}$, Se, Te; P, As, Sb), Phys. Chem. Miner., 1991, 18, 265-268.

290 E. Bastola, K. P. Bhandari, A. J. Matthews, N. Shrestha and R. J. Ellingson, Elemental anion thermal injection synthesis of nanocrystalline marcasite iron dichalcogenide $\mathrm{FeSe}_{2}$ and $\mathrm{FeTe}_{2}, \mathrm{RSC} A d v$., 2016, 6, 69708-69714.

291 X. Mao, J. G. Kim, J. Han, H. S. Jung, S. G. Lee, N. A. Kotov and J. Lee, Phase-pure $\operatorname{FeSe}_{x}(x=1,2)$ nanoparticles with one-and two-photon luminescence, J. Am. Chem. Soc., 2014, 136, 7189-7192.

292 B. Yuan, W. Luan and S. T. Tu, One-step synthesis of cubic $\mathrm{FeS}_{2}$ and flower-like $\mathrm{FeSe}_{2}$ particles by a solvothermal reduction process, Dalton Trans., 2012, 41, 772-776.

293 J. Xu, K. Jang, J. Lee, H. J. Kim, J. Jeong, J. G. Park and S. U. Son, Phase-selective growth of assembled $\mathrm{FeSe}_{2}$ nanorods from organometallic polymers and their surface magnetism, Cryst. Growth Des., 2011, 11, 2707-2710.

294 W. Shi, X. Zhang, G. Che, W. Fan and C. Liu, Controlled hydrothermal synthesis and magnetic properties of threedimensional $\mathrm{FeSe}_{2}$ rod clusters and microspheres, Chem. Eng. J., 2013, 215, 508-516.

295 X. Chang, J. Jian, G. Cai, R. Wu and J. Li, Three-dimensional $\mathrm{FeSe}_{2}$ microflowers assembled by nanosheets: synthesis, optical properties, and catalytic activity for the hydrogen evolution reaction, Electron. Mater. Lett., 2016, 12, 237-242. 296 G. D. Park, J. H. Kim and Y. C. Kang, Large-scale production of spherical $\mathrm{FeSe}_{2}$-amorphous carbon composite powders as anode materials for sodium-ion batteries, Mater. Charact., 2016, 120, 349-356.

297 B. G. Ganga, C. Ganeshraj, A. G. Krishna and P. N. Santhosh, Electronic and optical properties of $\mathrm{FeSe}_{2}$ polymorphs: solar cell absorber, arXiv preprint arXiv:1303.1381, 2013.

298 R. Jin, K. Zhao, X. Pu, M. Zhang, F. Cai, X. Yang, H. Kim and Y. Zhao, Structural and photovoltaic properties of $\mathrm{FeSe}_{2}$ films prepared by radio frequency magnetron sputtering, Mater. Lett., 2016, 179, 179-181.

299 D. Kong, J. J. Cha, H. Wang, H. R. Lee and Y. Cui, First-row transition metal dichalcogenide catalysts for hydrogen evolution reaction, Energy Environ. Sci., 2013, 6, 3553-3558.

300 J. Yang, G. H. Cheng, J. H. Zeng, S. H. Yu, X. M. Liu and Y. T. Qian, Shape control and characterization of transition metal diselenides $\mathrm{MSe}_{2}(\mathrm{M}=\mathrm{Ni}, \mathrm{Co}, \mathrm{Fe})$ prepared by a solvothermal-reduction process, Chem. Mater., 2001, 13, 848-853.

$301 \mathrm{X}$. Chen and R. Fan, Low-temperature hydrothermal synthesis of transition metal dichalcogenides, Chem. Mater., 2001, 13, 802-805.

302 S. Huang, Q. He, W. Chen, Q. Qiao, J. Zai and X. Qian, Ultrathin $\mathrm{FeSe}_{2}$ nanosheets: controlled synthesis and application as a heterogeneous catalyst in dye-sensitized solar cells, Chem.-Eur. J., 2015, 21, 4085-4091.

303 S. Huang, Q. He, W. Chen, J. Zai, Q. Qiao and X. Qian, 3D hierarchical $\mathrm{FeSe}_{2}$ microspheres: controlled synthesis and applications in dye-sensitized solar cells, Nano Energy, 2015, 15, 205-215.

304 W. Wang, X. Pan, W. Liu, B. Zhang, H. Chen, X. Fang, J. Yao and S. Dai, $\mathrm{FeSe}_{2}$ films with controllable morphologies as efficient counter electrodes for dye-sensitized solar cells, Chem. Commun., 2014, 50, 2618-2620.

305 D. Kong, H. Wang, Z. Lu and Y. Cui, $\mathrm{CoSe}_{2}$ nanoparticles grown on carbon fiber paper: an efficient and stable electrocatalyst for hydrogen evolution reaction, J. Am. Chem. Soc., 2014, 136, 4897-4900.

306 Y. Liu, H. Cheng, M. Lyu, S. Fan, Q. Liu, W. Zhang, Y. Zhi, C. Wang, C. Xiao, S. Wei and B. Ye, Low overpotential in vacancy-rich ultrathin $\mathrm{CoSe}_{2}$ nanosheets for water oxidation, J. Am. Chem. Soc., 2014, 136, 15670-15675.

307 R. Wu, Y. Xue, B. Liu, K. Zhou, J. Wei and S. H. Chan, Cobalt diselenide nanoparticles embedded within porous carbon polyhedra as advanced electrocatalyst for oxygen reduction reaction, J. Power Sources, 2016, 330, 132-139.

308 C. L. McCarthy, C. A. Downes, E. C. Schueller, K. Abuyen and R. L. Brutchey, Method for the solution deposition of phase-pure $\mathrm{CoSe}_{2}$ as an efficient hydrogen evolution reaction electrocatalyst, ACS Energy Lett., 2016, 1, 607-611.

309 J. Dong, J. Wu, J. Jia, S. Wu, P. Zhou, Y. Tu and Z. Lan, Cobalt selenide nanorods used as a high efficient counter electrode for dye-sensitized solar cells, Electrochim. Acta, 2015, 168, 69-75. 
310 I. T. Chiu, C. T. Li, C. P. Lee, P. Y. Chen, Y. H. Tseng, R. Vittal and K. C. Ho, Nanoclimbing-wall-like $\mathrm{CoSe}_{2} /$ carbon composite film for the counter electrode of a highly efficient dye-sensitized solar cell: a study on the morphology control, Nano Energy, 2016, 22, 594-606.

311 W. Y. Choi, Synthesis of $\mathrm{CoSe}_{2} /$ RGO composites and their application in a counter electrode of dye-sensitized solar cells, Master thesis, Department of Chemical Engineering, Graduate school of Ulsan National Institute of Science and Technology (UNIST), South Korea, 2015, http://scholarworks.unist.ac.kr/handle/201301/10604.

312 F. Gong, H. Wang, X. Xu, G. Zhou and Z. S. Wang, In situ growth of $\mathrm{Co}_{0.85} \mathrm{Se}$ and $\mathrm{Ni}_{0.85} \mathrm{Se}$ on conductive substrates as high-performance counter electrodes for dye-sensitized solar cells, J. Am. Chem. Soc., 2012, 134, 10953-10958.

313 H. Zhang, C. X. Liu, X. L. Qi, X. Dai, Z. Fang and S. C. Zhang, Topological insulators in $\mathrm{Bi}_{2} \mathrm{Se}_{3}, \mathrm{Bi}_{2} \mathrm{Te}_{3}$ and $\mathrm{Sb}_{2} \mathrm{Te}_{3}$ with a single Dirac cone on the surface, Nat. Phys., 2009, 5, 438-442.

314 P. A. Sharma, A. L. Sharma, M. Hekmaty, K. Hattar, V. Stavila, R. Goeke, K. Erickson, D. L. Medlin, M. Brahlek, N. Koirala and S. Oh, Ion beam modification of topological insulator bismuth selenide, Appl. Phys. Lett., 2014, 105, 242106.

315 Y. Sun, H. Cheng, S. Gao, Q. Liu, Z. Sun, C. Xiao, C. Wu, S. Wei and Y. Xie, Atomically thick bismuth selenide freestanding single layers achieving enhanced thermoelectric energy harvesting, J. Am. Chem. Soc., 2012, 134, 20294-20297.

316 S. K. Batabyal, C. Basu, A. R. Das and G. S. Sanyal, Solvothermal synthesis of bismuth selenide nanotubes, Mater. Lett., 2006, 60, 2582-2585.

317 H. Tang, X. Wang, Y. Xiong, Y. Zhao, Y. Zhang, Y. Zhang, J. Yang and D. Xu, Thermoelectric characterization of individual bismuth selenide topological insulator nanoribbons, Nanoscale, 2015, 7, 6683-6690.

318 Y. Zou, Z. G. Chen, Y. Huang, L. Yang, J. Drennan and J. Zou, Anisotropic electrical properties from vapor-solidsolid grown $\mathrm{Bi}_{2} \mathrm{Se}_{3}$ nanoribbons and nanowires, J. Phys. Chem. C, 2014, 118, 20620-20626.

319 H. Zhu, E. Zhao, C. A. Richter and Q. Li, Topological insulator $\mathrm{Bi}_{2} \mathrm{Se}_{3}$ nanowire field effect transistors, ECS Trans., 2014, 64, 51-59.

320 Y. Fan, G. Hao, S. Luo, X. Qi and J. Zhong, Photoresponse properties of $\mathrm{Bi}_{2} \mathrm{Se}_{3}$ nanoplates, Sci. Adv. Mater., 2015, 7, 1589-1593.

321 X. Zhang, F. Wen, J. Xiang, X. Wang, L. Wang, W. Hu and Z. Liu, Wearable non-volatile memory devices based on topological insulator $\mathrm{Bi}_{2} \mathrm{Se}_{3} / \mathrm{Pt}$ fibers, Appl. Phys. Lett., 2015, 107, 103109.

322 Z. Yuan, Z. Wu, S. Bai, W. Cui, J. Liu, T. Song and B. Sun, Layered bismuth selenide utilized as hole transporting layer for highly stable organic photovoltaics, Org. Electron., 2015, 26, 327-333.

323 Z. Li, Y. Hu, K. A. Howard, T. Jiang, X. Fan, Z. Miao, Y. Sun, F. Besenbacher and $\mathrm{M}$. Yu, Multifunctional bismuth selenide nanocomposites for antitumor thermochemotherapy and imaging, ACS Nano, 2015, 10, 984-997.

324 Z. Li, J. Liu, Y. Hu, K. A. Howard, Z. Li, X. Fan, M. Chang, Y. Sun, F. Besenbacher, C. Chen and M. Yu, Multimodal imaging-guided antitumor photothermal therapy and drug delivery using bismuth selenide spherical-sponge, ACS Nano, 2016, 10, 9646-9658.

325 L. Zhu, K. Y. Cho and W. C. Oh, Microwave-assisted synthesis of $\mathrm{Bi}_{2} \mathrm{Se}_{3} /$ reduced graphene oxide nanocomposite as efficient catalytic counter electrode for dye-sensitized solar cell, Fullerenes, Nanotubes, Carbon Nanostruct., 2016, 24, 622-629.

326 A. L. Prieto, M. S. Sander, M. S. Martín-González, R. Gronsky, T. Sands and A. M. Stacy, Electrodeposition of ordered $\mathrm{Bi}_{2} \mathrm{Te}_{3}$ nanowire arrays, J. Am. Chem. Soc., 2001, 123, 7160-7161.

327 L. Ma, Q. Zhang, Q. Zhao, Z. Li, C. Ji and X. J. Xu, Synthesis and characterization of $\mathrm{Bi}_{2} \mathrm{Te}_{3} / \mathrm{Te}$ superlattice nanowire arrays, J. Nanosci. Nanotechnol., 2016, 16, 1207-1210.

328 J. Lee, J. Kim, W. Moon, A. Berger and J. Lee, Enhanced seebeck coefficients of thermoelectric $\mathrm{Bi}_{2} \mathrm{Te}_{3}$ nanowires as a result of an optimized annealing process, J. Phys. Chem. $C, 2012,116,19512-19516$.

329 J. Gooth, R. Zierold, P. Sergelius, B. Hamdou, J. Garcia, C. Damm, B. Rellinghaus, H. J. Pettersson, A. Pertsova, C. Canali and M. Borg, Local magnetic suppression of topological surface states in $\mathrm{Bi}_{2} \mathrm{Te}_{3}$ nanowires, ACS Nano, 2016, 10, 7180-7188.

330 R. Du, H. C. Hsu, A. C. Balram, Y. Yin, S. Dong, W. Dai, W. Zhao, D. Kim, S. Y. Yu, J. Wang and X. Li, Robustness of topological surface states against strong disorder observed in $\mathrm{Bi}_{2} \mathrm{Te}_{3}$ nanotubes, Phys. Rev. B, 2016, 93, 195402.

331 J. S. Son, M. K. Choi, M. K. Han, K. Park, J. Y. Kim, S. J. Lim, M. Oh, Y. Kuk, C. Park, S. J. Kim and T. Hyeon, n-Type nanostructured thermoelectric materials prepared from chemically synthesized ultrathin $\mathrm{Bi}_{2} \mathrm{Te}_{3}$ nanoplates, Nano Lett., 2012, 12, 640-647.

332 H. W. Tsai, T. H. Wang, T. C. Chan, P. J. Chen, C. C. Chung, A. Yaghoubi, C. N. Liao, E. W. G. Diau and Y. L. Chueh, Fabrication of large-scale single-crystal bismuth telluride $\left(\mathrm{Bi}_{2} \mathrm{Te}_{3}\right)$ nanosheet arrays by a single-step electrolysis process, Nanoscale, 2014, 6, 7780-7785.

333 L. Miao, J. Yi, Q. Wang, D. Feng, H. He, S. Lu, C. Zhao, H. Zhang and S. Wen, Broadband third order nonlinear optical responses of bismuth telluride nanosheets, Opt. Mater. Express, 2016, 6, 2244-2251.

334 N. W. Park, J. Y. Ahn, A. Umar, S. G. Yoon and S. K. Lee, Thermoelectric properties of n-type bismuth telluride $\left(\mathrm{Bi}_{2} \mathrm{Te}_{3}\right)$ thin films prepared by RF sputtering, Sci. Adv. Mater., 2016, 8, 1172-1176.

335 Y. Dou, F. Wu, L. Fang, G. Liu, C. Mao, K. Wan and M. Zhou, Enhanced performance of dye-sensitized solar cell using $\mathrm{Bi}_{2} \mathrm{Te}_{3}$ nanotube/ZnO nanoparticle composite photoanode by the synergistic effect of photovoltaic and thermoelectric conversion, J. Power Sources, 2016, 307, 181-189. 
336 K. Wan, F. Wu, Y. Dou, L. Fang and C. Mao, Enhance the performance of dye-sensitized solar cells by $\mathrm{Bi}_{2} \mathrm{Te}_{3}$ nanosheet/ZnO nanoparticle composite photoanode, $J$. Alloys Compd., 2016, 680, 373-380.

337 T. Chen, G. H. Guai, C. Gong, W. Hu, J. Zhu, H. Yang, Q. Yan and C. M. Li, Thermoelectric $\mathrm{Bi}_{2} \mathrm{Te}_{3}$-improved charge collection for high-performance dye-sensitized solar cells, Energy Environ. Sci., 2012, 5, 6294-6298.

338 L. Hu, L. Fang, F. Wu and J. Wang, Effect of the size of $\mathrm{Bi}_{2} \mathrm{Te}_{3}$ nanoplates on the performance of $\mathrm{TiO}_{2}$-based novel hybrid DSSC combined PV and TE effect, in MRS Proceedings (Vol. 1640, mrsf13-1640), Cambridge University Press, 2014.

339 A. Hinsch, J. M. Kroon, R. Kern, I. Uhlendorf, J. Holzbock, A. Meyer and J. Ferber, Long-term stability of dye-sensitised solar cells, Prog. Photovoltaics, 2001, 9, 425-438.

$340 \mathrm{H}$. Pettersson and T. Gruszecki, Long-term stability of lowpower dye-sensitised solar cells prepared by industrial methods, Sol. Energy Mater. Sol. Cells, 2001, 70, 203-212.

341 P. M. Sommeling, M. Späth, H. J. P. Smit, N. J. Bakker and J. M. Kroon, Long-term stability testing of dye-sensitized solar cells, J. Photochem. Photobiol., A, 2004, 164, 137-144.

342 M. Grätzel, Photovoltaic performance and long-term stability of dye-sensitized meosocopic solar cells, C. R. Chim., 2006, 9, 578-583.

343 S. Dai, J. Weng, Y. Sui, S. Chen, S. Xiao, Y. Huang, F. Kong, X. Pan, L. Hu, C. Zhang and K. Wang, The design and outdoor application of dye-sensitized solar cells, Inorg. Chim. Acta, 2008, 361, 786-791.

344 Y. Takeda, N. Kato, K. Higuchi, A. Takeichi, T. Motohiro, S. Fukumoto, T. Sano and T. Toyoda, Monolithically series-interconnected transparent modules of dyesensitized solar cells, Sol. Energy Mater. Sol. Cells, 2009, 93, 808-811.

345 M. I. Asghar, K. Miettunen, J. Halme, P. Vahermaa, M. Toivola, K. Aitola and P. Lund, Review of stability for advanced dye solar cells, Energy Environ. Sci., 2010, 3, 418-426.

346 A. G. Kontos, T. Stergiopoulos, V. Likodimos, D. Milliken, H. Desilvesto, G. Tulloch and P. Falaras, Long-term thermal stability of liquid dye solar cells, J. Phys. Chem. C, 2013, 117, 8636-8646.

347 R. Jiang, A. Anderson, P. R. Barnes, L. Xiaoe, C. Law and B. C. O'Regan, 2000 hours photostability testing of dye sensitised solar cells using a cobalt bipyridine electrolyte, J. Mater. Chem. A, 2014, 2, 4751-4757.

348 F. Sauvage, A review on current status of stability and knowledge on liquid electrolyte-based dye-sensitized solar cells, Adv. Chem., 2014, 939525, DOI: /10.1155/2014/939525.

349 S. Yun, P. D. Lund and A. Hinsch, Stability assessment of alternative platinum free counter electrodes for dyesensitized solar cells, Energy Environ. Sci., 2015, 8, 34953514 .

350 C. J. Liu, S. Y. Tai, S. W. Chou, Y. C. Yu, K. D. Chang, S. Wang, F. S. S. Chien, J. Y. Lin and T. W. Lin, Facile synthesis of $\mathrm{MoS}_{2}$ /graphene nanocomposite with high catalytic activity toward triiodide reduction in dye- sensitized solar cells, J. Mater. Chem., 2015, 22, 2105721064.

351 H. Sun, L. Zhang and Z. S. Wang, Single-crystal $\mathrm{CoSe}_{2}$ nanorods as an efficient electrocatalyst for dye-sensitized solar cells, J. Mater. Chem. A, 2014, 2, 16023-16029.

352 N. Kato, Y. Takeda, K. Higuchi, A. Takeichi, E. Sudo, H. Tanaka, T. Motohiro, T. Sano and T. Toyoda, Degradation analysis of dye-sensitized solar cell module after long-term stability test under outdoor working condition, Sol. Energy Mater. Sol. Cells, 2009, 93, 893-897.

353 H. Matsui, K. Okada, T. Kitamura and N. Tanabe, Thermal stability of dye-sensitized solar cells with current collecting grid, Sol. Energy Mater. Sol. Cells, 2009, 93, 1110-1115.

354 G. Xue, Y. Guo, T. Yu, J. Guan, X. Yu, J. Zhang, J. Liu and Z. Zou, Degradation mechanisms investigation for longterm thermal stability of dye-sensitized solar cells, Int. J. Electrochem. Sci., 2012, 7, 1496-1511.

355 R. Harikisun and H. Desilvestro, Long-term stability of dye solar cells, Sol. Energy, 2011, 85, 1179-1188.

356 Y. Wu, W. H. Zhu, S. M. Zakeeruddin and M. Grätzel, Insight into $\mathrm{D}-\mathrm{A}-\pi-\mathrm{A}$ structured sensitizers: a promising route to highly efficient and stable dye-sensitized solar sells, ACS Appl. Mater. Interfaces, 2015, 7, 9307-9318.

357 R. Katoh, A. Furube, S. Mori, M. Miyashita, K. Sunahara, N. Koumura and K. Hara, Highly stable sensitizer dyes for dye-sensitized solar cells: role of the oligothiophene moiety, Energy Environ. Sci., 2009, 2, 542-546.

358 D. Joly, L. Pellejà, S. Narbey, F. Oswald, J. Chiron, J. N. Clifford, E. Palomares and R. Demadrille, A robust organic dye for dye sensitized solar cells based on iodine/ iodide electrolytes combining high efficiency and outstanding stability, Sci. Rep., 2014, 4, 4033.

359 Z. S. Wang, Y. Cui, K. Hara, Y. Dan-oh, C. Kasada and A. Shinpo, A high-light-harvesting-efficiency coumarin dye for stable dye-sensitized solar cells, Adv. Mater., 2007, 19, 1138-1141.

360 S. Kim, D. Kim, H. Choi, M. S. Kang, K. Song, S. O. Kang and J. Ko, Enhanced photovoltaic performance and long-term stability of quasi-solid-state dye-sensitized solar cells via molecular engineering, Chem. Commun., 2008, 4951-4953.

361 X. Lu, Q. Feng, T. Lan, G. Zhou and Z. S. Wang, Molecular engineering of quinoxaline-based organic sensitizers for highly efficient and stable dye-sensitized solar cells, Chem. Mater., 2012, 24, 3179-3187.

362 S. Yanagida, Y. Yu and K. Manseki, Iodine/iodide-free dyesensitized solar cells, Acc. Chem. Res., 2009, 42, 1827-1838.

$363 \mathrm{H}$. Tian and L. Sun, Iodine-free redox couples for dyesensitized solar cells, J. Mater. Chem., 2011, 21, 1059210601.

364 M. Wang, C. Grätzel, S. M. Zakeeruddin and M. Grätzel, Recent developments in redox electrolytes for dyesensitized solar cells, Energy Environ. Sci., 2012, 5, 93949405.

365 S. Ahmad, T. Bessho, F. Kessler, E. Baranoff, J. Frey, C. Yi, M. Grätzel and M. K. Nazeeruddin, A new generation of platinum and iodine free efficient dye-sensitized solar cells, Phys. Chem. Chem. Phys., 2012, 14, 10631-10639. 
366 J. Cong, X. Yang, L. Kloo and L. Sun, Iodine/iodide-free redox shuttles for liquid electrolyte-based dye-sensitized solar cells, Energy Environ. Sci., 2012, 5, 9180-9194.

367 F. Sauvage, S. Chhor, A. Marchioro, J. E. Moser and M. Grätzel, Butyronitrile-based electrolyte for dyesensitized solar cells, J. Am. Chem. Soc., 2011, 133, 1310313109.

368 J. Yoon, D. Kang, J. Won, J. Y. Park and Y. S. Kang, Dyesensitized solar cells using ion-gel electrolytes for longterm stability, J. Power Sources, 2012, 201, 395-401.

369 K. M. Lee, W. H. Chiu, M. D. Lu and W. F. Hsieh, Improvement on the long-term stability of flexible plastic dye-sensitized solar cells, J. Power Sources, 2011, 196, 8897-8903.

370 Y. Yang, C. H. Zhou, S. Xu, H. Hu, B. L. Chen, J. Zhang, S. J. Wu, W. Liu and X. Z. Zhao, Improved stability of quasi-solid-state dye-sensitized solar cell based on poly (ethylene oxide)-poly(vinylidene fluoride) polymer-blend electrolytes, J. Power Sources, 2008, 185, 1492-1498.

371 Z. Chen, H. Yang, X. Li, F. Li, T. Yi and C. Huang, Thermostable succinonitrile-based gel electrolyte for efficient, long-life dye-sensitized solar cells, J. Mater. Chem., 2007, 17, 1602-1607.

372 K. T. Dembele, R. Nechache, L. Nikolova, A. Vomiero, C. Santato, S. Licoccia and F. Rosei, Effect of multi-walled carbon nanotubes on the stability of dye sensitized solar cells, J. Power Sources, 2013, 233, 93-97.

373 S. R. Kim, M. K. Parvez, I. In, H. Y. Lee and J. M. Park, Novel photo-crosslinkable polymeric electrolyte system based on poly(ethylene glycol) and trimethylolpropane triacrylate for dye-sensitized solar cell with long-term stability, Electrochim. Acta, 2009, 54, 6306-6311.

374 F. Sauvage, M. K. Fischer, A. Mishra, S. M. Zakeeruddin, M. K. Nazeeruddin, P. Bäuerle and M. Grätzel, A dendritic oligothiophene ruthenium sensitizer for stable dyesensitized solar cells, ChemSusChem, 2009, 2, 761-768.
375 M. K. Parvez, I. In, J. M. Park, S. H. Lee and S. R. Kim, Longterm stable dye-sensitized solar cells based on UV photocrosslinkable poly(ethylene glycol) and poly(ethylene glycol) diacrylate based electrolytes, Sol. Energy Mater. Sol. Cells, 2011, 95, 318-322.

376 F. Bella, D. Pugliese, J. R. Nair, A. Sacco, S. Bianco, C. Gerbaldi, C. Barolo and R. Bongiovanni, A UVcrosslinked polymer electrolyte membrane for quasi-solid dye-sensitized solar cells with excellent efficiency and durability, Phys. Chem. Chem. Phys., 2013, 15, 3706-3711.

377 F. Bella, G. Griffini, M. Gerosa, S. Turri and R. Bongiovanni, Performance and stability improvements for dye-sensitized solar cells in the presence of luminescent coatings, J. Power Sources, 2015, 283, 195-203.

378 S. Singh and H. S. Nalwa, Nanotechnology and health safety-toxicity and risk assessments of nanostructured materials on human health, J. Nanosci. Nanotechnol., 2007, 7, 3048-3070.

379 Nanotoxicology-Interactions of Nanomaterials with Biological Systems, ed. Y. L. Zhao and H. S. Nalwa, American Scientific Publishers, Los Angeles, 2007.

$380 \mathrm{X}$. Hu and Q. Zhou, Health and Ecosystem Risks of Graphene, Chem. Rev., 2013, 113, 3815-3835.

381 E. L. K. Chng and M. Pumera, Toxicity of graphene related materials and transition metal dichalcogenides, RSC Adv., 2015, 5, 3074-3080.

382 J. Hao, G. Song, T. Liu, X. Yi, K. Yang, L. Cheng and Z. Liu, In vivo long-term biodistribution, excretion, and toxicology of PEGylated transition-metal dichalcogenides $\mathrm{MS}_{2}(\mathrm{M}=$ Mo, W, Ti) nanosheets, Adv. Sci., 2017, 4, 1600160, DOI: 10.1002/advs.201600160.

383 W. Z. Teo, E. L. K. Chng, Z. Sofer and M. Pumera, Cytotoxicity of exfoliated transition-metal dichalcogenides $\left(\mathrm{MoS}_{2}, \mathrm{WS}_{2}\right.$, and $\left.\mathrm{WSe}_{2}\right)$ is lower than that of graphene and its analogues, Chem.-Eur. J., 2014, 20, 9627-9632. 